\title{
Efficiency of employment subsidies and firms' recruitment strategies
}

Citation for published version (APA):

Welters, R. A. M. H. M. (2005). Efficiency of employment subsidies and firms' recruitment strategies.

[Doctoral Thesis, Maastricht University]. Universiteit Maastricht. https://doi.org/10.26481/dis.20050527rw

Document status and date:

Published: 01/01/2005

DOI:

10.26481/dis.20050527rw

Document Version:

Publisher's PDF, also known as Version of record

\section{Please check the document version of this publication:}

- A submitted manuscript is the version of the article upon submission and before peer-review. There can be important differences between the submitted version and the official published version of record.

People interested in the research are advised to contact the author for the final version of the publication, or visit the DOI to the publisher's website.

- The final author version and the galley proof are versions of the publication after peer review.

- The final published version features the final layout of the paper including the volume, issue and page numbers.

Link to publication

\footnotetext{
General rights rights.

- You may freely distribute the URL identifying the publication in the public portal. please follow below link for the End User Agreement:

www.umlib.nl/taverne-license

Take down policy

If you believe that this document breaches copyright please contact us at:

repository@maastrichtuniversity.nl

providing details and we will investigate your claim.
}

Copyright and moral rights for the publications made accessible in the public portal are retained by the authors and/or other copyright owners and it is a condition of accessing publications that users recognise and abide by the legal requirements associated with these

- Users may download and print one copy of any publication from the public portal for the purpose of private study or research.

- You may not further distribute the material or use it for any profit-making activity or commercial gain

If the publication is distributed under the terms of Article $25 \mathrm{fa}$ of the Dutch Copyright Act, indicated by the "Taverne" license above, 
(C)05 R.A.M.H.M. Welters, Maastricht.

All rights reserved. No part of this publication may be reproduced, stored in a retrieval system, or transmitted, in any form, or by any means, electronic, mechanical, photocopying, recording or otherwise, without the prior permission in writing, from the author.
Cover concept:
Patrick Cleiren
Cover design:
Patrick Cleiren
ISBN:
90-9019465-7
Printing:
PrintPartners Ipskamp, Enschede 


\title{
Efficiency of Employment Subsidies and Firms' Recruitment Strategies
}

\author{
PROEFSCHRIFT \\ Ter verkrijging van de graad van doctor \\ aan de Universiteit Maastricht \\ op gezag van de Rector Magnificus, \\ Prof, mr. G.P.M.F. Mols \\ volgens het besiuit van het College van Decanen, \\ in het openbaar te verdedigen \\ op vrijdag 27 mei 2005 om 12.00 uur \\ door
} Riccardo Anna Martinus Hubertus Maria Welters 


\section{Promotor:}

Prof. dr. M. Muysken

\section{Beoordelingscommissie:}

Pirof dr. C.J.N. de Neubourg (Voorzitter)

Prof dr. J.A.M. Heijke (ROA / Universiteit Maastricht)

Prof. dr. ir. J.C. van Ours (Universiteit van Tilburg)

\section{Financièle ondersteuning:}

Dit proefschnift en het daaraan ten grondslag liggende onderzoek is met een financiële bijdrage van de Maastricht research school of Economics of TEchnology and ORganizations (METEOR), tot stand gekomen. 


\section{Table of Contents}

Table of Contents i

List of Figures.

List of Tables $v$

Notation vii

Preface $\quad$ ix

Chapter I: Introduction 1

1.1 Motivation and research question $\quad 1$

1.2 The chameleonic traits of unemployment 3

1.3 Active labour market measures: a panacea for long-term unemployment 7

1.4 Firm hiring behaviour: tracing the culprit 13

1.5 Taking stock: dissertation outline $\quad 16$

Chapter II: Recruitment among Rejects 19

2.1 Introduction $\quad 19$

2.2 A sequential employer search model 21

2.3 The hiring model $\quad 26$

2.4 Introducing employment subsidies $\quad 32$

2.5 Applying the model to the Dutch case 36

2.6 Conclusions $\quad 39$

Chapter III: Outsmart the Outliers 41

3.1 Introduction 41

3.2 Wage subsidy schemes $\quad 42$

3.3 Training subsidy schemes $\quad 50$

3.4 Costs of preventing deadweight loss 57

3.5 Conclusions $\quad 58$

Chapter IV: Employer Search and Wage Subsidies 61

4.1 Introduction 61

4.2 A sequential employer search model 62

4.3 Empirical employer search literature $\quad 66$

4.4 Dutch wage subsidy $\quad 68$

4.5 Empirical results on Dutch data 73

4.6 British wage subsidy $\quad 76$

4.7 Empirical results on British data $\quad 79$

4.8 Overall results for wage subsidies 83

4.9 Conclusions 83

Chapter V: Employer Search and Training Subsidies 87

5.1 Introduction 87

5.2 Employer search and wage subsidies $\quad 88$ 
5.3 Employer search and training subsidies $\quad 88$

5.4 British training subsidy $\quad 94$

5.5 Empirical results on British training subsidy data 95

5.6 Taking stock: training versus wage subsidy schemes $\quad 102$

5.7 Conclusions $\quad 102$

Chapter VI: Making a Virtue of Need 105

6.1 Introduction 105

6.2 Philips Employment Scheme in retrospective 106

6.3 The Philips (youth) employment scheme 108

6.4 Effectiveness of the PES 110

6.5 The Philips Employment Scheme in perspective $\quad 114$

6.6 Keys to success of PES and lessons for public schemes $\quad 116$

6.7 Potential pitfalls of the PES 117

6.8 Private employment schemes as a contribution to the public initiative

6.9 Conclusions $\quad 120$

Appendix 6.1 121

Appendix 6.2 122

$\begin{array}{ll}\text { Chapter VII: Conclusions } & 125\end{array}$

7.1 Recapitulating $\quad 125$

$\begin{array}{ll}7.2 \text { Recommendations } & 127\end{array}$

$\begin{array}{ll}7.3 \text { Limitations } & 128\end{array}$

References 131

Summary in Dutch 139

Curriculum Vitae 144 


\section{List of Figures}

\section{Chapter I : Introduction}

Figure 1.1 Evolutions in long-term unemployment

Figure 1.2 Transition rates from short to long-term unemployment 4

Figure 1.3 Hazard rates for the Netherlands, 1987

Figure 1.4 Change towards active labour market measures 7

\section{Chapter II: Recruitment among Rejects}

Figure 2.1 Composition of active labour market measures, the

Netherlands 1990-2001

Figure 2.2 Link between unemployment duration and productivity $\quad 24$

Fugure 2.3 Overview of the hiring procedure

Figure 2.4 The effects of the screening device standard on the employment outcome

Figure 2.5 The impact of employment subsidies 34

Figure 2.6 The impact of profiling on subsidy efficiency 38

\section{Chapter III: Outsmart the Outliers}

Figure 3.1 A (search extension motivated) wage subsidy 43

Figure 3.2 Evolution of recruitment costs 44

Figure 3.3 Deadweight loss incidence in a wage subsidy 46

Figure 3.4 Deadweight loss incidence in a non-uniform wage subsidy 49

Figure 3.5 A training subsidy $\quad 53$

Figure 3.6 Potential threat of deadweight $\Downarrow$ oss in a training subsidy $\quad 56$

Figure 3.7 Avoiding deadweight loss by careful government intervention 57

\section{Chapter IV: Employer Search and Wage Subsidies}

\section{Chapter V: Employer Search and Training Subsidies}

\section{Chapter VI: Making a Virtue of Need}

Figure 6.1 Unemployment rates in the Netherlands 106

Figure 6.2 Schematic overview of the Philips Employment Scheme $\quad 109$

Figure 6.3 Outflow rates of PES participants 


\section{List of Tables}

\section{Chapter I: Introduction}

Table 1.1 Share of various types of active measures in total ALMP expenditures, 2002

Table 1.2 History of efficiency of employment subsidies in some

$\mathrm{OECD}$ countries

Table 1.3 Firm's recruitment channel choice, the Netherlands, $1986 \quad 14$

Table 1.4 Firm's recruitment channel choice, the Netherlands, 1991-199414

Table 1.5 Firm's hiring behaviour to industry, US, 1981

\section{Chapter II: Recruitment among Rejects}

Table 2.1 Characteristics Dutch employment subsidy measures

\section{Chapter III: Outsmart the Outliers}

Table 3.1 The firm's set of strategies following the government's subsidy grant

Table 3.2 The firm's strategy following the government's misperception 48

Table 3.3 The firm's incentives following a training subsidy

\section{Chapter IV: Employer Search and Wage Subsidies}

Table 4.1 Effects on intensive search costs 67

Table 4.2 Descriptive statistics VLW data 69

Table 4.3 Overlap between two constructs to measure deadweight loss 71

$\begin{array}{ll}\text { Table 4.4 Set of independent variables to test for deadweight loss } & 72\end{array}$

Table 4.5 Ordinal probit regressions of deadweight loss in VWL 74

Table 4.6 Descriptive statistics NDLTU data 78

Table 4.7 Deadweight loss construction $\quad 78$

Table 4.8 Ordinal probit regressions of deadweight loss in NDLTU 80

Table 4.9 Firm's recruitment behaviour given the number of applicants $\quad 82$

Table 4.10 Summary of results from Dutch and British data 83

\section{Chapter V: Employer Search and Traiming Subsidies}

Table 5.1 Summary of results from Dutch and British data 89

Table 5.2 Descriptive statistics NDYP data 95

Table 5.3 Ordinal probit regressions of deadweight loss in NDYP 96

Table 5.4 Ordinal probit/ tobit regressions of length training period 100

Table 5.5 Summary of results from Dutch and British data 101

\section{Chapter VI: Making a Virtue of Need}

Table 6.1 Explaining the outflow rate to employment

Table 6.2 Participant and labour market characteristics PES for cohorts 1997 and 2001

Table 6.3 PES characteristics and comparable programmes initiated 
by the govermment

Table 6.4 Characteristics Dutch wage subsidy schemes

Table 6.5 Characteristics Dutch unemployment pool

119

Table A6.1 Deadweight loss in the Philips Employment Scheme

121

Table A6.2 Contract duration Vermeend-Moor Act in 1988

Chapter VII: Conclusions 


\section{Notation}

\section{Lain alphabet}

A area representing unemployed who meet the screening device standard but not the productivity standard

a ability

$a_{\text {ewe }} \quad$ average ability of subsidy entitled unemployed

$a_{m a x}$ maximum ability

$a_{m i n}$ mimimum ability

$B$ area representing unemployed who meet the productivity standlard but not the screening device standard

b cost of carrying out an assessment

C area representing unemployed who meet both the productivity and the screening device standard

c periodical cost of foregone productivity

D area representing unemployed who neither meet the productivity standard nor the screening device standard

d cost to upgrade the productivity level of the most able applicant with a single productivity unit

E employment

$e$ cost of activating the cheapest recruitment channel

HC hiring costs

$i$ firm

j job seeker

$l^{n} \quad$ labour supply

$l^{d} \quad$ labour demand

$q \quad$ arrival rate of job seekers

$p$ productivity

$p^{*} \quad$ minimum productivity to be productive on the job

$p^{g} \quad$ minimum productivity level to be entitled to a training subsidy

$P P \quad$ participation profit

$p^{s} \quad$ minimum productivity to be considered for a job

$p^{s e} \quad$ maximum productivity to be entitled to a training subsidy

$p_{\max }$ maximum available productivity within an unemployment collort

$p_{m i n}$ minimum available productivity within an unemployment cohort

$r$ recruitment channel

$R C$ recruitment costs

$T$ total size of the unemployment pool

TC schooling costs

t unemployment duration

$t_{\text {trin }}$ first cohort of unemployed which contains unemployed whose productivity has depreciated below the productivity standard

$t_{\max }$ first cohort of unemployed which no longer contains unemployed who meet the productivity standard

screening device standard set by the firm

$i^{\text {sig }}$ first unemployment cohort to be subsidy entitled

$r^{r} \quad$ last unemployment cohort to be subsidy entitled

$u$ unemployment rate

$U$ unemployment outcome 
$\checkmark \quad$ vacancy rate

w wage

\section{Greek alphabet}

$\alpha$ probability to accidentally cause deadweight loss when pursuing the optimal hiring strategy

a average number of assessments needed to find an applicant who meets the productivity standard

8 productivity discount factor

e wage / training subsidy

d. mark-up on costs $d$, for training individuals having ability levels below the maximum ability level

$\eta \quad$ productivity discrepancy between the productivity standard and the job seeker's productivity

$\eta$ units of schooling costs needed to upgrade productivity to the productivity standard

a average number of applicants needed before a second arrives who meets the productivity standard

number of periods needed to fill the vacancy

distribution function of productivity over a cohort of unemployed

job separation rate

$\mu \quad$ mean

$\theta \quad$ labour market tightness

P productivity depreciation rate

$\sigma \quad$ standard deviation

廿 average number of periods between two applicants

$\xi$ mark-up on the costs of the cheapest recruitment channel of using a different recruitment channel 


\section{Preface}

When Joan Muysken contacted me to consider writing a Ph.D. back in autumn 1999; I was surprised. Not so much at the fact that he asked me, but more since it was only 30 minutes after I had told Tom wan Veen that I was pondering my future. Should I interpret that as a warm welcome or is it a bad omen if people want you desperately? Anyway, l've never regretted the decision to actually start writing the Ph.D.

I used the degrees of freedom Joan provided conceming the subject choice - anything, as long as it involved the labour market - to resume my interest in active labour market policy. A subject $\mathbb{I}$ dug into when writing my master thesis a few years earlier. It is a fascinating subject, since it is hard to grasp why governments spent - and continue to spend so much money on active labour market policy, while its effectiveness is consistently proved to be low.

In spring 2000 we had produced a research proposal which met with approval of METEOR, the Maastricht graduate research school. The subsequent grant enabled me to start my Ph.D. in September 2000. In the following four years I met some colleagues who made my stay at building excavation TS53 an interesting one and therefore deserve credit.

Special thanks go to Joan Muysken for putting trust in me and guiding me through the process. Though the number of officiall meetings we had must have been historically low, he never disappointed me when I used one of his favourite sayings to backfire on him: "frapper toujours'.

Next to my supervisor, I want to thank all colleagues and seminar / conference participants who at some stage contributed to this Ph.D. Special thanks go to the members of the reading committee Chris de Neubourg, Hans Heijke and Jan van Ours. Furthermore I thank Bertrand Candelon, Denis de Crombrugghe, Pieter Gautier, Christian Kerckhoffs, Ben Kriechel, Eric de Regt and Sybrand Schim van der Loeff who critically read preliminary versions of chapters of the thesis.

Subsequently, I would like to express thanks to three persons who made the data available, which allowed me to do the empirical analyses. Peter Donker van Heel of the Netherlands Economic Institute, Ton van der Bruggen of Philips Electronics and Jon Hales of the National Centre for Social Research do not know how valuable their support has been to me.

Next, I thank my room-mates. Arnald Kamning introduced me into his peculiar view on life in general and university in particular. Unfortunately, a lack of cubic content and later an asbestos pollution ended this partnership and my residence at the fourth floor. Subsequently, I moved to the first floor, where I built up a new partnership with Mark Sanders, whose general knowledge / interest is second to none. Students who conmitted plagiarism still regret the university's decision to mix us up in one room. After Mark's departure and the explosion of the General Economics department - though I am sure this time it is not building workers who were responsible for the damage - Geranda Notten accompanied me in the final stages of my Ph.D. Her determination in mastering STATA commands struck the eye and was a shining example to me to finish the tail end of my thesis. Finally, bearing in mind that I commuted 30 minutes daily by train, I roughly spent 20 days in railway carriages. Silvana de Sanctis, Ronald Peeters and Kirsten Rohde made it pleasant trips.

For his help in designing the thesis I thank Patrick Cleiren. Moreover, I thank my 'paranimfen' for standing by during the defence of this thesis and Sylvia Beenen, Celine Duijsens-Rondagh and Susan Roggen for minimizing bureaucracy in my working life.

Finally, I would like to thank all those outside the university for supporting me throughout the Ph.D. period and providing the necessary distraction. My parents Hilly 
Welters - Joris and Hub Welters, my brother Lando Welters and LB. Perhaps I have never been very explicit on what I exactly did the last few years, but please take comfort from the fact that it was not unwillingness but sheer incapability from my part.

RW, Maastricht, April 2005 



\section{Chapter I: Introduction}

\subsection{Motivation and research question}

At first sight, constructing a figure which provides a 35-year overview of the development in long-term unemployment seems an easy exercise, given its policy relevance and the wide variety of available data sources. Once actually searching for the relevant data, one finds out that the seemingly easy task is more complicated: data on long-term unemployment before 1975 are hardly available. The first easily accessible data beyond that date hint at the main reason for this lack of data availability: shares of long-term in total unemployment are low. As a consequence long-term unemployment was no policy issue before 1975 and subsequently there was hardly any data collection. Two consecutive oil crises in the seventies put the issue of long-term unemployment on the agenda. The quick succession of shocks meant that some of those who lost their job after the first shock did not find employment before the second shock and subsequently became long-term unemployed. Figure 1.1 shows the consequences for the composition of the unemployment pool.'

Equally noticeable as the strong upward trend in long-term unemployment from the mid seventies onwards is the lack of any trend in long-term unemployment in the late eighties and nineties, implying it remained at an unsatisfactorily high level. Consequently, 30 years after its introduction as a major policy concern, long-term unemployment is still very much on the agenda, which implies that economists and policymakers have not been able to solve it.

\section{Figure 1.1 Evolutions in long-term unemployment}

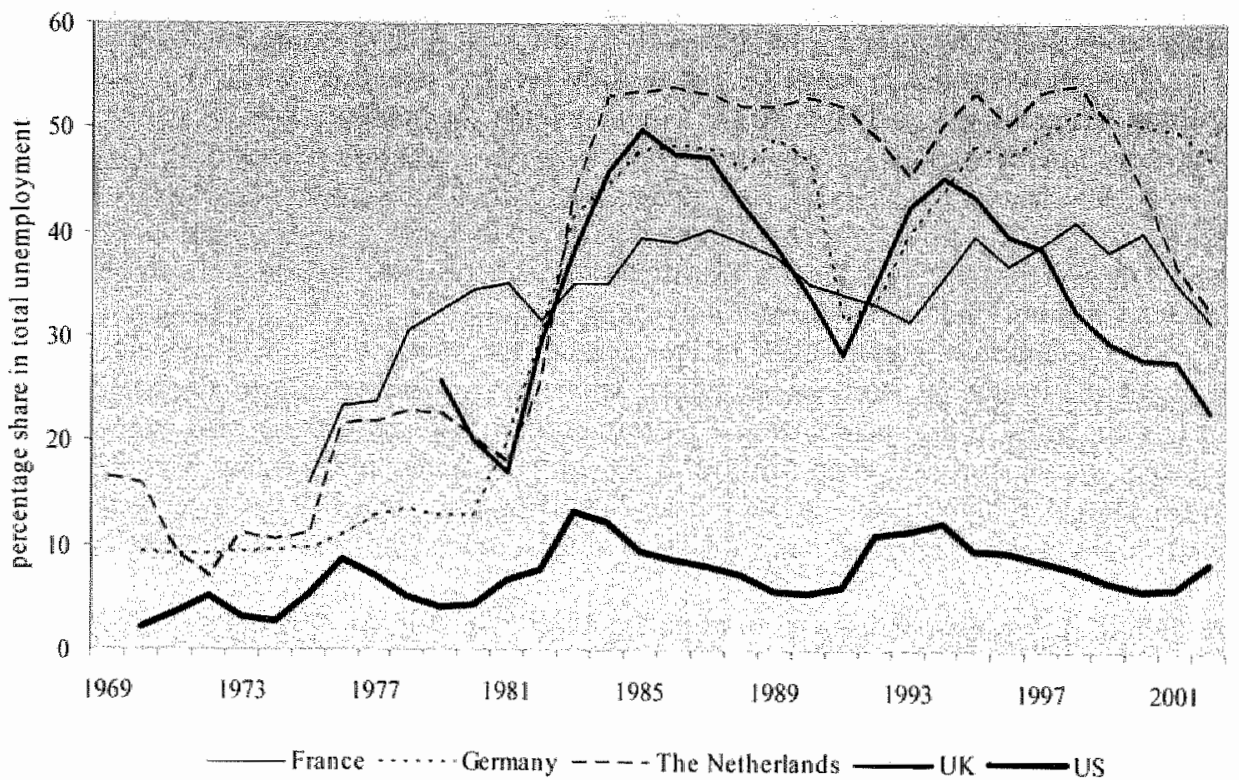

Source: OECD Labour Force Statistics, ILO Laborsta, CPB Macro Economic Outlook. European Conmission (1997) and ILO (1986)

The increase in the share of long-term unemployment in total unemployment has predominantly been a European phenomenon. OECD (1994) argues that downward wage rigidity has hindered employment growth in Europe, whereas wage flexibility has been the key to accommodate the US labour market after the oil shocks. 
Much of the efforts devoted to bringing rates of long-term unemployment down to pre-oil shock levels have been spent on the supply side of the labour market where the willingness and the ability of unemployed to find employment have been questioned. To increase the willingness of unemployed to look for work, governments have taken measures towards a tougher line on benefits, both in terms of the level and the duration of payments. An increasing pay gap between employment and non-employment should induce unemployed to increase their efforts to find a job. To improve the ability - in terms of productivity - of unemployed, policymakers have introduced active labour market policies, which focus on restoring depreciated productivity and rebuilding self-confidence.

Without intending to underestimate the value of measures targeted at improving the willingness of unemployed to find a job, this dissertation concentrates on ability improving measures. More precisely we focus on one of the main elements of active labour market measures: the employment subsidy measure. That is, a firm (private or public) obtains a temporary subsidy if it hires from an ex-ante defined target group (typically long-term unemployed). The reasoning is twofold. On the one hand, the subsidy allows the participant to improve his skills during the temporary stay at the firm, which enables him to find employment at the expiration of the subsidy. Since the participant restores his depreciated productivity during the subsidized stay, the subsidy need not be permanent. On the other hand, the subsidy enables the participant to signal his skills to the employer. If the pool of long-term unemployed contains job seekers who meet the firm's hiring standards, but who firms disregard simply because they are long-term unemployed, the subsidy will confront the firm with its erroneous screening strategy. The latter argument not only provides the participating long-term unemployed with a job, it might also induce the firm to revise its hiring strategy in favour of long-term unemployed. Again, the subsidy need not be permanent, as long as the participating unemployed receives sufficient time to signal his skills.

Though theoretically employment subsidy measures seem an attractive instrument to help long-term unemployed back to the labour market, in practice such measures appear to suffer from low efficiency. To measure inefficiency the literature relies on deadweight loss,
which is the share of subsidized participants who would have found an unsubsidized job
anyhow. As we will show throughout this disertition anyhow. As we will show throughout this dissertation this share is substantial in employment subsidy measures and consequently obstructs its goal: provide (subsidized) employment to
those who will not find employment otherwise.

The economic literature about measuring the exact size of deadweight loss in employment subsidy measures is abundant. However, surprisingly little attention has been paid to the causes of the incidence of deadweight loss. This dissertation will exactly address that issue: i.e. which firms obtain subsidies for long-term unemployed they would have hired ansubsidized and under which circumstances? And how can we use that information to design a deadweight loss free employment subsidy or at least reduce the deadweight loss?

Any attempt to answer that question requires a close look at the demand side of the labour market, as it is the firm's hiring behaviour we are interested in. That is, if skill upgrading is the main motive of an employment subsidy, a good match (both in terms of job level and job direction) is required, which justifies a closer look at the reasons of firms to participate in
such schemes. If questioning the employment subsidy, applying a demand side apping strategy is the main motive of an refuse to hire from long-term unemployed side approach is a necessity. That is, why do firms do so?

The ability of lirms to find qualified personnel amongst groups they supposingly disregard in hiring decisions has been studied before, but in a slightly different context: 
affrmative action. Affirmative action - which was introduced in the US labour narket in 1965 - entails that firms (public firms or private frms who hold public contracts) have to employ a quota of disadvantaged groups on the labour market (females and minorities), which firms supposingly disregard for a lack of quality. ${ }^{2}$ Holzer and Neumark $(1999,2000)$ explore whether firms that have to comply affirmative action legislation indeed suffer from a productivity decline, but do not find any evidence to support this hypothesis. Firms that have to comply with affirmative action spend more time screening among disadvantaged groups in order to find qualified candidates and apparently succeed in doing so.

The evidence arising from the empirical literature on affirmative action suggests that firms are able to successfully recruit among supposingly unqualified groups of unemployed. That is, if they are forced to do so, like in the case of affurmative action legislation. In the case of employment subsidies, participation is free. Nonetheless hiring cost structures or labour market conditions might "force" firms to recruit among disadvantaged groups in an attempt to minimize hiring costs.

Disentangling the firm's hiring behaviour therefore should shed light on the reasons why and when firms recruit from disadvantaged groups, which subsequently yields a prediction of deadweight loss incidence.

If indeed a pattern in the incidence of deadweight loss can be obserwed, the design of employment subsidy measures could be modified in ways to prevent the deadweight loss threat, which would improve the efficiency of such measures and hence reduce the subsidy wastage. It is this latter drawback that prevents many governments from introducing or applying employment subsidy measures at a larger scale.

The remainder of this introductory chapter provides a background of the subject at stake and also serves as a justification for the decision we took to focus on the efficiency of employment subsidy measures. Chapters II and III develop a theoretical framework which yields several hypotheses, that we empirically test in Chapters IV and V. Chapter VI is devoted to a privately financed employment subsidy scheme, Chapter VII summarizes the main conclusions of this dissertation.

\subsection{The chameleonic traits of unemployment}

Nowithstanding the substantial efforts governments have put into reducing unemployment, the surge of unemployment following the two oil shocks has never been completely reversed - especially not in some of the main European continental countries like France and Germany. Consequently, unemployment remains an important concen throughout most $\mathrm{OECD}$ countries.

Unemployment affects the economy in several ways. Not using employment up till its capacity implies production loss. Furthermore, those sidelined experience skill obsolescence which makes them less productive on their return to employment and subsequently widens wage inequality. Moreover, unemployment leads to social exclusion, which - though difficult. to measure economically - yields psychic costs. A positive effect is that unemployment increases leisure time. However, given the involuntary nature of unemployment, unemployed

\footnotetext{
${ }^{2}$ Hing under affirnative action legislation actually is a specilic case of an employment subsidy measure. Whereas in the latter case the firm obtains a subsidy for hiring from a pre-defined group, in the case of the former the firm pays a penaly (or in other words obtains a negative subsidy) for not hiving from this at ante defined group.
} 
apparently prefer working to forced consumption of leisure. Besides leisure, involuntary unemployment also serves as a mechanism to guide the actual unemployment rate back to its natural rate. That is, a high unemployment rate moderates aggregate wages - as unemployed job seekers constitute competition for employees bargaining for higher wages - which subsequently increases aggregate employment and vice versa.

Though the business cycle also affects the share of long-term unemployment in total employment, this share has never decreased to its pre-oil shock level but instead stabilized at 30 to $40 \%$. This suggests that the change in the composition of the unemployment pool is structural, which urges us to readdress economic thinking about unemployment. Apparently the burden of unemployment is not equally divided over the total labour force, but weighs on a specific group. As a consequence, skill obsolescence and psychic costs following unemployment are concentrated among particular groups in our society. Moreover, if large parts of the unemployment pool find it difficult to re-enter employment, the competitive threat of unemployed to employees vanishes, which reduces wage moderating effects of unemployment.

\section{Figure 1.2 Transition rates from short to long-term unemployment}

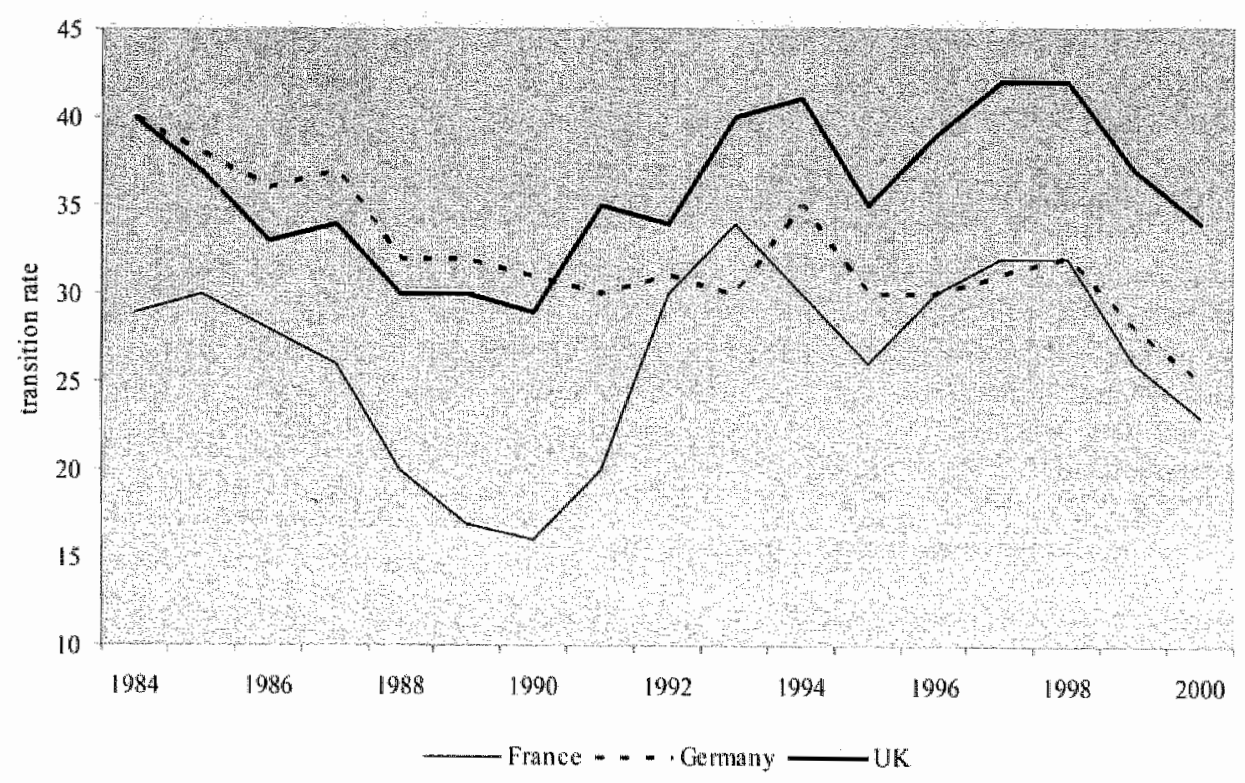

Souree: OECD (2002)

Figure 1.2 illustrates path dependence of unemployed in three major European countries. The figure contains the transition rate from short to long-term unemployment. For the United Kingdom (UK) as much as $40 \%$ of those unemployed for less than a year in the previous year are still without employment one year later, which implies they turned into long-term unemployed. Though these transition rates are somewhat lower in Germany and France, this 
nonetheless suggests that short-term unemployment is solid predictor of future long-tem: unemployment. ${ }^{3}$

Path dependence in re-employment probabilities of umemployed has been studied extensively - see Lancaster (1990) or Devine and Kiefer (1991) for an overview: These so-called hazard rate studies have provided evidence for path dependence in re-employment probabilities. In Figure 1.3 we present findings for the Netherlands, for both unemployed men and wonten, who looked for a job in 1987 . In the first few periods after job loss unemployed start looking for work, which takes some time to be productive (i.e. applying for a job takes time). Eventually this leads to a spike in the hazard rate at roughly half a year of unemployment. Beyond that spike the hazard rate starts declining both for men and women.

\section{Figure 1.3 Hazard rates for the Netherlands, 1987}

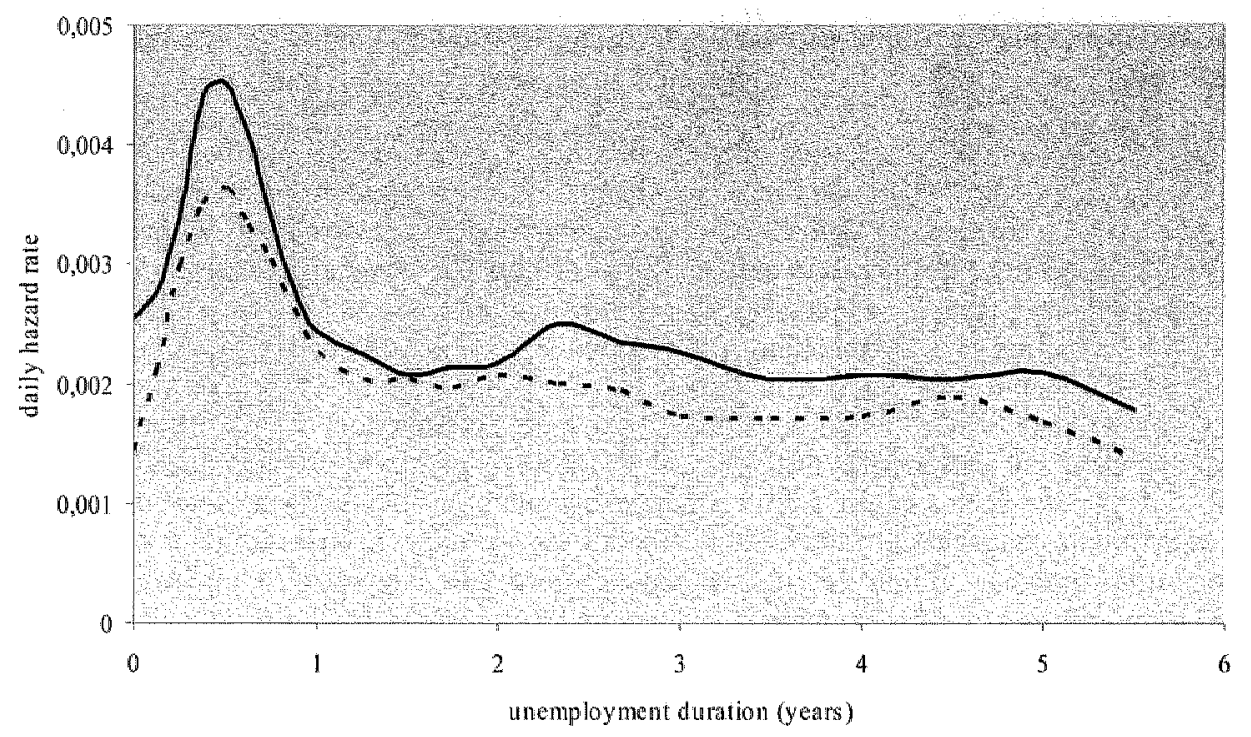

Source: Kerckhofts et al. (1994)

Several arguments have been put forward as to why this pattern is observed. One argument supporting path dependence is the negative duration dependence argument - see Vishwanath (1989), Lockwood (1991), Bean (1994) or Blanchard and Diamond (1994). That is, the duration of the unemployment spell influences re-employment probabilities. Here one can think of skill deterioration, which makes unemployed less attractive to hire for firms or discouragement effects of unemployed, which would show up in lower search effectiveness of unemployed. Both arguments explain the continuously reducing escape rates from

\footnotetext{
${ }^{3}$ OECD (2002) shows that long-term unemployment subsequently is a good predictor of very long-term unemployment (more than two years of continuous unemplloyment) and outllow out of the labour force (discouraged worker effects).

${ }^{4}$ Here we depict the semi-parametric specification with a gamma heterogeneity correction. Kerckhofls ar al. (1994) also apply different specifications to test the sensitivity of their resultis to such specifications, which is beyond the scope of the analysis presented here - see Ridder (1987) for a discussion of the effects of model specification choice on duration dependence estimates.
} 
unemployment. A second argument is a more statistical artefact: the heterogeneity argument. This argument states that the unemployment pool contains heterogeneous unemployed who subsequently experience heterogeneous re-employment probabilities. Assuming that unemployed having the highest remployment probabilities leave the unemployment pool first, this implies that the average re-employment probability goes down as the unemployment spell lengthens.

Though hazard rate studies have provided substantial evidence for path dependence in reemployment probabilities, they are less clear as to which of the two arguments dominates. Depending on the model specification and the richness of the dataset (i.e. the ability to correct for unobserved heterogeneity), some authors - once controlling for heterogeneity - reject the negative duration dependence hypothesis, like Ham and Rea (1987). Others still find negative duration dependence even when controlling for heterogeneity - see for example Van den Berg and Van Ours (1996) or Petrongolo (2001). On balance, it seems reasonable to assume that both arguments play a role in explaining declining hazard rates as the unemployment spells lengthen.

Part of the explanation of negative duration dependence arises from firm behaviour. That is, firms take the unemployment record of applicants into consideration when deciding to fill a vacancy, which suggests that firms use the unemployment record as a screening device. Lynch (1985, 1989 ), Van den Berg and Van Ours (1994) and especially Omori (1997) provide empirical evidence that firms indeed use unemployment duration as a screening device.

This finding has far reaching implications as it can explain the persistence of longterm unemployment as scheduled in Figure 1.1. Labour economics tells that unemployment rates above the natural rate can only be a temporary phenomenon, as excess supply on the labour market will drive down wages and subsequently increase employment. However, if firms a priori decide not to hire from certain groups of applicants (i.e. long-term unemployed) the latter are no longer part of the effective labour supply and consequently do not constitute a competitive threat to employed job seekers or short-term unemployed job seekers, which leads to hysteresis - see for example Blanchard and Summers (1987) or Lindbeck and Snower (1988, 1989) or for more recent applications Balmaceda et al. (2000), Leon-Ledesma (2002), Roed (2002) or Amisano and Serati (2003). Crafts (1989) and Budd ef al. (1988) provide eimpirical evidence that supports the above claim. Increases in the share of long-term unemployment in total unemployment have wage elevating effects, which, structurally, puts long-term unemployed out of contention for jobs.

This finding urged both economists and policy makers to readiress the targets of labour market policy. In the absence of long-term unemployment (before the 70 s of the last century), the probability to become unemployed appeared to be a random process, as was the outflow rate out of unemployment. This implied that labour market policy could be restricted to a passive policy, which provides a benefit system for those who became unemployed, the generosity of which balanced the social desire to provide financial support when out of employment and the incentive to find a job once unemployed and on benefits. Following the surge in long-term unemployment and the subsequent reaction of firms (i.e preferably not recruiting from long-term unemplloyed) passive labour market policy no longer sufficed. Labour market policy had and still has to focus on preventing unemployed from turning into long-term unemployed and on providing support for long-term unemployed to guide them back to employment. To do so governments aim at activating otherwise passive benefit expenditures. 
The need to 'activate' labour market measures has been acknowledged and taken up by governments throughout the OECD. Figure 1.4 shows the development in expenditures on active labour market measures as the share in total expenditures on labour market measures. Except for the US - where the incidence of long-term unemployment is substantially lower and hence the need to shift towards active measures - the sliare of active measures has increased considerably.

Figwe 1.4 Change towards motive labour matket measures

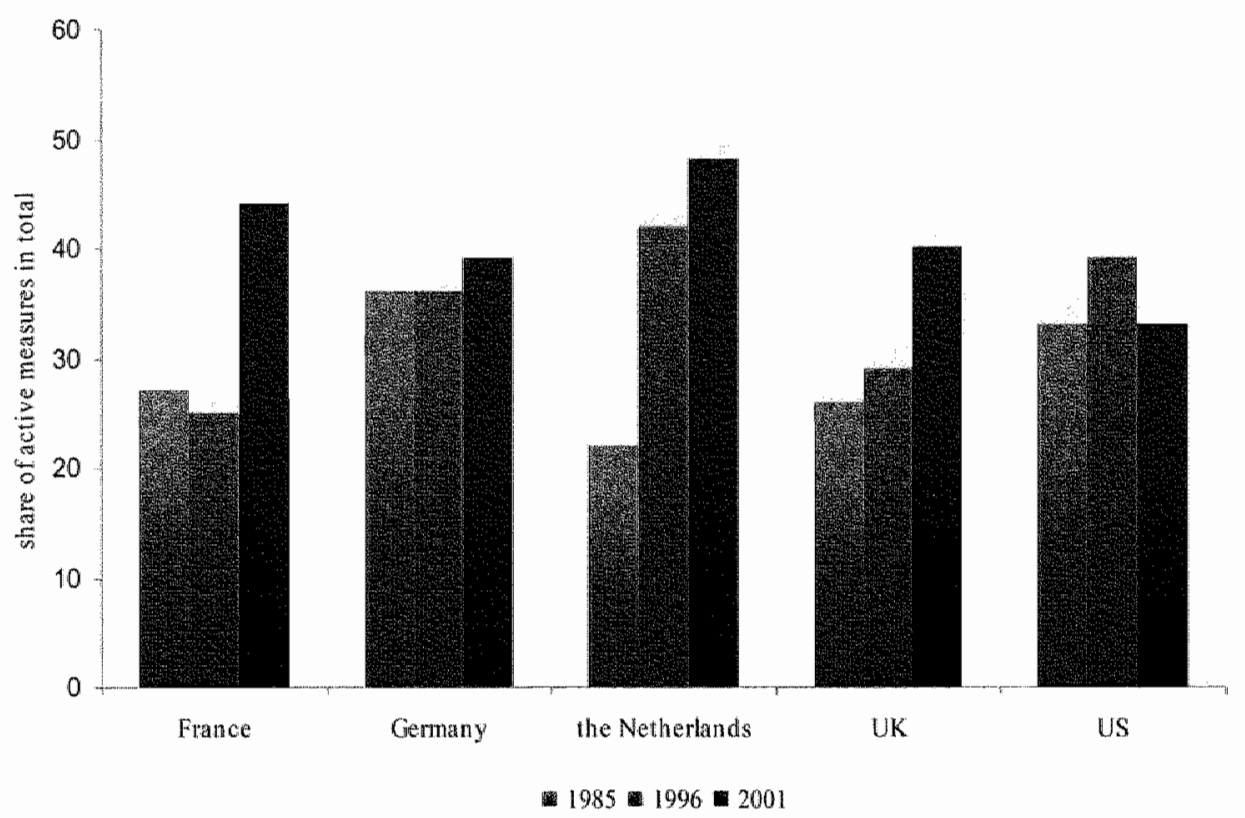

Source: OECD Labour Market Statistics

\subsection{Active labour market measures: a panacea for llong-term unemployment}

Active labour market measures aim at raising the (long-term) tmemployed"s employability, which has been hit by duration dependence. Since there are several reasons for duration dependence (discouraged workers, loss of work-habit or skill deterioration) there is a wide range of active measures. We mention the five (expenditure wise) main active measures.

Training is - in terms of expenditures - the most important active measure in continental Europe - see Table 1. . . It can be targeted at youngsters (who left school without a degree) but also at long-term unemployed whose skills deteriorated or got outdated due to non-employment.

Relief employment contains jobs created in the public sector targeted at long-term unemployed. The creation of such jobs generally serves two aims. On the one hand, long-term unemployed obtain a job which helps them to re-establish work-habit and potentially raises their re-employment probability (though the latter is typically no main target). On the other

\footnotetext{
${ }^{5}$ In 2001 expenditures on active labour market measures anounted to 0.15 and $0.37 \%$ of GDP in the US and the UK respectively. In coninental Europe these figures are higher. France, Grmany and the Netherlands spent $1.32,1.21$, and $1.74 \%$ of GDP respectively on active labour market measures in $2001-\sec$ OECD (2003).
} 
hand, the work done in relief jobs is socially desirable. As Table 1.l demonstrates, relief jobs are widely applied in cominental Europe, whereas hardly in Anglo-Saxon countries.

Enterprise start-up subsidies are allocated to unemployed who would like to start-up their own enterprise and consequently leave the unemployment pool. This active measure only constitutes a small part of active measures taken in major OECD countries.

Wage subsidies are awarded to firms who hire long-term unemployed. That is, the firm obtains a temporary tax deduction for employing a targeted unemployed worker. During the subsidized stay at the firm, the worker can upgrade his/her skills which would remove the need to continue the subsidization once the productivity of the participant has been upgraded sufficiently. France and the UK spend a considerable part of their active labour market measures budget on wage subsidies."

Job search assistance is provided by employment exchange offices. It is targeted at unemployed who have been discouraged to continue job search. In Anglo-Saxon countries job search assistance is the largest component of active labour market measures.

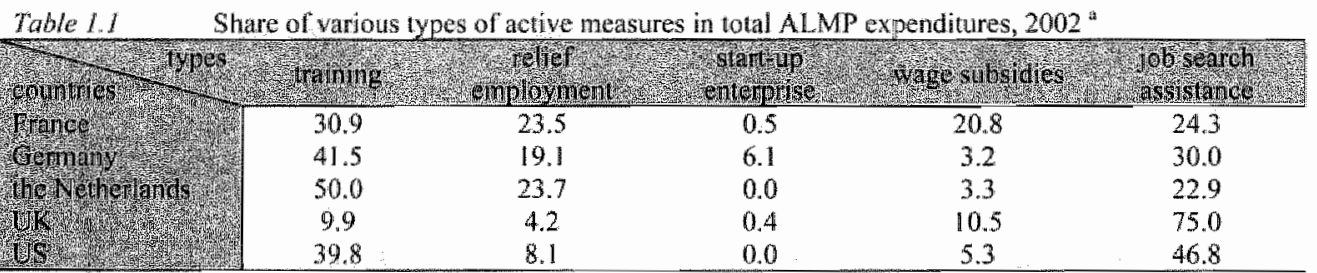

"ALMP expenditures on youth and disabled are not included.

Soturce: OECD Labour Market Statistics

If active measures accomplish their goals (i.e. raise the re-employment probability of unemployed), 'treated' unemployed return to the competitive labour supply. For a given. labour demand this would reduce the aggregate wage which would increase employment and more importantly from the government's budget perspective - reduce unemployment and subsequently benefit payments. Here also the economic rationale for government intervention in the labour market enters the scene: a market failure. It seems reasonable to assume that indiviclual firms when deciding who to hire do not take into consideration the beneficial aggregate wage and tax effects of hiring an applicant who is not part of the competitive labour force. The government - responsible for balancing the budget - has a direct interest in lowering unemployment. Basically it can use the discounted value of the future benefit payments it will pay to an unemployed to finance efforts aiming at re-employing that unemployed. "However, Calmfors (1993) argues that it is unlikely that active labour market measures function as a free lunch, since both low treatment effects and substantial macroeconomic side effects prevent budget neutrality of active labour market measures. We will address both issues separately.

\section{Mico treatment effects of active latow morket measures}

Theoretical considerations on testing treatment effects of active labour market measures have been studied extensively - see for a clear overview Friedlander et al. (1997). The treatment effect measures the impact of participation un an active labour market measure on an ex ante

\footnotetext{
"A relief scheme is a special canse of a wage subsidy scheme. That is, in a relief scheme public firms receive a subsidy to create additional employment, typically for very long-term unemployed. Hence both relief schemes and wage subsidy schemes are pallt or employment subsidy measures.

More precisely it is the product of the change in the re-employment probability and the discounted value of future benefit payments.
} 
determined indicator. Traditionally, two indicators for the treatment effect are used: the change in re-employment probabilities or the change in eamings due to participation in an active labour market measure. The test procedure can best be described using equations 1.1 and 1.2 .

$$
\begin{aligned}
& Y_{i t}=c_{i} X_{i t}+b_{i} P_{i 0}+u_{i i} \quad \text { ^ } \quad t>0 \\
& P_{i 0}=a_{0} Z_{i}+e_{i 0}
\end{aligned}
$$

In equation 1.1, $Y_{i}$ measures the proposed goal of the measure (be it remployment probabilities or earnings) for individual $i$ at period $t$, which is regressed on exogenous factors and personal characteristics which are captured in $X_{\text {if }}$ and a dummy variable for programme participation, $P_{i 0 .}{ }^{8}$ Obviously the interest goes out to coefficient $b_{s}$, which measures the treatment effect of participation. Equation 1.2 represents the participation decision, which is also regressed on individual characteristics. Regression results of $b_{t}$ are unbiased as long as $P_{i 0}$ and $u_{i t}$ are uncorrelated, which is unfortunately no straightforward assumption. First, if factors in $Z_{i}$ (like for example motivation to participate) are not in $X_{i j}$ but are expected to affect $Y_{i t}$ (like motivation probably does) $P_{i j}$ and $u_{i t}$ are correlated. Including $Z_{i}$ in $X_{i t}$ would solve the problem - see Barnow et al. (1980). Second, if both error tems, $e_{i 0}$ and $u_{i}$, are correlated, $P_{i 0}$ and $u_{i r}$ are also correlated. This is a more serious problem when trying to test for treatment effects as selection takes place through unobservables."

In order to test treatment effects empirically, two routes are available: nonexperimental testing and experimental testing. ${ }^{10}$ In both altematives a control group has to be constructed. The main advantage of an experimental analysis is that participants in the experiment are randomly assigned to the treatment or the control group, which ensures that $E\left(e_{i 0}, u_{i t}\right)=0$. This makes it the most popular route to analyse treatment effects of active labour market measures.

The empirical evaluation literature on the treatment effects of the five mentioned measures on long-term unemployed has been along the lines set out above. Forslund and Krueger (1994), Katz (1994), Fay (1996), Friedlander et al (1997), Martin (1998) and Dar and Tzannatos (1999) provide excellent overviews of the empirical evaluation literature.

Evaluation studies on treatment effects of training schemes yield mixed results. In some countries - especially the US - a number of programmes yield substantial earning effects and positive rates of return when the cost of the training scheme is taken into consideration - see Friedlander et al. (1997). Though the exact reasons for the success are unclear, as researchers fail to produce a motivation as to why training schemes tend to be more successful when targeted at women than at youngsters. These positive findings in the US have not been found in Europe - see Forslund and Kreuger (1994), who evaluated Swedish training schemes. Moreover, longitudinal studies show that if there are positive treatment effects of participation in training schemes, they vanish in the long run - see Meager and Evans (1998).

Evaluation studies on treatment effects of relief jobs are conclusive: relief jobs do not yield favourable treatment effects and hence have no significant impact on long-term

\footnotetext{
${ }^{8}$ At $t=0$, participation in the active labour marke measure starts. Hence, to measure the effects of panticipation: $1>0$ in equation 1.1 should hold.

"Using an ifstrumental variable which is correlated to the participation decision but uncorrelated to $Y_{i n}$ would solve the problem. But then the empirical problem is to find such an instrument - see for example Angrist et al. (1996) who mied this route.

in Heckman and Hotz (1996) demonstrate how cross sectional or panel data can be ulsed to deterinine the treament effect; Lalonde (1996) gives an overview of the literature on experimental data.
} 
uniemployment - see Marhin (1998) and Dar and Tzamnatos (1999). However, one should bear in wind that treatment effects are not the sole aim of relief jobs. Typically relief jobs are offered to very long-term unemployed, whose participation in a relief job is the first step in a process towards non-subsidized re-employment.

Evaluation studies on treatment effects of enterprise start-up schemes show that such measures have only limited treatment effects. Failure rates of new (subsidized) enterprises are in line with failure rates of non-subsidized start-ups. Fay (1996) finds that enterprise start-up schemes yield positive treatment effects in terms of employment outcomes, but negative treatment effects in terms of earnings. Given the small share of unemployed who wish to start up their own business, this measure can not be applied on a large scale, which makes it of limited importance to tackle the (long-term) unemployment problem.

Evaluation studies on treatment effects of employment subsidy measures have yielded promising results. Calmfors et $\mathrm{al}$. (2001) argue that wage subsidy schemes are more effective than relief jobs. However, treatment effects appear to be limited at the end of the subsidy period - see for example OECD (1993). Nonetheless, especially wage subsidy schemes that contain a training component yield positive treatment effects - see Bloom et al. (1994).

Evaluation studies on treatment effects of job search assistance have yielded positive results. Gueron (1990) and Meyer (1995) show for the US that job search assistance yields positive treatment effects, both in terms of re-employment probabilities and earnings. Though, treatment effects seem to be pro-cyclical. That is, treatment effects of job search assistance are more pronounced during an upturn.

\section{Macro side effects of active labour market measures}

Given the large scale application of active labour market measures, it is unlikely that their impact on the labour market is restricted to treatment effects on participants, only. Calmfors (1994) and Calmfors et al. (2001) summarize the main side effects of active labour market measures which need to be taken into consideration when evaluating such measures. Since active labour market measures aim at increasing employment prospects of participants, we concentrate on wage pressure effects arising from the introduction of such measures which endanger the job creation process needed to generate employment for long-term unemployed. We mention four of such potentially undesired side effects.

Though active labour market measures aim at increasing re-employment probabilities at the end of the measure, they cause the contrary during the participant's stay in the programme. That is participants focus on successfully fulfilling the tasks set out in the programme and not on finding a job-see Edin and Holmlund (1991). This lock-in effect which does not affect 'openly unemployed' - has effective labour supply reducing consequences, which might lead to wage pressure.

To ensure unemployed participate in active labour market measures (assuming participation in measures is not compulsory), the utility gained from participation should outweigh the utility from remaining openly unemployed. This extra utility raises the outside option of employees and hence their reservation wage, which leads to wage pressure. This extra utility could arise from higher wages that are paid in such schemes - see for example Calmfors and Forslund (1991) or Calmfors and Nymoen (1990). Participants could reap extra utility from the relevance of the work done - Korpi (1997). Or the additional utility arrives from the target of the measures: raise re-employment probabilities. If active labour market measures indeed increase re-employment probabilities, unemployment spells shorten, which raises the outside option - see for example Calmfors and Lang (1995).

Some active labour market measures (notably training and wage subsidy schemes) have productivity augmenting effects. Though valuable in terms of raising the production 
capacity, Bean el al. (1986) argue that productivity increases lead to proportionate wage increases, leaving the unemployment level unchanged.

If the gains from introducing active labour market policies in terns of increasing the tax base due to increased overall aggregate employment, do not outweigh the costs in terms of excess expenditures above passive policies (typically benefit expenditures) sucl policies are no free lunch and hence, tax effects need to be addressed as well. In reviewing the literature Calmfors (1993) argues that active labour market measures are unlikely to be free lunches. Consequently tax increases due to the introduction of such schemes might depress the aggregate employment outcome.

To address the aggregate wage and employment effects of the various active labour market measures, micro studies on treatment effects are too restricted and consequently macro or general equilibrium models have to be used. Though macro studies also suffer from several econometrical problems, they at least take general equilibrium effeets of active labour market measures into consideration. 11

Calmfors et al. (2001) review the empirical literature on macroeconomic consequences of introducing active labour market measures. These studies show that thete is little evidence that active labour market measures reduce aggregate wages. Calmfors and Forslund (1991) and Calmfors and Nymoen (1990) find wage pressure effects as a result of introducing active labour market measures; others find no such effects - like Newell and Symons (1987) and Forslund (1995) - or they find the desired wage depressing effects - like OECD (1993). These findings suggest that the side effects mentioned above cancel the wage depressing effect of increasing the effective labour supply, which active labour market measures aim at. Apparently side effects play a significant role, which implies that when evaluating active labour market measures we should concentrate on the outcomes of macro studies.

Though micro studies provide some evidence that wage subsidy schemes and job search assistance yield better results than training in terms of re-employment probabilities of participants, macro studies seem to argue the reverse... training is more effective in increasing employment than wage subsidy schemes - see Calmfors et al. (2001). ${ }^{12}$ That is partly because wage subsidy schemes lead to more wage pressure effects than training, which crowds out regular employment - see Jongen et al. (2003). Apart from wage pressure effects, wage subsidy schemes suffer from another important side effect: displacement. Displacement measures the share of subsidized jobs that are not additional to regular employment. One can distinguish three reasons why subsidized employment does not lead to an extension of aggregate employment.

First, the share of subsidized jobs that would have been filled with long-term unemployed in the absence of the subsidy, which is defined as deadweight loss. "That is, deadweight loss refers to the share of participants in the employment subsidy measure that would have also found a job in the absence of the subsidy. Second, the share of subsidized jobs that would have been filled with other than long-term unemployed in the absence of the subsidy, which is dubbed substitution. That is, substitution refers to the share of participants that would not have found a job in the absence of the subsidy but whose current subsidized.

\footnotetext{
"Besicles shortage of suitable data sets, the main econometrical problem of such macro studies is a causality problem. If expenditures on active labour market measures are time dependent (i.e. dependen on the stance of the economy), it is hard to assess whether changes in expenditures on active labour market measures cause changes in the unemployment rate or vice versa. Since expenditures on active labour market measures are typically driven by economic conditions, the causality problem is a relevant issue, which needs to be addressed see for example Calmfors et al. (2001).

12 The effects of job search assistance thave - to our knowledge - never been separately tested in macro economic studies.
} 
position is at the expense of employment for non-targeted (short-term) unemployed. Finally, external displacement refers to the reduction in employment elsewhere due to competition in goods rnarkets. That is $s_{3}$ due to the subsidy a firm might beat off competitors and increase market share, which leads to loss of employment elsewhere.

Both deadweiglat loss and substitution do not lead to an increase in overall employment. $^{13}$ Substitution at least improves the job find probability of long-term unemployed (although at the expense of short-term unemployed); deadweight loss does not even improve the job find probability of long-tern unemployed and hence falls to have wage depressing effects.

The size of displacement effects in wage subsidy schemes has been studied empirically via two routes. The first route makes use of questionnaires in which employers and/or subsidized employees were asked whether the subsidized participant would have found an unsubsidized job. If the answer is positive, displacement (be it deadweight loss or substitution) was confirmed. Fay (1996) and Dar and Tzannatos (1999) give clear overviews of the outcomes of such survey studies. Table 1.2 contains findings of survey studies conducted in several OECD countries throughout the last three decades. As can be seen, shares of subsidized jobs that are additional are generally low, which implies that displacement - of which deadweight loss is the most important contributor - is significant.

Table 1.2 History of efficiency of employment subsidies in some OECD countries

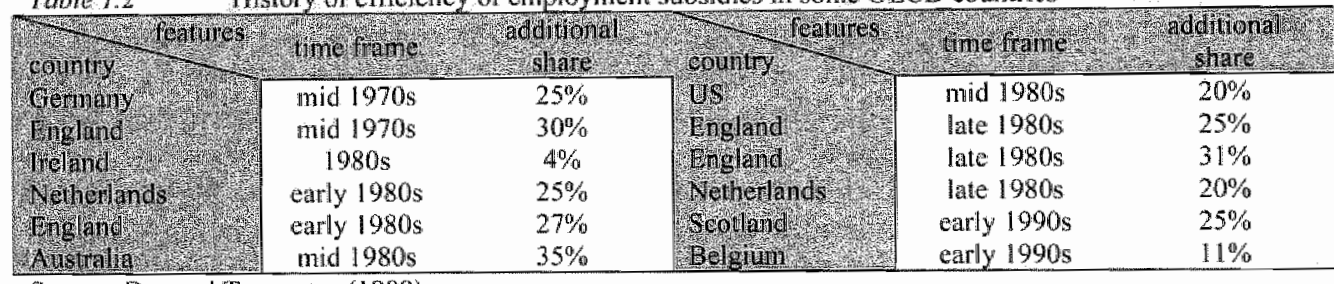

Source: Datr and Tzannatos (1999)

The second route applies econometric models to compare the employment outcome if wage subsidy schemes had and had not been installed - see Calmfors et al. (2001) for an overview of such studies performed on Swedish data. These studies find comparable or even higher displacement effects than the survey studies, which can be attributed to the difficulties respondents of questionnaires (be it employers or employees) meet to estimate the significance of external displacement, which is subsequently not taken into consideration.

Displacement effects can explain the contradictory findings of micro and macro studies conceming the effectiveness of wage subsidy schemes as a means to raise employment probabilities of long-term unemployed. That is, micro studies find that participants in wage subsidy schemes experience better employment prospects than non participants, but potentially tail to observe that these prosperous employment prospects do not exclusively stem from participation itself but also from the fact that the firm would have hired them anyway $-i$. in in the case of deadweight loss.

This hypothesis justifies an analysis into the origin and incidence of deadweight loss in employment subsidies. Preventing deadweight loss accomplishes four purposes. It reduces

\footnotetext{
Neither do external displacement effects. However, the fow studies that have tried to measure external displacement - see for sample Dar and Tzannatos (1999) - found that extemal displacement affects only play a minor role in total displacement compared to substitution effects and especially deadweight loss effects, which motivates us to neglect effects of external displacement.
} 
wastage of public expenditures as such expenditures do not change employer behaviour and consequently do not improve the labour market position of long-terin unemployed. It increases the wage depressing - and hence the aggregate employment augmenting - ability of employment subsidy measures as only unemployed who are not part of the competitive labour supply can participate. The prevention of deadweight loss also reveals the true "treatment effect' of employment subsidies and finally it ensures the government can target its active labour market policy on long-term unemployed who actually need help to return to the labour market. $^{14}$

\subsection{Firm hïring behaviour: tracing the culprit}

To explore the incidence of deadweight loss - which is the main focus of this dissertation we look at the demand side of the labour market. Following Omori (1997) we assume the firm to use unemployment duration as a screening device. That is, firms infer applicant quality from his/her employment history. To weed out unqualified from qualified applicants, the firm sets a screening device standard, i.e. a maximum threshold value of unemployment duration an applicant may experience to be still considered for the vacancy. The government also links programme participation to unemployment duration, $i . e$. the start value of subsidy entitlement is typically set in terms of a minimum unemployment duration. If both segments overlap, firms potentially receive a subsidy for unemployed they would have taken into consideration for the vacancy without the subsidy: deadweight loss.

Since the government's segment is generally invariable (wage subsidies can usually be obtained for unemployed experiencing an unemployment spell from one year onwards), it is the firm's choice of the threshold value of unemployment duration to be still considered for the job which determines the overlap and hence the incidence of deadweight loss. As we will claim throughout this dissertation, this threshold value depends on the firm's hiring behaviour. Hiring behaviour is not homogenous, but firm and job specific and also depends on labour market conditions. That is, firms differ with respect to the various aspects of hiring costs they face and respond in ways to minimize their individual hiring costs. This leads to different decisions regarding recruitment channel choice and subsequent screening decisions. Such differences eventually filter out in the decision of firms to recruit from long-term unemployed or not, which subsequently implies that some firms are more likely to cause deadweight loss than others.

The hiring strategy has several components, which we will discuss separately. The lirst component is the choice of the recruitment channel, which is needed to generate an arrival rate of applicants. The firm can choose from several formal and informal channels - see Rees (1966). ${ }^{15}$ Firms can use formal channels like advertisements, the labour exchange office and private employment offices (like head-hunters or temporary placement offices) or search via incumbent personnel or via external acquaintances which are informal channels. Table 1.3 contains information on recruitment channel choice of Dutch firms in 1986. It is the first recruitment channel the firms have used to fill a vacancy. The table shows that the choice of the recruitment channel depends on the educational requirement of the vacancy. Firms are more likely to use advertisements as a recruitment channel when educational requirements are high. The opposite holds for the labour exchange office as a recruitment channel. The use of

\footnotetext{
${ }^{14}$ Dar and Tranmatos (1999) argue that the other active Uabour market measure that yields promising resulis - job search assistance - also suffers from substantal deadweight loss effects. That is, assistance lo long-tem unemployed that would have found a job without assistance. This potentially explains the promising evaluation results of this measure and strengthens us to explote the incidence of deadweight loss.

is The firm can also choose to operate several recruitmern channels at the same time.
} 
informal chanels varies less with educational requirements. Recruitment channel choice is potentially through educational attainment - sector dependent. Industrial and construction firms predominatitly rely on the labour exchange office; whereas the public sector's most importan recruitment channel is the advertisement channel. Finally recruitment channel choice is also related to firm size. Small firms rely on the labour exchange office, medium sized firms on advertisements; whereas large firms extensively use their informal network.

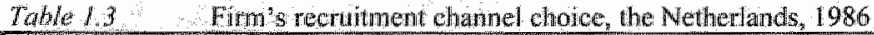

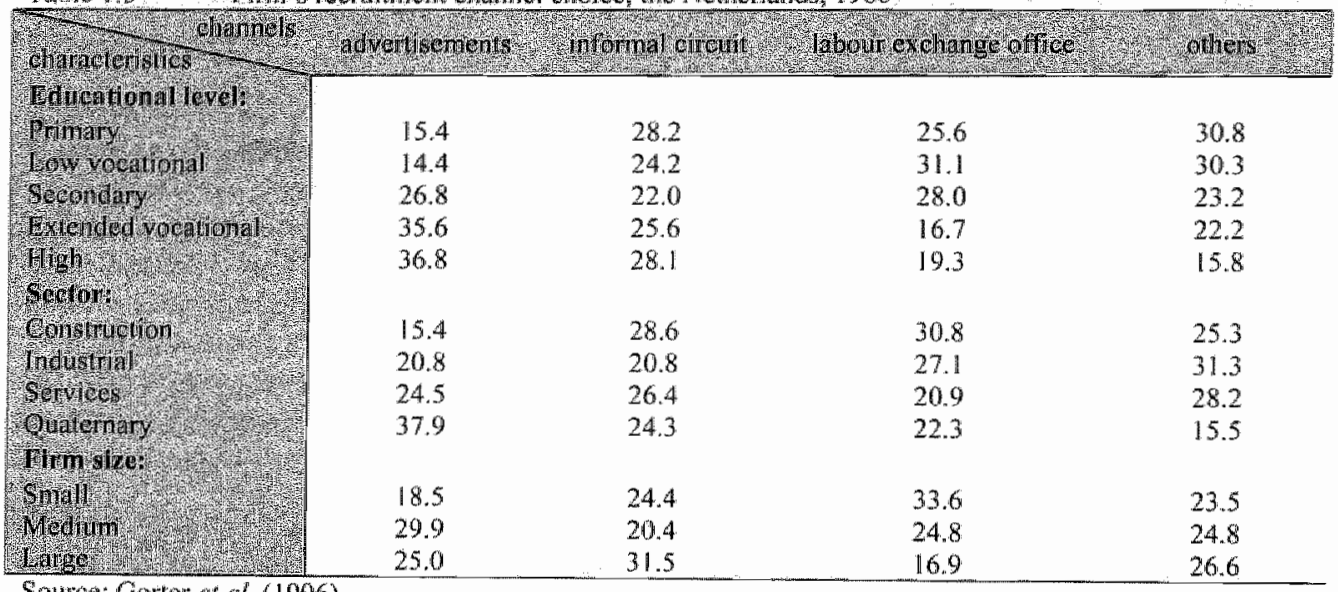

Source: Gorter ef al (1996)

Differences in recruitment channel choice have implications for the rest of the hiring procedure. As Table 1.4 demonstrates, advertisements generate a higher arrivall rate of applicants than any other recruitment channel. Apart from more applicants, advertisements also yield better qualified candidates - see for example Russo el al. (1997b). However, advertisements are expensive, especially compared to using the labour exchange office, which is usually free of charge. Besides, the large number of applicants yields high screening costs see Russo et al. (2000) and leads to prolonged hiring procedures, as Table 1.4 demonstrates. On the other hand, applicants generated from the labour exchange office are less qualified, sometimes unnotivated and unwilling to give up unemployment benefits - see for example Van Ours (1994) or Barron and Mellow (1982). Lindeboom ef al. (1994) show that informal channels are effective in generating qualified applicants. That is, colleagues that recommend applicants know the match between the qualities of those they recommend and the requirements of the job - see Montgomery (1991). The main disadvantage of informal channels is that they yield low applicant arrival rates, as Table 1.4 shows - see also Mencken and Winfield (1998).

Table 1.4 Firm's recuitment channel choice, the Netheriands, 1991-1994

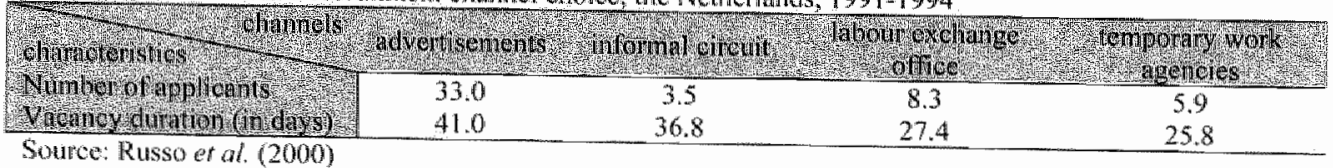

Consequently, in choosing the recruitment channel the firm has to make trade-offs about the desired atrival rate of applicants, the quality of applicants and the costs involved in activating a recruitment channel. Therefore, the recruitment channel choice is conditional on the costs that firms have to bear during the remainder of the hiring procedure, i.e. the selection phase. 
Firms that face high costs of a non-productive vacancy and subsequently want to fill the wacancy quickly, require a high arrival rate of job seekers; firms that face substantial costs of screening applicants, require high quality applicants, which ensures that few screens are needed.

Screening costs consist of two components: extensive and intensive costs. Extensive costs refer to the number of applicants the firm screens before it makes a job offer. Intensive costs refer to the effort (for example measured in hours spent per candidate) firms put into screening an applicant. Table 1.5 gives an overview of both screening cost aspects for the US. The first column gives the number of applicants per interview, which indicates the average number of applicants that arrive before the firm finds one that it deems qualified enough to screen carefully. Occupational levels matter, as firms appear to disregand twice as many applicants for blue collar wacancies than for higher occupational level vacancies. The second column hints at extensive search costs. That is, the number of interviews per job offer. This second column hints that firms interview less applicants per job offer for low than for intermediate or high occupational level vacancies. This observation suggests that though firms generally search non-sequentially, this does not hold for low paid jobs. Gorter er al. (1996) and Van Ours and Ridder (1992) indeed find empirical support for sequential search at the bottom side of the job spectrum. Firm size also matters, as large firms invite more job seekers for an interview than small firms. ${ }^{16}$

Table 1.5 Firm's hiring behaviour to industry, US, 1981

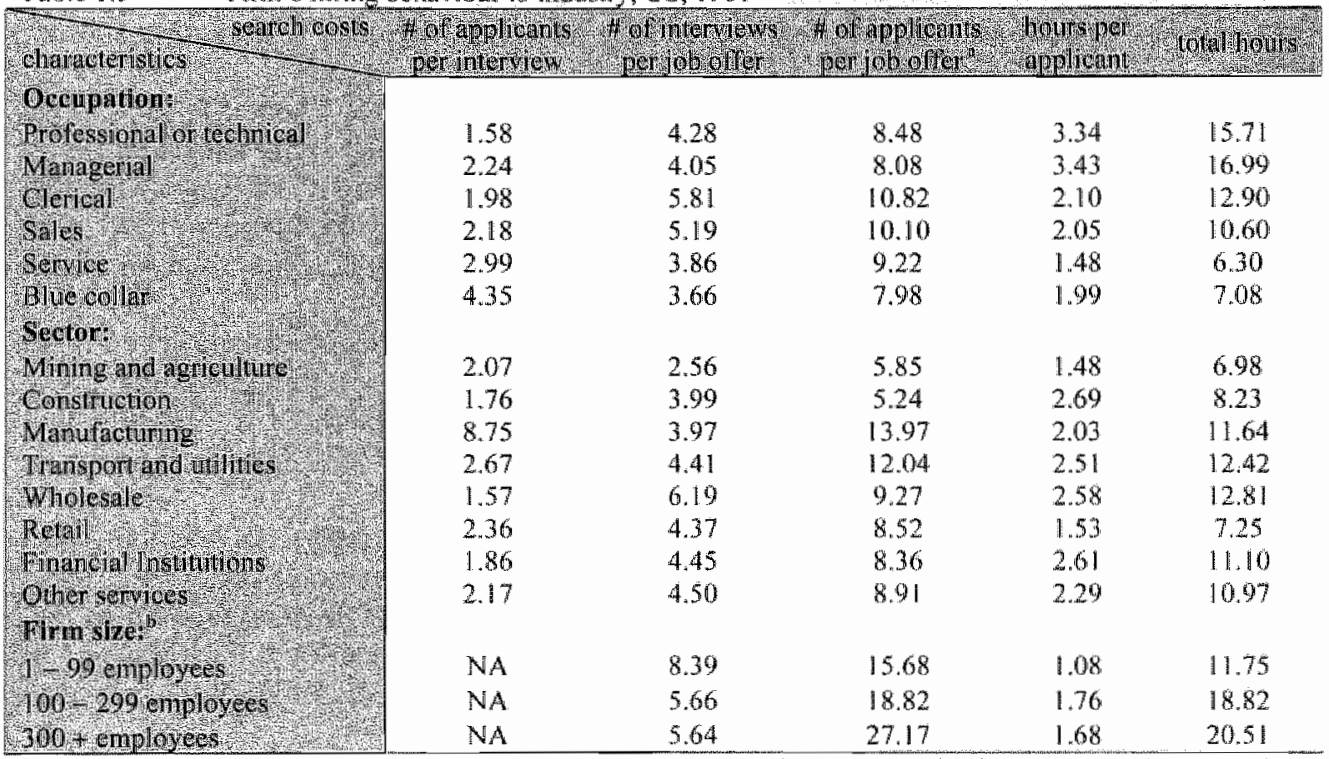

"Note that the figures presented are arithmetic means. Hence the product of colunns one and iwo need not correspond to figures in column three.

"data on firm size are 1993 US data.

Source: Barron and Bishop (1985), Barron ef al. (1997)

The fourth column indicates intensive search costs, measured as the number of hours spent per applicant, where the number of hours is a proxy for costs laid out on screening the

\footnotetext{
Whear in mind, that hiring costs not only depend on fintm size or occupational job llevel, but also on faclors like type of job contract, laboum market tighness and trainumg - see for example Barron et al. (1985) or Barron at al. (1987).
} 
applicant. Here we clearly see that there is a tendency of frms spending more time screening job seekers when the oceupational job level increases. Increasing job complexity, which requires careful selection could be the driving force here - see Barron et al. (1997). Large firms search more intensively than small firms. Holzer (1990) and Burdett and Cunningham (1998) suggest that high monitoring costs in large firms might induce firms to carefully screen entrants.

\section{L.5 Taking stock: dissertation outline}

The first objective of this dissertation is to link the firm's hiring behaviour to the incidence of deadweight loss. Chapter II is devoted to this objective. We define the labour market circunstances under which the firm will use unemployment duration as a screening device and relate the threshold value the firm will apply to the various hiring costs it encounters when recruiting. Parallel to the firm's decision we model the government"s motivation to introduce an employment subsidy, which can be twofold: providing a subsidy to compensate for extended search (a wage subsidy) or a subsidy compensating for upgrading skills (a training subsidy). Finally, we integrate both models which yields the potential incidence of deadweight loss.

Chapter III addresses the theoretical issues of averting the incidence of deadweight loss within employment subsidy measures under the condition that the government cannot trace firms that provoke deadweight loss. We discuss the incentives needed to be provided to firms to refrain them from causing deadweight loss, both in a wage and in a training subsidy scheme.

In Chapter IV we empirically test the model predictions from Chapter II for a wage subsidy. In doing so, we employ two data sets. One dataset on Dutch firms who hired longterm unemployed for whom they received a wage subsidy as part of the "afdrachtVermindering Langdurig Werklozen" ("VLW", tax Deduction Long-term Unemployed) and a second dataset on British firms who took part in the New Deal for Longterm Unemployed (NDLTU) programme.

Chapter $\mathrm{V}$ is - as Chapter IV - devoted to empirical testing. We use a data set on firms that took part in the New Deal for Young People (NDYP), which is a training subsidy. The theoretical model presented in Chapter II predicts a different pattern of deadweight loss incidence under a training subsidy than under a wage subsidy. We look for confirmation of this hypothesis.

Chapter VI explores the private initiative that Philips has undertaken to lead long-term unemployed back to employment. The Philips Employment Scheme (PES) is a largely unsubsidized scheme in which long-term unemployed can combine working at Philips and studying to accomplish a generally accepted vocational degree. We analyse the success rate of the scheme and its revemues to Philips, which are needed to explain Philips' sustained commitment to continue the scheme.

Chapter VIl concludes this dissertation and is dedicated to the lessons to be learned. 




\section{Chapter II: Recruitment among Rejects}

Assuming symmetric ignorance instead of asymmetric information prevents fims from applying hiring procedures relying on self-selection. To select applicants we introduce unemployment status as a screening device in an employer search model, which provides new insights into the exclusion of long-term unemployed in hiring procedures regardless their productivity level. Though efficient at the firm level; this exclusion is not efficient at the macroeconomic level, which justifies government intervention. Although no free lunch, temporary employment subsidy schemes provide structural employment for part of the otherwise neglected long-term unemployed, which leads to a welcome extension of relevant labour supply. Furthermore our model sliows that inefficient allocation of subsidies - deadweight loss - is closely related to the design of the subsidy scheme.

\subsection{Introduction}

Since the mid eighties active labour market policy (ALMP) constitutes a substantial part of the efforts governments put into fighting long-term unemployment - see for example OECD (2003). Policies targeted at long-term unemployed comprise a considerable and still growing part of ALMP. Figure 2.1 shows that the share of active labour market measures specifically targeted at long-term unemployed (LTU) increased from barely $2 \%$ of total expenditures on ALMP in the Netherlands in 1990 to $40 \%$ in 2001.

Figure 2.1 Composition of active labour market measures, the Netherlands $1990-200 \mathbb{1}^{17}$

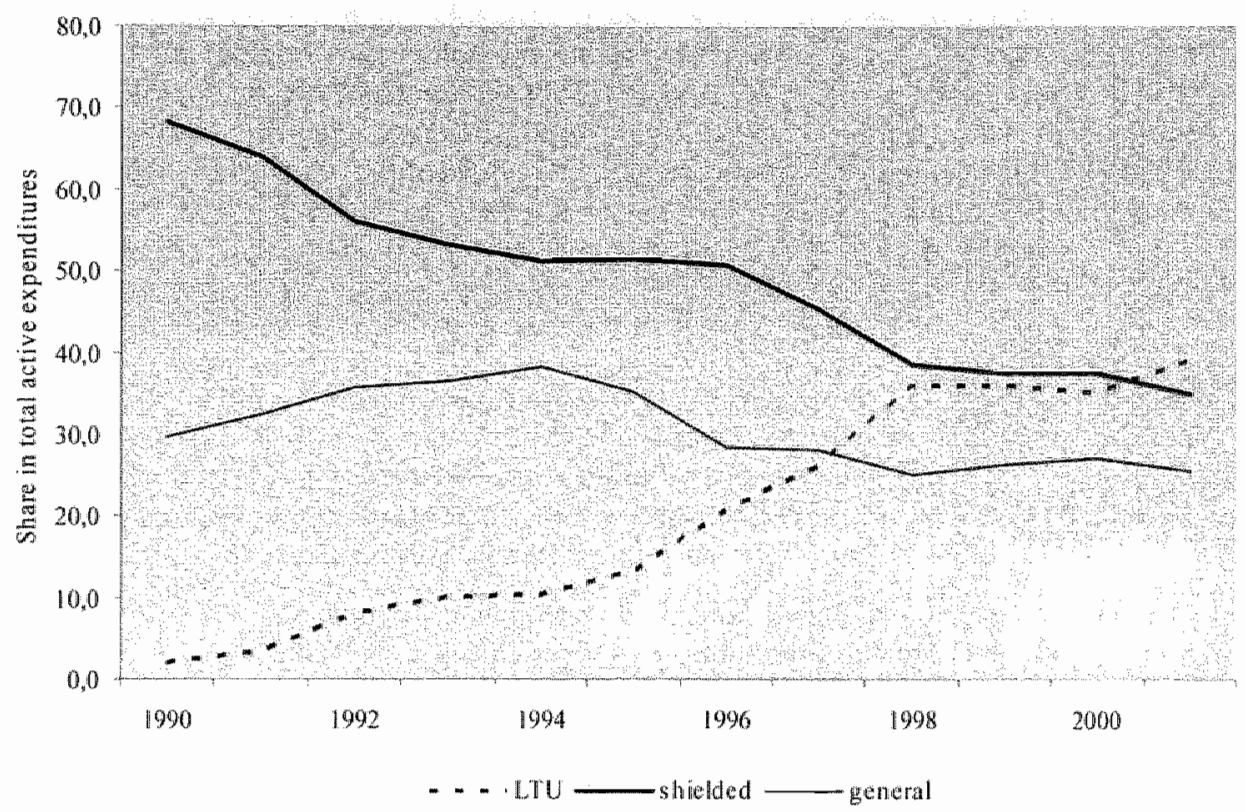

Source: Ministry SAE (2001)

\footnotetext{
${ }^{17}$ General employment subsidy measures comprise tax exemptions employers receive for all employees they employ at a wage at or just above the minimum wage. LTU employment subsidy measures are targeded at longterm unemployed only. Part of the money is spent on job creation in the public sector. The rest is available for employers in the private sector who hire long-lerm unemployed. Subsidized employment in the shielded sector aims at creating jobs for disabled unemployed who are not expected to find a non-subsidized job.
} 
At the root of our model is an employer search matching model in line with Mortensen (1982) and Pissarides $(1986,2000)$. Imperfect information on the labour market concening the productivity level of applicants induces the firm to use unemployment duration as a screening device in its hiring procedure. Introducing unemployment duration as a screening device which is a novelty to such models - splits the job seekers pool into two parts: those who are taken into consideration for the vacancy and those who are not: Since unemployment duration is no perfect proxy for productivity, the firm makes both type I errors (retaining unqualified job seekers in the selection process) and type Ill errors (excluding qualified job seekers from the selection process). Type I errors augment the failure rate of assessing candidates, which is a costly activity. Type $\mathbb{I}$ errors lead to a lengthening of the hiring procedure, which implies the firm foregoes productivity. Unfortunately the firm cannot simultaneously reduce bye 1 and type II errors, but has to trade them off, which implies firms accept a hiring cost minimizing combination of both type I and type II errors in their hiring procedure. Although efficient at the individual firm level, type II errots are inefficient at the aggregate, macroeconomic level. This provides room for introducing employment subsidies, of which we distinguish two kinds. The firm either uses the subsidy to recruit from applicants for whom the firm"s hiring costs are not minimized, or it applies the subsidy to finance training for its hirings.

Section 2.2 sets out our extensions to the standard employer search model. In Section 2.3 we introduce employment subsidies into our model. The fourth section discusses the link between the degree of efficiency in allocating subsidies and the design of the subsidy scheme. In Section 2.5 we apply our model to the Dutch situation. Section 2.6 concludes.

\subsection{A sequential employer search model}

Consider a competitive labour market in which there are / identical firms. Next to these furms there are $J$ unemployed job seekers, who differ with respect to their ability, $a_{j}$, and productivity level, $p_{j}$. The firm has a vacancy it wants to fill, but imperfect information prevents the firm from observing the productivity level of an applicant, which is relevant, since the firm requires a minimum productivity level, $p^{*}$ at the firm, which is exogenous to the model.

Think of the car manufacturing industry, which operates an assembly line requiring employees to produce within a fixed time window. This fixed time window requires a minimum productivity level of employees ensuring the assembly line to function properly. $\| t$ is this minimum productivity level, $p$, that we have in mind. Employees whose productivity level is below $p^{*}$ endanger the complete car manufacturing process; employees whose productivity level exceeds $p^{*}$ do not increase firm productivity. They are also tied to the speed of the assembly line, which can only be raised when all employees" productivity is augmented collectively. A possibility we dispose of in our analysis.

To augment the average productivity level of applicants, and as a result the probability of hiring an applicant meeting $p^{\text {* }}$, the theoretical literature provides several measures the firm can take. Weiss (1980) proposes to raise the wage offer. He argues that high productivity applicants have high reservation wages. Hence high wage offers increase the share of high productive applicants amongst the arriving job seekers, which raises the probability to hire an applicant who meets $p^{*}$. Guasch and Weiss $(1980,1981)$ propose to introduce ability tests, which enable firms to locate the most productive workers (tests on a pass/fail basis). The authors argue that the most productive workers will be most confident of passing the test and subsequently are more likely to do the test. Consequently the very fact of announcing that an 
ability test is part of the hiring procedure will discourage those to apply who expect not to pass the test, $i, e$ the low productive applicants. Greenwald (1986) proposes a third route to solve the information imperfection. He argues that employers should introduce probationary contracts. During a probationary period, the employer observes the otherwise "hidden" abilities of workers. At the end of this period the employer decides whether to continue the employment relation or not, based on the productivity of the worker. Applicants - not certain of surviving the probationary period - refuse probationary contracts, which therefore bave the same selection effects as introducing ability tests.

Probationary periods and ability tests constitute entry barriers for low productive applicants, whereas high wage offers provide incentives for high productive applicants to apply for the job. All three arguments lead to the desired effect of augmenting the average productivity level of applicants, but draw heavily on the assumption of asymmetric information. That is, firms do not know the productivity level of applicants; whereas the applicants themselwes do know their productivity level. Though the latter assumption is questionable in general - see Lazear (1998), it is even more questionable for long-term unemployed. Their long-term absence from the labour market questions their ability to know their true labour market value. Since this dissertation deals with recruitment from long-term unemployed we drop the option to rely on self-selection.

Moreover, the substantial expenditures firms spend on human resource management, arguably demonstrate that self-selection can only be part of the hiring strategy - cf. Hale (1998). Therefore we drop the asymmetric information assumption and instead assume - as Lazear (1998) defines it - symmetric ignorance to prevail on the bottom-side of the labour market. That is, both the applicant and the firm do not know the applicant's productivity level. Consequently, the firm cannot elicit signals of applicants about their productivity level and subsequently must search to find a qualified applicant.

As we will model, hiring costs depend both on the duration and the size (in terms of assessed candidates) of the hiring procedure. The quality of arriving applicants - in terms of their (hidden) productivity level - is vital in keeping hiring costs low. That is, if applicants arrive that are likely to meet $p^{*}$, the hiring procedure can be plain and short. Self-selection to augment the likelihood that arriving applicants meet $p^{*}$ is unavailable, but instead the firm can use an observable screening device in Stiglitz (1975) style. Though both the theoretical and enpirical literature predominantly focus on education as a screening device, we instead use anemployment duration as a screening device. ${ }^{19}$

To function as a useful screening device, a high correlation between the screening device and the unobservable characteristic is needed. Economic literature provides two arguments why unemployment duration and productivity levels are (negatively) correlated: duration dependence and heterogeneity. The former argument presupposes the non-use of: skills during unemployment spells to lead to atrophy of skills and hence to productivity loss see for an overview De Grip and Van Loo (2002). The latter presupposes the most productive workers to quickly find a job, leaving the less productive workers in the unemployment pool, whose share in the total job seekers pool therefore increases as unemployment duration

\footnotetext{
(19 The theoretical pioneer work on the use of education as a scmening device is from Spence (1973). Stiglitz (1975) and Riley (1976). The former introduces the signalfing role of education. That is, if job seekers know that lirms scren based on their educational attanments, job seekers will invest in their educational atianment to has triggered an interesting empirical debate. Soe Taubges (human capital versus screening argumentations) (1974). Wolpin (1977) or Lang and Kropp (1986) for some and Wates (1973), Layard and Psacharopoulos most papers is that firms use educational attanment as a screening empurical contributions. The bottom line of
} 
increases. Devine and Kiefer (1991) give an excellent overview of this strand of literature, while concluding that both heterogeneity and negative duration dependence play a role in explaining declining hazard rates.

Heckman and Borjas (1980), Lynch (1985, 1989), Trivedi and Alexander (1989), Wan den Berg and Van Ours (1994) and Omori (1997) not only use the length of the uncompleted spell of unemployment as a predictor of the re-employment probability but also earlier completed spells of unemployment. If earlier completed spells - which do not influence current productivity decay - matter for the current re-entoloyment probability, one could distinguish negative duration dependence from pure stigma effects, i.e. use unemployment history to infer unobserved worker characteristics. Omori (1997) - using a richer data set than others - finds clear empirical evidence that completed spells of unemployment reduce the current re-employment probability. The reason for the start of a completed spell of unemployment matters, as well as the labour market circumstances at that time. That is, loosing one's job through firing / in tight conditions - even though the subsequent spell of unemployment has been completed - reduces the current re-employment probability more than earlier job loss through quitting / in easy conditions.

As a result, there are not only clear reasons for suggesting that unemployment duration is negatively correlated with productivity, the Omori (1997) results also provide evidence that firms indeed use unemployment duration as a screening device. Moreover, the notion of stigma effects of unemployment duration also underpins the govenment"s reasoning to provide employment subsidies to firms who hire long-term unemployed. Both arguments validate our decision to integrate the role of unemployment duration as a screening device into Pissarides (2000) style matching models, when exploring the effects of employment subsidy measures on the firm's hiring behaviour.

Although firms cannot observe the productivity of a worker, $p_{j}$, nor her ability, $a_{j}$, the employer knows the ability distribution over all workers. The ability level of an employee initially equals ber productivity level; during unemployment the productivity level depreciates at a rate $p$, whereas (innate) ability is unaffected by the length of the unemployment spell, $t^{20}$ Hence, we assume the following link between ability and productivity for job seeker $j$ :

$$
p_{j}=\left[1-\rho\left(t_{j}, a_{j}\right)\right] \cdot a_{j} \quad \rho_{r}>0, \rho_{a}>0, \rho_{k}<0
$$

Where $\rho=1-\mathrm{e}^{-\delta[\alpha] y j}, \delta$ is a discount factor and $\delta_{j}>0$. We briefly ellaborate on the properties of the depreciation of productivity, since they condition the results of the rest of the chapter.

The first property, $\rho_{t}>0$, indicates the positive relation between productivity depreciation and unemployment duration, $t$. Skills get outdated following non-tuse and hence productivity declines. The empirical literature on post intermittence wage declines confirms this - see for example Mincer and Ofek (1982), Mincer and Polachek (1978), Kim and Polachek (1994) and Albrecht et al. (1998). But not only economists find this negative relationship, also psychologists do - see Arthur et al. (1998).

The second property, $\rho_{\alpha}>0$, assures a positive relation between productivity depreciation and ability level. High ability workers face a higher productivity depreciation rate than low ability workers following a given spell of unemployment. Albrecht et al. (1998) and Neumann and Weiss (1995) find empirical support for this hypothesis.

\footnotetext{
${ }^{20}$ Here we make the assumption that productivity loss as a result of a completed spell of unemployment will be nullified by a spell of employnent, which enables ws to abstract from the effect of earlier completed spells of unemployment on current productivity.
} 
The third property, $\rho_{t t}<0$, implies a diminishing increase in productivity loss as unemployment duration continues. The rationale belhind this property follows from the second property, which intuitively says: the more productive you are, the more there is to lose: Moreover, this assumption excludes negative productivity levels.

Figure 2.2 illustrates the consequences of equation 2.1 for the relationship between productivity and unemployment duration. As employees lose their jobs (or leave school), their unemployment spell starts, skill atrophy causes productivity to decline, which is represented by the two downward sloping curves. The upper curve represents the productivity depreciation of the most able individual, whose productivity is given by equation 2.2 .

$$
p_{\text {maxis }}(1)=a_{\text {max }} e^{-z_{\text {minas }} t}
$$

Hence $\delta_{m a}$ is the per-period discount factor of the most able individual and it yields the highest productivity level available for a given unemployment duration. The lower curve represents productivity depreciation of the least able individual.

$$
p_{\min }(1)=a_{\min } e^{-s_{\text {mats }} r}
$$

Since high ability individuals experience more productivity deterioration following non-use of skills than low ability individuals $\left(\rho_{\alpha}>0\right.$ in equation 2.1$): \delta_{\max }>\delta_{\min }$.

Figure 22 Link between memployment duration and productivity

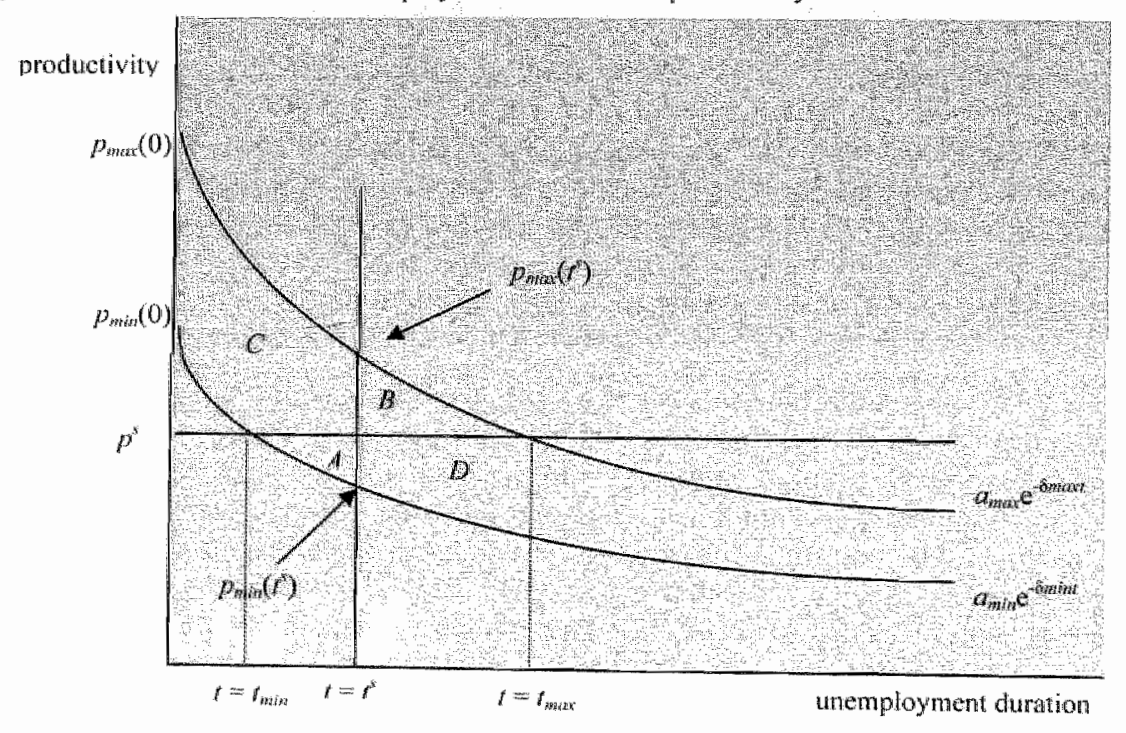

Before describing the hiring process we replace $p^{*}$ (the productivity level needed to be productive on the job) by $p^{s}$ (the minimum productivity level to be hired set by the firm). The firm can set $p^{s}<p^{*}$ and upgrade newcomers to $p^{*}$ providing training. As we show later,
setting $p^{*}<p^{*}$ may be cost efficient to the firm. Subsequently, from now on $p^{s}$ is the relevant productivity standard, bearing in mind that it might deviate from $p^{*}$. Figure 2.2 also contains this productivity standard $p^{s}$, which splits the unemployment pool into unemployed that meet 
the productivity standard and those who do not. The firm's aim now is to apply a hung cost mininizing strategy to find an applicant who meets $p^{3}$. In the same way as tims who use educational attamment as a screening device and who set a screening device standard (a minimum educational attamment to be taken into consideration for the vacancy), firns applying unemployment duration as a screening device set a standard, which sets a maxumum to the duration of the umemployed's uncompleted spell of unemployment to be considered for the vacancy. The screeming device standard, $f^{3}$, is included in Figure 2.2 , which together with $p^{s}$ allows us to identify type I and type II errors the firm incurs, which are areas $A$ and $B$, respectively. Shortly we will elaborate on the exact nature of hiring costs belonging to type 1 and II errors, but for the moment we want to stress that the firm's choice of $f^{t}$ and $p^{s}$ determines the balance (or trade-off) of type I and II errors.

Figure 2.3 summarizes the hiring procedure. We assune that the firm sequentially searches for new employees. The literature on employer search distinguishes sequential from non sequential search. Firms filling a vacancy sequentially assess each applicant separately and continue this process until they find a qualified candidate. Firms filling vacancies nonsequentially first form a pool of applicants, subsequently assess all of them and finally select the best candidate of the pool. Van Ours and Ridder (1992) and Gorter et al. (1996) show that recruitment from lower educated usually concerns sequential recruitment. Since the burden of (long-term) unemployment and subsequently the use of employment subsidies is predominantly devolved on lower or non-educated, we apply sequential search in our model.

The vacancy announcement yields a contact rate of applicants, $q$. Before assessing applicants, the firm first screens candidates setting a screening device standard, $t^{t}$. If $t_{j}>t$, the applicant will be rejected ${ }_{n}$ in case of $t_{j} \leq t^{s}$, the candidate will be assessed. During an assessment the true productivity level will be revealed. If $p_{i}<p^{s}$, the applicant will be rejected; if $p_{i} \geq p^{s}$, the applicant will be engaged and the hiring procedure closes. ${ }^{21}$

Figure 2.3 Overview of the hiring procedure

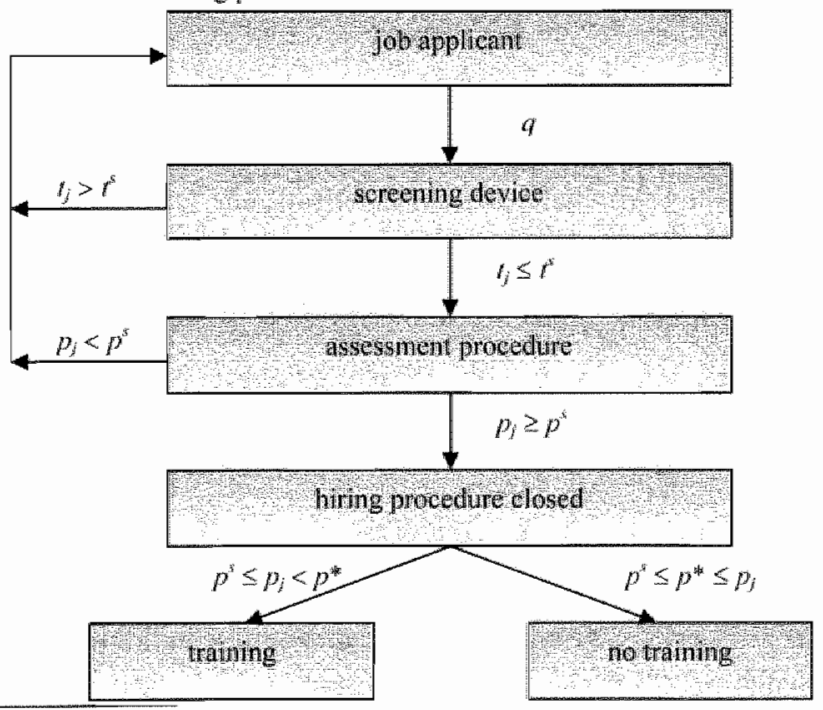

21 The employer and an applicant who is selected for an assessment sign a contract before the assessment, which stipulates that the firm must hire the applicant il he meets $p^{*}$, which excludes the possibility to continue search for an applicant who is more productive than the first who meets $p$. Given the production environment we assume it is also not profitable to continue searching for a more productive applicant. However, when discussing training subsidies in Chapter III, this assumption becomes relevant. 


\subsection{The hiring model}

Having outlined and justified the model choices we have made, we can now build the model analytically. The hiring procedure starts as the firm posts the vacancy to generate an arrival rate of job seekers. 22 The arrival rate of job seekers is autonomously determined at rate $q$. It depends negatively on labour market tightness, $\theta$, which is exogenous to the model and defined as the number of vacancies per unemployed. Consequently, the number of periods between two arriving applicants; $\psi$, equals $1 / q$. Hence $\psi=\psi(\theta)$ and $\psi_{\theta}>0$.

\section{Recruiment costs}

We distinguish two sources of recruitment costs in the model: the costs of carrying out an assessment, $b$, and per-period foregone productiviry, $c$. The latter costs refer to the productivity loss of a vacancy, which is an exogenous variable in our model.

Since the firm uses unemployment duration as a screening device, not all arriving candidates are allowed to enter the assessment procedure. The average number of candidates needed before a second arrives who is deemed assessable (i.e. who meets the screening device standard) is measured by $\varphi$. Therefore, the average number of periods passing by before a second candidate arrives who meets the screening device standard equals $\varphi \psi$.

Having defined the time period between two assessable candidates, we are able to define the total costs of one assessment, which consist of a direct and an indirect component. Direct costs of an assessment are costs $b$; indirect assessment costs are costs of foregone productivity - which are $c$ per period - and depend on the number of periods between two assessable applicants, $p \psi$. Total indirect assessment costs therefore are $p \psi c$, which implies that total costs of one assessment equal $b+c \psi \psi c$.

To complete recruitment costs, we need the average number of assessments needed to find a quallified candidate, which we define $\chi$. Equation 2.4 then summarizes recruitment costs.

$$
R C=\chi[b+\varphi \psi c]
$$

Obviously, both $\varphi$ and $\chi$ and consequently mecruitment costs depend on the screening device standard, $f$, and the productivity standard, $p^{B}$, that firms set. To explore these dependencies, we use areas $A, B, C$ and $D$ in Figure 2.2. Areas $A$ and $B$ represent type $I$ and type II errors respectively. Area $C$ represents unemployed who meet both $p^{s}$ and $f^{s}$; area $D$ represents unemployed who neither meet $p^{s}$ nor $f^{3}$. Together these four areas constitute the total size of: the unemployment pool, $T$.

We can express $\varphi \psi$ and $\chi$ in terms of areas $A, B, C$, and $D$. The average number of assessments needed to find a qualified candidate, $\chi$, is:

$\chi=\frac{A+C}{C}=1+\frac{A}{C}$

The average number of periods passing by before a second candidate arrives who meets the screening device standard, $\varphi \psi$, is:

\footnotetext{
${ }^{22}$ In Chapters $V$ and $V$ we endogenize the choice of the recruitment charmel, which is a useful exercise in tracing firms whose subsidy was allocated inefficiently. However, to understand the general nodel, inciuding the choice of the recruitment channel has no added value and can be abstracted from without any loss of generality.
} 
$\varphi \psi r=\frac{T}{A+C}$

Subsequently, we can substitute equations 2.5 and 2.6 into equation 2.4 to obtain recruitment costs in terms of areas $A, C$, and $T$.

$R C=\frac{A+C}{C}\left[b+\frac{T}{A+C} \cdot c \mid\right]=\frac{A+C}{C} b+\frac{T}{C} c$

Next we make assumptions about the productivity distribution, $\kappa$, over cohorts of unemployed. Herrnstein and Murray (1994) argue that the intelligence (or in our model ability) distribution over the population is a Bell curve, which empirically appears to be close to a normal distribution. Consequently we also assume $k$ to be normally distributed. Furthermore we assume a stationary population of unemployed. That is, each year a new cohort enters and the eldest cohort retires. ${ }^{23}$ The productivity distribution for the new cohort is identical to that of the previous year.

Consequently, for a given $t$, productivity is normally distributed in such a way that the job seeker's productivity lies in the range $\left[p_{\min }(t), p_{\max }(t)\right]$. Therefore, we can solve the mean $\mu(t)$ and standard deviation $\sigma(t)$ from: $\mu(t)=0.5\left[p_{\max }(t)+p_{\text {mis }}(t)\right]$ and $\sigma(t)=0.25 \| p_{\max }(t)-$ $\left.p_{\min }(t)\right]$. From properties $\rho_{r}>0$ and $\rho_{a}>0$ of equation 2.1 respectively we know that $\mu(t)$ and $\sigma(t)$ decrease in $t$. Define the normal distribution of productivity at $t$ by $\kappa[\mu(t), \sigma(t)]$. Area $A$ is then given by:

$$
A=\int_{t_{\min }}^{r} \int_{P_{\operatorname{man}}(t)}^{p^{s}} \kappa[\mu(t), \sigma(t)] d p d t
$$

And area $C$ is given by:

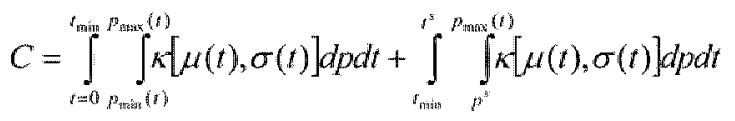

Here $t_{\min }$ is the first cohort of unemployed which contains unemployed whose productivity has depreciated below $p^{s}$. In Figure 2.2 we also include $t_{\max }$, which is the first cohort of unemployed that no longer contains unemployed who meet $p^{s}$. The cumulative distribution of $\kappa$ over the interval $\left[p_{1}, p_{2}\right]$ is given by $\mathrm{K}\left[\mu(t), \sigma(t), p_{1}, p_{2}\right]$. For area $A$ the distribution of productivities is given by:

$$
A=\int_{t_{\text {minin }}}^{t} \mathrm{~K}\left[\mu(t), \sigma(t), p_{\mathrm{min}}(t), p^{s}\right] d t
$$

For area $C$, it is given by:

\footnotetext{
${ }^{23}$ Each unemployment cohort contains unemployed experieneing identical lengths of unemployment duration.
} 


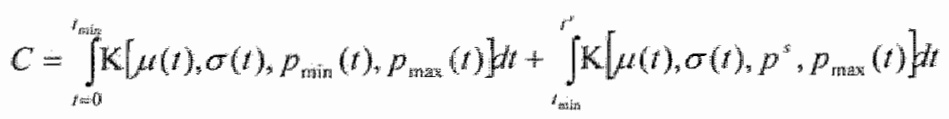

Obviously, the firm will set the screening device standard between $t_{\text {mans }}$ and $t_{\text {suar }} . t^{5} \leq t_{\text {man }}$ leads to the exclusion of qualified applicants; not to the exclusion of unqualified applicants, whereas $t^{s} \geq t_{\text {max }}$ does no longer lead to the inclusion of qualified applicants. To understand the firm"s eventual choice of the screening device standard, we have to explore the links between $t^{\prime \prime}$ and $\varphi \psi$ and $\chi$, which we do in terms of areas $A$ and $C$. Using Leibnitz rule we find the partial derivative of area $A$ with respect to $t^{s}$, which is positive:

$$
\frac{\partial A}{\partial t^{3}}=K\left[\mu(t), \sigma(t), p_{\text {math }}(t), p^{s}\right]
$$

Applying the same rule, we can also find the partial derivative of area $C$ with respect to $t^{3}$, which is positive:

$$
\frac{\partial C}{\partial t^{s}}=K\left[\mu(t), \sigma(t), p^{s}, p_{\max }(t)\right]
$$

Both partial derivatives are positive, which is also clear from figure 2.2. Now that we know that $C_{1}$ and $A_{t}$ are both positive we can infer the effect of $t^{5}$ on $\varphi \psi$ and $\chi$ using equations 2.5 and 2.6 , respectively. ${ }^{24}$ From equation 2.5 we can derive $\partial \chi / \partial t^{3}$, which is given by equation 2.14.

$$
\frac{\partial \chi}{\partial r^{x}}=\left[\frac{A}{A}-\frac{C}{C} \mid \frac{A}{C}\right.
$$

Using the first order condition of minimizing recruitment costs we can determine the sign of $\chi$. Equation 2. I 5 represents this first order condition.

$$
\frac{\partial R C}{\partial t^{\prime \prime}}=0: \quad\left[\frac{A}{A}-\left.\frac{C}{C}\right|_{b}\right]=C, \frac{A T}{C} C
$$

Since $C_{t}$ is positive, we know that $A_{t} / A>C_{v} / C$ and consequently $\chi_{t}>0$. Therefore we conclude that a less strict screening device standard increases the average number of assessments needed to find an applicant who meets the productivity standard. As is also clear from Figure 2.2, the relative increase in area $A\left(i . e . A_{t} / A\right)$ is larger than the relative increase in area $C$ (i.e. $C_{i} / C$ ) following an increase in $r$. This evolution increases the failure rate of assessments $[(\chi-1] / \chi)$, which explains the increase in $\chi$.

From equation 2.6, we can derive $\partial(\rho \psi) / \partial r^{s}$, which is given by equation 2.16.

$$
\frac{\partial(\varphi \psi)}{\partial t^{*}}=-\frac{\left(A_{t}+C_{t}\right) T}{(A+C)^{2}}
$$

\footnotetext{
3. Partial derivatives of a variable $x$ with respect to $t$ are for the sake of simplicity cenoted by $x$.
} 
Using equations 2.12 and 2.13 , we know that $(\varphi \psi)_{i}<0$. That is, if firms set a less strict screening device standard, more applicants will be allowed into the recruitment process, which speeds up this process. However, this is only a partial effect. We know from equation 2.14 that an increase in $t^{s}$, also increases the number of assessments needed to find a qualified applicant, which raises the length of the recruitment process. This effect subsequently crowds out part of the gaining in time due to the higher applicant arrival rate. To determine the overall effect of a shift in the screening device standard on the length of the recruitment period, we need to know $\partial(\chi \varphi \psi) / \partial r^{s}$. We know that $\chi \varphi \psi r=T / C$, hence, $\partial(\chi \varphi \psi) / \partial r^{s}$ is given by equation 2.17 .

$$
\frac{\partial(x \varphi \psi)}{\partial r^{3}}=-\frac{C}{C} \frac{T}{C}
$$

Since $C_{t}$ is positive, $\partial(\chi \varphi \psi) / \partial r^{s}$ must be negative. Therefore we conclude that the increase in the length of the recruitment period due to more assessment failures is more than offset by the reduction in the length of the recruitment period thanks to an increase in the arrival rate of assessable applicants.

We can present the effects of changing the screening device standard also in a 'type $1 /$ type I] error' setting. The left hand side of equation 2.15 represents the increase in type I errors, i.e. the increase in the probability to assess applicants who do not meet $p^{z}$. This probability does not equal the enlargement of area $A$ following an increase in $r^{s}$, but is partially offset by the simultaneous enlargement of area $C$. Nonetheless, we know that $A_{t} / A>C_{t} / C$, which implies that the likelihood to produce a type I errors increases for a less strict screening device standard. The right hand side of equation 2.15 represents the decrease in type II errors, i.e. the decrease in the probability to exclude applicants from the assessment procedure who meet $p^{3}$. Notice that, for a given $p^{s}, C_{i}=-B_{*}$. It Hence, the increase in area $C$ following an increase in $r^{s}$, can also be interpreted as the decrease in area $B$, which contains the type II errors the firm makes for a given screening device standard. To minimize recruitment costs, the firm searches for the right balance of type I and II errors, which obviously depends on costs $b$ and $c$. In this dissertation we will use this trade-off to determine the firm's screening device standard which we will link to deadweight loss incidence.

Besides the screening device standard, the firm can also use the productivity standard to manipulate recruitment costs. From Figure 2.2 and equations 2.10 and 2.11 we can deduce that $A_{p}>0$ and $C_{p}<0$ or more precisely $A_{p}=-C_{p}$, at $p=p^{s}$. That is, changing the productivity standard only leads to relocating applicants from area $A$ to $C$ and vice versa. Equation 2.18 gives the partial derivative of the average number of assessments needed to find a qualified candidate, $\chi$, to $p^{s}$.

$$
\frac{\partial \chi}{\partial p^{x}}=\left[\frac{A_{p}}{A}-\frac{C_{p}}{C}\right] \frac{A}{\sqrt{C}}
$$

Since $A_{p}>0$ and $C_{p}<0$, we conclude that $\chi_{p}>0$. That is, an increase in the productivity standard makes it more difficult for applicants to pass the assessment. Hence the passing rate of assessments $(1 / \chi)$ decreases, and subsequently the average number of assessments needed to find a qualified candidate increases. Equation 2.19 gives the partial derivative of the average number of periods passing by before a second applicant arrives who meets the screening device standard, $\varphi \psi$, to $p$. 


$$
\frac{\partial(\rho \psi)}{\partial p^{x}}=\frac{\left(A_{p}+C_{p}\right) T}{(A+C)^{3}}
$$

Since $A_{p}=-C_{p}$, $(\varphi \psi)_{p}=0$, i.e. shifting the productivity standard does not change the arrival rate of atssessable applicants; only shifts in the screening device standard have such effects. ${ }^{25}$

This summarizes recruitment costs. We know that $\chi=\chi\left(f^{s}, p^{s}\right)$ and $\chi_{s}>0$ and $\chi_{p}>0$, and $\varphi=$ $\varphi(t)$ and $\varphi_{i}<0$. Equation 2.20 represents recruitment costs. ${ }^{25}$

$$
R C=\chi\left(t_{+}^{*}, p_{+}^{s}\right)\left[b+\varphi\left(t_{-}^{s}\right) \cdot \psi(\underset{+}{\theta}) \cdot c\right]
$$

\section{Training costs}

Besides recruitment costs the firm faces training costs when it deviates $p^{s}$ from $p^{*}$. Equation 2.21 represents the first order condition for minimizing recruitment costs with respect to the productiwity standard. It shows the impact of reducing the productivity standard on recruitment costs.

$\frac{\partial R C}{\partial p^{*}}=0: \quad A_{p} C b-C_{p} A b-C_{p} T c=0$

This first order condition suggests that the firm should set its productivity standard as low as possible. However, so far we have not discussed the costs of reducing the productivity standard below $p^{*}$. If the firm sets $p^{*}=p^{*}$, total hiring costs equal total recruitment costs, as new employees do not need additional training to meet $p^{*}$. Allowing for $p^{s}<p^{*}$ implies that hiring costs may deviate from recruitment costs since we include training costs in the former; not in the latter.

Introducing training possibilities enlarges the firm's trade-off, as training constitutes a third factor influencing the firm's hiring behaviour. To upgrade the productivity level to $p^{*}$, the firm uses a training programme, which is a continuum of educational stages. Every participant enters the training programme at the adequate stage (i.e. at $p_{j}$ ) and leaves the programme at the required level, $p^{* 2}{ }^{27}$ The productivity shortage (i.e. $p^{*}-p_{j}$ ) that needs to be bridged is defined, $\eta$. Given the assumptions about function $\kappa[\mu(t), \sigma(t)]$, we obtain the expected productivity level of an applicant that meets both the screening device standlard and the productivity standard:

$$
E\left[p_{\lambda} \mid r_{i} \leq t^{x}, p_{j} \geq p^{*}\right]=\int_{0}^{t} \frac{1}{2}\left[\left[p_{\max }(t)\right]^{2}-\left[p^{s}\right]^{2}\right] \mathrm{K}\left[\mu(t), \sigma(t), p^{*}, p_{\max }(t)\right] d t
$$

Using the first property of equation 2.1 (i.e. $p_{s}>0$ ), we know that $\partial p_{\text {max }}(t) / \partial t<0$. This ensures that $\partial E\left[p_{j} \mid t_{j}<t^{s}, p_{j} \geq p^{s}\right] / \partial f^{s}<0$. Intuitively, skill atrophy ensures that productivity

\footnotetext{
25 Since mamipulating $p$ " has no eflect on the arrival rate of applicants, raising the productivity standard lengthens
the recruitment period because of the increase in the failure rate of assessments.

${ }_{27}^{27}$ Signs below arguments indicate the sign of the (partial) deriwative.

${ }^{27}$ We assume that every participant in the training programme will finish the programme successfully.
} 
goes down as unemployment increases. That is increasing $r^{s}$, allows unemployed into the assessment procedure who if they meet $p^{*}$, they do so only just. This reduces the expected productivity of a chosen candidate and subsequently increases $\eta$.

Obviously, an increase in the productivity standard raises the expected productivity of a chosen candidate: $\partial E\left[p_{j} \mid t_{j}<t^{5}, p_{j} \geq p^{s}\right] / \partial p^{3}>0$. This rather straightorward result follows directly from equation 2.22 .

Finally, costs to bridge each infinitely small educational stage are constant for a typical trainee, but dependent on the (innate) ability level of that trainee. That is, the firm bears costs $d$, to upgrade the productivity of the most able trainee (i.e. an unemployed characterized by $a_{m a x x}-$ see Figure 22) with a single unit. The ability level of an - assessed and selected hence chosen - candidate is positively related to $t^{s}$. Productivity decay ensures this positive relation. As at longer unemployment spells productivity decay is substantial, still to meet $p^{s}$, candidates must have had high initial productivity which must be the result of high ability. As a result adding cohorts of unemployed experiencing longer uncompleted spells of unemployment raises the average ability level of the chosen candidate. Raising the productivity standard directly augments the ability level of a chosen candidate as can be inferred from Figure 2.2. To measure the ability effect of a chosen candidate we introduce $\phi$, which is a mark-up on costs $d$ for training individuals having ability levels below $a_{n \text { mat }}$. Subsequently, $\phi=\phi\left(r^{s}, p^{x}\right)$ and $\phi_{i}<0$ and $\phi_{p}<0$. Equation 2.23 summarizes training costs.

$$
T C\left(t^{s}, p^{s}\right)=\left[d \cdot \phi\left(t^{s}, p^{s}\right) \ln \left(t^{s}, p^{s}\right)\right.
$$

Again there is a trade-off to be made by the firm concerning the screening device standard. A higher $t^{s}$ raises the ability level of chosen applicants which reduces mark-up $\phi$ over per educational stage costs $d$, but at the same time it reduces the average productivity level of a chosen candidate, which implies that more educational stages are needed to upgrade productivity to $p^{*}$.

Raising the productivity standard, $p^{s}$, augments both the productivity and the ability level of a chosen candidate, which unambiguously reduces total training costs. However, raising $p$ also unambiguously increases recruitment costs, which leaves the final effect of a change in $p^{s}$ on hiring costs in doubt. Equation 2.24 presents hiring costs (which are the sum of recruitment and training costs) and finalizes our model.

$$
H C\left(t^{*}, p^{s}\right)=\chi\left(t_{+}^{s}, p_{+}^{s}\right)\left[b+\varphi\left(t_{-}^{s}\right) \cdot \psi(\theta) \cdot c\right]+\left[d \cdot \phi\left(t_{+}^{*}, p^{s}\right)\right] \eta\left(t^{*}, p^{s}\right)
$$

Assuming the firm to operate in a competitive labour market, it aims at minimizing hiring costs, which - in case it has zero bargaining power - maximizes the wage offer it can pay to its employees or - in case the firm has some bargaining power - maximizes its profits. To minimize equation 2.24 the firm chooses an optimal combination of the screening device standard, $t^{s}$, and the productivity standard $p^{*}$, which yields the optimal - since hiring cost are minimized - combination of type I and type II errors. 28

\footnotetext{
25 See Chapters IV and $V$ for an extensive discussion on the contuparative statics of this model in terms of the optimal $r^{s}$ and $p^{s}$ the lim sets.
} 


\subsection{Introducing employment subsidies}

The firm optimizes equation 2.24 and subsequently sets an optimal screening device standard, $f^{s}$, that splits the unemployment pool into two parts: those who are taken into consideration in hiring procedures $\left(t \leq t^{5}\right)$ and those who are not $\left(t>r^{5}\right){ }^{29}$ Figure 2.2 demonstrates that some unemployed experiencing $t_{j}>l^{s}$ are qualified for the vacancy $\left(p_{j} \geq p\right)$, that is, those in area $B$. These unemployed pay a price for the inaccuracy of the screening device used by the firm to circumvent imperfect information on the labour market. Nonetheless the type II errors the furm makes - its decision to neglect unemployed out of area $B$ or more generally its recruitment behaviour - is efficient at the firm level, as reducing type $I$ errors would simultaneously lead to more type lerrors.

Meanwhile at the aggregate, macroeconomic level the picture looks different. The screening device standard firms set, determines the relevant share of labour supply, which contains current employees and short-term unemployed $\left(t_{j} \leq t^{5}\right)$, but not long-term unemployed $\left(t_{j}>t\right)$. It is this relevant labour supply which is decisive in wage negotiations with firms. More precisely, the individual or collective wage claim reflects the employment composition of the relevant labour supply. If large parts are unemployed, wage claims will be moderate to enhance employment. If the majority of the relevant labour supply is employed, the risk of job loss is small which elicits substantial wage claims. Employees and short-term unemployed do not take the position of long-term unemployment into consideration in wage negotiations, as firms categorically neglect them as contenders for employment at the firm, which excludes them as competitors for employees and short-term unemployed - see Budd et al. (1988) and Crafts (1989) for empirical evidence. They show that increases in long-term unemployment lead to increases in wage claims, which hints at low competitive strength of long-term unemployed on the labour market. ${ }^{30}$ That is, for a given labour force, an increase in long-term unemployment implies a reduction in the relevant labour supply, which ceteris paribus elicits the wage claims Budd et al. (1988) and Crafts (1989) observe.

Since it is firms that decide on the position of $t^{s}$, firms can - through $t^{s}$ - manipulate both the size and composition (employee/short-term unemployed) of the relevant labour supply and subsequently wage claims. That is, a less strict $t^{s}$ increases the relevant labour supply and increases the share of short-term unemployed in total relevant labour supply. Both effects reduce wage claims. However, we decided to exclude these effects from our analysis in Section 2.2, as these are aggregate effects. It seems reasonable to assume that indvidual firms are too small to decisively inthence the size and composition of the relevant labour supply and subsequent wage claims and therefore do not take wage effects into account when setting $t^{*}$ to minimize hiring costs to fill a vacancy.

Consequently, employees and short-term unemployed - neglecting the situation of long-term employed - are able to negotiate above equilibrium wages which lead to a lower employment outcome. The - for a given labour supply - subsequent higher unemployment rate yields more government expenditures on benefits. ${ }^{3}$. This leads us to the conclusion that

\footnotetext{
We consider unemployment duration $f^{5}$ to split the job seekers pool into short-term unemployed $\left(t_{j} \leq f^{*}\right)$ and
long-term unemployed $\left(t_{j}>f^{*}\right)$.

The symmetric ignorance assumption ensures that unemployed do not know their current productivity level. If woy would, unemployed out of area $B$ in Figure 2.2 might - articipating a further productivity decay, which would reduce their productivity below $p^{s}$ in due time - offer themselves on the labour market at below subsequenty keep them in job which would prevent their productivity from depreciating below $p^{s}$, which would competitors for enployed andention for future employment. In that case, long-term unemployed would be pompetitors for employed and short-term unemployed job seekers, but symmetric ignorance rules out this
posibility.

"And other social undesirable effects of long-term unemployment, like for example higher crime rates.
} 
although the firm's choice of $t^{8}$ might be efficient from the individual firm's point of view, tt is not efficient from a macro point of view. As a result, we are dealing with a market fathe.

To internalize this market failure, the firm should be persuaded to recruit from unemployed experiencing a spell of unemployment beyond $r$. A hiring strategy that requires firms to recruit beyond $t$ is not a cost minimizing strategy. Hence to induce firms to recruit beyond $f^{t}$, a subsidy is needed. ${ }^{32}$ Figure 2.2 clearly shows why hiring costs increase to the right of $t^{*}$. To the right of $t^{y}$, the gains from extending $t^{s}-$ in terms of less falsely disregarded unemployed (type II errors) - diminish, whereas the costs of extending $t^{*}$ - in terms of falsely retaned unemployed (type I errors) - increases. If the balance between type I and II errors is optimal at $r^{s}$, it can neither be optimal anywhere to the right, nor to the left of $t$.

Figure 2.44 The effects of the screening dewice standard on the employment outcome

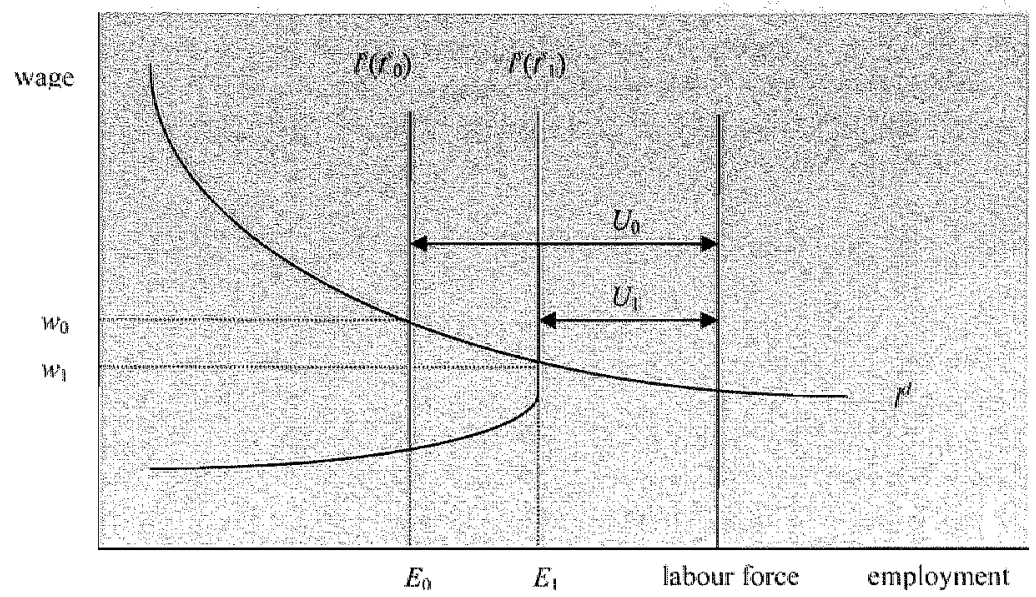

If the government - by means of providing a subsidy - succeeds in inducing the firm to extend its screening device standard beyond $r^{s}$, it enlarges and decomposes the relevant labour supply. Both effects have wage moderating consequences, which enlarge aggregate employment and subsequently reduce benefit expenditures, which enables the government to recover part of its expenditures on employment subsidies. "Figure 2.4 illustrates the process. If firms set $r_{0}^{s}$, the relevant labour supply is $E_{0}$, which cuts off the labour supply curve at $E_{0}$ and results in a wage $w_{0}$. If the government by means of an employment subsidy persuades firms to increase $t^{s}$ (from $r_{0}^{s}$ to $r_{1}^{s}$ ), employment goes up and wages and unemployment go down. Here we also want to stress the difference between wage subsidy schemes and relief schemes, which together constitute employment subsidy measures. The latter aim at providing subsidized employment (typical of the public sector) for very long-term unemployed, $i e_{*}$

\footnotetext{
${ }^{32}$ The subsidy can also be provided to the long-term unemployed who use it to compensate the firm for the additional hiring costs it is faced with, when hiwing from the cohort the long-term unemployed is parth of. This will lead to the same effects as awarding the subsidy to the firm - cf. Snower (1994).

${ }^{33}$ Here we refer to the ex-post wage moderating effect of employment subsidies. That is, the ability of the subsidy to increase the relevant labour supply which has wage moderating effects. The ex-posi wage moderating effect should be distinguished from the ad interim wage raising effect of employment subsidies. In Chapter I we discussed the ad inverim effect, i.e. the existence of an employment subsidy improves the outside option of employees which leads to wage claims. Empirically both effeets are hard to disentangle since employment subsidy schemes are run on a continuous basis, which implies that ad interim effects thave a continuous impact. Nonetheless it seems unlikely that employment subsidies are a free lunch - see for example Calm fors (199.3),
} 
unemployed whose productivity falls substantially short of $p^{s}$. Wage subsidy schemes, as we diseuss them here, focus on unemployed in area $B-$ see Figure 2.2 . That is, unemployed who meet the firm's productivity standards, but not its screening device standard. ${ }^{34}$ Relief schemes are merely justified using equity arguments; wage subsidy schemes are justified using efficiency arguments. We will elaborate on this difference in Section 2.5 .

The above analysis demonstrates that the added value of an employment subsidy should be an extension of the relevant labour supply. We discuss two types of employment subsidies that meet that requirement: an employment subsidy that compensates for increased hiring costs and an employment subsidy that compensates for training costs.

When using the subsidy to pay for training costs needed to upgrade the productivity level of newly hired employees is no option, the subsidy should be targeted at unemployed who do not meet $t^{s}$ but who meet $p^{s}$ and hence can be integrated in the firm without costs. In Figure 2.5 these unemployed are found in areas $B$ and $E$, which sets a maximum to the range of the subsidy (i.e. unemployed for whom the firm obtains a subsidy), which is $t_{j}=T_{n}^{35}$

Figure 2.5 The impact of employment subsidies

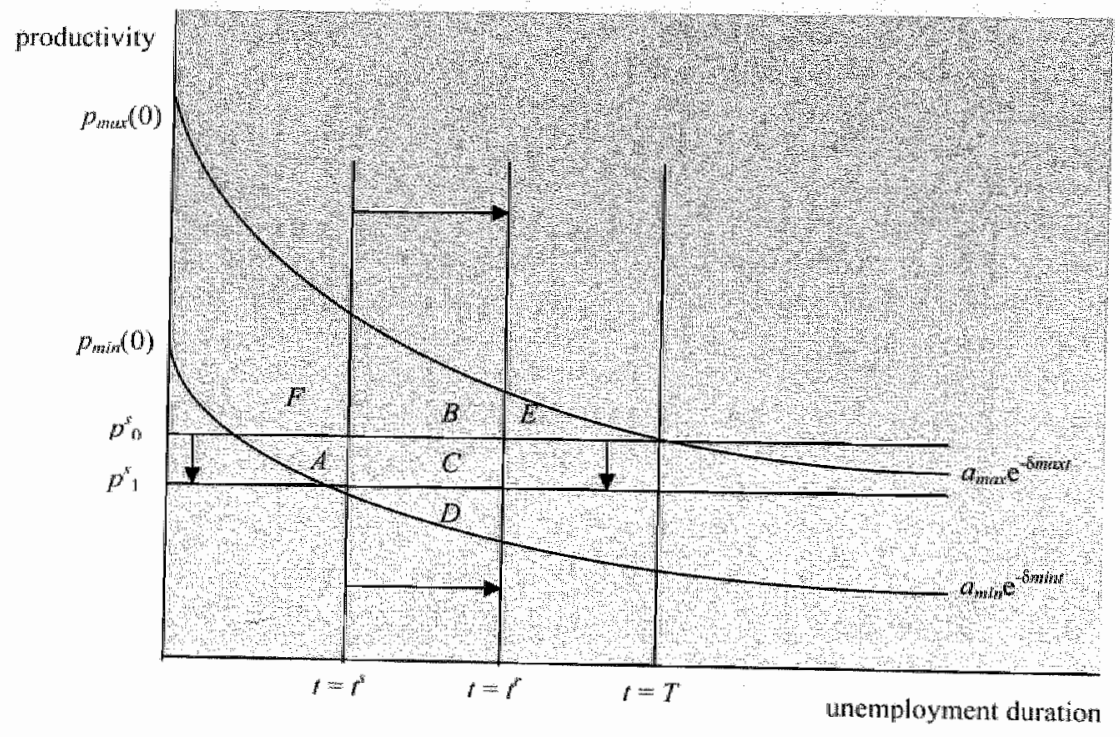

To persuade firms to recruit from unemployed out of areas $B$ and $E$ a subsidy is needed, since hiring from these cohorts of unemployed is not cost efficient to the firm. Hiring costs increase for every additional cohort of unemployed the firm takes into account to the right of $t^{s}$, as in that region the increase in hiring costs related to making type I errors outweigh the hiring cost reduction of making fewer type II errors. Consequently if the firm has to recruit to the right of $r^{s}$ to obtain a subsidy, its hiring costs will be lowest if it recruits from cohort $r^{x+1}$, only. To ensture that the firm applies a screening device standard ranging from $t^{5}$ up to for example $r$, the subsidy level has to depend (positively) on the unemployment duration of an applicant. ${ }^{36}{ }^{\prime}$

\footnotetext{
34 Or in case the subsidy is used to train unemployed whose productivity is close to $p$.
35 or course the government conld decide to concerate

efficiency point of view it does not make sense to exeratrate the subsidy on part of this total range, but from an

36. In Chapter III we discuss the link between extend subsidy ent it lement beyond $x_{j}=T$.

the soheme in depth.
} 
Since the subsidy leads to the selection of an applicant whose productivity meets the standard $p^{s}$, the temporary subsidy leads to structural employment for the formerly long-term unemployed. This increases the relevant part of labour supply and hence this type of employment subsidy meets the requirements outlined above.

Besides persuading firms to look for qualified applicants in unfamiliar recruitment territory, the government could also provide a subsidy to firms who hire unqualified appliciants but use the subsidy to train them up to the required qualifications. ${ }^{38}$ Making such a training subsidy available means that the firm can lower the productivity standard, $p^{s}$, to for example $p^{*}$ in Figure 2.5. The effect of a reduced productivity standard is that - given the original $r^{s}-$ making type I and type II errors becomes respectively less and more likely. Given the hiring cost structure this induces the firm to raise the sereening device standard, to for example in Figure 2.5. Areas $D$ and $E$ now respectively contain type I and type II errors the firm potentially makes.

The availability of the training subsidy does not necessarily mean that the firm will make use of it. If the firm finds an unemployed out of areas $F$ or $B$, training is unnecessary. Assuming the govermment only grants a subsidy to a firm that proves its employee followed training, no subsidy has to be granted in this particular situation. ${ }^{39}$ Only if the firm finds an unemployed out of areas $A$ and $C$, the subsidy has to be allocated. Since recruitment takes place to the left of (the new) screening device standard, $t$, the subsidy may be uniform as opposed to the search extension employment subsidy.

Due to the training subsidy firms potentially recruit unemployed out of areas $B$ (for whom no subsidy is needed), $A$, and $C$. All three groups would not have been taken into consideration for the job due to too low productivity (area $A$ ) or too high unemployment duration (area $B$ ) or both (area $C$ ). Although the design of the training employment subsidy differs from that of the search extension employment subsidy, both yield the same outcome: a temporary employment subsidy leads to permanent employment for otherwise excluded job seekers.

\section{Efficiency of employment subsidy measures}

As shown in Chapter $\mathbb{I}$ and in the introduction of this chapter, the efficiency - in terms of subsidy allocation - of employment subsidy measures has been poor so far. ${ }^{40}$ Calmfors (1994) develops three concepts to measure the (injefficiency of employment subsidy measures: deadweight loss, substitution and displacement.

Deadweight loss is defined as the share of subsidized jobs that would have been filled with long-term unemployed in the absence of the subsidy. Hence deadweight loss refers to the share of participants in the employment subsidy measure that would have also found a job in the absence of the subsidy. Substitution is defined as the share of subsidized jobs that would have been filled with other than long-term unemployed in the absence of the subsidy. Hence substitution refers to the share of participants that would not have found a job in the absence of the subsidy but whose current subsidized position goes at the expense of employment for

\footnotetext{
St Stuctural in the sense that the long-term unemployed whose unemployment spell has ended due to the temporary subsidy experiences the same job separation rate, $\lambda$, as other employaes.

38 The level of the subsidy depends on the costs of training, which depend on $d$ and the number of educational stages needed to upgrade productivity to $p^{g}$ - set Chapter III.

${ }^{30}$ Nonetheless, the potentral availability of the subsidy is needed to persuade the lim to considet unemployed ont of area $B$ for the vacancy.

4ta Throughout this dissertation the effetency of an enuployment subsidy measure refers to subsidy allocation (deadweight loss); the effechiveness of an employment measure refers to the treatment effect of the measure (reemployment probability).
} 
non-targeted (short-term) unemployed. Finally, displacement refers to the reduction in employment elsewhere clue to competition in goods markets. That is, due to the subsidy a firm might beat off competitors and increase market share, which leads to loss of employment elsewhere.

Both deadweight loss and substitution do not lead to an increase in overall employment." Substitution at least improves the job find probability of long-term unemployed (although at the expense of short-tern unemployed); deadweight loss does not even improve the job find probability of long-term unemployed. Earlier in this section, we have defined the added value of an employment subsidy as to its ability to extend the relevant labour supply. Substantial substitution shares do not threaten the added value of the employment subsidy; substantial deadweight loss shares do. Therefore in the rest of the chapter and the dissertation we will concentrate on deadweight loss as main indicator of inefficiency of an employment subsidy measure.

Vital in determining deadweight loss is the ability to distinguish between job seekers that the firm would have and would not have hired in unsubsidized circumstances. The model we present in this chapter is able to make this distinction as all unemployed experiencing an unemployment spell shorter than the screening device standard $t$, are taken into consideration for the job. Allocating a subsidy to firms hiring from these unemployed is unnecessary and can be labelled deadweight loss. To prevent deadweight loss the government is of course interested in unveiling $t^{s}$. If the government knows $t^{5}$ and sets the start value of subsidy entitlement, $t^{g}$, equal to $t^{\prime \prime}$, there can be no deadweight loss. However, if $t^{\prime g}$ is set to the left of $i$, unemployed experiencing unemployment spells between $t^{\text {s: }}$ and $r$ are potential deadweight loss recruits of firms. ${ }^{42}$

\subsection{Applying the model to the Dutch case}

Table 2.1 gives an overview of Dutch employment subsidy measures throughout the last two decades of which deadweight loss estimates are available. Together with relief schemes that have never been evaluated on deadweight loss incidence (like the Melkert I, III and IV programme), wage subsidy schemes aimed at youngsters (JWG), or general employment subsidies measures (like the SPAK), the Dutch have had substantial experience with employment subsidy measures. ${ }^{43}$ Nonetheless, in 2002 the Dutch government decided to abolish all employment subsidy measures. At the root of this decision was the Ministry of SAE (2001) report, which evaluates the effectiveness of expenditures on - amongst others wage subsidy schemes and relief schemes. The evaluation report concludes that treatment effects of relief schemes were disappointingly low and the mefficiency of wage subsidy schemes was typically high. Based on these conclusions the Dutch government put an end to expenditures on both wage subsidy schemes and relief schemes.

\footnotetext{
"1) Naither do displacement effects. However, the few studies that have tried to messure external displacement see for example Dar and Tzannatos (1999) - found that external displacement effects only play a minor role in neglect effects of external displacement.

${ }^{4}$ For an analysis of the determinants of ${ }^{2}$ - see Chapters do to prewent the potential threat of deadweight loss to mature wind $V$; for an analysis of what the government can ${ }^{4}$ General employment subsidy measures differ from (mare without exactly knowing $t^{s}$ - see chapter III. them in this dissertation) as to the target group they aimarginal) enployment subsidy measures (like we discuss additional employment. That is, the firm receives a subsidy for employment subsidy scheme aims at both additional and axisting for hiring a long-term unemployed. A general subsidy might be provided to firms that offer low paying jobs.
} 
Table 2.1 gives some supporting evidence of the clains made in this report. Relief sehemes like the Vermeend-Moor act, the WEP and the Banenpool aim at very long-term unemployed and experience modest deadweight loss shares; wage subsidy schemes like the VLW, Melkert II and RAP aim at more promising long-term unemployed and subsequently suffer from higher deadweight loss shares. These findings are not surprising, as one may expect that an employment subsidy in which participants experience a shorter average unemployment duration - which indicates a low $t^{s g}$ - cause a higher deadweight loss share.

\section{Tighthess and efficiency employment subsidy measures}

Table 2.1 also contains information on the year of introduction of the various employment subsidy measures. Schemes introduced during the late eighties were targeted to unemployed experiencing considerably longer spells of unemployment than schemes introduced in the mid nineties, which is illustrative of the policy change regarding ALMP that took place in the Netherlands: a change from equity-justified (relief schemes) to efficiency-justified (wage subsidy schemes) employment subsidy measures.

Efficiency-justified schemes follow the arguments set out in this chapter so far. "That is, there are market failures in the labour market that prevent qualified job seekers from finding employment. Providing a subsidy for hiring these job seekers means they rewenter the relevant labour supply, which depresses the aggregate wage outconne in the labour market and increases equilibrium employment. Typical features of efficiency-justified programmes are temporary subsidization, private sector employment and participants having above average perspectives on the labour market compared to other unemployed.

Besides efliciency reasons, the Dutch government also justifies the use of employment subsidy measures referring to equity. That is, the government justifies the use of ALMP to help long-term unemployed escape from social isolation and to grant them a right to work. Not only long-term unemployed benefit from equity-based programmes, also society does, as these subsidized jobs are typically created in socially valuable sectors that are short of personnel. Features of equity-justified programmes are structural subsidization, public sector employment and participants having relatively low perspectives on the labour market compared with other unemployed.

Both efficiency-justified and equity-justified programmes suffer from typical problems. Efficiency based programmes suffer from substandial deadweight loss shates, whereas equity-based programmes suffer from low outflow rates (i.e. to regular employment) and vice versa- of. Welters (1998).

Following the improvement of labour market conditions throughout the nineties, the need to offer equity-based employment subsidy schemes evaporated, which induced Dutch authorities to substitute equity-based for efficiency-based schemes, as Table 2.1 shows. As a consequence the efficiency of subsidy allocation worsened. However at the same time, the effectiveness of the schemes in terns of treatment effects increased - see for some descriptive evidence Table 6.4. The Dutch authorities used the former argument to abolish employment subsidy measures disregarding the latter.

\footnotetext{
An Chapters IV and $\mathrm{V}$ we tho that an increase in thightness induees firms to reduce the screening dowice standard. This effect moderates the increase in subsidy wastage following reduction in the start value of subsidy entitlement, $f$, which is the govemment 's reaction to tightening aonditions.
} 
Efficiency of employment subsidies is not only determined by the design of the particular scheme, also other policy measures interfere. To improve the results (both in terms of effectiveness and efficiency) of employment subsidy measures, Dutch authorities structure the allocation of long-term unemployed towards the various programmes. Employment Offices set up profiles of unemployed. These profiles indicate the re-employment probabilities of unemployed, which serve to allocate unemployed to the programme that suit them best - see for example Kooreman (1999). That is, if a profile indicates that unemployed have relatively low re-employment probabilities, participation in relief schemes is proposed; if reemployment probabilities are relatively high other alternatives are available like employment subsidy schemes.

Though profiling augments transparency on the labour market - and hence should be welcomed - it also affects the efficiency of employment subsidy measures in terms of subsidy wastage, as also firms benefit from the additional information.

Figure 2.6 illustrates the mechanism. If the authorities succeed in filtering out the most promising long-term unemployed, the firm can use this information to reduce making type I errors in the hiring procedure, which is represented in Figure 2.6 by the upward shift of the lower productivity bound. The reduction in potential type $I$ errors (from $A_{0}+A_{1}$ to $A_{1}$ ), enables the firm to increase the screening device standard $\left(r_{0}^{b}\right.$ to $\left.t^{s}\right)$ to restore the balance between type I and type II errors.

For a given start value of subsidy entitlement, $t^{s \%}$, the increase in the firm's screening device standard augments the likelihood that $t^{t}$ is to the right of $f^{\text {sg }}$, which raises the potential threat of deadweight loss. Consequently, not only the design of the employment subsidy measure matters for its efficiency in allocating the subsidy, also indirect measures taken by a government influence this efficiency and hence should be accounted for.

Figure 2.6 The impact of profiling on subsidy efficiency

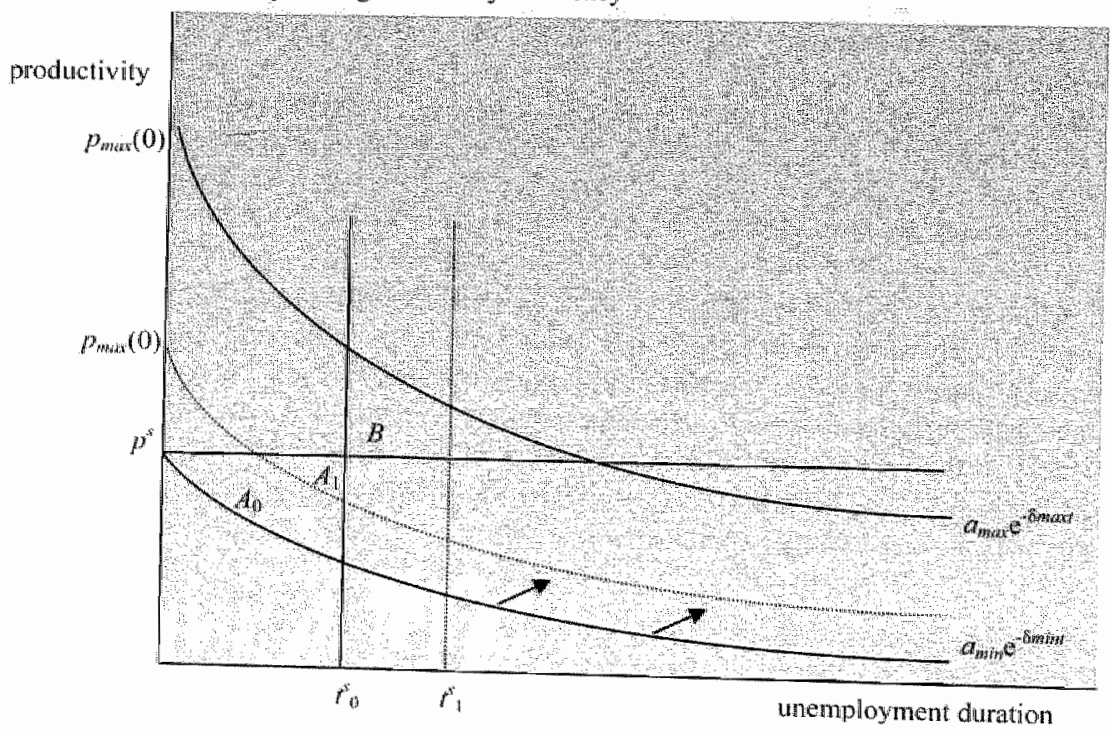




\subsection{Conclusions}

Assuming symmetric ignorance regarding the productivity level of job seekers, we internalize the use of unemployment status as a screening device into an employer search model. The use of such a device leads to the exclusion of qualified long-term unemployed in hiring decisions. Although efficient at the firm level, it leads to a market failure at the aggregate macroeconomic level.

Government intervention by means of introducing temporary employment subsidy measures provides two alternative solutions to repairing the market failure. Firms use the subsidy as compensation for extended search among long-term unemployed or firms use the subsidy to train long-term unemployed up to the required productivity level. Both alternatives lead to structural employment for unemployed who otherwise would not have found work, which consequently leads to an extension of the relevant labour supply.

Though similar in outcome, the design of both alternative employment subsidy measures should be different. A training subsidy should be a uniform subsidy; the level of a subsidy targeted at search extension must depend on the length of the unemployment spell of a participant.

Furthermore the model enables us to link the inefficiency of allocating employment subsidies - in terms of deadweight loss - to the design of the subsidy - in terms of the start value of subsidy entitlement. We have shown that whenever the start value of subsidy entitlement - expressed in terms of unemployment duration - is close to the screening device standard, the risk of deadweight loss is present. Moreover we have shown that labour market policy, not directly related to the employment subsidy scheme, influences the efficiency of such a scheme. 


\section{Chapter III: Outsmart the Outliers}

Employment subsidies and substantial deadweight loss go hand in hand, which indicates the difficulties governments meet to identify the recruitment strategies of fims correctly. In this dhapter we do not focus on that apparent difficulty, but accept the government's shortcomings in this matter and explore how the government may prevent potential deadweight loss to materialize. To answer this question we apply a sequential employer search model and conclude that the government is able to provide incentives, which ensure that fims adopt recruitment strategies, which are less vulnerable to deadweight loss. The proposed incentives are conditional on the type of employment subsidy. A wage subsidy asks for a treatment that differs from a training subsidy.

\subsection{Introduction}

Friedlander et al. (1997), Martin (1998), and Dar and Tzannatos (1999) review the effectiveness of employment subsidies in OECD countries and find disappointing results. The results are unsatisfactory for two reasons. On the one hand, the microeconomic treatment effect of employment subsidy measures appears to be moderate and if present short-lived. On the other hand, macro evaluation studies - like Calmfors et al. (1991), Jongen ef al. (2003) or Heckman ef al. (1998) - show that employment subsidy measures hardly lead to additional employment for long-term unemployed during the subsidy period. That is, displacement effects are generally high - see Table 1.2. Displacement is defined as the share of subsidized jobs that is non-additional, i.e. employment that would also have existed in the absence of the subsidy. Displacement effects are generally around $75 \%$. Hence three quarters of the subsidized jobs do not lead to additional employment, though governments usually demand from firms that the subsidy is used to create additional employment. Moreover, Table 1.2 shows that a downward trend in displacement throughout the years - indicating policy makers' ability to improve the effectiveness of employment subsidy measures - is absent.

To stand any chance of survival as an adequate remedy to fight long-term unemployment, the design of employment subsidy measures has to be adjusted to increase the re-employment probabilities of participants as well as (subsidized) employment opportunities of long-term unemployed. In this chapter we will focus on this issue.

Deadweight loss - the share of subsidized employees the firm would also have hired in the absence of the subsidy - is the main contributor to displacement effects - see Dar and Tzannatos (1999). Deadweight loss is not only the main contributor to displacement, it is also the most harmful contributor. The other main contributor to dispiacement - substitution, which is the share of subsidized jobs that would have been filled with other than fong-term unemployed in the absence of the subsidy - leads to an increase in employment opportunities for long-term unemployed, though at the expense of short-term unemployed - see Calmtors (1994). Consequently, in this chapter - like in the rest of the thesis - we will focus on deadweight loss.

To study deadweight loss in an employment subsidy we apply an employer search model under symmetric ignorance regarding the productivity level of applicants $-c$. Chapter II. In Chapter II we argue that firms - in order to find an applicant who meets a certain productivity standard - apply unemployment status as a screening device to reduce hiring costs. As a result firms set a screening device standard, which deprives part of the job seekers (i.e. long-term unemployed) of the possibility to apply for the job. If the government introduces an employment subsidy measure, it should be targeted at the latter group. If the government succeeds in learning the firm's screening device standard, it can exclude the incidence of deadweight loss by cleverly designing the employment subsidy measure: i.e. the 
government can outsmart the outliers (the deadweight loss provoking firm). If the government does not succed - and the figures in Table 1.2 clearly suggest the government does not deadweight loss and employment subsidy measures go hand in hand.

In this chapter we accept that the government is unable to identify correctly the screening device standard firms set and henceforward runs the risk of offering firms the opportunity to claim a subsidy for hiring unemployed they would also have considered without the subsidy. 45 Accepting the government's inability in this respect means we can concentrate on the goverument's options to control damage. We explore these options for an employment subsidy, which firms use as compensation for recruiting of unemployed for whom hiring costs are non-optimal (which we define a wage subsidy) and an employment subsidy used to train long-term unemployed up to the required productivity level (which we define a training subsidy). ${ }^{46}$

The chapter is organized as follows. In Sections 3.2 and 3.3 we discuss the design of and the appropriate incentives to prevent deadweight loss in a wage and training subsidy scheme respectively. Section 3.4 addresses the costs of such incentives, Section 3.5 concludes.

\subsection{Wage subsidy schemes}

The notion of a wage subsidy that encourages firms to extend their search for qualified job seekers beyond a threshold value of unemployment, $t^{*}$, is based on the assumption that the screening device (i.e. unemployment duration) employers use, is an imperfect proxy for productivity. Firms use unemployment duration as a screening device to filter out applicants who meet the productivity standard, $p^{s}$, the firm requires. As we argue in Chapter II, both skill deterioration and heterogeneity effects explain for a negative link between unemployment duration and productivity. This negative relationship reduces the probability to find a qualified unemployed from a cohort of unemployed experiencing a more prolonged spell of unemployment. As a result of the imperfectness of the proxy the firm makes type I errors in its hiring procedure, i.e. the firm includes applicants in the procedure that meet $t^{5}$ but not the productivity standard, $p^{s}$, which is a costly exercise. Type I errors increase in unemployment duration and hence induce the firm to set a strict $t$. This however, leads to the exclusion of applicants who meet $p^{s}$, but not $f$ (type II errors), which is also a costly exercise, as the arrival rate of applicants is not maximized. Extending search activities - by means of a wage subsidy - beyond the screening device standard confronts employers with the latter consequence of
using the imperfect proxy.

A wage subsidy widens the effective labour supply (as the firm finds out that some of its rejects $\left(r_{j}>r\right)$ meet its productivity requirement $\left.\left(p_{j} \geq p^{s}\right)\right)$. Following empirical evidence from Crafts (1989) and Budd et al. (1988), this increase in the effective labour supply decreases the equilibrium wage and hence the equilibrium unemployment rate. The subsequent drop in social security expenditures goes to the government, not to the firm, which explains why firms do not take these effects into consideration and the subsidy is needed to
increase the effective part of the labour supply, as we argue in Chapter II.

\footnotetext{
Dropping thapter we assume identical fims, meaning that the screening device standard set by firms is identical. Dropping that assumption opens th the possibiltity to relate deadweight loss to firm, job and labour market th in this chapton we discuss the tho address this issue. search only; not on taingng) and the pune training subsidy (the wage subsidy (the subsidy is spent on extended In practice internediate schemes are awalable, bu we peculiarities of both schemes.
} 
In Figure 3.1 we model the wage subsidy based on extended search. Like in Chapter II, we assume that the distribution function of productivity over unemployment cohorts, $R(p)$, is normally distributed, for each period. To minimize hiring costs the firm optimally sets $r^{5}$, which leads to an optimal trade-off between costs related to committing type 1 (area $A$ ) and type II errors (area $B$ ), as discussed in Chapter II. Productivity decay limits the maximum range of the wage subsidy in tenms of length of the unemployment spell of potential participants. That is, productivity decay ensures that no unemployed experiencing an unemployment spell beyond $t$, meets the productivity standard, $w^{s}$, of the firm - see Figure $3.1{ }^{47}$ Hence in this hypothetical example, the maximum subsidy range of a wage subsidy is from $t^{s}$ up to $t^{r}, 48$

Figwre $31 \quad$ A (seareh extension motivated) wage subsidy

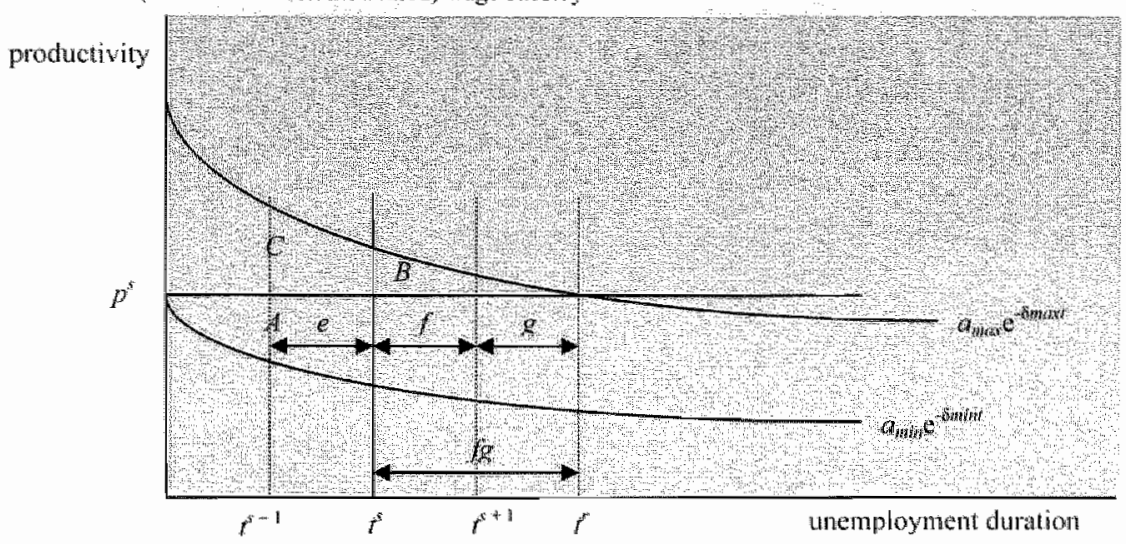

A full range wage subsidy excludes deadweight loss, as firms do not receive a subsidy for an applicant they would have taken into consideration without the subsidy and includes all applicants that meet the productivity standard of the firm. However, if the government wants to ensure that firms consider all unemployed experiencing an unemployment spell between $t^{\prime \prime}$ and $t$ for the vacancy, the subsidy should not be uniform, but depend on the length of the uncompleted spell of unemployment of the selected subsidized unemployed. We show why this should be the case in a wage subsidy scheme, using Figures $3.1,3.2$ and the formal framework to discover recruitment costs we developed in Chapter II.

We know from the analysis in Chapter II that recruitment costs can be presented as [ I $+A / C] b+[T / C] c$, where area $A$ contains applicants who meet the screening device standard, but not the productivity standard (i.e. applicants that thil the assessment), area $C$ contains applicants who meet both the screening device standard and the productivity standard, area $T$ constitutes the total unemployment pool. Figure 3.1 clearly shows that for every individual subsequent cohort recruitment costs must increase as area $A$ increases at the expense of area $C$. This implies that each individual subsequent cohort produces both more assessment costs, $b$, and foregone productivity costs, $c$. The firm's optimal hiring strategy

\footnotetext{
${ }^{47}$ For the sake of convenience we assume that area $B$ comprises only two unemployment cohorts $\left(r^{5}\right.$ " and $r$ ). Likewise, area $A$ comprises only colsorts $t^{3-1}$ and $f^{5}$.

th This does not necessarily inply that the government provides a subsidy for the full range. The govemnent might, for example, decide only to provide a wage subsidy for individuals out of employment for $t$ " "to $f$ " periods, if it wants to concentrate on unemployed whose productivity drops below $p^{s}$ in the short-lem as a result of productivity decay.
} 
$\left(H C_{m i n}\right)$ comprises recruiment from applicants whose unemployment duration does not exceed $t^{*}$ (hence cohorts $t^{-1}$ and $t^{\text {) }}$ ).

In Figure 3.2 we show the evolution of hiring costs, when adding cohorts of unemployed. Say a firm decides to recruit from cohort $t^{5-1}$ only. This is not an optimal strategy as adding cohort $t$ reduces hiring costs further. The reason is that the hiring cost reducing effect of adding cohort $f^{t}$ (filling the vacancy more quickly, hence less costs $c$ ) dominates the hiring cost increasing effect (more assessment failures, hence more total costs b). This no longer holds for cohorts beyond $t^{s}$. Since for recruitment of subsequent cohorts, area $A$ increases at the expense of area $C$, we assume recruitment costs to increase convexly for subsequent cohorts. This also explains the asymmetry of the hiring cost curve in Figure 3.2. That is, the convexity of recruitment costs ensures that deviating from the optimal recruitment strategy by dropping cohort $f^{\prime \prime}$ in the recruitment procedure and consequently recruiting up till $t^{-1}$ leads to a lower cost increase than adding cohort $t^{3+1}$ to the optimal recruitment strategy: $\varepsilon_{e}<\varepsilon_{f}\left(<\varepsilon_{g}\right)$.

Figure 3.2 Evolution of pecruitment cosis

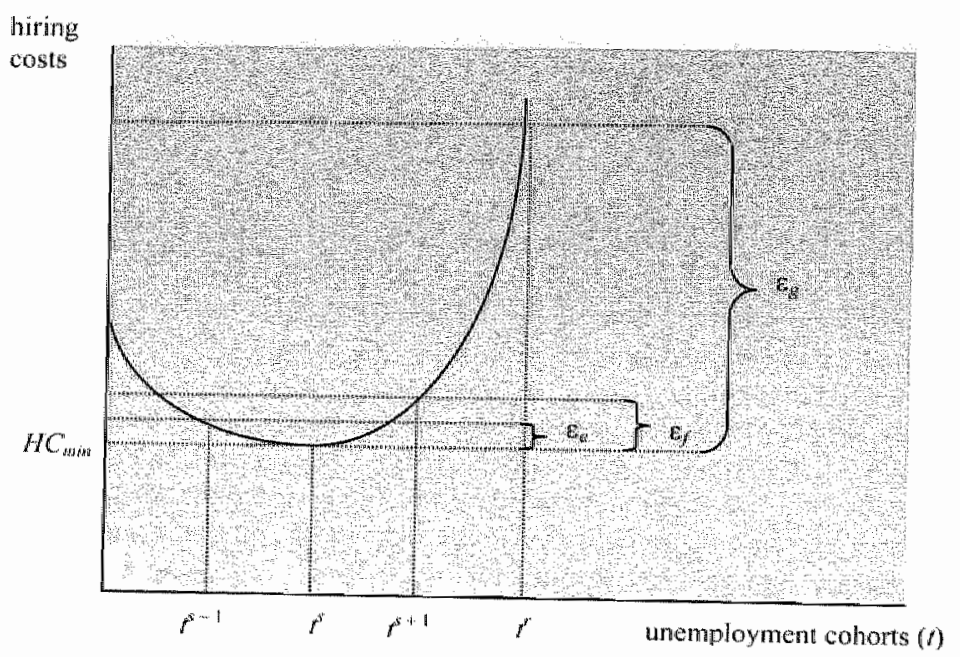

If the government wants to induce firms to recruit from $r$ up to $r$ (range $f g$ in Figure 3.1), a subsidy is required. Lef us consider the firm"s hiring costs when recruiting from unemployed whose unemployment spell ranges from $f^{5}$ to $t$ are $H C_{k}$. The wage subsidy, $\varepsilon$, should then make up for the hiring cost difference to make the firm indifferent between pursuing its optimal recruitment strategy, $H C_{m i n}$ and the government's desired strategy, $H C_{g}$. Though such a uniform wage subsidy induces firms to change their hiring strategy, the
firm will only partially adopt the government's desired strategy. The reason for this is related to the development of recruitment costs to the right of $f$. Hiring costs continuously increase for each subsequent cohort of unemployed to the right of $t^{5}$. Consequently: $H C_{f}<H C_{g}$ and since $H C_{f g}$ is some weighted average of $H C_{f}$ and $H C_{g}$, it follows that: $H C_{f}\left(=H C_{m i n}+\varepsilon_{g}\right)<$
$H C_{f g}\left(=H C_{m i n}+\varepsilon_{g}\right)<H C_{g}\left(=H C_{m i n}+\varepsilon_{g}\right)$.

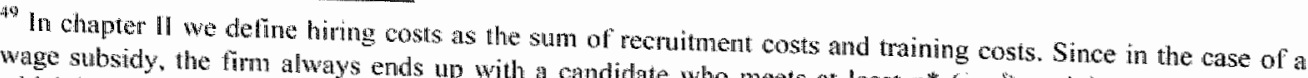
wage subsidy, the fim always ends up with a candidate who meets at least $p^{*}\left(=p^{*}\right)$, training costs are zero,
which implies that hiring costis equal recruitment costs.
} 
Table 3. I contains the firm's set of strategies following the availability of a wage subsidy. If the govermment grants a wage subsidy $\varepsilon_{\text {f }}$ to employers who recruit from area ff in Figure 3.1 , the firm will adopt this strategy. The same holds for a government awarding $\varepsilon_{\mathrm{g}}$ to firms recruiting from area $g$. However, a government designing a wage subsidy, which grants firms a subsidy worth $\varepsilon_{f g}$ for recruitment from unemployed out of area $f g$, will induce firms to accept the subsidy, but to recruit only from a subsection of $f g$ : area $f$. Recruiting from area $f$ involves less hiring costs and since it is a subset of area $f g$, the firm does not obstruct the government's requirements and enjoys a profit from participation. ${ }^{50}$

Consequently, to prevent firms from making a profit on participating in a wage subsidy scheme, the government should link the level of the subsidy to the length of the unemployment spell of the participating unemployed. Unfortunately, unemployment duration dependent (i.e. non-uniform) wage subsidy schemes are rare in practice.

Table $3.1 \quad$ The firm"s set of strategies following the government's subsidy grant

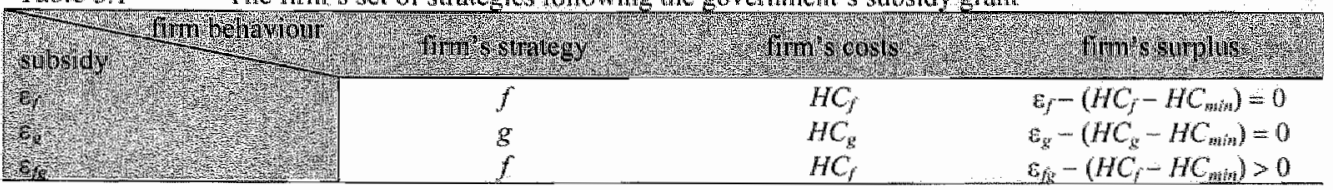

\section{Damage control in a wage subsidy scheme}

The non-uniformity of a wage subsidy not only prevents firms from claiming more subsidy than is strictly necessary, it can also serve as an effective instrument to prevent firms from claiming a subsidy at all when the subsidy is unnecessary, i.e. in case of deadweight loss. "To demonstrate how the government can use the non-uniformity of a wage subsidy to prevent firms from accidentally or deliberately causing deadweight loss, we drop the assumption that the government is able to identify $t^{s}$ correctly. Dropping that rather optimistic assumption opens up the potential threat of deadweight loss. That is, if the govermment sets the start value of subsidy entitlement, $t^{s g}$, to the left of $t^{s}$, it provides a subsidy to firms for unemployed they consider in their hiring decision regardless the availability of the subsidy. It remains a potential threat, as long as firms do not capitalize on the government's misperception. Unfortunately, under the setting of a uniform wage subsidy (i.e. the subsidy level does not depend on the unemployment duration of the participant) the firm always has a tendency to recruit as closely as possible to $t^{g g}$, as hiring costs increase the further an employer recruits to the right of $f^{\text {sg }}$ - see Figure 3.2. As a result, the probability that a potential threat of deadweight loss materializes is rather high, which justifies the conclusion that a uniform wage subsidy is vulnerable to deadweight loss.

The same holds good for a non-uniform wage subsidy scheme. That is, also a monuniform wage subsidy scheme is vulnerable to deadweight loss, owing to a government misperceiving $t^{*}$. To show this we focus on the hiring strategy of firms within a non-uniform wage subsidy scheme. In Figure 3.3 we describe a situation in which deadweight loss potentially arises. On the horizontal axis we position both the firm's reality concerning the value of $r^{s}$ and the government's perception of $t^{s}$ (which it uses to determine $r^{\text {sig }}$ ). We illustrate a situation in which the government regards the true vallue of $t^{3}$ (set by the firm) to be lower than the actual value. Hence, $t^{8 g}<t^{6}$. In Chapters IV and $V$ we provide several reasons why firms decide to change $r^{s}$. One of them is the stance of the labour market. We will show that

\footnotetext{
50 A uniform wage subsidy, like $\varepsilon_{g g}$, not only leads to firm profits, but also reduces the chances of unemployed holding the weakest labour market position (i.e. those experiencing an unemployment spell close to $r$ ) to find a subsidized job.
} 
firms increase $t^{5}$ in for example slack labour market conditions. A government that does not take a change in the stance of the labour market into account when setting $t^{5}$, could end up in a situation as depicted in Figure 3.3 .

As we present it here, the government has been overtaken by one unemployment spell. That is, the screening device standard used by firms is not $t^{s}$ but $t^{t}$ and this misperception runs through the rest of the model (e.g. the subsidy range should be from $t^{s}$ to $t^{r}$, but is from $t^{g}$ to $t^{\text {sin }}$ instead).

Figure 3.3 Deadweight loss incidence in a wage subsidy

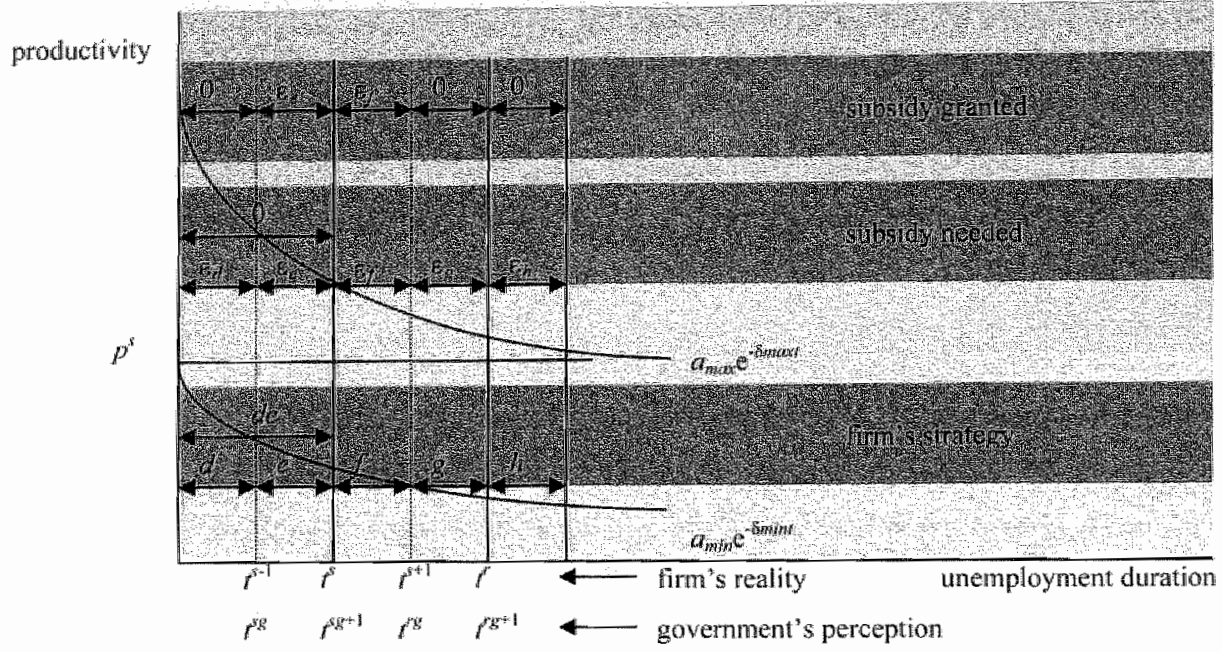

To assess the deadweight loss vulnerability of a non-uniform wage subsidy, we need to study employer behaviour following the misperception of the government about $t^{\prime \prime}$. Figure 3.3 contains six potential hiring strategies the firm can pursue. We are interested in strategies that contain recruitment from area $e$, which is the area that contains subsidized unemployed the firm considers for the job without a subsidy (i.e deadweight loss). Two strategies include areat $e$ in its recruitment teritory: strategies $e$ and de. Firms pursung strategy e deliberately focus on unemployed for whom a subsidy is avalable; fims pursumg strategy de accidentally cause deadweigh loss in part of its hings (the share depending on the relative size of area $e$ compared to $d$ ). Any other strategy does not lead to deadweight loss incidence and hence should be prefered to strategies or de assuming the government is interested in minimizing deadweight loss. We therefore review all six strategies to see which one maxinizes the firm's profit and subsequently will be chosen by the firm.

Stategy $e$, recruting from area $e$, only: a fim recruting from area e receives a wage subsidy $\mathrm{f}_{\mathrm{a}}$. The hiring costs of a fim tecuiting from area $e$ are sub optimal, since area $e$ is only part of the ideal recmiment strategy - which is stategy de - and consequently the firm needs a subsidy, $\varepsilon_{*}$, to be persuaded to recruit from area $e$. The firm obtains $\varepsilon_{w^{*}}$ and considers pursung strategy $e_{3}$ if $\varepsilon_{e^{\prime}} \geq \varepsilon_{\alpha}$. We know the government is wrong about $f^{\prime}$ by one period, which implies that it the firm recruits fron area $e$ and hence needs a subsidy worth $\varepsilon$, it receives a subsidy it wouth hawe needed if the frm had decided to recruit from the next cohort of unemployed, area $f$ the subsidy of which is worth $\varepsilon_{f}{ }^{31} \mathrm{As}$ a consequence $e$ is a viable strategy, since $H C_{R}(=$

${ }^{31}$ That is $\varepsilon_{p}=\varepsilon_{y}$ and subsequemly $\varepsilon_{f}=E_{p}$ 
$\left.H C_{\text {mäh }}+\varepsilon_{e}\right) \leq H C_{f}\left(=H C_{\text {min }}+\varepsilon_{f}\right)$, as we showed in Figure 3.2. This inplies that the firm obtains a subsidy for recruiting from area $e$, which more than covers its hiring costs. Hence the strategy that makes firms focus on causing deadweight loss is a viable one.

Strategy de, recruiting from area de: area de is the optimal recruitment area in terms of hiring cost minimization, when there is no subsidy availlable. To induce firms to recruit from this area, no subsidy is required. Nonetheless, in some cases the firm still obtains a subsidy. If the firm takes on an applicant from the $d$ part of area de, the firm does not receive a subsidy; hiring someone from the $e$ part of area de does yield a (unnecessary) subsidy: $\varepsilon_{*}\left(=\varepsilon_{j}\right)$. Assume the probability to select a candidate whose unemployment duration is between $t^{5-1}$ and $t^{s}$ after pursuing strategy de to be $\alpha$, then the firm"s surplus from recruiting from area de is positive, $\alpha \varepsilon_{j}$, and hence viable. This implies that also the strategy that leads to the accidental incidence of deadweight loss is a viable strategy.

The remaining strategies do not lead to deadweight loss and hence should be preferred from a government point of view. But are they viable from the firm's profit maximizing point of view?

Strategy $d$, recruiting from area $d$ : a firm pursuing recruiting strategy $d$ does not receive a subsidy for hiring an applicant. The government awards a subsidy from $f^{\mathrm{gg}}$ to $t^{\mathrm{rg}}$. Applicants in area $d$ do not meet these criteria. Though no subsidy is granted, the firm needs a subsidy to recruit from area $d$ as this recruitment strategy is sub optimal. That is, shifting the screening device standard from the optimal value $t^{s}$ to $t^{s-1}$ (i.e. reducing the screening device standard) reduces type I errors and it increases the incidence of type II errors. Since the shift in the screening device standard takes place at the left of the optimal screening device standard, the hiring cost reduction following the reduction in type I errors does not outweigh the hiring cost increase involved in the increasing number of type II errors. Hence hiring costs go up, when shifting from strategy de towards $d$. Since there is no subsidy available for pursuing recruitment strategy $d_{n}$ recruiting from area $d$ is no viable recruitment strategy.

Strategy $f$, recruiting from area $f$ : a firm recruiting from area $f$ receives a subsidy, $\varepsilon_{f}$. Due to the misperception of the government, the value of subsidy $\varepsilon_{f}$ is sufficient to cover the additional hiring costs that arise from pursuing strategy $\mathrm{g}$ instead of strategy $f:$ i.e. $\varepsilon_{f}=\varepsilon_{g}$. Consequently the firm will pursue strategy $f$ as long as $H C_{f}\left(=H C_{\text {mith }}+\varepsilon_{j}\right) \leq H C_{g}\left(=H C_{\text {min }}+\right.$ $\left.\varepsilon_{g}\right)$. Carrying on the argument set forward in analysing the viability of strategy $e$, shows that pursuing strategy $f$ yields a profit to the lirm, which makes strategy $f$ a viable strategy.

Strategy $g$, recruiting from area $g$ : recruting from area $g$ is not viable. To persuade the firm to recruit from this area a subsidy $\varepsilon_{\mathrm{g}}$, is required. However, the government perceives area $g$ to be outside the subsidy range and does not allocate a subsidy to a firm recruiting from this area. ${ }^{52}$ Recruiting from this area leads to a loss: $-\varepsilon_{\mathrm{g}}$.

Table 3.2 summarizes the potential strategies. Three strategies are viable: strategies $e$, de and f. The first two lead to deadweight loss; the latter does not. We show that the firm prefers a strategy that leads to accidental incidence of deadweight loss, if the government's misperception of $t^{s}$ is substantial. However, the government can use the non-uniformity of a wage subsidy to provide incentives to the firm to pursue strategy $f$, which enables the government to avert the deadweight loss risk, without exactly knowing $t^{s}$.

\footnotetext{
${ }^{52}$ The same holds for any recruitment strategy to the right of strategy g (e.g. strategy h). None of them are viable and hence we do not discuss them here.
} 
Table 32 The Trm's strategy following the gowernments mispereption

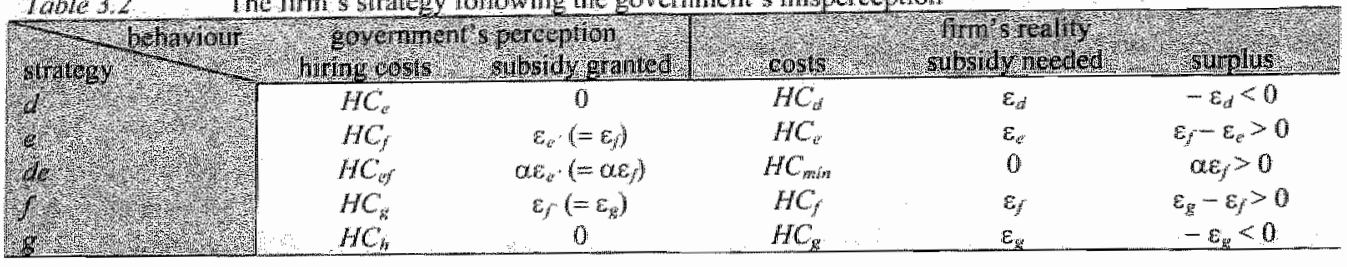

If damage control is the main criterion for design selection, the strategy leading to the least abuse (in terms of deadweight loss) should be preferred. Using this criterion, strategy $f$ should be preferred to both e and de, as under strategy $f$ the deadweight loss share is $0 \%$. Strategies $e$ and de both lead to $100 \%$ deadweight loss. ${ }^{53}$ Still the government should not be indifferent to strategies $e$ and $d e$, since the size of the abuse (in absolute terms) is lower under strategy de than under strategy e. A firm pursuing strategy $e$ is completely focusing on recruiting subsidy entitled applicants it would have hired anyway, whereas a firm pursuing strategy de unintentionally causes deadweight loss to occur in part $\alpha$ of its recruits. Assuming that firms are successful in meeting their employment needs regardless the recruitment strategy they pursue, strategy e leads to more subsidy abuse (in absolute terms) than strategy de.

Consequently the first question we want to address is: under what conditions (in terms of the design of the wage subsidy scheme) does a firm - participating in a wage subsidy scheme - deliberately or accidentally cause deadweight loss, leaving the other recruitment strategies aside?

The firm prefers pursuing strategy de (accidentally causing deadweight loss) to strategy $e$ (deliberately causing deadweight loss) when equation 3.1 holds:

$$
\varepsilon_{0}>(1-\alpha) \varepsilon_{i} \quad \text { м } \quad 0<\alpha \leq 1
$$

Since from Figure 3.2 we know that $\varepsilon_{f}>\varepsilon_{e}$, the value of $\alpha$ decides on the firm's intention whether accidentally or deliberately - only to focus on causing deadweight loss. Remember that $\alpha$ measures the probability to select a candidate whose unemployment duration is between $r^{-1}$ and $r^{*}$ after pursuing strategy $d e$.

If $\alpha$ is close to zero (hence the government only slightly misperceives $r$ ), this condition is not met. That is, if the government only slightly misperceives $t$, the probability to obtain an unnecessary (hence profitable) subsidy when pursuing strategy de is small. This induces the firm to concentrate on reaping revenues from the alternative strategy $e$, which subsequently leads to substantial deadweight loss abuse in absolute terms.

If $\alpha$ is close to unity (hence the government largely misperceives $t^{\delta}$ ), the probability to obtain an umnecessary (hence profitable) subsidy when pursuing strategy de is large, which induces the firm to pursue strategy de instead of strategy e. However, since the probability to cause accidental deadweight loss is large for large $\alpha$ 's, the size of deadweight loss abuse in absolute terms is also significant for large $\alpha$ 's.

\footnotetext{
33 This would suggest that deadweight loss shares in wage subsidy schemes are either $0 \%$ or $100 \%$, which is at odds with empirical evidenee. These extreme scenarios arise from the assumption that all firms are identical (and hence apply the same screening device standard). In Chapters IV and $V$ we drop this assumption, which allows
for all hatermediate deadweight loss shares.
} 
For $\alpha=\left(\varepsilon_{f}-\varepsilon_{e}\right) / \varepsilon_{f}$ the deadweiglt loss abuse in absolute terms is mimimized. That value of $\alpha$ makes the firm indifferent to pursuing strategy $e$ and de and makes it the least probable that a firm pursuing strategy de accidentally causes deadweight loss. ${ }^{34}$

Unfortunately, the government does not know $\alpha$ - since if it did, it would know $\gamma^{x}$ - and subsequently would focus on providing incentives which ensure that firms pursue the "deadweight loss free' strategy $f$. A government that anticipates deadweight loss solves $f \succ$ $\max [d e ; e]$ :

$$
\varepsilon_{\mathrm{g}}-\varepsilon_{j} \geq \max \left[\alpha \varepsilon_{f} ; \varepsilon_{f}-\varepsilon_{i}\right]
$$

The firm does not know $\alpha$. To ensure that it pursues strategy $f$, two conditions have to be met: $f>e$ and $f \succ$ de. Firms prefer strategy $f$ to $e$ if equation 3.3 holds:

$$
\varepsilon_{a}+\varepsilon_{g} \geq 2 \varepsilon_{j}
$$

The convexity assumption of hiring cost increases following the addition of subsequent cohorts to the recruitment strategy ensures that equation 3.3 holds. This implies that firms prefer strategy $f$ to $e$.

Firms prefer strategy $f$ to de if equation 3.4 holds:

$$
\varepsilon_{\mathrm{g}}>(1+a) \varepsilon_{r}
$$

We know that $\varepsilon_{g}>\varepsilon_{f}$. Hence the size of $\alpha$ decides whether equation 3.4 holds. This trade-off is similar to the trade-off between strategies $e$ and de discussed above. For small values of $\alpha$ (i.e. $\left.\alpha<\left(\varepsilon_{g}-\varepsilon_{j}\right) / \varepsilon_{j}\right)$, the probability to obtain an unnecessary (hence profitable) subsidy from pursuing strategy de is too small to pursue strategy de instead of $f$. Firms switch towards accidentally causing deadweight loss, if the government misperceives $t$ by large.

To summarize, we review the reaction of the firm following the size of the misperception of the government concerning $t^{3}$ in the scope of a non-uniform wage subsidy scheme. Figure 3.4 illustrates the three potential responses. 55

Figrae 3.4 Deadweight loss incidence in a non-unitomn wage subsidy

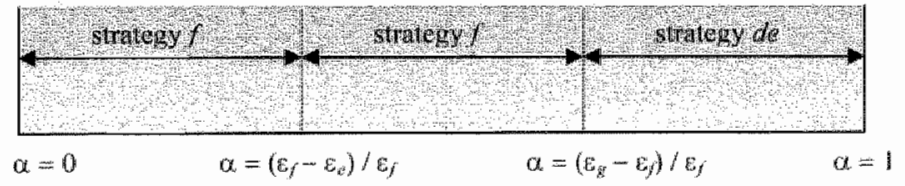

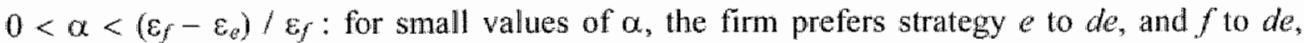
consequently the firm pursues strategy $f$.

\footnotetext{
34 Consequently, the deadweight loss abuse (in absolute terms) is u-shaped in $a$.

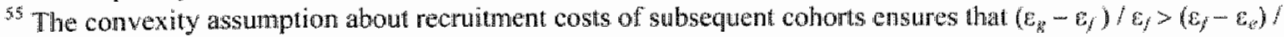
$\varepsilon_{j}$
} 
$\left(\varepsilon_{f}-\varepsilon_{e}\right) / \varepsilon_{f}<a<\left(\varepsilon_{g}-\varepsilon_{f}\right) / \varepsilon_{f}$ for internediate values of $\alpha$, the firm prefers strategy de to $e$ and $f$ to de and consequently chooses strategy $f$.

$\left(\varepsilon_{g}-\varepsilon_{f}\right) / \varepsilon_{f}<a<1$ : for large values of $\alpha$, the firm prefers strategy de to $e$ and de to $f$, hence the firm pursues strategy de.

The above analysis demonstrates that if a government fails to identify $f^{s}$ correctly within a non-uniform wage subsidy scheme, the participating firms pursue a hiring strategy that leads to accidental deadweight loss if the misidentification of $t^{5}$ is large. If the misidentification is small, firms adopt strategies that do not lead to deadweight loss. Nonetheless, neither a uniform, nor a non-uniform wage subsidy is deadweight loss resistant if the government misperceives $t^{s}$. A government that does not take measures to prevent the consequences of misperceiving the fim 's screening device standard elicits firms either to employ accidentally or to exploit the government's mistakes and focus on hiring from subsidy entitled unemployed it would have considered in the absence of the subsidy.

However, the non-uniformity of the wage subsidy also provides an opportunity to the government to provide incentives to firms to pursue the preferred strategy $f$. Equations 3.3 and 3.4 show that a raise in $\varepsilon_{g}$ (i.e. the government should raise $\varepsilon_{f}$ ) would shift the balance towards the preferred strategy $f{ }^{56}$ This would make non-uniform wage subsidies deadweight loss resistant. Consequently, a non-uniform wage subsidy scheme is more accurate to steer the frrm"s hiring behaviour than a uniform wage subsidy scheme. Consequently, a non-uniform wage subsidy scheme enables a more precise target group policy and a lower deadweight loss incidence.

\subsection{Training subsidy schemes}

The notion of a training subsidy that encourages firms to train unqualified job seekers is based on the assumption that individual firms do not take the macroeconomic effects of training into consideration. The firm only internalizes the microeconomic productivity effects of training, not the macroeconomic labour supply effects. Training unqualified unemployed leads them back to the effective labour supply, leading to the same macroeconomic effects as a search extension motivated wage subsidy.

In this section we explore whether a training subsidy scheme is - like a wage subsidy scheme - vulnerable to deadweight loss. We show that it could be possible, depending on recruitment costs, training costs and the design of the training subsidy. Since the government controls the design of the training subsidy scheme, it can also provide incentives which induce firms not to exploit deadweight loss potential.

The design of a training subsidy scheme is more complicated than the design of a search extension motivated wage subsidy. The introduction of training endogenizes the productivity standard of the firm, $p^{\prime \prime}$, into the model. Consequently, when discussing a training subsidy, we distinguish two productivity standards. The first standard refers to the productivity level necessary to be productive on the job, $p^{*}$; the second refers to the productivity level necessary to be considered for a job, $p^{s}$. The availability of training allows the firm to bridge the potential productivity gap, $p^{*}-p^{*}$.

\footnotetext{
${ }^{95}$ Remind that reducing $\varepsilon_{\text {; }}$ would be an option to solve the misperception problem. However, reducing $\varepsilon_{e}$ and/ or $\varepsilon_{r}$ would temove any incentive at all to participate in the programme. Subsequently reducing $\varepsilon_{p}$ and $/$ or $\varepsilon_{f}$ is
no option.

${ }^{57}$ Remember that in a wage subsidy scheme, training was no option, hence the firm could not set $p$ below $p *$.
} 
Along the lines of Chapter II, we assume the government provides the subsidy to firms that spend the subsidy on upgrading the productivity level of long-term unemployed they enploy. whose productivity ranges between $p^{g}$ and $p^{s g}\left(p^{g}<p^{s}\right)$. The upper bound, $p^{\text {se }}$, is the govemment's perception of the productivity standard, $p^{s}$, the firm applies in its hiring decision. It is no use setting $p^{s g}$ above $p^{s}$, because in that case, the govermment subsidizes training, that the firm would have been willing to finance privately, which is the first potentid source of subsidy wastage. ${ }^{5 s}$ The lower bound, $p^{g}$, is an independent ohoice of the government. The choice of $p^{g}$, limits the size of the training subsidy both in terms of training opportunities and expenditures. ${ }^{59}$ The choice of $p^{g}$ is exogenous to our model.

To attain the vocational degree (leading to $p_{i}=p^{s g}$ ), the participant has to follow a continum of educational stages. ${ }^{60}$ The construction of the training schedule allows every memployed to enter the programme at an adequate level. This set up allows us to make the costs of training dependent on the productivity discrepancy (i.e. $p^{\text {s. }}-p_{j}$ ) that needs to be bridged. Moreover we assume the costs of attaining an educational stage depend negatively on the ability level of an unemployed. That is, more able trainees finish an educational stage more quickly - see Section 2.3.

Since participant ability affects the costs of attaining an educational stage, these costs need to be linked to the subsidy level per educational stage, the govermment provides. "This implies that the government has one more decision variable: the ability level to base the pereducational stage subsidy level on. We assume the government uses the average ability level of the subsidy entitled long-term unemployed, $a_{\text {ave }}$, to base the level of the per-educational stage training subsidy on. Consequently, a firm participating in the training subsidy scheme can make a profit out of participation whenever it finds a subsidy entitled long-tem unemployed who has an ability level that exceeds $a_{z w}$. The ability surplus (which determines the profit per educational stage the firm can reap) and the number of stages that have to be completed (i.e. $p^{s g}-p_{j}$ ) determine total participation profit.

In its decision how to adapt its hiring behaviour to the new situation in which a training subsidy is available, the firm considers three aspects: its recruiment costs, its (privately financed) training costs (to cover productivity shortages from $p^{s g}$ up to $p^{\text {*⿻ }}$ ) and its participation profit. We will show that these three aspects induce the firm to hire from a subset of the Jong-term unemployed the government provides a subsidy for. This frm behaviour is evatually crucial in the deadweight loss vulnerability of a traning subsidy schene - as we will show later $=$ and hence the government should include incentres in we scheme which discourage participating firms from cawing deadweight loss, if the potential to do 50 is avalable.

The introduction of training into our model allows the firm to reduce its productivity standard, $p^{x}$, below $p^{*}$. The subsequent productivity shortage can be nullified by training which is aither publicly hranced $\left(p^{g}\right.$ to $p^{\mathrm{xg}}$ ) or privately financed $\left(p^{\text {sg }}\right.$ to $\left.p^{*}\right)$. Lowering $p^{*}$ upsets the balanee between types $I$ and II errors, i.e. the balance of recruitment costs. The incidence of type errors diminishes, as - for a given $r$ - more applicants meet the reduod productivity standard. That is, $A_{P D}>0$, which follows from equation 2.12 . The incidence of type II errors

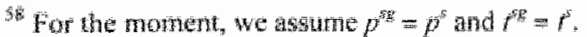

54 Think of the subsidy being linked to attining a certain wocational degere, which also puts an upper bound on the nuximum atainab productivity level, which in this case is $p^{s e}$.

Wa Wa asume that every participan that starts training for the degree eventually attains the degree.

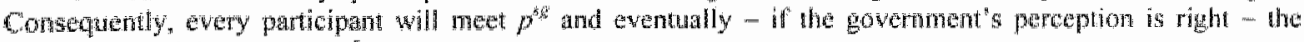
firm ${ }^{*}$ s productivity standand $p^{5}$.
} 
increases, as - for a given $f^{f}$ - more applicants who meet the reduced productivity standard are excluded from the recritment procedure. That is, $C_{p j}<0$, which follows from equation 2.13 . Consequently, a reduction of the productivity standard makes the screening device standard a more effective instrument to reduce hiring costs, which induces the firm to increase its screening device standard. ${ }^{61}$ The rightward shift of the screening device standard implies that the firm considers long-tern unemployed for a vacancy whom it would not have considered for the job in the absence of the subsidy.

The influence the introduction of the training subsidy has on recruitment costs and the subsequent adaptations in the productivity and screening dewice standard the firm makes have consequences for the expected ability and productivity level of the selected candidate. These changes in the expected ability and productivity level of the selected candidate matter for the firm"s training costs and the participation profit. In Section 2.3 we argue that the expected ability level of a selected candidate depends positively on both the productivity and the screening device standard, i.e. $\phi=\phi\left(f^{s}, p^{s}\right)$ and $\phi_{1}<0$ and $\phi_{p}<0$. To minimize privately financed training costs and to maximize the participation profit the firm's objective is to select a high ability candidate. Furthermore, to maximize the participation profit the firm looks for low productive candidates. From Section 2.3, we know that the expected productivity of a selected candidate decreases as the screening dewice standard increases and increases as the productivity standard increases.

The implications of the introduction of a training subsidy are illustrated in Figure 3.5 . For the moment we assume that the government correctly identifies the screening device standard and the productivity standard firms apply in the absence of a subsidy $\left(t^{s}=t^{s g}\right.$ and $\left.p^{s}=p^{s s}\right)$. Later we drop both assumptions as it becomes relevant to do so when exploring the threat of deadweight loss. All unemployed in the large rectangle of Figure 3.5 - the training territory are subsidy entitled for whom two requirements hold. The unemployment spell of potential participants has to surpass $t^{3 y}$, and their productivity level has to be between $p^{g}$ and $p^{s g}$. If $p_{j}<$ $p^{z}$; there is no subsidy available to upgrade to participant's productivity up to $p^{g s}$. If $p_{j} \geq p^{s g}$; there is no need for training and hence no subsidization. The former requirement also sets a maximum to the length of the unemployment spell to be still entitled to subsidization, $T$.

Nonethelless, this does not necessarily mean that the firm uses the training territory as scheduled in Figure 3.5 as its hiring territory. Depending on recruitment costs, training costs and participation profits, the frm might find it not optimal to recruit from the large rectangle, but instead prefers to hire from a subset of it: the small rectangle - the hiring territory - which is bounded by $r^{s t}$ and $r$ (i.e. the minimum and maximum unemployment duration a participant may experience to be considered for the job) and $p^{s i}$ (i.e. the ninimum productivity level to be considered for the job). ${ }^{62}$

Before discussing the determinants of the position of the hiring territory within the training territory, we want to emphasize that its position is crucial in explaining the deadweight loss incidence in a training subsidy scheme. That is, the firm"s decision on $t^{i}$

\footnotetext{
o1 The extent to which the firm shifts its screening device standard, depends on the extent to which the firm can

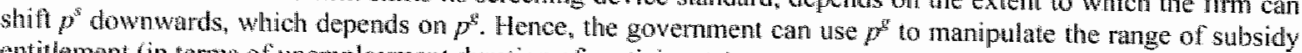
ant thement (in terms of unemployment duration of participants).

Superscript indicates that these variables are choice variables of the fim. Also $f^{*}$ is a choice variable of the lim, as it is the optimal screening device standard in the absence of the subsidy, which the government uses to demareate the official subsidy range (to deternine $f^{\prime \prime}$ ). The crucial difference between $t^{5}$ on the one hand and $p^{s f}$, $r^{3 i}$, and $r^{\prime \prime}$ on the other hand is that the fim determines the latter after the introduction of the maining subsidy, whereas the former is determined betore its introduction. The fom has no incentive to deviate from the

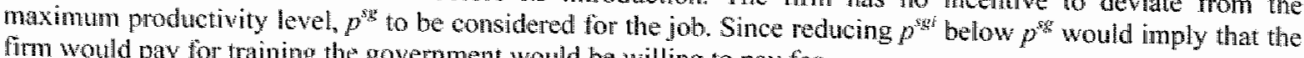
firm would pay for training the government would be willing to pay for.
} 
determines the margin between the firm's hiring strategy (in terms of unemployment duration of applicants) and $t^{s g}$. It is this margin that determines the maximum misperception the government may make about the unsubsidized $t^{b}$ to prevent potental deadweight loss from materializing.

\section{Figure 3.5 A training subsidy}

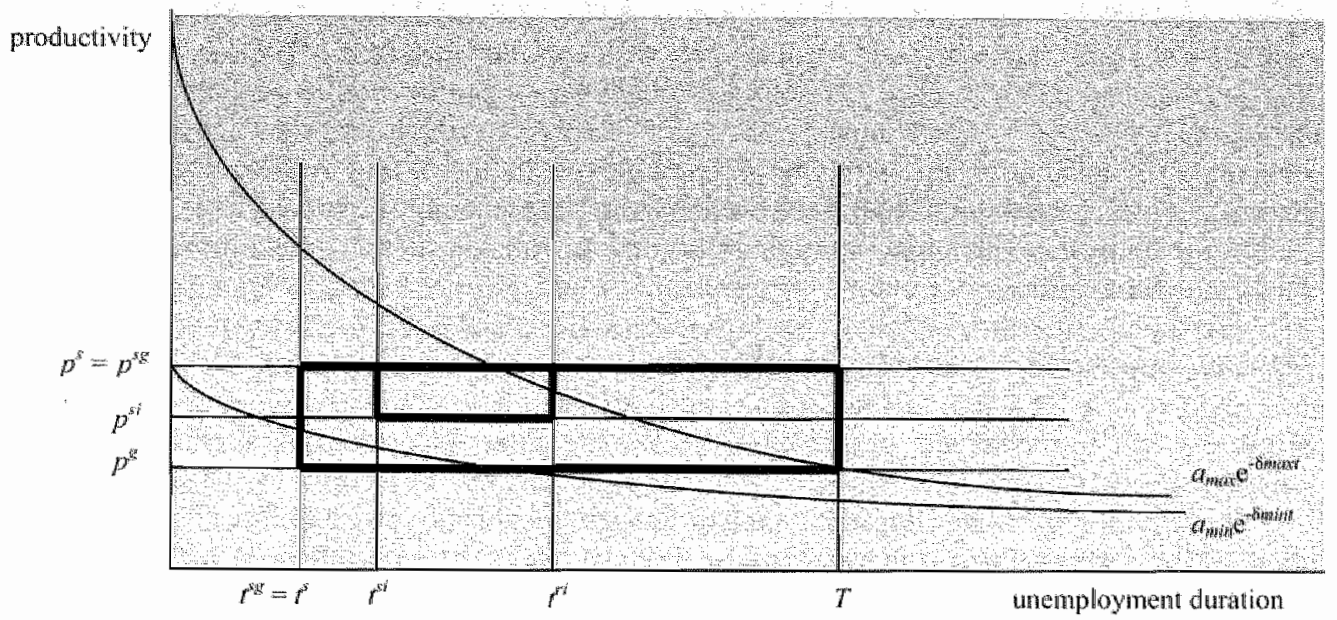

The exact position of the hiring territory within the training territory depends on three factors: recruitment costs, training costs and participation profits. We discuss each aspect separately.

\section{Recruitment costs and the hiring territory}

To study the effect of a training subsidy on recruitment costs, we discuss the effects of shifts of the boundaries (i.e. $t^{s i}, t^{r i}$ and $p^{s i}$ ) on $\chi$ (the expected average number of assessments needed to find a qualified applicant) and $\chi \varphi \Psi$ (the expected length of the hiring procedure). The former determine total assessment costs; the latter total foregone productivity costs. Together they constitute recruitment costs.

From equation 2.14 (and equation 2.15) we know that $\partial \chi / \partial r^{r}>0$. That is, productivity decay ensures that adding cohorts to the hiring rectangle at the right side of the hiring rectangle, reduces the average productivity within the hiring rectangle. This increases the failure rate of the assessment and subsequently the expected number of assessments needed to find a qualified candidate. Extracting cohorts from the hiring rectangle at the left side of the hiring rectangle, has the same effect. Consequently, $\partial \chi / \partial r^{i /}>0$. The same holds for raising $p^{s i}$, which makes it more difficult to meet the productivity standard: $\partial \chi / \partial p^{s i}>0$ ).

From equation 2.17 it is clearly perceptible that any measure that enlarges the number of applicants in the hiring rectangle (within the training rectangle) who meet both the productivity standard $\left(p^{s i}\right)$ and the screening device standards $\left(f^{s i}\right.$ and $\left.r^{r}\right)$, reduces the lengil of the hiring procedure and hence leads to less costs of foregone productivity. Figure 3.5 shows that $\partial(\chi \varphi \psi) / \partial t^{s i}>0, \partial(\chi \varphi \psi) / \partial r^{r i}<0$ and $\partial(\chi \varphi \psi) / \partial p^{s i}>0$.

To summarize, both increasing $f^{s i}$ and $p$ augments recruitment costs; the effect of a change in $t^{\prime}$ on recruitment costs is indeterminate. 
Training costs refer to the costs the firm has to finance privately to upgrade the employee's productivity level from $p^{s g}$ up to $p^{*}$. Since $p^{*}$ is exogenous to the model and long-term unemployed who participate in the training scheme all upgrade their productivity level to $p^{s g}$, the firm has to fimance an identical number of educational stages for every employee it employs. However, the ability Jevels, $a$, of wnemployed need not be identical, which subsequently also holds for training costs. We deduce from section 2.3 that $\partial a / \partial t^{s i}>0, \partial a /$ $\partial t^{i}>0$, and $\partial a / \partial p i>0$. That is, productivity decay implies that productivity levels go down as unemployment duration continues. Hence, to find an unemployed who meets $p^{5 i}$, though the average unemployment duration of unemployed in the hiring rectangle goes up (an increase in $t^{r}$ and/or $t^{\text {fi }}$ ensures this), implies that that unemployed must have had a high initial productivity, which hints at high ability levels. Raising $p^{\text {si }}$ for a given hiring rectangle yields the same effect.

\section{Participation profits and the hiring territory}

Three factors influence the proffit level the firm realizes from participating in a training subsidy scheme.

First, the likelihood to select a candidate who is subsidy entitled. The firm prefers to find a candidate who is subsidy entitled, as the firm can realize a profit from participation in the training subsidy scheme. ${ }^{63}$ The firm would forego this profit if it would find a candidate meeting $p^{\text {sg }}$ right away.

Second, the ability level of the selected candidate. To realize a participation profit $(P P)$, the firm needs to select a candidate whose ability exceeds that of the average subsidy entitled long-term unemployed. If the firm succeeds, it realizes a profit for each educational stage that needs to be bridged. When discussing privately financed training costs we found: $\partial a$ $/ \partial r^{s i}>0, \partial a / \partial r^{r i}>0$, and $\partial a / \partial p^{s i}>0$.

Third, the productivity level of the selected candidate. The ability gap between the selected candidate and the average subsidy entitled long-term unemployed determines the per educational stage profit. The total number of educational stages to be bridged, determine the participation profits. Consequently, the firm is looking for a low productive participant for wo reasons. On the one hand to reduce the likelihood to find a candidate who meets $p^{s g}$ right away and on the other hand to increase the number of educational stages needed to upgrade the productivity level of the chosen candidate to $p^{s k}$. Equation 2.22 gives the expected productivity of a chosen candidate (i.e. a candidate who meets both the screening device standards and the productivity standard). The firm looks for a low productive applicant. Equation 2.22 combined with the properties of equation 2.1 ensure that $\partial\left(\mathrm{E}\left[p_{j} \mid p_{j}>p^{s i}, t^{s i} \leq t_{j}\right.\right.$ $\left.\left.\leq t^{\prime i}\right]\right) / \partial r^{s i}<0, \partial\left(\mathrm{E}\left[p_{i} \mid p_{j}>p^{s i}, t^{s i} \leq t_{j} \leq t^{r i}\right]\right) / \partial t^{\prime i}<0$, and $\partial\left(\mathrm{E}\left[p_{j} \mid p_{j}>p^{s i}, t^{s i} \leq t_{j} \leq t^{r i}\right]\right) / \partial p^{s i}>$ 0 . Shifting both $f^{b i}$ and $f^{i}$ to the right lengthens the unemployment spell of the average unemployed within the hiring rectangle. Productivity decay then ensures that the expected productivity of a selected candidate goes down. Raising $p^{\text {si }}$ obviously increases the expected productivity of a selected candidate.

Table 3.3 summarizes the unambiguous qualitative effects of shifting $t^{5 i}, t^{\text {ri }}$ and $p^{s i}$ on the three cost aspects of hiring subsidized unemployed via a training subsidy, which can be deduced.

\footnotetext{
63 Since the firm and the assessable applicant signed a contract (signed before the assessment) stating that the firm has to hire the applicant if the outcome of the assessment is that he meets $p^{\text {si }}-$ see Section $2.2-$ the from cannot continue search for another candidate if at finds one which meets its productivity standard.
} 
from the model. The information is not sufficient to locate the three boundaries of the hing territory within the training territory.

However, since this dissertation discusses the potential risk of deadweight loss incidence, we are interested in the firm's choice of $f^{i i}$, only. We know that an increase in $f^{\text {i }}$ increases both assessment costs and costs of foregone productivity. Both cost increases contribute to increasing recruitment costs (i.e. $\partial \mathrm{RC} / \partial \mathrm{f}^{s i}>0$ ). An increase in $r^{\text {sit }}$ improves the expected ability level of a selected candidate, which reduces training costs $\left(i, e . \partial T C / \partial r^{s i}<0\right)$. Finally, an increase in $t^{s i}$ deteriorates the expected productivity level of a selected candidate, which also increases the likelihood to find a subsidy entitled candidate and together with the increased expected ability level of a selected candidate, it augments the participation profit (i.e. $\left.\partial P P / \partial f^{s i}>0\right)$.

Since the ability level - via its link to the per-educational stage subsidy level influences the participation profit, the government has an instrument to manipulate $f^{\text {si }}$. That is, if the government decides to lower the ability level on which it bases the per-educational stage subsidy level (i.e. it raises the per-educational stage subsidy) the firm has an incentive to focus its hiring strategy more intensively on low productive unemployed and that for two reasons. First, it reduces the probability that a selected candidate meets $p^{\text {se }}$ and hence is not subsidy entitled, which would imply the firm would forego the extra profitable training subsidy. Second, it reduces the expected productivity of a selected candiclate, which implies that more (extra profitable) educational stages would be required. Shifting $f$ to the right is a key feature of such a strategy. ${ }^{64}$ A government targeting the training subsidy at very longterm unemployed should apply the same strategy. Table 3.3 shows that an increase in the participation profit induces the firm also to raise $r$, which allows very long-term unemployed into the hiring procedure.

Table 3.3 The firm's incentives following a training subsidy

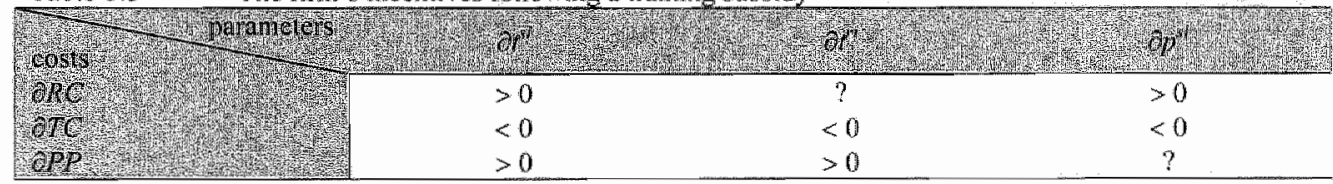

\section{Danage control in a training subsidy}

To assess the severity of deadweight loss in a training subsidy, we drop the assumption we made earlier in this section that the government is able to identify $r^{5}$ and $p^{\prime \prime}$ cotrectly. In Chapters IV and $\mathrm{V}$ we show that $f^{s}$ and $p^{s}$ are no static standards but vary with, for example, the stance of the economy: in slack labour market conditions firms increase $r$. A government that does not adapt its standards $p^{\text {sg }}$ and $f^{\text {sg }}$ to the new situation runs the risk of providing training subsidies to firms hiring unemployed they would have hired anyway: deadweight loss. Hence - in contrast with a wage subsidy scheme - in a training subsidy deadweight loss can only arise if two conditions are met: $p^{\text {sg }}<p^{s}$ and $r^{s g}>t^{s}$. We discuss both conditions and their implications separately.

We illustrate the inability to identify $p^{38}$ correctly in Figure 3.6. In the left panel we depict the ideal situation in which the government identifies $p^{\prime \prime}$ (hence $p^{s}=p^{s s}$ ) correcily. The productivity level of a candidate is between $p^{s i}$ and $p^{s y}$, thus this candidate is subsidy entitled.

\footnotetext{
Guch an increase in the participation profit has to be traded of against an increase in recruitment costs. Consequenty, the firm"s responsiveness (in terms of $t^{7}$ ) following an increase in the participation profit partly depends on the development of recruitment costs, as $f$ increases. In the following two chaptars we will ellaborate on the structure of assessment costs and costs of formgona productivity.
} 
The firm receives a training subsidy ("public" in Figure 3.6) to upgrade the productivity level up to $p^{s g}$. Subsequently, the firm privately finances training to upgrade the productivity level from $p^{\text {st }}$ to $p^{*}$. In this situation there is no subsidy wastage, as the firm does not receive a subsidy for a candidate's productivity range the training of which it would have financed privately.

Now suppose the government fails to identify $p^{s}$ correctly. The middle (overestimation of $p^{s}$ ) and right panel (underestimation of $p^{5}$ ) demonstrate the two options. If the govermment overestimates $p^{*}-$ and subsequently sets $p^{s g}$ above the actual $p^{s}$ as in the middle panel - the government is willing to finance training publicly from $p_{j}$ to $p^{\text {sg }}$, whereas the firm is willing to finance training privately for $p^{s}$ to $p^{*}$. The firm is willing to finance the overlap in training privately, but will be provided publicly: wastage.

The right panel of Figure 3.6 shows the consequences of a government that underestimates $p$. An easy labour market enables firms to sharpen their requirements, leading to a higher $p^{\prime s}$. The candidate needs training which enables him to upgrade his skills from $p_{j}$ to $p^{*}$. The government is willing to finance from $p_{j}$ up to $p^{s g}$; the firm is willing to finance from $p^{s}$ up to $p^{*}$, but there is no funding available for the upgrade from $p^{\text {sg }}$ up to $p^{s}$. As a result, the firm will not make use of the training subsidy.

The subsidy wastage as discussed above is not necessarily deadweight loss. Although the subsidy overlap in the middle panel of Figure 3.6 illustrates wastage of public money, it is not evident that the concerning unemployed would also have been hired in the absence of the training subsidy. Therefore we now turn to the potential threat of deadweight loss and its determinants, which is related to the government's choice of $p^{\text {sg }}$.

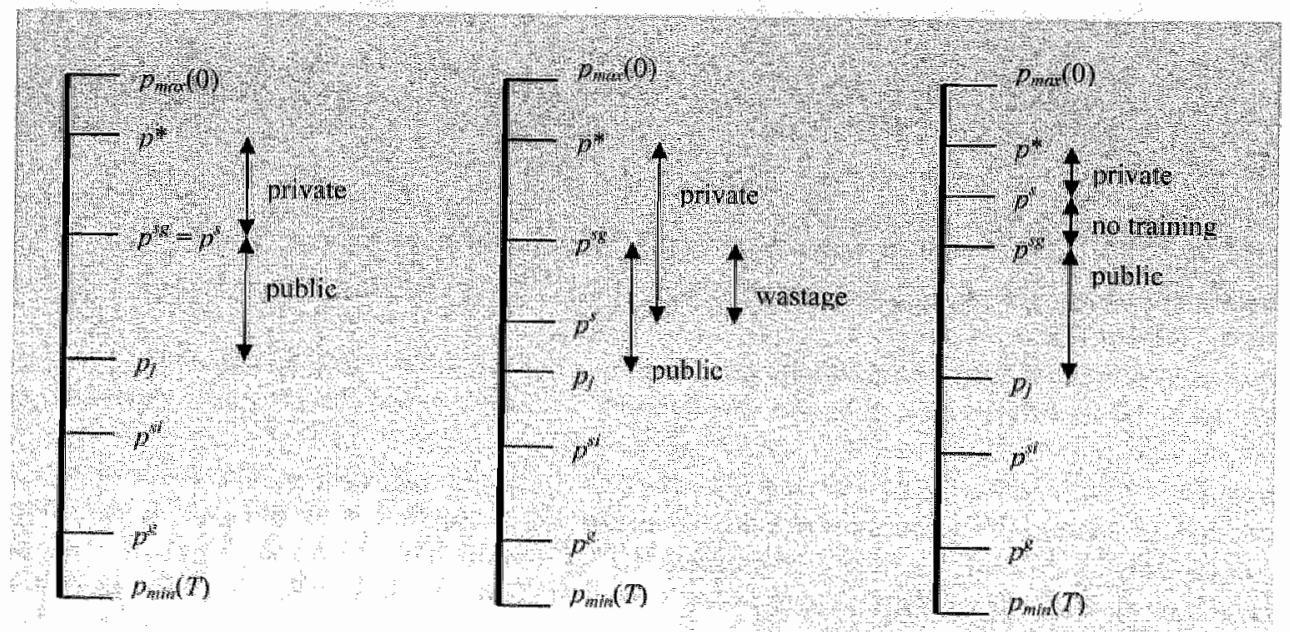

In Figure 3.7 we outline the origin of deadweight loss in a training subsidy by focusing on the training territory, as it was presented in Figure 3.5. Let us assume two time periods, period 0 and 1 . The firm decides to increase $r^{s}$ and decrease $p^{s}$ at the start of period $1\left(i\right.$ e. $t_{0}^{s}<t_{1}$ and $\left.p^{s}>p^{s}{ }_{1}\right)$.

If the govemment does not observe these changes in the firm's hiring behaviour - and subsequently leaves $p^{\text {sig }}$ and $r^{\mathrm{g}}$ unchanged at period 0 levels in period 1 - the government causes a situation in which there is a potential risk of deadweight loss. This potential risk shows up in the northwest corner of Figure 3.7. In period 1, the firm is willing to attract 
inemployed not meeting $f_{0}^{3}$ but $f_{1}^{s}$ instead and unemployed not meeting $p_{0}^{s}$ but $p^{s}$ instead and the firm is willing to provide training for them. But the firm can save the training expenditures, as the government is willing to provide at training subsidy.

Throughout this thesis we assume that - based on the results in Table 1.2 - the government is not able to identify $t^{s}$ and $p^{3}$ correctly and consequently the emphasis of the government should be on preventing the potential risk of deadweight loss to materialize. In this section we have argued that the firm only recruits from a subset of the training territory. Moreover we have shown that the government can influence the boundaries of the hiring territory by manipulating the participation profit. A close inspection of Figure 3.7 shows that preventing the materialization of the potential deadweight loss risk means preventing any overlap between the deadweight loss area and the hiring territory. The all-important parameter to prevent or reduce this overlap is $t^{\text {si. }}$. From Table 3.3 we deduce that the government could influence the firm's choice of $t^{\text {si }}$ via the participation profit: increasing the per-educational stage subsidy induces firms to shift $t^{s i t}$ to the right.

Fignre 3.7 Avoiding deadweigh loss by caneful gowernment interwention

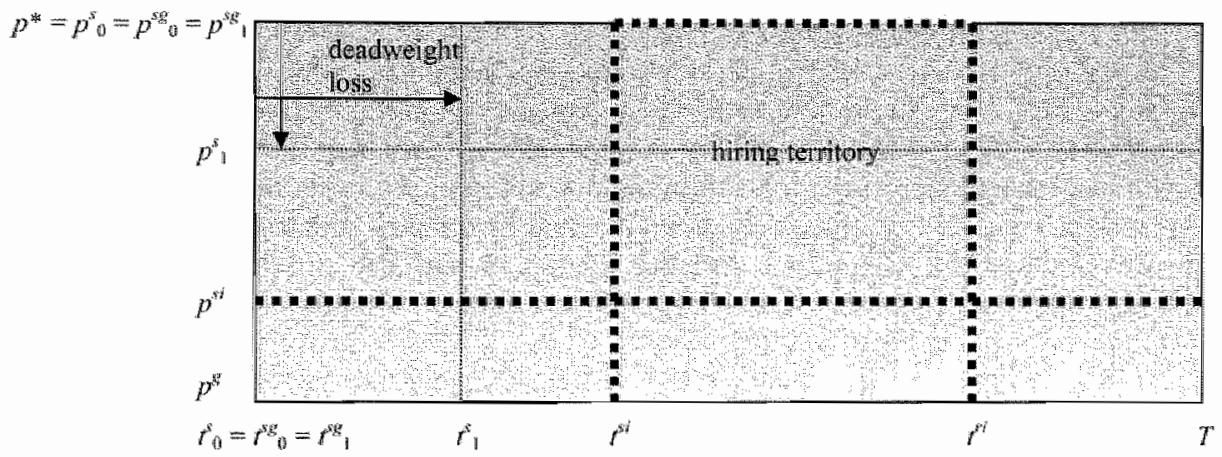

Figure 3.7 illustrates this point. Though the government causes potential deadweight loss risk by not adapting $p^{\mathrm{sg}}$ and $f_{0}^{\mathrm{sg}}$ to $p^{s}$ and $f_{1}^{s}$ respectively, it simultaneously prevents the materialization of the potential deadweight loss risk by inducing firms to start recruiting for subsidized unemployment from $f^{s i}$ onwards, which is to the right of $f^{s} .{ }^{65}$

\subsection{Costs of preventing deadweight loss}

Preventing the materialization of potential deadweight loss risk as described for both a wage and a training subsidy involves certain costs, as the government has to provide (costly) incentives. The level of these costs depends on the measure of uncertainty the government is faced with in determining $p^{s}$ and $t^{*}$. The more certain the govemment is about determining. these parameters, the less reason there is to provide incentives to induce firms not to exploit their informational advantage. The provided incentives can therefore be seen as an insurance premium. The more risk there is, the higher the premium will be.

It is not surprising that the benefits of the proposed incentives go to the informed party: the firm. Although the intention of an employment subsidy is not merely transferring

\footnotetext{
65 Note that the subsidy wastage - as discussed in the middle panel of Figure 3.6 - cannot be prevented by manipulating the subsidy gain of the subsidy. Only knowledge of lirm's behaviour regarding $p$ " can prevent this kind of subsidy wastage.
} 
public expenditures to firns, the proposed incentives are a typical example of that. Nonetheless, if the government can prewent the huge deadweight loss expenditures as scheduled in Table 1.2 by spending part of that money on providing the right incentives, socity will benefit.

\subsection{Conclusions}

In this chapter we have analysed the vulnerability of employment subsidy measures to the incidence of deadweight loss, when accepting that a government is not able to identify the recruitment strategy of a firm correctly. We distinguish two types of employment subsidies: a (search extension motivated) wage subsidy and a (training motivated) training subsidy.

A whiform wage subsidy is vulnerable to the incidence of deadweight loss, as it is likely that firms intentionally try to cause deadweight loss. Moreover a uniform subsidy is not constructive in helping unemployed who hold the poorest position on the labour market back to work. The same does not hold good for a non-uniform wage subsidy. Though, depending on the size of the government's misperception of the firm's hiring strategy, firms might cause cleadweight loss accidentally. Nonetheless, the non-uniformity structure of a wage subsidy scheme enables the government to steer the firm's applicant selection choice. This allows the government to avert the deadweight loss risk.

A training subsidy is less vulnerable to the incidence of deadweight loss than a wage subsidy, since a second condition has to be met. Not only should the government misperceive the firm's screening device standard, it should also misperceive the firm's productivity standard. Nonetheless, depending on recruitment costs, training costs and the design of the training scheme, deadweight loss is a potential threat in training subsidy schemes. Since the government controls the design of a training schente, it can also provide incentives which cover the risk that a potential threat of deadweight loss incidence materializes. 




\section{Chapter IV: Employer Search and Wage Subsidies}

In this chapter we merge insights of the literature on wage subsidy evaluation and that on enployer search to explore uncharted teritory: the firm and job characteristics leading to deadweight loss in wage subsidy schemes. We develop a model, which integrates warious arguments found in the existing employer search literature. Using a survey of Dutch and a survey of British firms both for 1999, the model predictions are confirmed, using the richness of the data set to construct some new measures. We find that firms which experience low screening costs (large firms), firms that forego substantial production due to unfilled jobs (vacancies for full-time jobs) and firms that operate in slack labour market conditions cause significantly more deadweight loss.

\subsection{Introduction}

A decade ago, Calmfors (1994) summarized the potential relevance of marginal employment subsidies - which focus on temporarily subsidizing employers who hire long-tem unemployed - to fight long-term involuntary unemployment. A few years later Fay (1996), Friedlander et al. (1997) and Martin (1998) reviewed the employment subsidies applied in the OECD countries and found disappointing results: the subsidy wastage is immense. Hence the optimism to fight unemployment applying employment subsidies in the early nineties was moderated considerably within a few years after its widespread introduction.

The empirical literature in this field can be divided into two parts: microeconometric and macroeconometric evaluations. Microeconometrics focuses on the so-called "treatment" effects of subsidy schemes. In order to do so, the job find probability of participants is compared to job find probabilities of non-participants controlling for individual characteristics. To measure treatment effects two routes are available. Lalonde (1996) gives an overview of the literature on experimental data; Heckman and Hotz (1996) demonstrate how cross section or panel data can be used to determine treatment effects. Macroeconometrics extends the analysis into another direction in an attempt to incorporate the general equilibrium effects of the subsidy. Calmfors et al. (2001) give a clear overview of this strand of literature.

Although different in many respects, both micro- and macroeconometric empirical evaluations apply the concept of deadweight loss. This loss is a measure for subsidy wastage, as it consists of the share of participants in the employment subsidy scheme that would have even found a job in the absence of the subsidy.

Much of the empirical attention focuses on determining the size of deadweight loss precisely, which is - as Dar and Tzannatos (1999) clearly demonstrate - substantial in employment subsidy schemes. Surprisingly, much less attention has been paid to the characteristics of deadweight loss. That is, which firms (and for what jobs) hire subsidized unemployed they would have hired without the subsidy? The answer to that question is relevant, as knowing firm or job characteristics contributing to deadweight loss is a necessary step in reducing its disappointingly large extent.

In this chapter the first steps are taken to give an answer to that question, combining the literature on employment subsidy evaluation and employer search. Embroidering on Chapter II, we employ an employer search model in which we introduce unemployment duration as a screening device, which the firm uses to split the job seekers pool into two parts: those who are taken into consideration for the vacancy and those who are not. ${ }^{6 / 9}$ The threshold

\footnotetext{
The modet we employ is a partiall equilibrium model, implying that we cannot model the full macroeconomic conseguences of a wage subsidy scheme. Since we only focus on firm behaviour following the availability of a wage subsidy scheme, a partial equilibrium model is sufficiently rich to answer our research question.
} 
vallue of the screening device standard depends on frm, job and sector characteristics, as the employer search literature predicts. The higher it is, the more the furm recruits from long-term unemployed and hence the more likely it hires subsidized long-term unemployed it would have also hired in the absence of the subsidy, $i$ e. the firm causes deadweight loss.

Section 4.2 summarizes the main features of the employer search model we introduced in Chapter I and we derive some comparative statics. We utilize this to sketch the conditions under which employers are willing to recruit from (subsidized) long-term unemployed and to analyse their wulnerability to cause deadweight loss. Since this chapter only deals with wage subsidies, we disregard training costs. ${ }^{67}$ However, we add recruitment channel choice to the model outlined in Chapter II. Section 4.3 reviews the empirical employer search literature. Sections 4.4 and 4.5 are devoted to a data set on a survey of Dutch firms from 1999 to test the predictions of our model. Sections 4.6 and 4.7 are devoted to a data set on a survey of British firms from 1999 to replicate the test results arising from section 4.5 . In section 4.8 we compare the Dutch and British findings. Section 4.9 concludes.

\subsection{A sequential employer search model}

We use a sequential employer search model of an employer attempting to fill a vacancy, developed in Chapter II. The employer posts a vacancy, which draws a periodical arrival rate of job seekers. Imperfect information prevents the employer from observing the productivity of job seekers free of costs. Following Omori (1997), we assume the employer to use unemployment duration as a screening device. If the job candidate experiences an unemployment spell shorter than the screening device standard $t^{8}$, the employer decides to assess the job candidate. Otherwise the job candidate is rejected. During the assessment the otherwise hidden - applicant's productivity level, $p_{j}$ is revealed. The employer employs a minimum productivity standard, $p^{s}$. If the job candidate meets the productivity standard $\left(p_{3} \geq\right.$ $\left.p^{s}\right)$ she is hired and the search process closes; if not, the employer waits for the next applicant to arrive.

\section{The determinams of hiring costs}

Assessing applicants is not free of costs: each assessment costs $b$. The same holds for a vacancy: each period it is not filled, the firm foregoes productivity, $c$. As a result firms try to generate a high arrival rate of high productive applicants, which ensures a quick filling of the vacancy so that few assessments are needed. The firm has two instruments to influence the arrival rate and the quality of applicants, as we elaborated in Chapter $11 .{ }^{68}$ On the one hand, the firm can shift the screening device standard. Reducing $r$ increases the average quality of applicants who are entitled to an assessment, as skill obsolescence ensures a negative link between productivity and unemployment duration. However, this will reduce the arrival rate of applicants, as more job seekers are excluded from the recruitment procedure.

In addition to the analysis in Chapter II, we recognize that the firm can also use the type of recruitment channel to influence the arrival rate and the quality of applicants. We concentrate on recruitment via the labour exchange offices and advertisements. ${ }^{69}$ " 7 "hese

\footnotetext{
6? Chapter $V$ addresses training aspects of hiring costs, as in that chapter, we empirically test a training subsidy scheme.

${ }^{6 *}$ We ignore here the possibility that the firm lowers its productivity standard, $p j^{3}-$ this possibulity, which implies that employees may need additional training, is elaborated in Chapter 11 and tested in Chapter V.

(6) Recruiting from long-term unemployed - which is a prerequisite in this dissertation - restricts the number of relevant recruitment channels to two: advertisements and the labour exchange office. It is typical of long-term unemployed that they do not have a social network, which makes recruiting via informal contacts difficult: see for example Gorter et al. (1996). Private employment agencies are often reluctant to mediate long-term
} 
channels have typical characteristics as regards their ability to generate a high arrival rate and high productive applicants. The firm's choice of a recruitment channel can therefore be seen as an investment decision, where costs of operating a recruitment chamel depend positivelly on the channel's ability to generate both a high arrival rate and high productivity applicants.

Van Ours (1994) shows that the probability to find a qualified applicant from a public employment agency is usually low. Gorter er al. (1996) and Russo et al. (1997a) show that firms prefer advertisements to the labour exchange office as a recruitment channel when job requirements are high. Moreover, Russo et al. (1997b) and Russo et al. (2000) show that advertisements produce both a higher response rate and a higher average quality pool of applicants than recruiting via the labour exchange office.

Consequently, advertisements outperform the labour exchange office as a recruitment channel in terms of the former"s ability to attract both more and better applicants. We proceed on the assumption that the cost of the cheapest recruitment channel $(r=0)$ is $e^{70}{ }^{70}$ The mark-up factor, $\zeta$, on the costs of the cheapest recruitment channel of the channel $r$ chosen is then positive in $r$, hence $\zeta(0)=1$ and $\zeta_{r}>0$.

The firm operates in a competitive labour market and minimizes hiring costs in order to make a competitive wage offer. Hiring costs have three origins: assessment costs, recruitment channel costs and the costs of periodically foregone productivity. The cost of foregone productivity per assessment consists of two factors. On the one hand, it depends on the average number of periods between two successive candidates, $\psi$ - the latter is inverse to the arrival rate of job seekers, consequently $\psi$ is positive in labour market tightness, $\theta$, hence $\psi(\theta)$ and $\psi_{\theta}>0 .^{71}$ On the other hand, it depends on the average number of candidates needed to find one, who is entitled to enter the assessment procedure, $\varphi$. This depends negatively both on the screening device standard, as a higher $t^{\prime \prime}$ allows more applicants to enter the assessment, and on the chosen recruitment channel as advertisements generate higher quality candidates than the labour exchange office. Hence, $\varphi\left(r^{5}, r\right)$ and $\varphi_{t}<0$ and $\varphi_{r}<0$. The product of $\varphi$ and $\psi$ equals the average number of periods between two candidates who are both entitled to enter the assessment procedure.

Finally, the average number of assessments needed to find a qualified candidate, $\chi$, is positive in $t^{s}$ and negative in $r$. Raising $t$, decreases the average quality of applicants, which reduces the success rate of an assessment; raising $r$ increases the quality of applicants. Hence, $\chi\left(r^{s}, r\right)$ and $\chi_{r}>0$ and $\chi_{r}<0$. Hiring costs are then given by:

$$
H C\left(t^{s}, r, \theta\right)=\chi\left(t_{+}^{s}, r\right)\left[b+\varphi\left(t_{-}^{s}, r\right) \psi(\theta) c\right]+\zeta(r) e
$$

Equation 4.1 intuitively yields an appealing outcome. Costs $\zeta e$ are needed to generate an arrival rate of job seekers with a certain average quality. Between brackets we find the clirect and indirect costs of each assessment. Direct costs of an assessment are costs $b$; indirect costs originate from the unproductive period in between the arrivals of two assessable candidates. Multiplying these assessment costs with the number of assessments needed to find a qualified candidate and adding the costs of activating the recruitment channel yield total hiring costs.

unemployed, as profit margins on mediating them are generally low. Self-confidence of long-term unemployed is, generally speaking, low - $f$ f Layard ef al. (1991), which diminishes the relevance of recruiting via open application.

${ }^{70}$ We treat the recruitment channel $r$ as a continuous variable. The cheapest recruitment channel $(r=0)$ is the labour exchange office, which yields a base levell arrival rate of applicants and a basic quality level of applicants.

" Labour market tightness is defined as $\theta=w / u$, where $v$ represents vacancies and $u$ unemployment. Its impact on the arrival rate of job seekers is elaborated in Pissarides (2000). 
To minimize hiring costs, the firm sets optimal values for $t^{s}$ and $r$. Before turning to the comparative statics of the model, we first limk the firm's choice of $f$ to the incidence of deadweight loss. To keep the design of the wage subsidy simple, govermments usually apply a uniform subsidy start value, $t$, entitling every employer who wants to participate, regardless of, for example, labour market, and sector or job characteristics. However, firms may experience different exogenous values of wariables as in equation 4.1 , which means that $t$ is essentially sector, firm or even job specific. We know from the analysis in Chapter II that deadweight loss might arise when the firm sets $t^{s}>t^{3 g}$. To analyse the incidence of deadweight loss, the relationship between the screening device standard $t$ and these exogenous variables should therefore be scrutinized.

\section{Comparative statics}

From the logic in the previous section it follows that we should derive the optimal hiring standard $r$, and look at the effect of changes in the four exogenous variables $b, c, e$ and $\theta$ on $f$. To facilitate the analysis we rewnite equation 4.1 as follows:

$$
H C\left(t^{s}, r\right)=\mathcal{Z}\left(t^{*}, r\right) b+\varphi^{*}\left(t^{s}, \theta, r\right) c+\zeta(r) e
$$

where $\varphi^{*}=\chi \varphi \psi$, and $\varphi^{*},<0$, which follows directly from the analysis in Chapter $\mathbb{I}$, since $\chi$ $\varphi \psi=T / C . \varphi{ }^{*},<0$ implies that the type Ill error effect of shifting $t^{s}$ on the length of the hiring procedure (i.e. an increasing arrival rate of job seekers reduces the length of the hiring procedure) dominates the type I error effect of shifting $t^{s}$ on the length of the hiring procedure (i. e. more assessment failures lengthen the hiring procedure).

Furthermore, we can infer from the conditions for a relative extremum that $H C_{r r} H C_{f r}-$ $\left(H C_{t r}\right)^{2}>0$ and - since we are minimizing hiring costs that - both $H C_{n}$ and $H C_{r r}$ are positive. Additionally, we assume that the effectiveness of $t^{s}$ to reduce hiring costs increases for higher levels of $r$, i.e. $H C_{r}<0$. The reason for this is that a higher $r$ increases the average quality of the applicants and as a result increases the success rate of the assessment. The negative effect of raising $f^{s}$ on applicant quality and subsequently on the success rate of the assessment therefore moderates for a higher value of $r$. This makes raising $r$ more effective to reduce hiring costs.

Using the implicit function theorem we derive the four partial derivatives $\left(\partial r^{6} / \partial c_{\text {, }}\right.$ $\partial r^{3} / \partial b, \partial r^{5} / \partial e$ and $\partial r^{5} / \partial \theta$ ) we are interested in. For the impact of costs of foregone productivity on the screening device standard we find:

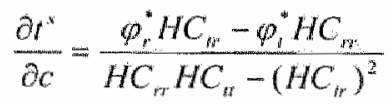

The properties of $H C$ imply that the numerator of equation 4.3 is positive; the conditions for a relative minimum ensure that the denominator is also positive, which together imply that $\partial r / \partial c>0$. This is also consistent with empirical evidence of Barron et al. (1997) and Burdett and Cunningham (1998) - who show that firms take more time to fill a vacancy when $c$ is low - because raising $t$ speeds up the recruitment procedure. ${ }^{72}$

\footnotetext{
We use the condition that the denominator is positive to interpret $\partial r / \partial b, \partial \% / \partial e$ and $\partial r / \partial \theta$, which have identical denominators.
} 
The intuition behind equation 4.3 is that firms have two instruments to speed up the recruitment procedure in order to limit the effects of increased foregone productivity costs: increase $r$ and/or $r$. Increasing the screening device standard $r$ speeds up the recrutment procedure and hence limits foregone productivity $(\varphi *<)$. The impact of this effect is captured by the second term in the numerator of equation 4.3 , where $H C_{r}$ measures the effectiveness of using the alternative, the recuitment channel $r$. The higher the current level of $r$, the less effective a change in $r$ will be $\left(H C_{r r}>0\right)$. Subsequently, the more the firm must rely on $t^{5}$ and hence the more sensitive $t^{s}$ is to changes in $c$.

The first term in the numerator of equation 4.3 shows an indirect effect on $t^{5}$ due to changes in foregone productivity $c$ through $r$. Increasing $r$ speeds up the recruitment procedure and hence limits foregone productivity $\left(\varphi^{*}{ }_{r}<0\right)$ and will therefore be used un continuation of an increase in $c$. Subsequently, an increase in $r$ reduces the negative effect that raising $t^{s}$ has on the quality of applicants and as a result its effect on hiring costs $\left(H C_{t^{m}}<0\right)$. Consequently, the firm increases $r$ indirectly following an increase in $r$. The impact of the indirect effect of $r$ on $t^{s}$ depends on $H C_{r r}$. Both the direct and indirect effects of a change in $c$ on $t^{s}$ are positive, which ensures $\partial r^{s} / \partial c>0$.

The impact of assessment costs on the hiring standard follows from:

$$
\frac{\partial t^{s}}{\partial b}=\frac{\chi_{r} H C_{t r}-\chi_{r} H C_{x r r}}{H C_{r r} H C_{t r}-\left(H C_{r r}\right)^{2}}
$$

Firms facing high costs $b$ try to limit the number of assessments needed to find a qualified candidate. Upgrading the quality of applicants is the answer, for which two instruments are available.

Raising $r$, which has an indirect positive effect on $t^{r}$ (as described under $\partial r^{3} / \partial c$ ), or decreasing $t$, which raises the quality level of applicants $\left(\chi_{t}>0\right)$. Assuming the direct effect to dominate the indirect effect, an increase in assessment costs leads to a lower $t^{s}: a r^{s} / \partial b<0$.

The impact of recruitment channel costs on the hiring standard follows from:

$$
\frac{\partial r^{s}}{\partial e}=\frac{s_{r} H C_{w}}{H C_{r s} H C_{v t}-\left(H C_{t r}\right)^{2}}
$$

Since the cost of using advertisements as a recruitment channel is modelled as a mark-up on the costs, $e$, of using the labour exchange office, an increase in costs $e$ widens the recrutment channel cost gap between advertisements and the labour exchange office. Hence an increase in $e$ makes advertisements a relatively more expensive recruitment channel than the labour exchange office. Consequently, to limit costs $e$ the firm has only one instrument at its disposal: avoid using advertisements - which explains why the nominator of equation 4.5 contans only one factor. Or formally, the firm reduces $r$ and subsequently (through $H C_{i r}<0$ ) decreases $t^{k}$ indirectly, which explains for $\partial r^{3} / \partial e<0$.

Finally equation 4.6 presents $\partial r^{s} / \partial \theta$.

$$
\frac{\partial r^{s}}{\partial \theta}=c \frac{\varphi_{s \theta}^{*} H C_{r r}-\varphi_{t \theta}^{*} H C_{r r}}{H C_{r r} H C_{n}-\left(H C_{r r}\right)^{2}}
$$


A change in labour market tightness influences the effectiveness of $t$ and $t$ to reduce hiring costs. From the properties of $\varphi^{*}$, we know that both $\varphi^{*}$, and $\varphi$ " $\varphi$ are negative.

$\varphi^{*}$ a $<0$ means that the effectiveness of using the screening device standard to reduce the length of the hiring period increases for higher levels of tightness. To explain this effect, one should interpret tightness as a mark-up on the length of the hiring period which is beyond the employer's control. That is, if tightness increases, more time evolves between two applicants, which lengthens the hiring periad. Consequently, the reduction in the length of the hiting period following an increase in $t$ is more pronounced when this mark-up is high, i.e. in tight labour market conditions.

We explain $\varphi^{*}{ }^{\prime}<0$ in similar fashion as $\varphi^{*}<0$. Moreover, there is an additional empirical argument - which is not captured in our model - why $\varphi^{*}, 0<0$, which is related to on-the-job search. Burgess (1993) and Burda and Wyplosz (1994) show that on-the-job search is pro-cyclical. Since advertisements are the main search channel of employed job seekers (see for example Russo et al. (1997b)), in tight labour market conditions, advertisements become more effective to fill jobs as both the arrival rate of applicants and the quality of job seekers are boosted by employed job seekers. This additional effect, which is exclusively attributable to advertisements, supports $\varphi^{*} \theta<0$. Though, this effect should not be overestimated since it is a distinguishing feature of employed job seekers, searching through advertisements, not to look for low paid jobs - cf. Holzer (1996).

Nonetheless both the direct effect of an increase in $\theta$ on $t^{s}$ and the indirect effect through $r$, suggest $\partial r^{\prime} / \partial \theta>0$.

Since we found $\partial r^{i} / \partial c>0, \partial r^{s} / \partial b<0, \partial r^{s} / \partial e<0$ and $\partial r^{5} / \partial \theta>0$, our model predicts that firms facing low costs $b$, high costs $c$, low costs $e$ and high levels of $\theta$ set a high screening device standard and subsequently have a higher incidence of deadweight loss. ${ }^{73}$

\subsection{Empirical employer search literature}

We take the insights gained from the analysis in Section 4.2 as starting point for our empirical analysis on the explanatory power of employer search behaviour in the composition of deadweight loss. We distinguished three variables in our model related to deadweight loss: assessment costs (b), foregone productivity costs (c) and labour market tightness $(\theta)$. We found that firms facing low costs $b$, high $\operatorname{costs} c$ and high levels of $\theta$ set a high screening device standard and subsequently have a higher incidence of deadweight loss. Now we use insights arising from the empirical employer search literature to link variables $b, c$ and $\theta$ to firm and job characteristics. In Sections 4.5 and 4.7 we will use these insights to test whether there is a link between deadweight loss incidence and firm and job characteristics, as our model predicts. The richness of our data sets allows us to extend the measurement of variables $b, c$ and $\theta$ beyond the current level applied in the literature.

Hypothesis $1\left(\partial r^{\prime} / \partial b<0\right)$ : If assessment costs are high. firms are reluctant to weaken the screening device standard. which reduces the probability that such firms hire subsidized memployed they would have hired in the absence of the subsidy.

The enpirical literature splits assessment costs into two parts: intensive and extensive costs. Intensive costs refer to the intensity with which firms assess candidates (costs $b$ in our

\footnotetext{
Te do not heve data that nelate costs e to firm, sector and/or job characteristics; hence we leave costs e out of the andysis.
} 
setting). Extensive costs refer to the number of candidates the from assesses per job offer it makes. We focus on the intensive costs in our analysis. ${ }^{74}$

Table 4.1 summarizes four variables that are typically employed in empirical swodies to explain intensive search cost differences between firms. The main theoretical rationale is that firms will increase intensive search when the job task is complicated (e.g. training of experience is required), the costs of montoring employees are high (eg. in large thrus) of when it is costly to fire employees (e.g. employees on a fixed contract). Careful assessment of candidates is necessary in such situations, which increases intensive sereening costs. The empirical studies confirm most of these expectations, except for the firm size effect on intensive search costs. The empirical results are inconclusive and, if any, predict a negative effect. Barron et al. (1987) argue that firms applying assessments on a regular basis, experience economies of scale and employ an internal assessment centre, which is a cost saving activity. This argumentation would suggest that large firms could economize on intensive search costs, which offsets the monitoring argument that monitoring costs are high in large firms.

Table $4.1 \quad$ Effects on intensive search cosis ${ }^{\text {a }}$

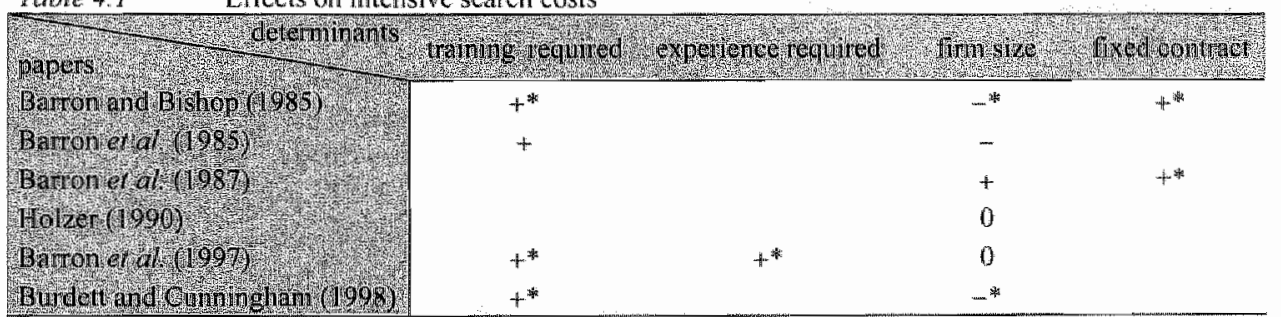

An asterisk indicates the coefficient is significantly different from 2 ero at the 0 , 10 significance luevel

Hyporhesis $2\left(\partial t^{s} / \partial c>0\right)$ : If per period foregone productivity costs are high, firms are more willing to weaken the screening device standard, which increases the probability that such firms hire subsidized unemployed they would have hired in the absence of the subsidy.

In comparison to providing indicators for assessment costs, the empirical literature on measuring costs of foregone productivity is less abundant. Barron et al. (1997) and Burdett and Cunningham (1998) use advance notice of a vacancy as an indicator of costs $c$. That is, a firm that knows in adwance that a job will be broken up and hence needs to be filled at a future date can search for a new employee while the job is still productive. In such circumstances foregone productivity costs are absent.

Hypothesis $3\left(0 f^{5} / \partial \theta>0\right)$ : If tightness increases, the screening device standard becomes more effective to fll vacancies quickly, which leads to a higher t. The indirect effect through r reinforces the direct effect of tightness on $t^{s}$.

To measure labour market tightness the empirical literature generally applies year, sector or regional dummies - $c f$. Russo (2000) and Gorter at al. (2002). If the dataset provides alternative indicators, these are used. Barron and Bishop (1985) exploit a data set, which comprises information on the number of applicants who came and had a look or phoned for a job, which they use as a proxy for tightness.

"4 Since our model is sequential, we disregard extensive search costs. 
To test our model predictions, we use a dataset of a study on the employment effects of a Dutch wage subsidy scheme (VLW), conducted in 1999 by the Netherlands Economic Institute - Van Polanen Petel et at. (1999). The VLW was introduced in 1996 and closed in 2003. The scheme aimed at increasing the employment opportunities of long-term unemployed. An employer who hired an unemployed facing an uncompleted unemployment spell of at least one year was entitled to a subsidy of 2,160 euros at most, if he paid the unemployed wages amounting to no more than $130 \%$ of the legal minimum wages. ${ }^{36}$

NEI sent 1,966 questionnaires to enployers who had hired or continued to hire employees in the period 1996 to 1999 inclusive and for whom they had received a VLW wage subsidy. The response rate was $186 \%$ resulting in a dataset of 365 cases. The VLW subsidy was also applied to finance relief jobs for long-term unemployed. This type of application of VLW wage subsidies has been left out in the analysis, which further reduces the firm sample to 129.

\section{Description of the $V L W$ data}

In Table 4.2 we present a brief description of the variables in the data set that we use in our analysis. The table is divided into four groups of variables. Most variables are categorical variables; some are continuous variables. Categorical variables consist of two or three categories, except for DWL2, which consists of four categories.

Participant and job related variables do not measure a specific characteristic of the participant population or the pool of jobs, participants occupy. Instead they indicate employer behaviour regarding the type of participants they hire and the type of jobs they offer to participants. Consequently, the variable 'gender' does not represent the share of participants who are male rather than female, but instead the share of firms that employ only male participants ( $44 \%$ ), the share of firms that employ both male and female participants (24\%) and the share of firms that employ only female participants $(32 \%)$. Furthermore, Table 4.2 indicates that firms prefer to employ subsidized workers who are above 25 years of age.

The workload variable is split at 36 working hours a week. We observe that the distribution of part-time versus full time jobs is balanced. The same holds for the "job activity" variable, which divides job activity in supportive and main activity. A supportive job is not considered by the firm to be its main on core activity. The variable relevance of the job' reters to the priority attached to the work the subsidized participant does. The job is considered non-relevant if the employer would have decided to drop the workload (now done by the participant) in case capacity constraints had forced him to decide which workload was crucial and which was not. The majority of employment done by subsidized employees is considered relevant.

Next, we consider some employer related characteristics. The variable "fulfilling expectations' is a construct of two other variables. First, employers was asked whether the productivity of subsidized participants was comparable to that of regular employees.

\footnotetext{
\%5 VLW is an abbreviation of afdrachtsVermindering Langdurig Werklozen (tax Deduction Long-term Unemployed).

${ }^{76}$ Employers situated in regions facing high unemployment rates (typical of large cities and northern provinces) could obtain a subsidy for unemployed experiencing at least 6 months of unemployment. Hence, $t^{g s}$ is not tunitorm as we claim. Still this does not disqualify our claim, as $f^{\text {ss }}$ is not demand side detemined but supply side determined instead.
} 
Table 2 Descriptive statistics VLW data

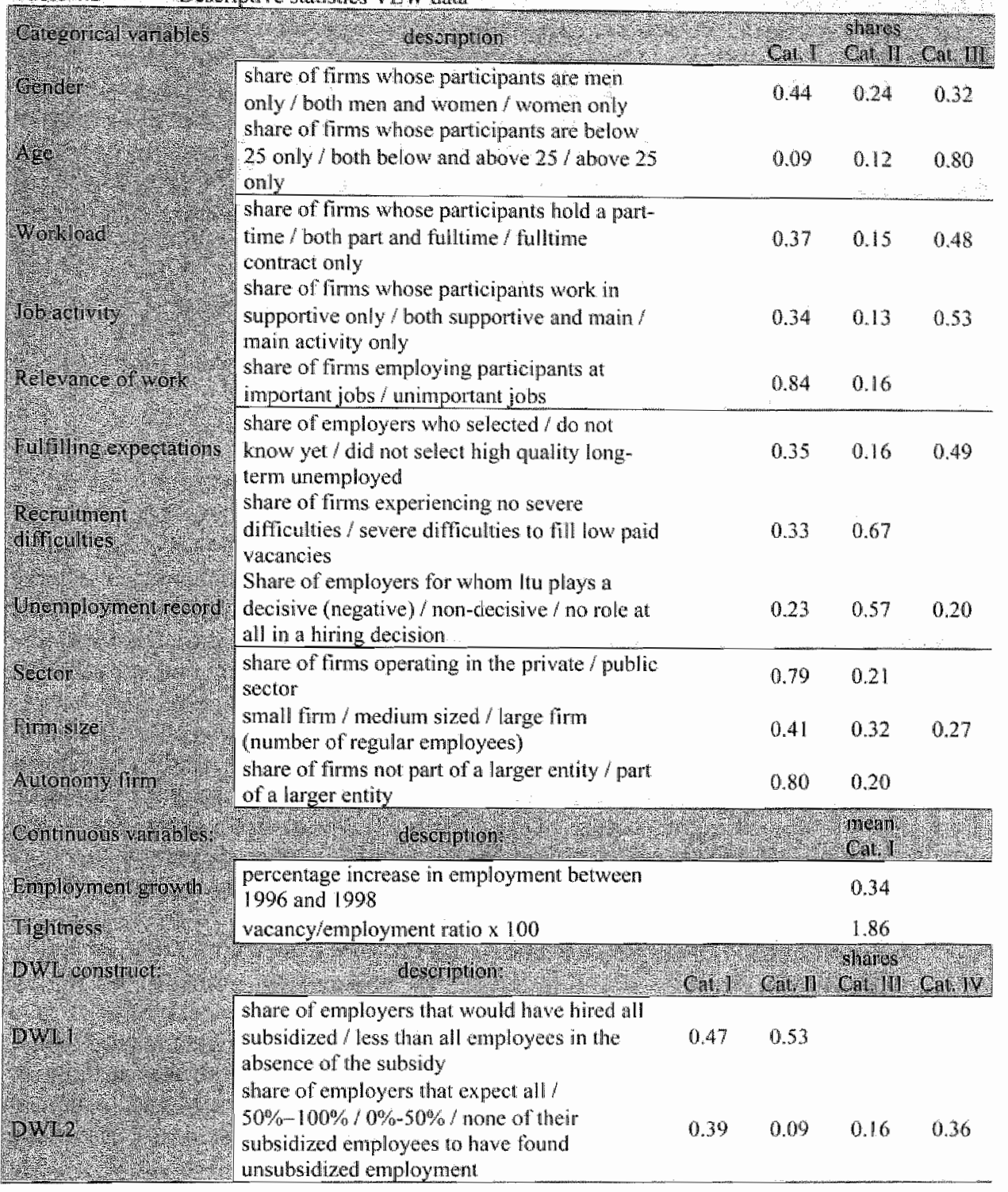

Next, employers was asked whether they expected the participants to be as productive as they turned out to be. Enployers answering both questions positively, thave found a high quality long-term unemployed without being surprised to have found such an employee within the pool of long-term unemployed. These employers constitute a separate category (35\%). Next there is a category of employers who are not (yet) able to assess the qualities of the subsidized participants (16\%) and finally there is a category of employers who answered at least one of both questions negatively (49\%). The variable "recruiment difficulties" indicates the firm's difficulties in filling low-paid vacancies like the one that is now filled by the subsidized longterm unemployed. Two thirds indicate they indeed face severe difficulties to fill low paid jobs. The variable "unemployment record" entails firms who reject long-term unemployed in 
hifing decisions categorically (23\%), employers who use long-term unemployment next to other screening devices $(57 \%)$ and employers for whom long-term unemployment is no criterion in hiring decisions $(20 \%)$.

Additionally, we consider some firm/sector related characteristics. The majority of subsidized jobs are created in the private sector. Firm size refers to the number of employees within the firm, which is divided into three categories in which 10 and 50 employees are the thresholds. Large firms employ $27 \%$ of all subsidized employees, $80 \%$ of all participating firms are autonomous, in the sense that they are not part of a larger entity. The survey presents a continuous variable measuring employment growth between 1996 and 1998 . We add tightness to the data as a continuous variable specified by sector on a yearly basis. The variable is constructed as the vacancy / employment ratio, using data from Statistics Netherlands. ${ }^{77}$

\section{Deadweight loss construct}

Table 4.2 concludes with two measures of deadweight loss: "DWL1", the share of employers who would have hired all subsidized employees in the absence of the subsidy, and "DWL2", the share of employers who expect all their subsidized employees to have found unsubsidized employment. ${ }^{78}$ Since the first measure relates to the unsubsidized job find probability within the firm and the second to the unsubsidized job find probability both within and outside the firm., one would expect DWL1 to be strictly smaller than DWL2. Table 4.2 shows that this is not the case, which might indicate that responding firms have not interpreted DWL2 as the overall "unsubsidized job find probability" but as the "unsubsidized job find probability" outside the firm.

In Table 4.3 we show the overlap between both measures. There are two main groups of employers. One group $(32 \%)$ who admit that the subsidized employee would have found a job without the subsidy and one group $(30 \%)$ who indicate that the subsidized employee would not have found a job in the absence of the subsidy. The less certain firms are that the participant(s) would have found a job without the subsidy, the less often they argue that they would have hired the participant(s) even without a subsidy. This expected tendency follows clearly from Table 4.3 .

Since the definition of deadweight loss contains the unsubsidized job find probability both inside and outside the firm, the deadweight loss indicator we want to use in our regression should contain both elements. Therefore we need to amalgamate DWL1 and DWL2. The overlap between both measures suggests a first potential amalgamation, DWL3, which consists of three (ordered) categories. The northwest and the southeast partition in Table 4.3 ( $32 \%$ and $30 \%$ respectively) belong to the pure deadweight loss and to the no deadweight loss at all category respectively; the six remaining partitions are classified into the middle category. Furthermore we develop wo alternative indicators, DWLA and DWL5, in which we exploit the informational value of the matrix in Table 4.3 , to reclassify the six partitions out of the middle category of DWL3. Though reclassified, the ordinal structure

\footnotetext{
"Ideally we would like to use the it / ratio, but then we need unemployment rates specified to sector, which leads to problems on defining as to what sector the unemployed belong to. We decided to abstain from this definition problem and to rely on vacancies over total employment within a seotor.

${ }^{73}$ Bear in mind tha these shares do not measure deadweight loss percentages comparable to the typical shares found in the smpirical literature. The latter deadweight loss shates refer to the share of participants that would have tound an unsubsidized job. Here we measure the share of firms that expect its subsidized employees to have found an unsubsidized job. Since the vast majority of participating firms employ one subsidized employee only, both shares only differ marginally.
} 
remains intact in DWL4 and DWL5. ${ }^{79}$ Preservation of the ordinal structure of the DWLconstruct prevents the development of more variants of the DWL-construct. Since there is no theoretical argument to prefer one of the three mentioned constructs to the others, the eventual choice we will make, is empirically motivated - see Section 4.5 .

Toble 4.3 Overlap between two constructs to measure deadweight loss

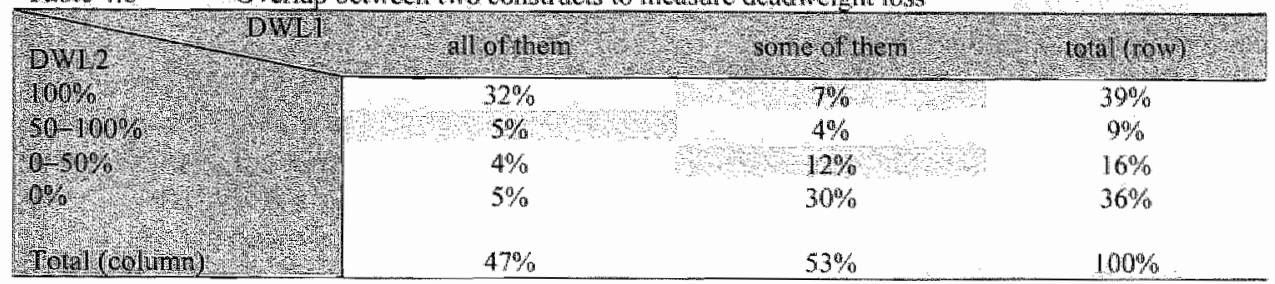

\section{Predicted deadweight loss}

We distinguished three variables in our model related to deadweight loss: assessment costs (b), foregone productivity costs $(c)$ and labour market tightmess ( $\theta$ ). We found that firms facing low costs $b$, high costs $c$ and high levels of $\theta$ set a high screening device standard and subsequently have a higher incidence of deadweight loss. Now we relate variables included in our data set to variables $b, c$ and $\theta$ which we subsequently link - using insights arising from Section 4.3 - to firm and job characteristics. In Section 4.5 we will use these insights to test whether there is a link between deadweight loss incidence and firm and job characteristics, as our model predicts.

Hypothesis $1\left(\partial r^{8} / \partial b<0\right)$ : If assessment cosis are high, firms are reluctant to weaken the screening device standard, which reduces the probability that such firms hive subsidized unemployed they would have hired in the absence of the subsidy.

Our data set contains only one of the four measures mentioned in Table 4.1: firm size, which we include in the regression. To separate the economies of scale argument from the monitoring effect, we include the variable "autonomic firm". Firms that are part of a larger conglomerate can borrow screening expertise from its partners, which means that they exploit economies of scale regardless their size.

Moreover, we include 'supportive job', 'meeting (high) expectations" and 'unemployment record' as variables related to assessment costs $b_{\text {. }}$ A supportive job is of less strategic value to the firm than a job in its main activity - compare the positive impact of experience and/or training required in Table 4.1. Consequently, to fill a supportive job, screening can be less strict and consequently cost $b$ is lower. Moreover we include the share of employers who anticipated the participants' productivity levels correctly, as their levels equalled those of regular employees. This variable shows the firm's awareness of the qualities of long-term unemployed and hence indicates low screening costs. Finally, we include the use of the unemployment record as a screening device. A firm assigning a decisive role to the unemployment record in hiring decisions finds it difficult or costly to apply more sophisticated recruitment methods. This firm apparently faces high costs $b$.

\footnotetext{
${ }^{79}$ DWL 4 and DWLS differ from each other and from DWL3 with respeet to the allocation of the grey ellements in Table 4.3. The elements "50\% - 100\%, all of them" and "100\%, some of them" ane included in the top category of DWL4 and in a separate category between top and middle category of DWL5. The element " 0 $50 \%$, some of them" is included in the bottom category of DWL 4 and in a separate category between middle and botton category in DWLS.
} 
The above discussion of how variables in our data set are related to screening costs is summarized in Table 4.4. Since screening costs are negatively related to the hiring standard $t$, we expect firns who have high screening costs $b$ to cause less deadweight loss. The variables in Table 4.4, which are supposed to correllate positively with $b$, are then supposed to decrease deadweight loss, whereas the negatively conelated variables increase deadweight loss. Table 4.4 also contains a first glimpse of the results resulting from the regression analysis, which we discuss in more detail in Section 4.5 .

Hypothesis $2(0 \mathrm{f} / \partial \mathrm{c}>0)$ : If per period foregone productivity costs are high, firms are mone willing to weaken the screening device standard, which increases the probability that such fims hive subsidized unemployed they would have hired in the absence of the subsidy.

Our data set does not contain a direct measure for advance notice. However, we try to measure it indirectly, including "employment growth" in our regression, using the following argumentation. Vacancies can arise for two reasons: filling a vacant position or extending the work force. In the case of the former, costs $c$ are low since the firm has advance notice of that particular job opening, however, when expanding this need not be the case. As firms experiencing employment. growth have relatively more often extension vacancies, we expect employment growth to be more correlated with costs of foregone productivity $c$.

Because a vacancy for a part-time job only leads to limited production loss, we expect foregone productivity costs also to increase with the size of the job in terms of hours worked per week. Moreover, vacancies for which subsidized employees have been recruited, but which would not have been filled in the absence of a subsidy, are typically non-priority jobs. For these jobs the same holds as for part-time vacancies.

Again Table 4.4 summarizes the impact of the variables discussed above on costs of foregone productivity $c$. The variables which are supposed to cause higher costs will then also induce a tighter $r^{*}$ and therefore it is less likely that firms, showing such characteristics, cause deadweight loss.

Table 4.4 Set of independent variables to test for deadweight loss

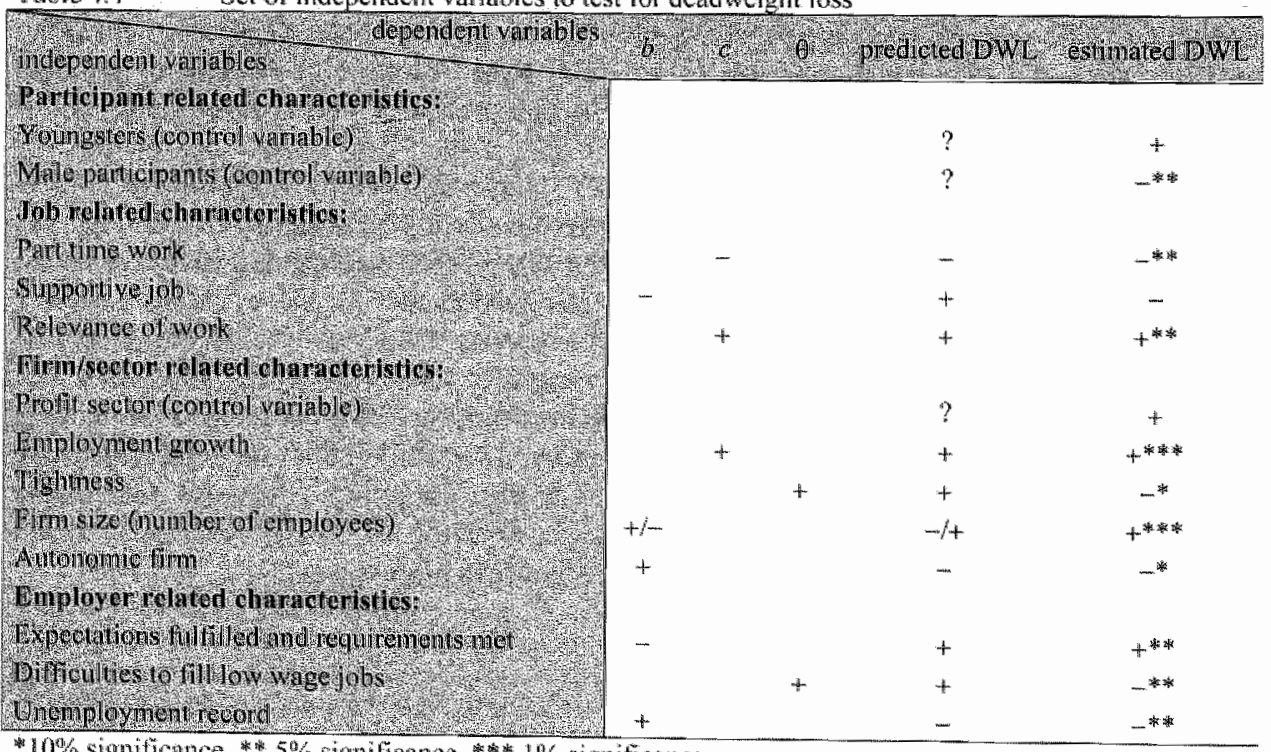

* $10 \%$ significunce * $5 \%$ significance, * $1 \%$ significance 
Hypothesis $3\left(\partial t^{5} / \partial \theta>0\right)$ : If tighthess increases, the screening device stawdord becomes more effective to fill vacancies quickly, which leads to a higher tr. The indirect effect through $r$ reinforces the direct effect of tightmess on $t^{t}$.

We include the variables 'difficulties to fill. low wage jobs" and "tightness' in our equation. Both variables directly measure tightness. From the analysis above it follows that they are expected to correlate negatively with deadweight loss.

The variables 'youngsters', 'male participants' and 'profit sector' in Table 4.4 are control variables, for which we do not have a clear theoretical indication about their sign and hence no predicted sign in the regression.

\subsection{Empirical results on Dutch data}

To test the hypotheses spelled out in section 4.4 above, we specify five equations. All five are ordered probit regressions - cf. McCullagh (1.980). ${ }^{30}$ The first two equations - see Table 4.5 are devoted to the two availlable deadweight loss indicators in the data set (DWLI and DWL2). For model selection we rely on the Akaike, Schwarz and the Hannan-Quinn criterion. All three criteria measure goodness of fit based on the log likelihood function, but differ with respect to the penalty function for including too many variables. Though the regressions that we will present all have the same structure in terms of independent variables, they differ with respect to the structure of the dependent variable in terms of the number of ordinal categories. This implies we cannot rely on the Likelihood Ratio Statistic.

It is not surprising that all three model selection criteria predict the first equation to yield a superior fit. DWL1 refers to the behaviour of the firm in the absence of the subsidy, whereas DWL2 refers to the behaviour of participants and other firms in the absence of the subsidy, which is more difficult to judge by the firm hiring the subsidized participant. ${ }^{81}$ Throughout this thesis, deadweight loss is defined as the share of subsidized employees that would have found an unsubsidized job. Since this unsubsidized job could have been found both within and outside the current firm, both DWL1 and DWL2 should be taken into consideration in our analysis. Therefore, we expect the most pregnant results to come from DWL3, DWL4 or DWL5 - which are amalgamations of DWL1 and DWL2 - and consequently we restrict the analysis to these three regressions.

Though slightly different all three model selection criteria indicate that the DWL4 specification yields the best model fit, which implies that our decision to reallocate the six middle partitions in Table 4.3 paid off. Subsequently in analysing the empirical results we refer to the fourth equation in Table $4.5{ }^{82}$ We interpret the marginal differences between the outcomes of all five equations as evidence for the cogency of our results. ${ }^{8.3}$

Except for DWL1, which has only two categories and hence boils down to a binary probit regression.

81. More generally one could question the ability of employers to assess the empioynent probabilities of unemployed in an unsubsidized world, which would endanger the validity of using survey studies to lest for deadweight loss patterns, as we do. Calmfors er al. (2001) find that macro econontetric studies used to measure additional enployment effects of wage subsidies lead to slightly lower estimates of additional employment than survey studies. This indicates that employers somewhat overestimate the unsubsidized employment probabilities of participants. Calmfors er al. (2001) put this difference down to external displacement, i.e. subsidized employment leads to a reduction in employment elsewhere dwe to competition in goods markets. Controlling for external displacement brings the outcomes of survey and macro econometric studies into line, which leads us to the conclusion thai deadweight loss estimates firms provide are accurate.

12. We have considered selectivity bias, as employers are reluctant to report causing deadweight loss, which, from a social point of view, is an unsatisfactory answer. Therefore we expect employers causing deadweight loss to be verer represented in the nonmesponse, which causes a selectivity bias. However, the dataset does not contain any variable related to non-responding tirms, which blocks testing for selectivity bias. Still, we think selectivity bias is no nugjor problem to our empirical results, as our interest is not in the share of employers causing deadweight 


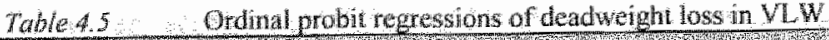

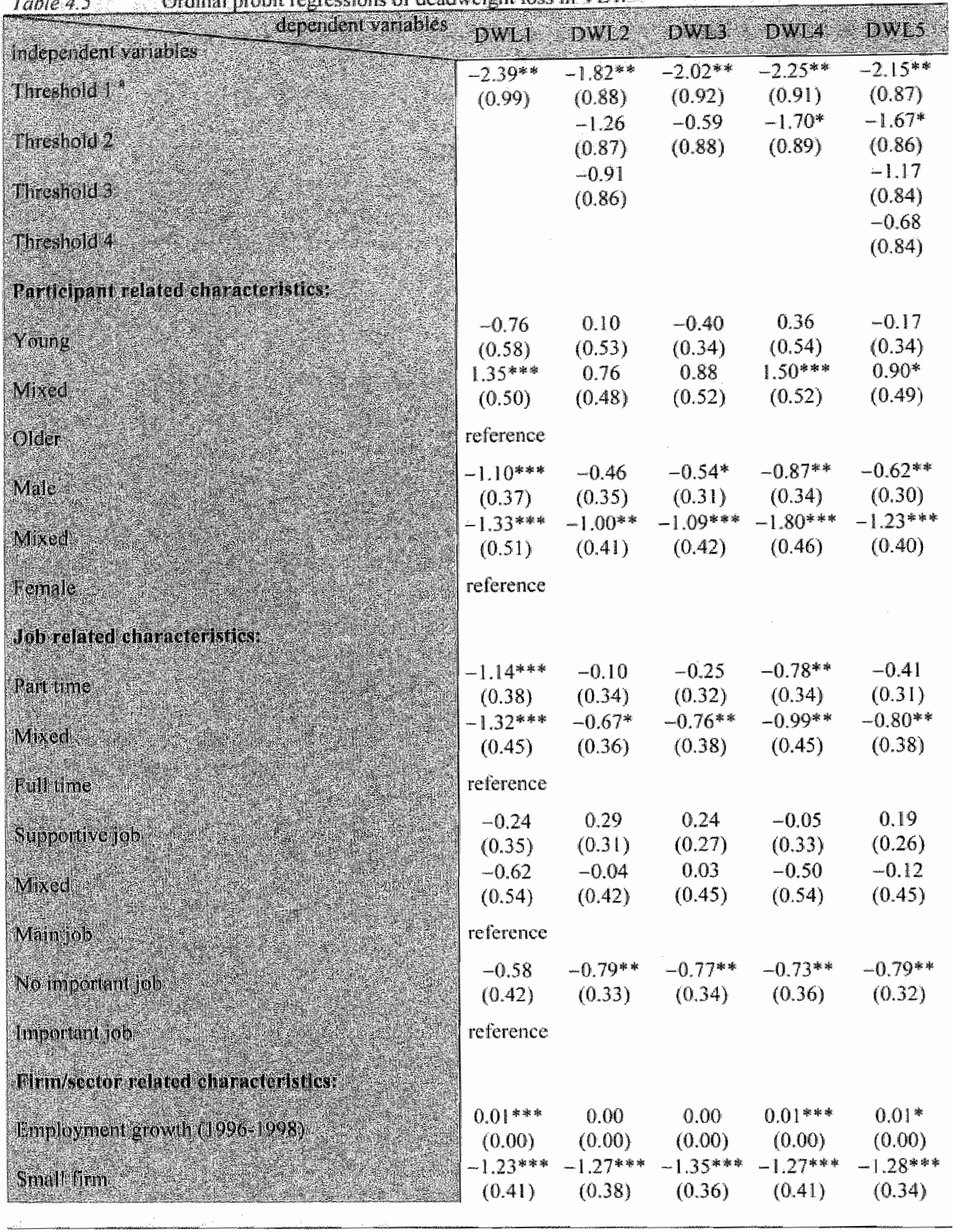

loss, but in the diflerence in characteristics between deatweight loss provokers and non provokers. Table 4.2 shows that our data do not suffer hom ack of firms that admit they provoked deadweight loss. As long as characieristics of non-responding deadweight loss provoking lims do not differ from responding deadweight loss provoking tirms, the analysis does not suffer from selectivity bias We do not thave any reasons to assume this variation exists.

Moreover, we respecified DWL4 using an ordered logit regression to analyse the sensitivity of our results for potential outhers. The logit and probit specifications duffer only rarginally, which we interprer as turther evidence for the cogency of our results. 
Table 15 Ordinal probit regressions of dendweight loss in VLW (condined)

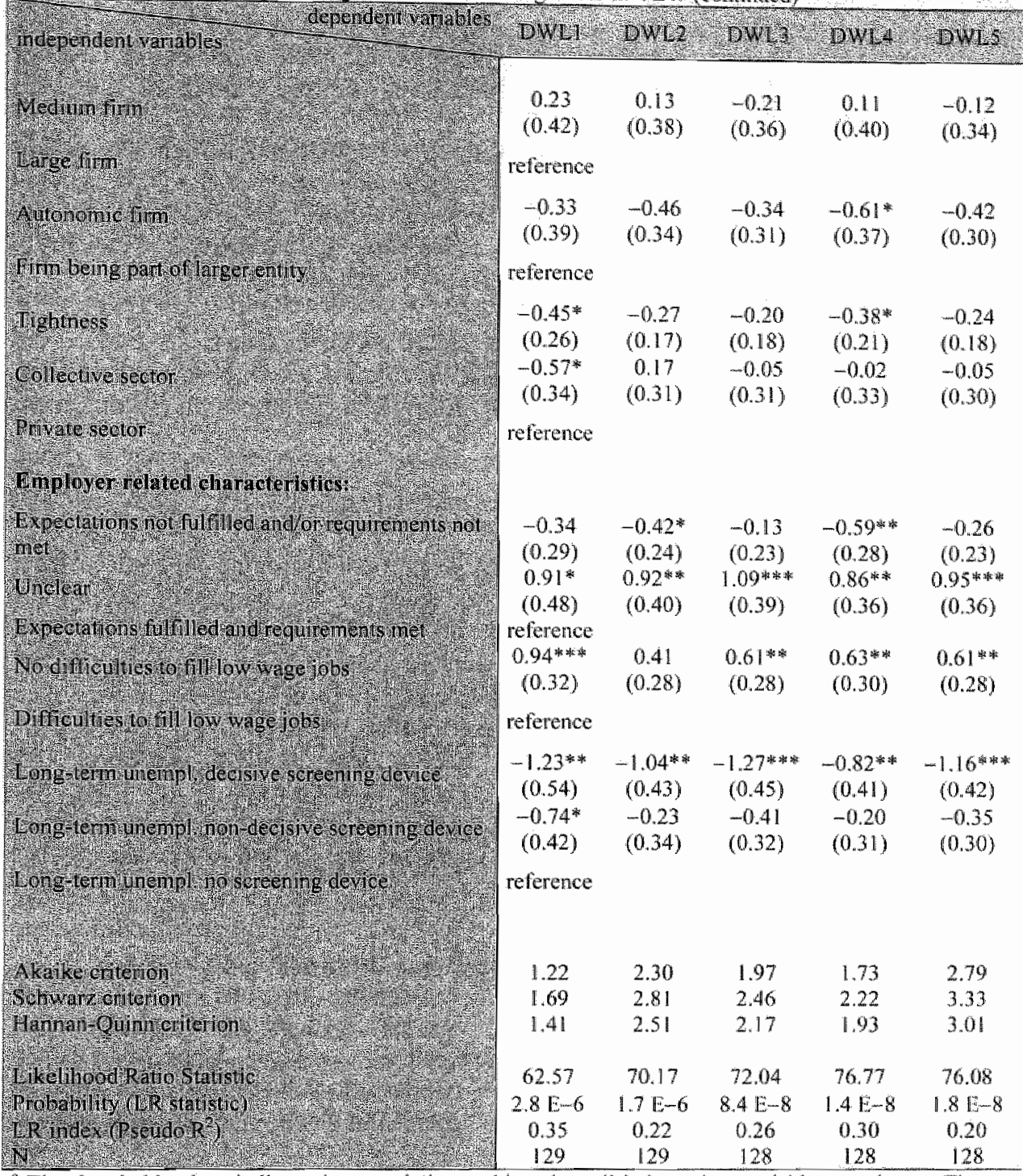

a The thresthod walues indicate the cumulative probits when all independen variables equal pero. The negative values for eg. threshold 2 (ie. DWL2 $=2$ in spectication DWL2 mean that the predicted probability of scotes of 2 or less on the dependent wariable are smaller than for scores greater than 3 . The thresholds are necesary for" calculating predicted values but are relatively minteresting. Hence we do not mention thenth.

Stanclard errors in parentheses

* 10\% significance, $5 \%$ significance, * $1 \%$ sigmificance

Hypothesis $1\left(\partial r^{\prime} / \partial b<0\right)$ : Four out of five variables included testing hypothesis 1 yield the expected effect; only the variable "supportive job" is not significantly different from zero.

Deadweight loss is positively correlated to firm size. That is, small firms cause significantly less deadweight loss than large firms. The firm size effect disappears for medium sized firms, whose incidence of deadweight loss does not significantly deviate from large sized firms, which implies that also medium sized firms enjoy economies of scale. In order to 
test the existence or econonies of scale in screening decisions in a different way we inchuded the varable "dutonomic frm". Our hypothesis is confirmed as autonomous firms (controling for firm size cause less deadweight loss. Therefore we conclude that the moderating effect of economies of scale on soreming costs $b$ dominates the elevating effect of increased monitoring on screening costs.

Firms that correctly anticipate the productivity of subsidized participants whose productivity equals that of regular employees cause significantly more deadweight loss. This finding is also in line with our theoretical considerations. Finally, the same holds for the variable 'umemployment record": frms attaching decisive value to unenployment status as a cheap screening device cause - as expected - signifrcantly less deadweight loss.

Hypothesis $2\left(\partial r^{5} / \partial c>0\right)$ : All three variables inchuded testing hypothesis 2 produce the expected effect. The variable "part time work" negatively correlates with deadweight loss; important jobs lead to more deadweight loss. Finally, firms facing strong employment growth cause significantly more deadweight loss.

Hypothesis $3\left(0 r^{5} / \partial \theta>0\right)$ : The two variables included testing hypothesis 3 both yield the (significant) opposite effect as expected. Apparently, the screening device standard becomes less effective when used to reduce the length of the hining period (in order to reduce hiring costs), as tightness goes up. Consequently frms reduce $t^{5}$ in tightening conditions. Explanations for this unambiguous finding must lie outside out model. One potential explanation is that $\chi$ - the average number of assessments needed to find a qualified candidate - is not only a function of $f^{*}$ and $r$, but also of $\theta$, where $\chi_{0}<0$. If the most able memployed profit more than proportionaly from improving labour market conditions, they have left the themployment pool in tight conditions. This implies that in tight conditions the unemployment poof consists predominanty of low ability unemployed, which raises the failure rate of assessment. If this effect through $\chi$ is large enough, firms will set a stricter screening device standard in tight conditions, which explains the decline in deadweight loss incidence in such conditions.

The estimation results presented in Table 4.5 support our theoretical analysis presented in Section 4.2 above partly. The regressions confirm our predicted effects of assessment costs and foregone productivity costs. The predicted effect of tightness on deadweight loss incidlence is not confirmed. On the contrary, we find that tightness is correlated negatively to deadweight loss. Overall, it turns out that assessment costs, costs of foregone productivity and labour market tightness can be considered important factors in determining deadweight loss and indirectly the screening device standard.

\subsection{British wage subsidy}

To test the generality of the results found for the Dutch VLW wage subsidy scheme, we replicate that analysis but instead use a dataset on firms participating in the British New Deal for Long-Term Unemployed (NDLTU). The New Deal programme - the NDLTU is part of was launched in 1997 under the Blair government to fight (long-term) unemployment. The NDLTU aims at increasing the employment possibilities of long-term unemployed. Employers offering at least a 30 -hours-a-week job to a job seeker who is over 25 years of age 
and has been out of employment for over two years obtain a weekly grant of $\$ 75$ for a maximum period of six months. ${ }^{8.4}$

The National Centre for Social Research conducted a study of firm behaviour within the New Deal programme. We use the dataset they constucted for their study. Besides testing the generality of the Dutch results, we have three additional reasons for using the NDLTU data to reproduce the VLW analysis.

Firstly, the Dutch analysis has been made on a rather small dataset (sample size is 128), which might lead to specificity problems that direct the results. The sample size of the British dataset is 1,340 , which is large enough to exclude the effect of data specificity safely.

Secondly, the Dutch dataset suffers from a low response rate. Only $18 \%$ of consulted firms returned the questionnaire. Poorly filled questionnaires further limit the sample size to $6 \%$. Firms" reluctance to (adequately) fill the questionnaire might indicate the firms' hesitation to report their recruitment behaviour as regards to hiring subsidized enployees. Therefore the Dutch dataset might be vulnerable to selection bias, which we cannot control for. The response rate of the British dataset is at $84 \%$ considerably higher. Controlling for poorly filled questionnaires leaves an effective response rate of $74 \%$, which reduces the urgency to investigate the potential role of selection bias. ${ }^{85}$

Thirdly, part of the firms in the VLW dataset employ more than one subsidized employee, but are only once in the dataset which means that for these firms there is no oneon-one relationship available between the employer and each subsidized employee. This renders the analysis of job and employee characteristics more difficult. In the British dataset, firms having hired more than one subsidized employee enter the dataset for each subsidized employee enabling us to explore each employer/employee relationship separately.

\section{Description of the NDLTU data}

Table 4.6 summarizes the independent variables that we use in the NDLTU regression. analysis. A quick scan of the table shows that participants are mainly male. Two thirds of all participants work 30 to 40 hours a week, which we consider a fulltime job. Only one in ten participants has supervisory tasks; most participants hold a job classified as a medium or low occupational level job.

To make this classification we rely on the Standard Occupational Classification 2000 $(S 0 C 2000)$. We narrow down the nine standard categories to three. High occupational level jobs contain "managers and senior officials", "professional occupations" and "associate professionals and technical occupations'. Medium occupational level jobs contain "administrative and secretarial occupations', 'skilled trades occupations" and "personal service occupations". Low occupational level jobs contain 'sales and customer service occupations', 'process, plant and machine operatives' and 'elementary occupations'. Small firms offer the majority of subsidized jobs. Most firms are single, independent firms. Though $1 \%$ is part of a larger international entity, but the single firm of that entity in the UK; $17 \%$ is part of a larger entity, which operates several firms in the UK. Nearly $60 \%$ of the firms experienced an increase in activities in the last twelve months. The vast majority of firms received few applications for the vacancy but nonetheless quickly filled it. Finally we include a sector variable, based on the Standard Industrial Classification 1992 (SIC92). We distinguish twelve sectors;, sector 'Retail, wholesale and hotels' covers one quarter of all subsidized employees.

\footnotetext{
S4 Employers receive $\$ 30$ per week, for contracts stortel than 30-hours-a-week.

s. Though the potential role of selection bias in our andysis is limited, we still need to sxplone the potential role of "socially desired answering" in our type of research. Since causing deadweight toss is an muwnted activily; employers might be reluctant to report it. If this reluctance is related to any of our dependent wariables, our results will be biased. When discussing our regression results we explain how we take this effect into account.
} 


\subsection{Empirical results on British data}

Table 4.8 contains the results of the ordinal probit regressions we ran. Since the second construct (DWL2a) yields the best fit, we confine the discussion of the results of our analysis to that specification. We interpret the slight differences in the results of using DWL 1 or DWL $2 \mathrm{a}$ as dependent variables as evidence for the cogency of our results. "To explore the presence of 'socially desired answering', we ran a regression using the second construct and included four variables which might - like our deadweight loss construet - be vulnerable to "socially desired answering". 88 If "socially desired answering" is a major concern to our analysis, we would expect these additional variables to be related to our dependent variable or the inclusion of such variables to affect the relationship between our dependent and independent variables. However we do not find such effects, which allows us to assume that 'socially desired answering' does not play an important role in our data set.

In the VLW analysis we included workload in the regression as a proxy for costs $c$. Since the loss of foregone productivity is less for a part-time wacancy than for a fullitime vacancy, we expect - making use of $\partial t^{s} / \partial c>0$ - a part-time job to lead to less deadweight loss, which was confirmed in Section 4.5. Table 4.8 reconfirms this result for the British data. However, the British data allow the possibility to split the group of fulltime employees into two parts: those working fulltime and those working overtime. The right column (DWL2b) of Table 4.8 shows the results of splitting the workload variable into three categories. The significant difference between part-time and fulltime employment vanishes. Instead, overtime has a significantly positive effect on the incidence of deadweight loss, which still is in line with our expectations, whereas the lack of a significant difference between fulltime and parttime is not.

The VLW analysis does not contain the effect of supervisory tasks within the subsidized job. Supervisory tasks affect both costs $b$ and $c$. On the one hand, the applicant's choice for filling a job, which contains supervisory tasks, not only affects the productivity of that job but also the productivity of the jobs that need supervision. Consequently careful screening is necessary, which implies that costs $b$ are high for such jobs. Given $\partial t / \partial b<0$, this would suggest that supervision leads to less deadweight loss. On the other hand, one might. claim that not filling a job, which contains supervisory tasks, not only leads to foregone productivity for that particular job but also for the jobs that need supervision, which implies. that costs $c$ are high. Given $\partial r^{s} / \partial c>0$, this would suggest that supervision leads to more deadweight loss. As a result, the net effect of superwision is ambiguous. The results in Table 4.8 show that supervision leads to more deadweight loss, which raises a presumption that the effect through $c$ dominates the effect through $b$.

In Section 4.5 we did not have the opportunity to include the occupational tevel of a job; the richer British dataset allows for this option. Subsidized employees - i.e long-term unemployed - are specifically recruited for low and medium occupational level jobs. Assuming such firms have had similar vacancies in the past, they have some experience in recruiting from target group members and consequently face low assessment costs, $b$.

\footnotetext{
87 Moneover, we specitied DWL2a using an ordered logit regression to analyse the sensitivity of our resulta lor potential outliers. The logit and probit specifications differ only marginally, which we interpret ans futher evidence for the cogency of oulr results.

8* The four (dummy) variables relate to the time and effort the firm spert on creating atm environment which maximizes the success rate of its New Deal participation. The socially desired answer would of course be to spend as much time and effort on this process as possible. The variables concern whether the firm llad appointed an mentor who guided the subsidized employee, whether the form tad invested in traing regular employees who guided the subsidized employee, whether the firm lat had contact with the employmervit office during the sulasidzed stay and whether there was someone within the organization who had on-goimg responsibility for New Deal antairs.
} 
Toble 4

Ordina forobit repressions of deadweight loss in NDLTU

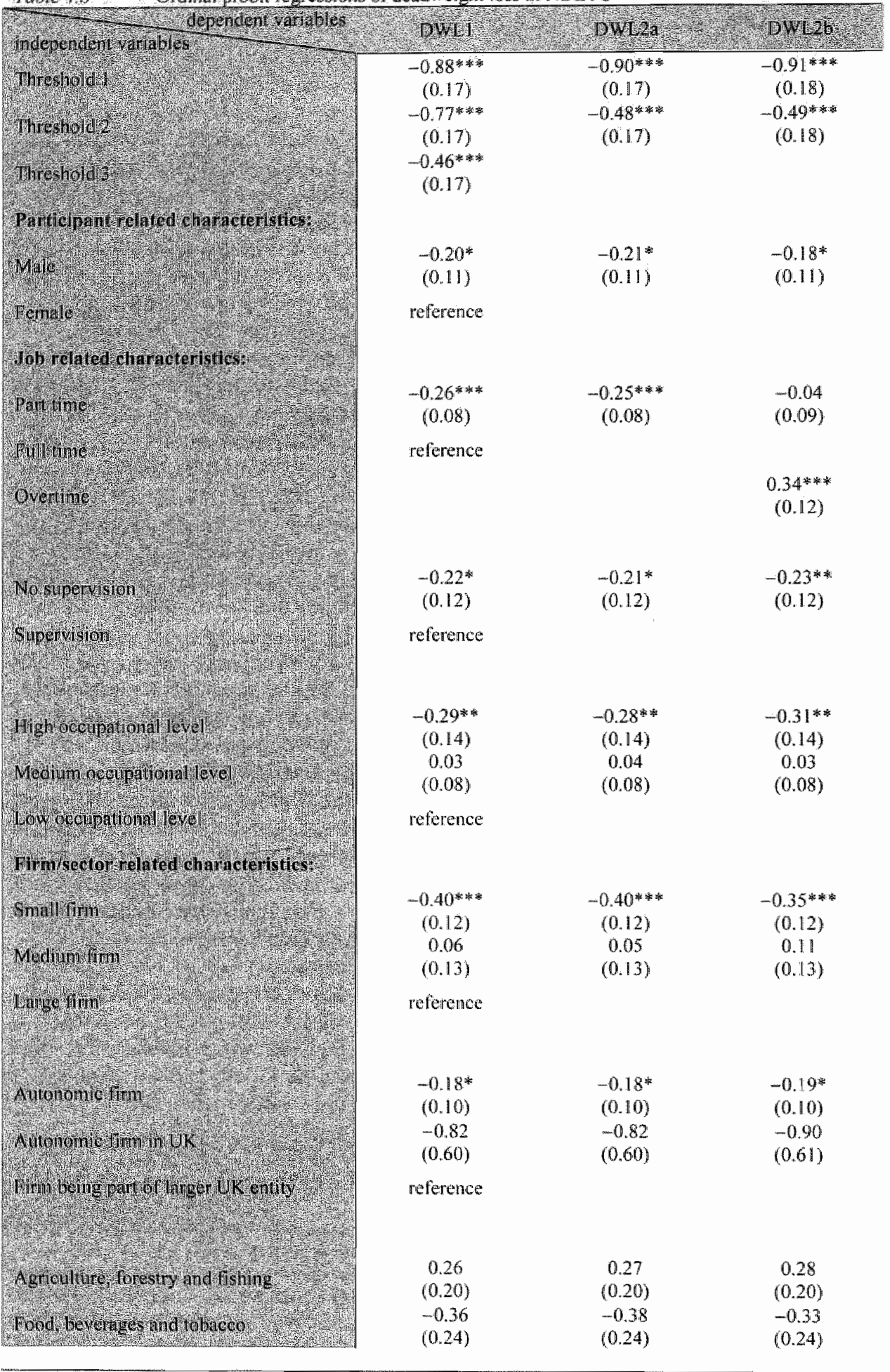


Toble 40. Ordinal probit regressions of dadweight loss im NDL TU (continued)

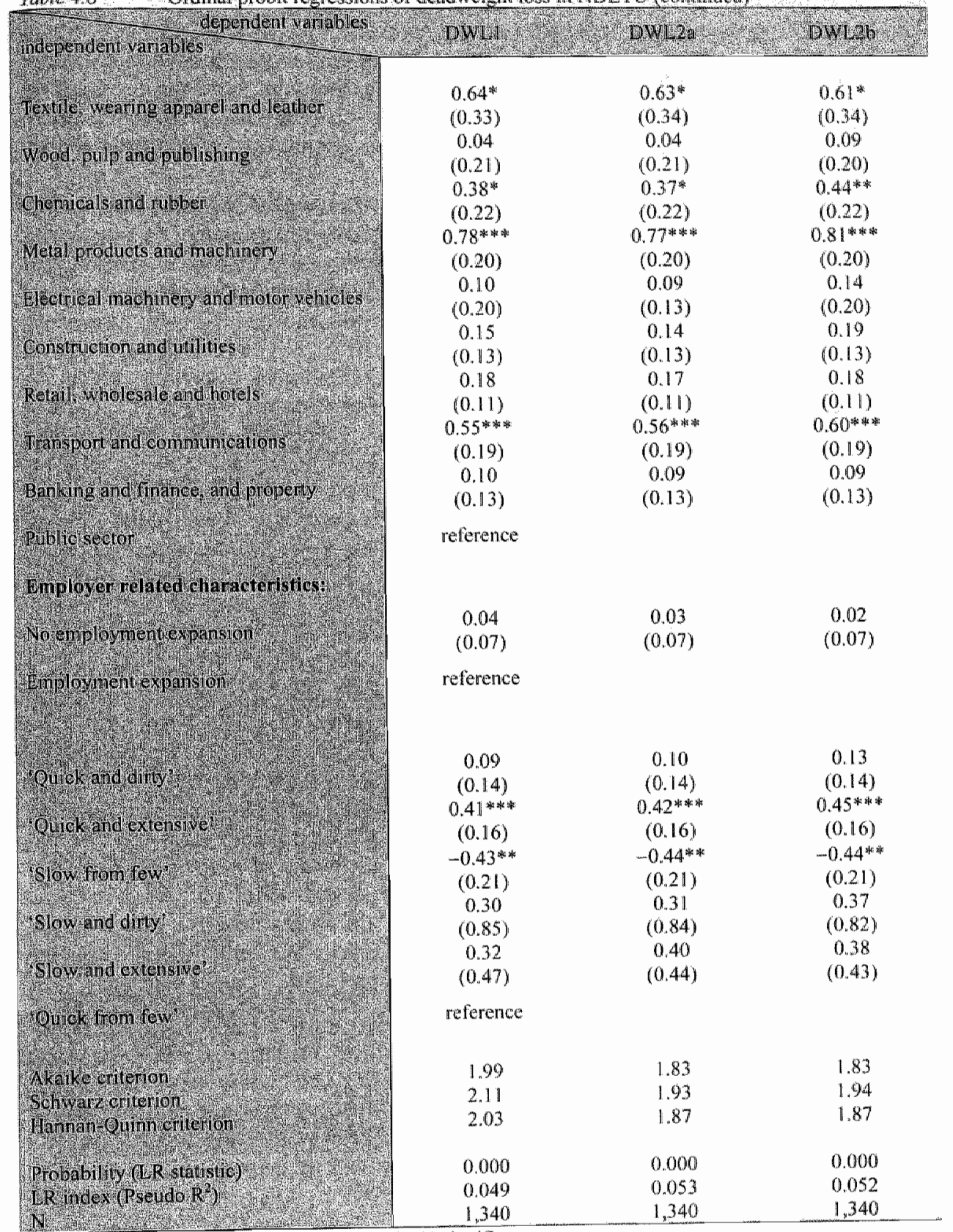

* $10 \%$ significance, * 5\% significance, ** 1\% significance

Standard errors un parentheses

Firms unorthodoxly aiming at filling a high occupational level job with a subsidized longterm unemployed miss out on these cost advantages. Therefore, given $\partial r^{\prime} / \partial b<0$, we expect employers trying to fill high occupational level vacancies to cause less deadweight loss than 
firms filling low or medium occupational level vacancies. The analysis in Table 4.8 confirms the significant difference between both groups of employers.

In the VLW analysis we included firm size and firm autonomy to test for the existence of economies of scale in recruitment. The British results are in line with those results, ie. large firms enjoy economies of scale in recruitment, which leads - just like umbrella organizations that transfer recruitment expertise throughout their divisions - to a more frequent incidence of deadweight loss.

In the VLW analysis we included employment expansion as a proxy for advance notice of a vacancy, which reduces foregone productivity costs, $c$. Given $\partial f^{s} / \partial c>0$, this should lead to less deadweight loss. The Dutch analysis finds evidence to support this hypothesis; the British data, however, do not provide a significant effect of employment growth on the incidence of deadweight loss.

Finally, we include a variable encompassing the firm's recruitment behaviour, given the number of applicants a vacancy attracts. Since the firm can influence the number of applicants by changing the recruitment channel, the number of applicants is no proxy for labour market tightness. Gorter et al. (2002) show that firms do this to keep the arrival rate of applicants roughly constant during business cycles. Sanders and Welters (2004) hint at pro-cyclical on the job search, which induces firms to switch towards the advertisement channel in tight labour market conditions. Given the number of applicants the firm still has to take (at least) two decisions, which signal its costs $b$ and $c$.

On the one hand, the firm decides on the number of applicants it will short-list, i.e. the number of applicants that it invites for assessment. ${ }^{89}$ If the firm receives many applications, it must decide on short-listing many of them or only a few. The latter outcome suggests high assessment costs; the former low casts $b$. On the other hand, the firm decides on the length of the recruitment period. A firm deciding to fill the vacancy quickly, signals it has significant costs of foregone productivity; otherwise costs $c$ are low.

Table 4.9 summarizes the above analysis. Given $\partial t^{8} / \partial c>0$ and $\partial t^{8} / \partial b<0$, four of the six partitions predict a significant effect on deadweight loss. The partition "quick from few" predicts more deadweight loss; the partition "slow from few" less. The partition "quick and extensive' predicts an even stronger positive effect on the incidence of deadweight loss than: partition "quick from few", since the former incorporates the additional effect of low assessment costs. The partition "slow and dinty" predicts a stronger negative effect on the incidence of deadweight loss than partition 'slow from few', since the former incorporates the additional effect of high assessment costs. The other two partitions - 'quick and dirty' and "slow and extensive"- lead to ambiguous predictions as the effects of $b$ and $c$ on deadweight loss counteract. 90

Table 4.9 Firm"s recruitment belaviour given the number of applicants

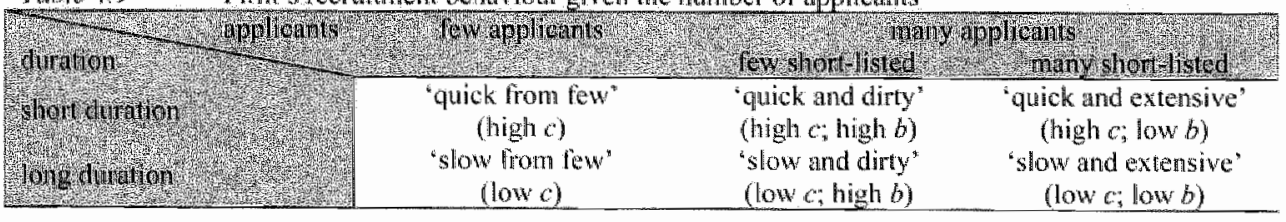

\footnotetext{
Short-listing is only relevant for frms receiving many applications. We assume that shortatisting is not a decision waruble to the furm whenever it receives less than five applications. Remember that short-listing is not in line with our theoretical model which assumes sequential search. Short-listing is a feature of non-sequential search. Nonetheless we present shortisting in our empirical analysis as it has clear links to costs $b$ and $c$.

90 The partitions "slow and dirty' and 'slow and extensive" are too small to expect any" significant estimates. We therefore do neither discuss them there nor when anglysing the New Deal for Young People in Chapter $V$.
} 
The results in Table 4.8 confirm our expectations. The slow from few partition leads to significantly less deadweight loss than the quick from fow partion. The quick and extensive" partition leads to significantly more deadwerght loss than the gurck from few" partition.

\subsection{Overall results for wage subsidies}

Tablle 4.10 summarizes the results from the analysis of the Dutch and British data Both data sets largely comply with the predictions from the underlying theoretical nodel. Moreover; the overlapping variables in both data sets yield mutually consistent results, except for the expected effect of employment growth (advance notice). These findings strengthen our perception that the incidence of deadweight loss is, to some exten, predictable and can therefore be prevented.

Table $4.10 \quad$ Summary of results from Dutch and British data

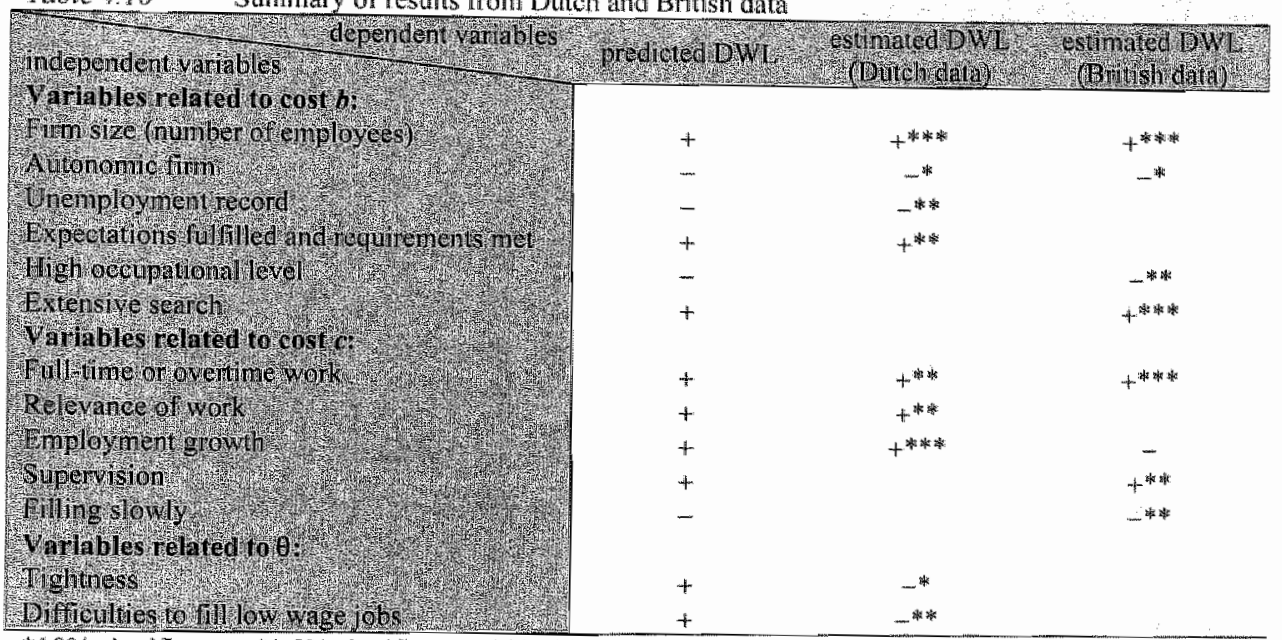

$* 10 \%$ significance, ** $5 \%$ significance, *** $1 \%$ significance

\subsection{Conclusions}

In this chapter we have questioned the government's implicit assumption that, in designing wage subsidy schemes, firms apply a uniform screening device standard. Based on that assumption the government justifies a uniform start value of subsidy entitlement. In this chapter we have shown that this notion is invalid and forms an important source of the deadweight loss shanes found in wage subsidy schemes.

Differences in firm, job and labour market characteristics induce firms to apply different optimal values of the screening device standard, which henceforward requires a differentiated start value of subsidy entitlement set by the government to minimize deadweight loss. It is obvious that such a differentiation might have the unwanted side effect of complicating the design of a wage subsidy. Nonetheless, we think it would be worth while to consider two deviations.

First, our results show that large firms (in terms of employees) cause substantially more deadweight loss than small firms. Most wage subsidy schemes are dealt with by tax authorities that have the number of employees at a firm readily available. This makes differentiating the start value of subsidy entitlement to firm size a feasible option. In that case 
large firns should, in order to obtain a wage subsidy, recruit from unemployed facing a longer spell of unemployment thatn unemployed in small firms do.

Second, our results show that low levels of labour market tightness lead to more deadweight loss. This finding should make policymakers conscious of the fact that, if a government wants to reserve entry into the subsidy scheme only to unemployed, who will not find employment without help, the government has to be alert, especially in tight labour market conditions. As the interest to participate is large in slack labour market conditions, the entrance condition should be strict: In tight labour market conditions the need to use unemployment duration as a selection mechanism is less urgent. In such conditions any unemployed willing to participate may be considered unable to find a job without help. In addition, a government that brings the start value of subsidy entitiement in line with labour market conditions lowers deadweight loss shares. 


\section{Chapter V: Employer Search and Training Subsidies}

Using an extended data set for the UK, we find that deadweight loss patterns are present in training subsidy schemes. Additionally, we show - both theoretically and empirically - that employer search is different under a wage subsidy scheme when compared to a training subsidy sehene. This difference in search behaviour subsequently leads to differences in deadweight loss pattens. In a wage subsidy scheme the level of assessment costs plays a prime role in explaining the incidence of deadweight loss, whereas the role of costs of foregone productivity is more important in a training subsidy scheme. These findings suggest that averting deadweight loss asks for a different approach with regard to a wage subsidy scheme and a training subsidy scheme.

\subsection{Introduction}

Theory predicts that employment subsidy schemes are a valuable instrument in reintegrating long-term unemployed into the labour market - see for example Layard and Nickell (1980), Whitley and Wilson (1983), Calmfors (1994) or Richardson (1997). Empirical studies focusing on the micro economic effects of employment subsidy schemes, i.e. wage or employment status differences between otherwise comparable participants and nonparticipants, find some evidence of positive treatment effects - see for overview articles Friedlander et al. (1997) or Calmfors et al. (2001). However, empirical macro studies, which focus on general wage and employment outcomes of employment subsidy schemes, produce less promising results - see Calm fors et al. (2001) or Jongen et al. (2003).

One of the main causes for the contradicting findings is the incidence of deadweight loss. This loss is the share of participants in the employment subsidy scheme that would have found a job even in the absence of the subsidy, which appears to be large - see for example Dar and Tzannatos (1999) or Martin (1998). Micro studies fail to observe the effect of deadweight loss as they concentrate on treatment effects of participants, apparently suffering from unobserved heterogeneity since they do not observe that these favourable employment prospects do not exclusively stem from participation itself but also from the fact that the firm would have hired them anyway. Macro studies observe the incidence of deadweight loss as employment levels fail to increase when deadweight loss shares are substantial and are subsequently less positive on the results of employment subsidy schemes. Consequently, substantial deadweight loss makes understanding the incidence of it a rellevant issue. Not only to improve the effectiveness of such schemes but also to reconcile empirical micro and macro findings.

To understand the incidence of deadweight loss, we use an employer search model which provides insights into firms' hiring behaviour of long-term unemployed - see Chapter II. In this chapter we focus on training subsidies as opposed to Chapter IV where we discussed wage subsidies. Firms making use of the former are required to use the subsidy to train the worker. In a wage subsidy scheme this compulsion is absent, though the firm might still decide to use the subsidy to train the subsidized cmployee. We examine whether a training subsidy yields a dissinilar pattern of deadweight loss compared to a wage subsidy, which subsequently asks for a different remedy.

To explore potential differences between a wage subsidy and a training subsidy we analyse British firm data on the New Deal for Young People (NDYP) and compare our findings to those of Chapter IV - especially to the NDLTU. In terms of deadweiglt lloss incidence both schemes differ only marginally - see Hales et al. (2000).

The chapter is organized as follows. Section 5.2 briefly discusses the theoretical model, its: predictions and the empirical results arising from analysing wage subsidies in Chapter IV. Section 5.3 considers the extension of the theoretical model - as presented in Section 5.2 - 
when compulsory training is taken into consideration. Moreover this section develops several hypotheses concerning the expected deadweight loss pattern in a training subsidy scheme. Section 5.4 discusses a data set on a survey of British firms from 1.999 that we use to test our hypotheses in Section 5.5 . Section 5.6 compares our empirical findings of wage subsidies and: training subsidy schemes, while Section 5.7 concludes.

\subsection{Employer search and wage subsidies}

Chapter IV focused on deadweight loss patterns in two - a British and a Dutch - wage subsidy schemes. Here we replicate the main findings to ease the comparison between wage subsidy schemes and training subsidy schemes in terms of the deadweight loss pattern.

In the setting of a wage subsidy scheme the firm is minimizing hiring costs, summarized in equation 5.1 .

$$
H C\left(t^{s}, r\right)=\chi\left(t^{s}, r\right) b+\varphi\left(t^{s}, r, \theta\right) c+\zeta(r) e
$$

where $b, c$, and $e$ measure assessment costs, periodically foregone productivity and costs of operating a recruitment channel, respectively. To minimize hiring costs, the firm sets an optimal screening device standard $r$. We derived four hypotheses.

Hypothesis $1\left(\partial r^{s} / \partial b<0\right)$ : If assessment costs are high, firms are reluctant to weaken the screening device standard, as that would increase the average number of assessments needed to find a qualified candidate. This reluctance reduces the probability that those firms hire subsidized unemployed they would have hired in the absence of the subsidy.

Hypothesis $2\left(\partial r^{*} / \partial c>0\right)$ : If per period foregone productivity costs are high, firms are more willing to weaken the screening device standard to speed up the recruitment procedure, which increases the probability that such firms hire subsidized unemployed they would have hired in the absence of the subsidy.

Hypothesis $3\left(\partial t^{\prime} / \partial e<0\right)$ : If advertisements become a relatively more expensive recruitment channel, the firm will avoid using it. This reduces the quality of applicants, which induces firms to set a strict $r^{\text {. }}$.

Hypothesis $4\left(\partial t^{*} / \partial \theta>0\right)$ : If tightness increases, the effectiveness of the screening device standard to fill vacancies quickly, increases. Hence firms raise the screening device standard in tight conditions.

Usimg data on a Dutch wage subsidy scheme (VLW) and a British wage subsidy scheme (NDLTU) we discovered some patterns in the incidence of deadweight loss. Table 5.1 summarizes the main findings." It appears that a pattern in deadweight loss incidence exists in a wage subsidy scheme. Firms having low assessment costs (large firms), high foregone productivity (full time jobs) and/or operating in easy labour market conditions are more likely to cause deadweight loss.

\subsection{Employer search and training subsidies}

Not all wage subsidy schemes allow participating firms to spend the wage subsidy freely. One type - the training subsidy scheme - requires that the firm spends the subsidy on training.

\footnotetext{
We do mot thave data that relate costs e form, sector and/or job characteristics; hence we leave costs e out of the encpirical analysis.
} 
This section discusses the implications of that restriction for the theoretical model we briefly outlined in Section 5.2 .

Thble 5.1 Summary of results from Dutoh and British data

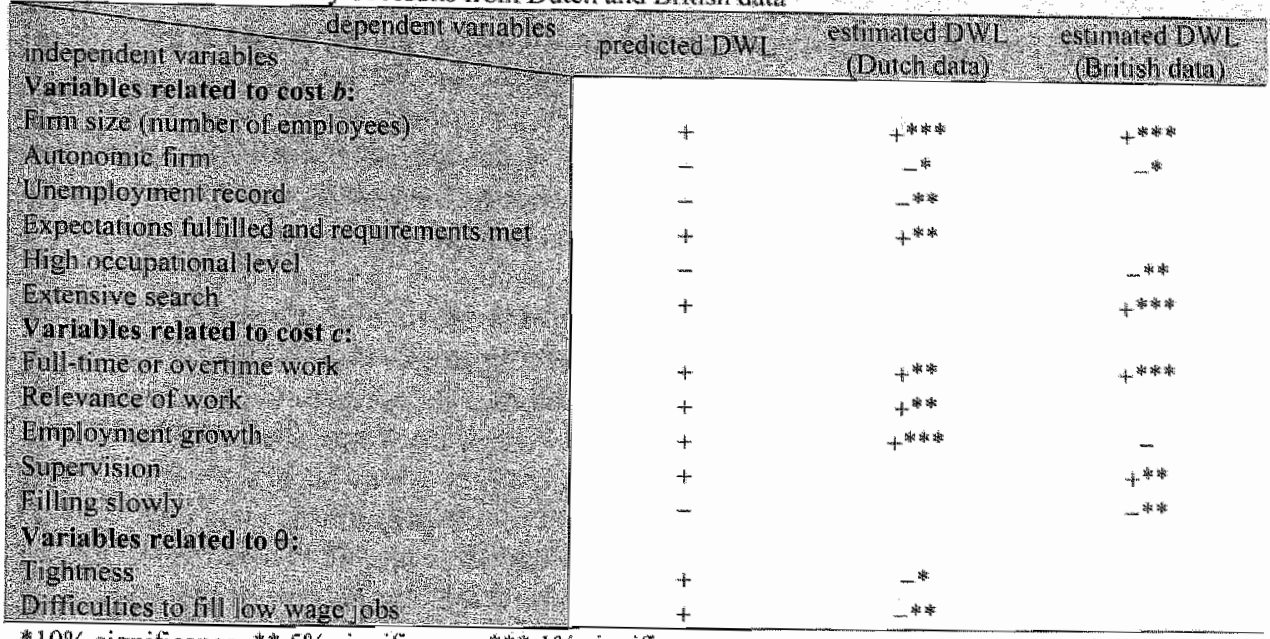

$* 10 \%$ significance, ** 5\% significance, *** $1 \%$ significance

In discussing wage subsidies, we have so far excluded the possibility to use the subsidy to train employees, which would allow firms to reduce the productivity standard as a means to reduce hiring costs. ${ }^{92}$ Endogenizing the productivity standard implies that we have to incorporate training costs in equation 5.1, which leads to two extensions - see Chapter II. On the one hand, training leads to an additional source of hiring costs: training costs. On the other hand, changing the productivity standard affects the success rate of an assessment and subsequently the vacancy duration, which has consequences for total assessment costs and total foregone productivity costs respectively. Equation 5.2 contains the implications of introducing training in equation 5.1 :

$H C\left(r^{s}, r, p^{s}\right)=\chi\left(t^{5}, p^{x}, r^{n}\right) b+\varphi^{*}\left(t^{s}, p^{s}, r^{4}, \theta\right) c^{a}+\eta^{*}\left(t^{*}, p^{*}, r\right) d+\zeta(r) e$

Though reducing the productivity standard below $p^{s}$ in recruitment decisions is allowed for from now on, productivity of a chosen candidate has to be upgraded to $p^{\text {* }}$, the minimum productivity levell to be productive on the job (so far we assumed $p^{*}=p^{*}$ ). This upgrading is captured by the third term on the right hand side of equation 5.2. Costs $d$ represent the costs of upgrading the productivity level of a chosen candidate, $p_{j}$, with one unit of productivity. Function $\eta$ " measures the productivity distance between $p_{j}$ and $p^{*}$ and simultaneously controls for the ability level of the chosen candidate which influences training costs per productivity unit. This is a function of the screening device standard, the productivity standard and the recruitment channel choice, hence $\left.\eta^{*}\left(r^{s}, p^{s}, r\right)\right)^{193}$ The negative relationship between

\footnotetext{
92 Though under a wage subsidy scheme the firm is free to spend the subsidy on training and hence able to reduee the productivity standard, we abandoned this option to highight the potential difference between a wage subsidy and a training subsidy.

${ }^{3}$ Here we deviate from the model outlined in Chapter 11 . That is, we aggregate functions $\eta$ and $\phi$ to function $\eta{ }^{*}$. We assume $\eta_{t} / \eta+\phi_{i} / \phi>0$. This implies that an increase in $f$ raises training costs - due to an increase of the productivity gap - more than the same raise in $r^{3}$ reduces training costs owing to an increase in the ability level of the chosen candidate. Hence $\eta *$, $>0$
} 
productivity and unemployment duration ensures that raising $t$ leads to a lower expected productivity level of an assessed candidate, $\eta^{*}>0$. Raising $p^{s}$ obviously augments the expected productivity of an assessed candidate; the same holds for switching from recruitment channel towards advertisements, hence: $\eta_{p}^{*}<0$ and $\eta^{*}<0$.

While reducing the productivity standard leads to additional hiring costs in terms of required productivity upgrading, it might still pay off to decrease the productivity standard as it also yields revenues. These rewenues are twofold. Reducing $p$ decreases the failure rate of assessments, which reduces the average number of assessments needed to find a qualified candidate $\left(\alpha_{p}>0\right)$. Moreover, this reduction in necessary assessments speeds up the recruitment procedure $\left(\varphi_{p}^{*}>0\right)$, which saves hiring costs in terms of foregone productivity.

Though, introducing training into the analysis complicates the derivation of partial derivatives - needed to predict firm behaviour -, the expressions found for $\partial t^{s} / \partial c^{*}, \partial t^{3} / \partial b, \partial t^{s} / \partial \theta, \partial r^{s} / \partial e$, and $\partial f^{*} / \partial d$ still, instinctively, produce an appealing outcome. Before providing this outcome we assume the following about second order effects. First, we assume the effectiveness of changing the productivity standard as a means to reduce hiring costs to become more effective at higher values of $r\left(H C_{p r}<0\right)$. Fundamental for this assumption is that the average productivity level of arriving applicants increases for higher levels of $r$ - see for example Russo et al. (1997). Consequently - at higher levels of $r$ - raising the productivity standard leads to a lower increase in the number of assessment failures than such an increase would have yielded at a low $r$. Second, the opposite holds for the effectiveness of the productivity standard to reduce hiring costs at higher levels of $t^{s}\left(H C_{p t}>0\right)$. The reasoning is similar. The average productivity of arriving applicants reduces, as the screening device standard is less strict. Consequently, raising the productivity standard - at higher levels of $f^{s}$ - leads to a higher increase in the number of assessment failures than for low levels of $t^{s}$. Third, we assume $H C_{r r}<0$. The reason for this is that a higher $r$ increases the average quality of the applicants and as a result increases the success rate of the assessment. The negative effect of raising $r^{s}$ on applicant's quality and subsequently on the success rate of the assessment therefore declines for a higher value of $r$, which makes raising $r$ more effective to reduce hiring costs. The final assumption we make is that direct effects dominate indirect effects.

Equation 5.3 represents the impact of costs of foregone productivity on the screening device standard:

$\frac{\partial t^{*}}{\partial C}=\frac{1}{\Omega}\left(-\varphi_{i}^{*} A+\varphi^{*} B+\varphi^{*} C\right)$

where:

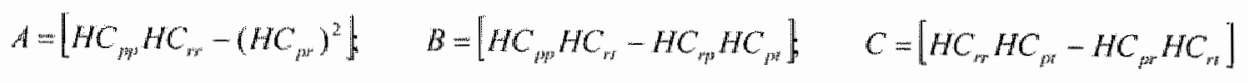

and

\footnotetext{
The partial deriwatives in Chapter IV for wage subsidy schemes are speciall cases of the more generalized partial derivatives we derive here tor training subsidy schemes. That is, for $H C_{p r}=0, H C_{p s}=0$ and $H C_{p p}=1$ (or $H C_{p}=-1$, however since we have $H C_{p}>0$, this option is not open) equation 5.3 boils down to $\partial \mathrm{r}^{s} / \partial \mathrm{c}$ found in Chapter $I \mathrm{~V}$. Conditions $H C_{p i}=0$ and $H C_{p q}=0$ cancel interaction effects of shining $p^{*}$ on the effectiveness of $r^{3}$ and $*$ to reduce hiring costs. Condition $H C_{F p}=1$ ensures that the marginal effectiveness of $p$ to reduce hiring costs is constant. Subsequently, in equilibrium the actual choice of $p^{3}$ is irrelewant, which allows for $p^{5}=p^{*}$, which is the mam assumption of a wage subsidy scheme, as discussed in Chapter IV.
} 
$\Omega=H C_{i r} A-H C_{r f} B-H C_{p H} C$

Equation 5.3 tells that a change in costs of foregone productivity affects the optimal sereening device standard through three channels, as can also be deduced from equation 5.2. The latter equation informs that a firm has three options to counteract an increase in hiring costs due to an increase in costs $c$ : increase $t^{5}$ or $\gamma$, or reduce $p^{r}$. The first effect is a direct effect of changes in $c$ on $t^{3}$; the second and third are indirect effects of changes in $c$ on $t^{*}$ through $r$ and $p^{3}$ respectively. We discuss them separately.

The first effect, $\varphi^{*},(<0)$, measures the direct effect of a change in $c$ on $r$. However, the use the firm makes of the screening device standard as a means to offset hiring costs not only depends on the effectiveness of $t^{5}$, but also on the effectiveness of its alternatives $r$ and $p$. If that effectiveness erodes quickly for higher levels of $r$ and $p^{3}$ (i.e. if $H C_{r r}$ and $H C_{p p}$ are high), the relative effectiveness of $f^{s}$ to reduce hiring costs compared to $r$ and $p$ increases, which induces firms to intensify the use of $r$. This effect is captured by the first term of factor $A$. The second term in factor $A$ captures an additional - though indirect - effect. Lowering $p^{*}$ to offset a hiring cost increase not only affects its own future effectiveness to reduce hiring costs $\left(H C_{p p}>0\right)$ but also the effectiveness of $r$ to reduce hiring costs (through $H C_{p r}$ ) and vice versa. Again these changes in effectiveness of $p^{5}$ and $r$ influence the relative effectiveness of $f^{s}$ to reduce hiring costs as costs of foregone productivity increase.

The second effect, ${ }^{*}{ }_{r}(<0)$, measures the first indirect effect of a change in $c$ on $t$ through $r$. The impact of this indirect effect is captured by factor $B$, which again exists of two terms. The first term tells that if the effectiveness of $p^{s}$ erodes quickly $\left(H C_{p p}\right.$ is high) - which boosts the relative effectiveness of using $r$ - and the effect a change in $r$ has on the effectiveness of $t^{s}$ is large $\left(H C_{r t}\right)$, the indirect effect of a change in $c$ on $t^{b}$ through $r$ is subsequently also large. The second term is a side effect of raising $r$ on the effectiveness of $p^{*}$ $\left(H C_{r p}\right)$, which through $H C_{p r}$ also affects the effectiveness of $t^{\prime \prime}$ and hence its optimal value.

The third effect, $\varphi_{p}{ }^{*}(>0)$, measures the second indirect effect of a change in $c$ on $r^{*}$ through $p^{s}$. The impact of this indirect effect is captured by factor $C$, which also exists of two terms. The reasoning is identical to factor $B$, though factor $C$ measures the impact of $p^{s}$ on $f^{s}$ instead of $r$ on $t^{s}$.

Given the above assumptions we are able to identify the sign of the numerator of equation 5.3 , which is positive. ${ }^{95}$ The sign of the denominator, $\Omega$, is also positive as it represents one of the second order conditions for a minimum. Consequently, $\partial r^{i} / \partial c$ is positive. This is also consistent with empirical evidence of Barron ef al. (1997) and Burdett and Cunningham (1.998) - who show that firms take more time to fill a vacancy when $c$ is low - because raising $r^{5}$ speeds up the recruitment procedure. ${ }^{96}$

Firms facing high costs $b$ try to limit the number of assessments needed to find a qualified candidate. Augmenting the probability that applicants pass the assessment procedure is the answer, for which three instruments are available - see equation 5.4 .

Applying a stricter screening device standard augments the expected average productivity level of applicants, which raises the probability an applicant passes the assessment and subsequently leads to the direct effect in equation 5.4 . The firm can also raise

\footnotetext{
${ }^{3}$ Bear in mind that we assume direct effects to dominate indirect effects, which ensures $A>0, B<0$, and $C>0$, as the first direct effect dominates the second indirect effect.

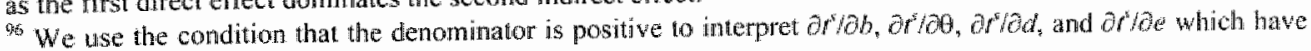
identical denominators.
} 
$r$, to augment the quality of applicants, which has an indirect effect through $r$ on $r$. Finally, the firm can lower the productivity standard to increase the success rate of the assessment, which, again, has an indirect effect - through $p^{s}-$ on $r^{s}$. Using the assumption that direct effects dominate indirect effects, we come to the conclusion that $\partial f^{5} / \partial b<0$.

$$
\frac{\partial r^{s}}{\partial b}=\frac{1}{\Omega}\left(-\chi_{1} A+\chi_{n} B+\chi_{p} C\right)
$$

In Chapter IV we argue why both $\varphi^{*} \theta$ and $\varphi^{*} \theta$ are negative. The opposite holds for $\varphi^{*} p$. In prosperous economic conditions the most productive unemployed find employment first, reducing the average productivity level of the remaining unemployed. This quality decline decreases the effectiveness of raising the productivity standard to reduce hiring costs. That is, due to a lower average productivity level of applicants, raising the productivity standard leads to a higher increase in assessment failures. As a consequence, $\varphi^{*}>0$. Again, proceeding on the assumption that the direct effect outweighs the indirect effects, we come to $\partial t / \partial \theta>0$.

$$
\frac{\partial v^{*}}{\partial \theta}=\frac{c}{\Omega}\left(-\varphi^{* \prime \prime} A+\varphi^{*} B+\varphi^{*} C\right)
$$

Firms confronted with a relative increase in the cost of operating advertisements as recruitment channel instead of using the labour exchange office (which is a consequence of increasing $e$ - see Chapter $V^{2}$ ), will devate away from using advertisements, which explains $\partial t^{5} / \partial e<0$. Bear in mind that $t^{5}$ and $p^{s}$ are not available to reduce costs $e$ - see equation $5.2 .^{9}$ ?

$\frac{\partial t^{*}}{\partial e}=\frac{1}{\Omega}(\zeta, B)$

Finally, firms facing high costs $d$ look for high productive applicants whose need for training is limited. To guarantee a high average productivity level of applicants, the firm can set a low $r^{*}$, a high $r$, or a high $p^{s}$. Equation 5.7 contains these three effects. Proceeding on our assumptions we expect $\partial f^{8} / \partial d<0$.

$\frac{\partial t^{*}}{\partial d}-\frac{1}{\Omega}\left(-\eta_{i}^{*} A+\eta_{i}^{*} B+\eta_{i}^{*} C\right)$

Having identified the implications of introducing training into the model, we can explore the differences in terms of deadweight loss incidence between training subsidy schemes (tss) and wage subsidy schemes (wss). For the latter type, our model predicts that firms facing low assessment costs and high toregone productivity costs as well as firms operating in a tight labour market are most likely to apply a high screening device standard and hence are most likely to cause deadweight loss. The above analysis shows that we expect the same results to hold for a training subsidy, though the introduction of training infuences the magnitude of expected effects, as we describe in hypotheses 5 to 7 . Hypothesis 8 contains our expectations about the link between the level of training costs and the incidence of deadweight loss.

\footnotetext{
${ }^{27}$ Since neither the Dutch nor the British data sets contain information about cosis $e$, we leave costs $e$ ont of the empirical analysis.
} 
Hypothesis $5\left(\partial t^{s} / \partial b_{\text {wss }}<\partial t^{\prime} / \partial b_{\text {tos }} \leq 0\right)$ : the option to lower the productivity standord in a training subsidy scheme enhances the (low) effectiveness of using the screening device standard to reduce hiring costs when assessment costs are high. Therefore we expect that assessment costs have less explanatory power in predicting the incidence of deadweight loss under a training subsidy scheme (tss) than under a wage subsidy scheme (wss).

If assessment costs are high the effectiveness of using the screening device standard to manipulate hiring costs is low, as an increase in $r^{s}$ triggers additional assessments. The alternative under a wage subsidy (raise $r$ to increase quality and subsequently reduce the failure rate of an assessment) indireetly improves the effectiveness of $t$ to reduce hiring costs, since $H C_{r i}<0$. The additional alternative - only available under a training subsidy scheme (lower $p^{s}$ to reduce the failure rate of an assessment directly) - also indirectly improves the effectiveness of $t^{s}$ to reduce hiring costs since $H C_{p t}>0$. Consequently, both indirect effects counteract the direct effect.

Hypothesis $6\left(0<\partial t^{3} / \partial d_{w s s}<\partial t^{s} / \partial d_{\text {sss }}\right)$ : the option to lower the productivity standard in a training subsidy scheme enhances the (high) effectiveness of using the screening device standard to reduce hiring costs when costs of foregone productivity are high. Therefore we expect that costs of foregone productivity have more explanatory power in predicting the incidence of deadweight loss under a training subsidy scheme than under a wage subsidy scheme.

If costs of foregone productivity are high, the firm tries to fill the vacancy as quickly as possible. The effectiveness of shifting the screening device standard to manipulate hiring costs is high under such circumstances. The alternative under a wage subsidy (raise $r$ to increase quality and subsequently reduce the failure rate of an assessment, which speeds up the recruitment process) indirectly improves the effectiveness of $t^{3}$ to reduce hiring costs, since $H C_{s t}<0$. The additional alternative - only available under a training subsidy scheme (lower $p^{s}$ to reduce the failure rate of an assessment directly, which speeds up the recruitment process) - also indirectly improves the effectiveness of $f^{t}$ to reduce hiring costs since $H C_{p r}>$ 0 . Consequently, both indirect effects reinforce the direct effect.

Hypothesis $7\left(0<\partial t /\left.\partial \theta\right|_{\text {uss }}<\partial t^{s} /\left.\partial \theta\right|_{\text {tss }}\right)$ : the option to lower the productivity standard in a training subsidy scheme enhances the (high) effectiveness of using the screening device standard to reduce hiring costs when the labour market is tight. Therefore we expect that the level of labour market tighthess has more explanatory power in predicting the incidence of deadweight loss under a training subsidy scheme than under a wage subsidy scheme.

If labour market tightness is high, the firm tries to augment the arrival rate of job seekers. The effectiveness of shifting the screening device standard to manipulate hiring costs is high under such circumstances $\left(\varphi_{10}<0\right)$. The alternative under a wage subsidy (raise $r$ to increase the arrival rate directly) indirectly improves the effectiveness of $r^{8}$ to reduce hiring costs, since $H C_{r r}<0$. The additional alternative - only available under a training subsidy scheme (lower $p^{5}$ to reduce the failure rate of an assessment directly, which reduces the need to have a sufficiently large arrival rate) - also indirectly improves the effectiveness of $t$ to reduce hiring costs since $H C_{M}>0$. Consequently, both indirect effects reinforce the direct effect.

Hypotheses $8\left(\partial r^{s} / \partial d<0\right)$ : if training costs increase, firms are reluctant to increase the screening device standard, which reduces the probability that such firms hire subsidized unemployed they would have hired in the absence of the subsidy. The indirect effects through $r$ and $p^{5}$ counteract each other and their net outcome is therefore not expected to dominate the direct effect. 
This hypothesis results from equation 5.7. Training is not included in the model for a wage subsidy scheme. Subsequently, we cannot compare both types of schemes concerning the effect of training on the incidence of deadwetght loss.

\subsection{British training subsidy}

To test the hypotheses formulated in Section 5.3 we employ a British data set on firms participating in the New Deal for Young People (NDYP). The National Centre for Social Research used the data set to study firm behaviour within such a wage subsidy scheme. Like the NDLTU, the NDYP was established in Great Britain in 1997 and it focuses on the integration of unemployed into the labour market. The NDYP aims at improving labour market conditions for young people (aged between 18 and 25 years), who have been out of employment for at least six months. Unlike the NDLTU, the NDYP explicitly focuses on training. That is, a firm can only obtain the NDYP subsidy when it offers at least a six-month contract to an unemployed youngster for whom it develops a training plan aimed at an approved qualification. The subsidy is worth $£ 750$. Part of the subsidy is contingent on the development of the training plan; another part is contingent on the achievement of the qualification. 98

\section{Description of the NDLTU data}

Table 5.2 provides descriptive statistics on the independent variables we use in our NDYP analysis. We compare Table 5.2 to Table 4.6 to explore differences in terms of participating firms and unemployed between the NDLTU and the NDYP.

The tables show that women more often participate in the NDYP than in the NDLTU, though still constitute a minority. Jobs offered in the training subsidy scheme are more often fulltime jobs, which does not cause a surprise, as training is an investment made by the firm. To reap the future benefits in terns of increased productivity, a fulltime contract yields more benefits than a part time contract. Supervision rarely occurs, also under a training subsidy scheme. Firms participating in the NDYP more often provide medium instead of low occupational level jobs as compared to firms participating in the NDLTU. Firms participating in the NDYP are more often of medium size instead of large size as compared to firms participating in the NDLTU. Moreover firms participating in the NDYP are less often independent firms. Finally, $69 \%$ of the employers participating in the NDYP indicate they enrolled their subsidized employee in an existing training programme they ran, without making any adaptations to the needs of the employee.

The response rate of the NDYP is $84 \%$. Controlling for poorly filled questionnaires leaves an effective response rate of $70 \%$. However, we excluded the variable "type of training provided" from this effective response rate, as it is a poorly filled question in the questionnatre. Including it in the response rate would reduce the effective response rate to $39 \%$

\footnotetext{
Next to the training subsidy, firms participating in the NDYP also receive a weekly subsidy ( $f 60$ ) for providing employment. This sulsidization lasts 6 months.

This signilicant reduction in the effective response rate caused by the variable "type of training provided, urges us to consider selection bias. We check the sample means of all independent variables before and after introducing the variable 'type of training provided' and find no major changes, which ensures that selection bias can play no important role in our data set. Nonetheless, we decide to exclude the variable "type of training provided" where possible to conserve the richness of the data set.
} 
To ensure comparability of the results, we follow the regression specification we used to analyse the NDLTU data as closely as possible when analysing the NDYP data. Consequently we use the same DWL-construct (DWL2) to analyse the NDYP data. The second column of Table 5.3 (DWL2c) contains the results of analysing the NDYP data. ${ }^{100}$ Moreover DWL2e contains the same independent variable structure as DWL2b. Later on we will discuss the effects of training costs $d$, separately.

Table 52 Descriphe statistics NDYP data

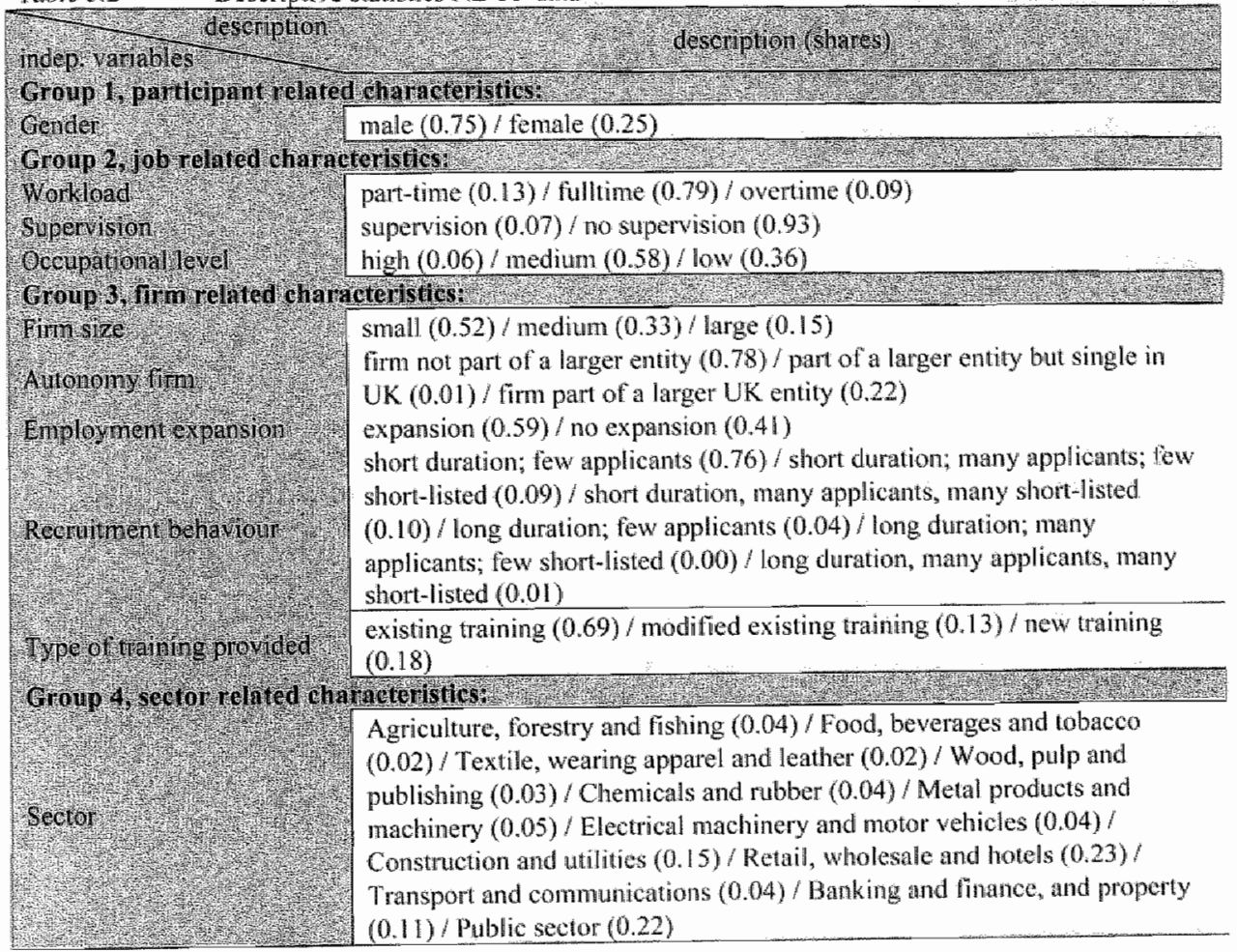

\subsection{Empirical results on British training subsídy data}

We expect the effect of assessment costs to be less pronounced under a training subsidy scheme than under a wage subsidy scheme. In terms of the empirics of this chapter this hypothesis implies that we expect firm size and autonomy to be less relevant in explaining the incidence of deadweight loss.

This is exactly what we find in analysing the NDYP data - see Table 5.3. Large firms and firms that are part of a larger entity are no longer the only firms that can use the screening device to reduce the recruitment period. Small and independent firms - that face high

\footnotetext{
104 Since our data set does not contain information on labour market tighthess, we are not able to test hypothesis

We checked - like we did earlier for the NDLTU - for affects of "socially desired answering". Again, we do not find any indications which suggest 'socially desired answering' is an important issue in the NDYP.
} 
Table 53 Ordinal probit regressions of deadweight loss in NDYP

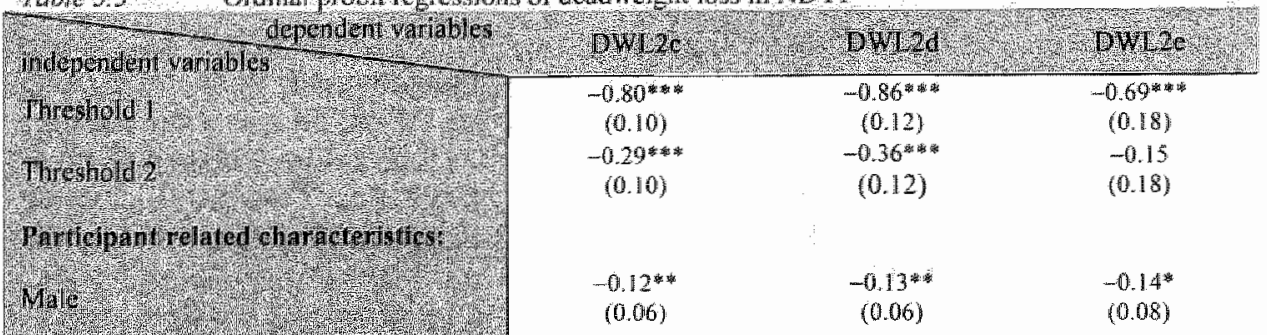

reference

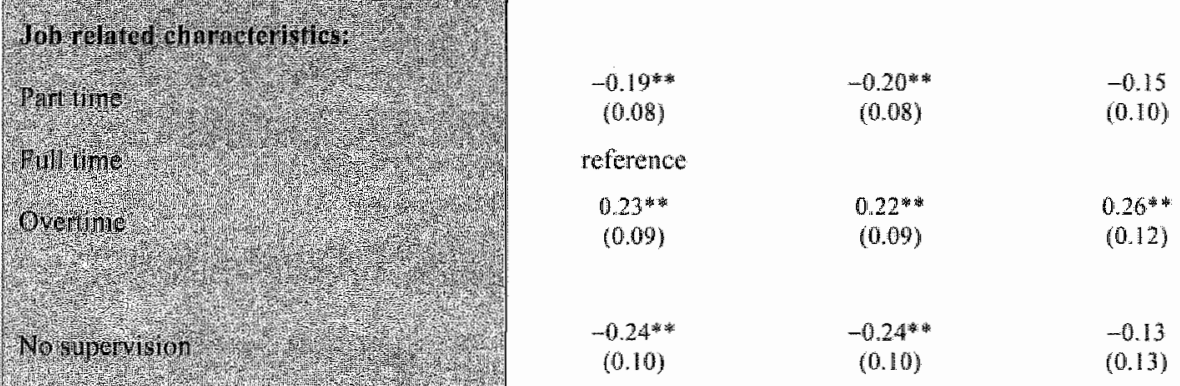

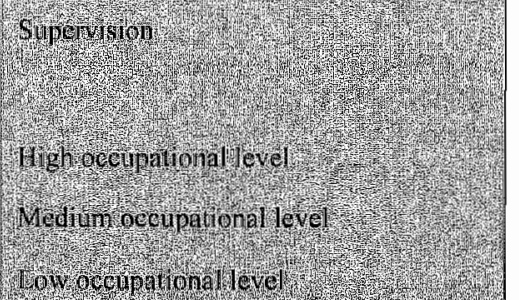

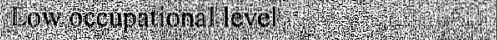

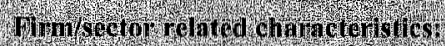

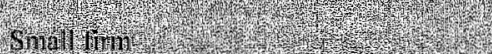

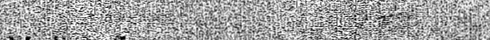

H)

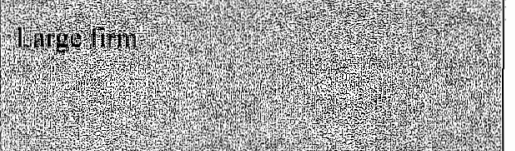

H)

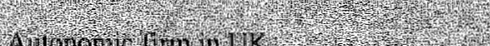

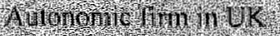

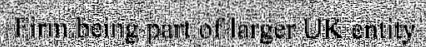

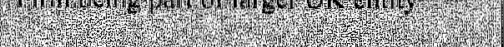

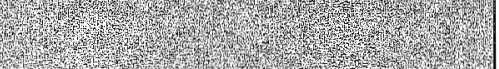

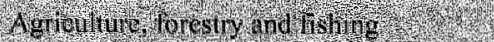

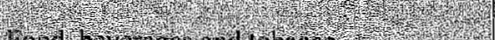

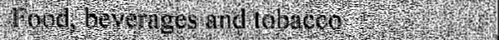

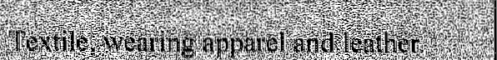

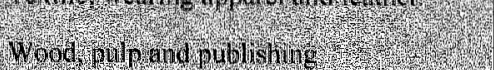

W14

reference

$\begin{array}{ccc}-0.31^{* * * *} & -0.35^{* * * *} & -0.42^{* * *} \\ (0.11) & (0.11) & (0.14) \\ -0.14^{* * * *} & -0.15^{* * *} & -0.13^{* *} \\ (0.05) & (0.05) & (0.07)\end{array}$

reference

$\begin{array}{ccc}-0.02 & -0.02 & 0.01 \\ (0.08) & (0.08) & (0.11) \\ 0.11 & 0.11 & 0.11 \\ (0.07) & (0.07) & (0.10)\end{array}$

reference

$\begin{array}{ccc}0.05 & 0.05 & 0.04 \\ (0.06) & (0.06) & (0.09) \\ 0.22 & 0.21 & 0.02 \\ (0.30) & (0.30) & (0.48)\end{array}$

reference

$\begin{array}{ccc}0.16 & 0.15 & 0.14 \\ (0.14) & (0.14) & (0.18) \\ 0.63^{* * *} & 0.61^{* * *} & 0.92^{* * *} \\ (0.19) & (0.19) & (0.29) \\ 0.39^{* *} & 0.39^{* *} & 0.39 \\ (0.17) & (0.18) & (0.24) \\ 0.28^{*} & 0.28^{*} & 0.28 \\ (0.15) & (0.15) & (0.23) \\ 0.26^{* *} & 0.25^{* *} & 0.33^{*} \\ (0.12) & (0.13) & (0.18)\end{array}$


Table 53. Ordinal probit regressions of deadweight loss in NDYP (continued)

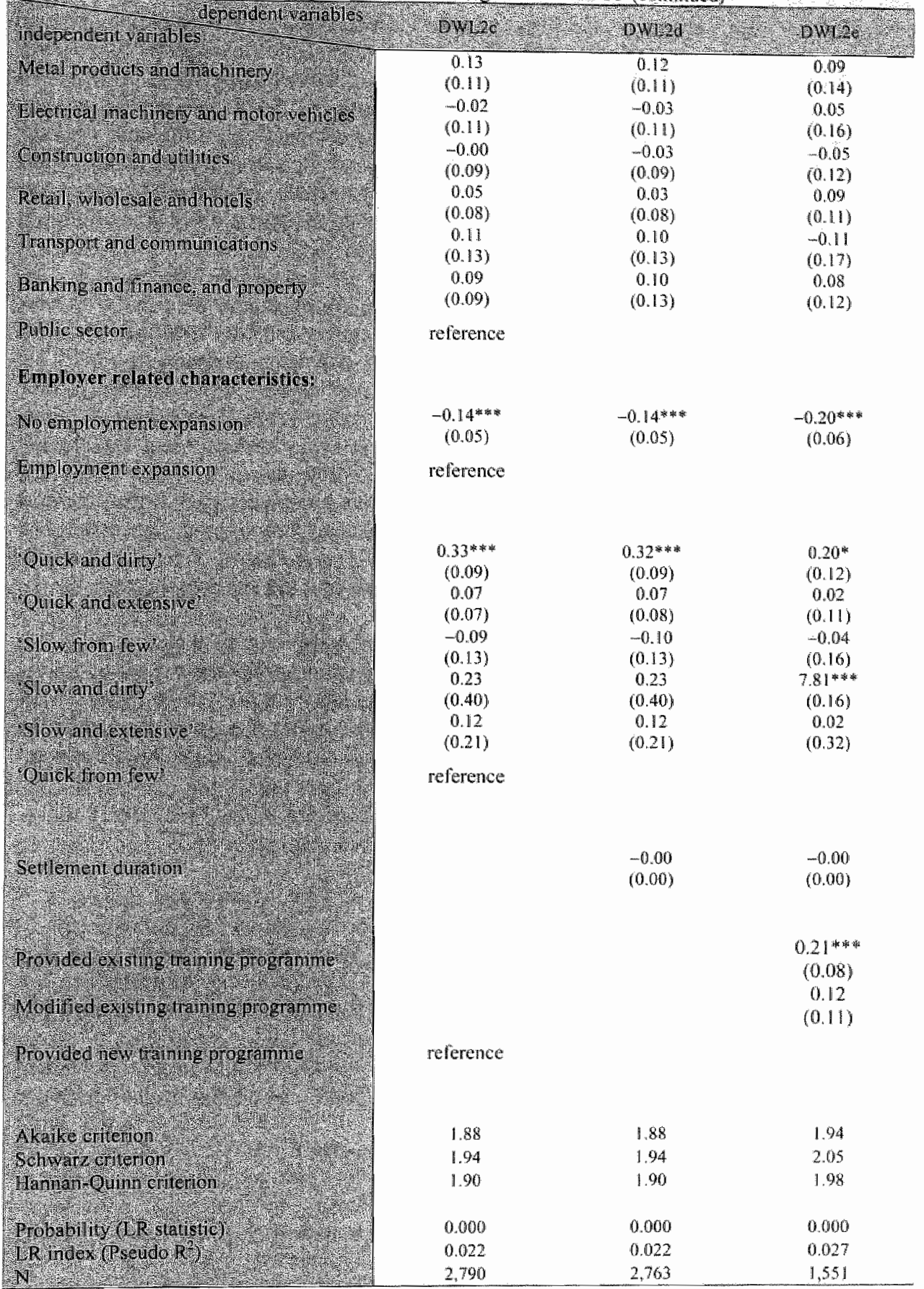

* $10 \%$ significance, * $5 \%$ significance, $1 \%$ significance

Standard ertors in parentheses. 
assessment costs - can offet the increase in the fallure rate of assessments following an increase in $t$, by reducing the productivity standard. The impact of the third indicator of assessment costs $b$ - the occupational level of the job-remains significant under the NDYP. Possibly there is interference between the cost of training and the occupational level.

If costs of training are higher for high occupational level jobs than for low occupational level jobs, the attractiveness to reduce the productivity standard for high occupational level vacancies is limited as that would lead to substantial training costs. Unfortunately - as will appear when analysing the eighth hypothesis - we do not have a proxy for costs $d$ that links these costs to occupational level and therefore we are not able to control for interference between occupational level and training costs.

We expect the effect of foregone productivity costs to be more pronounced under a training subsidy scheme than under a wage subsidy scheme. This implies that we expect proxies for $c$ which were statistically relevant indicators of deadweight loss when analysing the NDLTU remain statistically significant under the NDYP; however proxies for $c$ that were statistically irrelevant under the NDLTU might become relevant when analysing the NDYP.

Table 5.3 also sustains this hypothesis. Superwision and workload were statistically relevant indicators of deadweight loss under the NDLTU and remain relevant under the NDYP. In the NDYP analysis, we are not only able to discriminate significantly between overtime and fulltime and neither between part time and fulltime. Employment expansion had no explanatory power under the NDLTU, but is highly significant under the NDYP, demonstrating the relevance of foregone productivity under a training subsidy scheme.

We also reproduced the variable indicating the recruitment behaviour of the firm, which is related to both costs $b$ and $c$ - see chapter IV. The most apparent effect we expect to find is that the difference in deadweight loss incidence between 'quick from few' (high $c$ ) and 'slow from few' (low c) should be more pronounced for a training subsidy than for a wage subsidy. However, we find the contrary. Also the partitions 'quick and dirty" and 'quick and extensive' do not yield plausible results.

\section{Measuring training costs per wnit of productivity}

To tesi hypothesis 8 we need proxies for training costs $d$. Costs $d$ represent the costs of upgrading the productivity level of a chosen candidate, $p_{j}$, by one unit of productivity. In Table 5.2 we included the variable "training provided" which indicates whether the firm enrolled the subsidized employee in an existing training programme or whether the firm modified an existing programme or developed a completely new training programme. The latter two options are more expensive than the first.

However, we also expect training costs to depend on the complexity of the job and subsequently training costs are sector and occupation dependent. To measure job complexity we follow Barron et al (1999) who consider the number of weeks it takes a newly hired employee to become fully trained and qualified for his job as a proxy for job complexity (settlement duration). Unfortunately, the NDYP data set does not contain such a question, preventing us from measuring job complexity directly. Therefore we derive job complexity via an alternative route: the Skills Survey of the Employed British Workforce 1997. This data set - which is like the NDYP British - contains the following question: "How long did it take 
you to learn to do this type of job well, after you started?". "Employees can choose from seven potential answers, which we use to rum an ordinal probit regression. ${ }^{103}$

The results of this ordinal probit regression are shown in Table 5.4. We have included six control variables to come to a pure estimate of costs $d$. The revenues to the firm of training employees in terms of future productivity gains are lower for employees having a part time contract and more insecure for those having a temporary contract or for women (higher separation rate). Therefore we expect firms to offer simple jobs to such employees, as simple jobs require less training. Table 5.4 confirms this. Next, we control for firm size, as we expect large firms to enjoy economies of scale in training, which induces them to offer more complex jobs. The empirical analysis however, does not lend any support to this expectation. We also include training received for the type of work the respondent currently does, to control for employees who did not receive any training at all and, hence, had to figure out for themselves how to do the job well, which lengthens the settlement phase.

Finally, we control for the match between the educational stock-in-trade of the employee and the educational requirement of the job. We do so for two reasons. On the one hand, we want to take into consideration the fact that we are only measuring the conception of employees about job complexity. We expect that the way in which an undereducated employee judges job complexity of a given job differs from that of an overeducated employee. On the other hand, educational mismatch (more specifically under education) lengthens the period to learn to do the job well and that for two reasons. First, an undereducated employee needs to be educated up to the required level, before he can start training aimed at doing the job well. Second, an overeducated employee will accomplish the training task more quickly owing to a higher ability level. Function $\eta$ " measures this affect and as we want to isolate costs $d$, we control for educational mismatch. We distinguish six educational categories, implying that, potentially, we have five degrees of over education, five degrees of under education and one category indicating congruence between the employee's educational attainment and the educational requirement for the job. The expected pattern follows clearly from Table 5.4. Overeducated employees experience jobs less complex than employees who hold a job that requires their achieved educational level. On the other hand, undereducated employees experience jobs more complex than employees who hold a job that requires their achieved educational level.

Now that we have a pure estimate of job complexity, we indeed ascertain that it is sector and occupation dependent. To visualize training complexity more clearly - the ordinal probit regression does not yield coefficients measured in weeks - we also ran a tobil regression - see right column of Table $5.4 .^{104}$ Now we ascertain that especially the occupational level is an important indicator of job complexity.

Based on the Skills Survey of the Employed British Workforce we derive average settlement duration in a four dimensional matrix (sector, occupational level, workload, and gender). To ensure adequate filling of the cells of the matrix we confine the 12 -category

\footnotetext{
${ }_{162}$ If the employee had not yet completed this leaming process she was asked to estimate the expected time it would take her to learn to do the job well.

103 These six categories are: 'less than a week., 'less than a month', 'one month, up to three months', "over three months, up to six months', 'over six months, up to one year', 'over one year, up to two years', and 'over 2

years".
ion we transformed the seven categories of the dependent variable into a variable that measures the number of weeks it took the employee to learn to do the job well. That is, for example for the third category cone month, up to three monihs', we take the average which is two months or eight weeks. This approach however, poses a problem for the last category ("over 2 years"). This category is open-ended and hence we cannot translate it into weeks. Consequently, our dependent variable is right censored, which we have to control for in chonsing our model specification. For this reason we select a tobit specification.
} 
Table 5.4 Ordinal probit/ tobit regressions of length training period

\begin{tabular}{|c|}
\hline 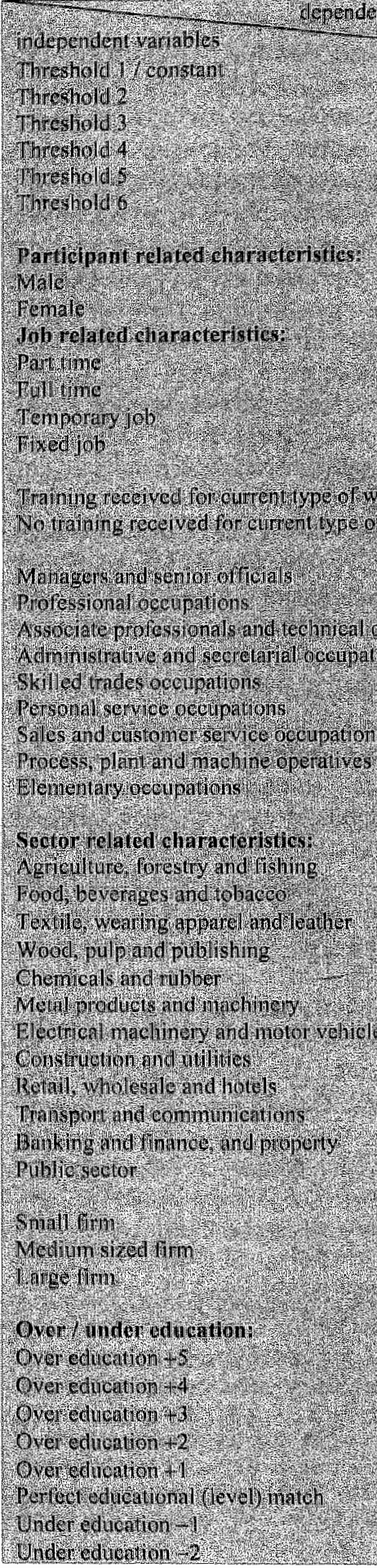 \\
\hline
\end{tabular}
oddinat rit 6 .

$0.25(0.13)$
$0.96(0.14)^{*}$
$1.60(0.14)^{*}$
$2.00(0.14)^{*}$
$2.43(0.14)^{*}$
$2.85(0.14)^{*}$

$0.14(0.06)^{*}$ reference

$-0.38(0.07)^{*}$ reference

$-0.51(0.10)^{*}$ reference

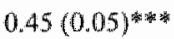
reference

\begin{tabular}{|c|c|}
\hline $1.32(0.12)^{*}$ & $38.50(4.66)^{\text {* }}$ \\
\hline $1.63(0.12)^{* * * 4}$ & $54.11(4.95)^{* * *}$ \\
\hline $1.28(0.12)^{* * * *}$ & $36.62(4.94)^{*}$ \\
\hline $0.77(0.10)^{\text {***; }}$ & $8.83(4.24)^{2}$ \\
\hline $1.30(0.13)^{*}$ & $39.73(5.13)^{* * * *}$ \\
\hline $0.69(0.12)^{* 4}$ & $12.33(4.69)^{4}$ \\
\hline $0.48(0.111)^{* * * *}$ & $2.29(5.12)$ \\
\hline $\begin{array}{c}0.34(0.13)^{* 3 *} \\
\text { reference }\end{array}$ & $5.82(4.90)$ \\
\hline
\end{tabular}

$0.27(0.23)$ $-0.32(0.16)^{* * *}$ $-0.51(0.19)^{* * * *}$ $-0.09(0.17)$ $-0.27(0.15)^{*}$ $0.01(0.14)$

$-0.01(0.11)$ $0.39(0.13)^{* * *}$

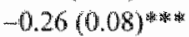
$-0.02(0.10)$

$-0.07(0.07)$ reference

$0.03(0.07)$

$-0.02(0.05)$

Reference

$4.3 .4(2.84)$

$-1.19(2.24)$

$4.98(8.71)$

$-12.78(6.38)^{\text {tw }}$

$-26.14(8.14)^{*}$ 为的

$-2.92(6.59)$

$-5.07(5.96)$

I. $.46(5.49)$

$-1.75(4.43)$

$17.22(5.18)^{3 * * *}$

$-9.48(3.38)^{* * * *}$

$-5.12(4.25)$

$-3.23(3.21)$

$\begin{array}{cc}-0.27(0.28) & -10.44(12.26) \\ -0.21(0.26) & -11.58(9.95) \\ -0.28(0.10)^{* *} & -9.04(4.26)^{* *} \\ -0.18(0.07)^{* *} & -7.58(2.93)^{* * *} \\ 0.01(0.08) & 1.40(2.96) \\ \text { relerence } & \\ 0.12(0.08) & 4.21(3.40) \\ 0.11(0.09) & 3.04(4.07)\end{array}$


Table 5.4. Ordinal probit/ tobit regressions of length training pertiod (continued)

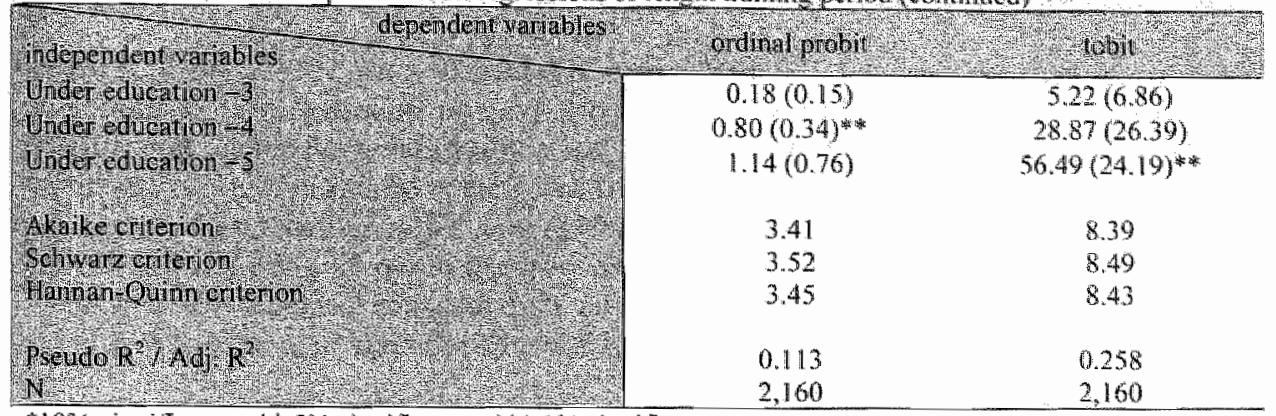

*10\% significance, $*$ * $5 \%$ significance,

Standard errors in parentheses

sector variable and the 9-category occupational job level category to 4-category variables each. The clustering is based on the results in Table 5.4, i.e. sectors and occupational level jobs having similar job complexity are merged. We use this constructed variable in the NDYP analysis to test for settlement duration through job complexity.

The results of introducing training costs into the empirical analysis were stated in Table 5.3. In specification DWL2d we have introduced settlement duration. ${ }^{105}$ Though settlement duration yields the expected (negative) sign it is not significantly different from zero. In the final ordinal probit regression (DWL2e) we also included the variable "training provided'. Here we find evidence for the expected negative link between deadweight loss and training costs $d$. We expect training costs to be more substantial for frms who design a new training scheme than for firms who enrol the subsidized employee in an existing scheme. Consequently we expect the latter to cause more deadweight loss than the former wo categories. The analysis in Table 5.3 confirms our expectations.

Table 5.5 Summary of results from Dutch and British data

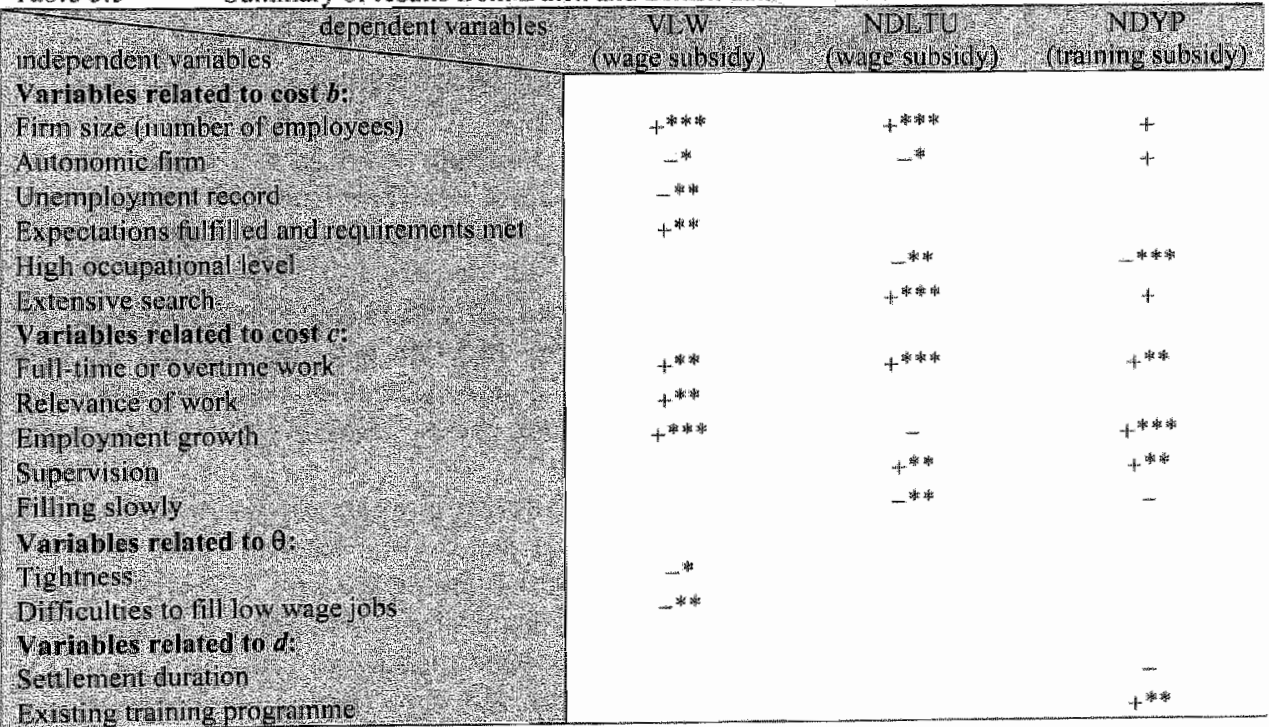

* $10 \%$ significaree, * $5 \%$ significanee, * $1 \%$ significance

Ins Because of the considerable dats loss, we introduce the variable 'training provided' separately in the last specification. 


\subsection{Taking stock: training versus wage subsidy schemes}

Table 5.5 summarizes the empirical findings from Chapter IV and $\mathrm{V}$. The most apparent conclusion is that variables related to assessment costs play an important role in explaining deadweight loss patterns in wage subsidy schemes, but not in training subsidies. This finding is in line with our theoretical considerations. Cost of foregone productivity play an important role in explaining deadweight loss pattern both in wage subsidy schemes and in training subsudy schemes. The variable 'enmployment growth' - when comparing the NDLTU to the NDYP - provides some support for the hypothesis that foregone productivity is a more important predictor of deadweight loss in training subsidy schemes than in wage subsidy schemes, as our theoretical model predicted.

\subsection{Conclusions}

In this chapter we have explored employer behaviour in a training subsidy scheme (NDYP) and compared the results to employer behaviour in a wage subsidy scheme. Our theoretical model suggests that the role assessment costs play in explaining the incidence of deadweight loss is more important in a wage subsidy scheme than in a training subsidy scheme. The training option allows firms that have high assessment costs (i.e. small firms) to lower the productivity standard they set and subsequently to recruit from long-term unemployed. This eliminates any expected difference in deadweight loss incidence between firms that face high or low assessment costs. The empirics employed in this chapter confirm this view. Assessment costs explain the incidence of deadweight loss in a wage subsidy, but do not in a training subsidy.

Furthermore, our theoretical model predicts that costs of foregone productivity play a more important role in a training subsidy scheme than in a wage subsidy scheme. The availlability of training reduces the need to keep the productivity standard high, which opens the door to recruit from long-term unemployed. This increases the arrival rate of applicants, which speeds up the recruitment procedure and consequently reduces the total costs of an unproductive vacancy. The empiricall analysis provides some support for this prediction. Foregone productivity is a more important indicator of deadweight loss under a training scheme than under a wage subsidy scheme.

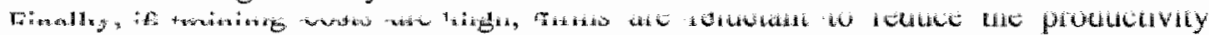
standard they apply in hiring decisions and are more inclined to refrain from hiring from longterm (i.e. low productive) unemployed. The empirical analysis supports this prediction.

Though the shares of deadweight loss differ only marginally between the NDYP and the NDLTU - implying both schemes are equally (in)efficient - the patterns of firms causing deadweight loss are different. This also implies that a government that aims at reducing inefficiency of an employment subsidy scheme should choose different routes to tackle inefficiency.

A govermment trying to reduce the share of deadweight loss in a wage subsidy scheme should focus on firms having low assessment costs, like large firms who are more likely to cause deadweight loss than small firms. One might think of linking the level of the subsidy to firm size. A government trying to reduce the share of deadweight loss in a training subsidy scheme should focus on firms having high costs of foregone productivity of a vacancy. One might think of linking the level of the subsidy to the workload. Both, linking the subsidy level to firm size and to workload can be implemented quite easily, as tax authorities - who specifically execute employment subsidy schemes - dispose of the necessary information as regards firm size and workload. 


\section{Chapter VI: Making a Virtue of Need ${ }^{106}$}

Shares of deadweight loss in wage subsidy schemes are generally large. This suggests that firms know better than the government which long-term unemployed are employable. In this chapter we show using the example of Philips - that private firms not only achieve better results in terms of treatment effects than public schemes, but also without major subsidization. Private employment schemes generate revenues to firms, which make subsidizing unnecessary. Scaling-up private employment schemes would therefore be a welcome contribution to public efforts to fight long-term unemployment.

\subsection{Introduction}

The effectiveness of employment subsidy schemes has been severely questioned in the empirical literature - see Martin (1998). Both the microeconomic treatment effect on longterm unemployed and the macroeconomic wage moderating effect due to an increase in the effective labour supply appear to be small and short-lived, if present at all. An important reason for these poor results is the substantial share of deadweight loss (DWL) involved - see Dar and Tzannatos (1999). This loss measures the share of participants that would have found a job even in the absence of the subsidy. Such participants apparently were already part of the effective labour supply (hence no macro effect) and if they enjoyed a treatment offect of employment, it should not be attributed to the subsidy (hence no micro effect).

Dutch experiences are no exception to the rule that employment subsidy schemes and substantial deadweight loss go hand in hand - see Welters (1998). The Dutch government has developed several employment subsidy schemes throughout the last fifteen years. DWLshares in these schemes range from one third to half of all participants, which indicates the magnitude of the problem at stake. Apart from considerable abuse of public expenditures, these DWL-shares also indicate that firms know better which long-term unemployed are employable than the government does. This raises the question whether the firm's superior knowledge should not be employed in reintegrating long-term unemployed. That is, can we make an issue for privatizing the reintegration of at least part of the long-term unemployed, which allows the government to concentrate on poorly qualified long-tern unemployed?

To find out whether privatization is a serious alternative, we explore the efforts Philips puts into reintegrating long-term unemployed within its Philips Employment Scheme (PES). Philips has run the PES for more than twenty years. A protit maxinizing firm like Philips would not continue such a largely unsubsidized scheme if it would not generate sufficient revenues to compensate for the costs involved. We inspect the revenues Philips generates from the PES to find out whether a properly functioning private employment scheme could be applied more in general, which wou'd make it an alternative to publicly funded wage subsidy schemes. We will argue that the private scheme can outperform the success rate of public efforts for some groups of unemployed.

This chapter is organized as follows. Sections 6.2 and 6.3 describe the origin and design of the PES respectively. In section 6.4 we develop a success measure for the scheme. We use this success measure to compare the performance of private to public efforts in reintegrating long-term unemployed in Section 6.5. Section 6.6 discusses the success factors of the PES;

tor We are indebted to Ton Van der Bruggen. Will Cuypers, Ton Van Roon, Frangois Stallaert (all of them Philips), Peter Haima (Brug naar Werk), Ger Van Rooij (KLAO), Angelique Smits (PCN) and Jan Sweegers (CWI), for their willingness to provide insignts into the Philips Employment Scheme. 
Section 6.7 its potential pitfalls. Section 6.8 explores the extent to which private employment schemes could be applied to reintegrate as to which type of long-term unemployed, while Section 6.9 concludes.

\subsection{Philips Employment Scheme in retrospective}

Labour market conditions in the early eighties worsened to unprecedented levels in the aftermath of the Second World War. As can be observed in Figure 6.1, the unemployment rate tripled in four years time to reach almost double figures in 1984 . The main reason for that incline was the poor economic climate in the Netherlands following the second oil shock, which led to massive lay-offs. But also the increasing participation rate of women and the relatively large share of school leavers added to significant inflows into the unemployment pool.

\section{Figure 6.1 Unemployment rates in the Natherlands}

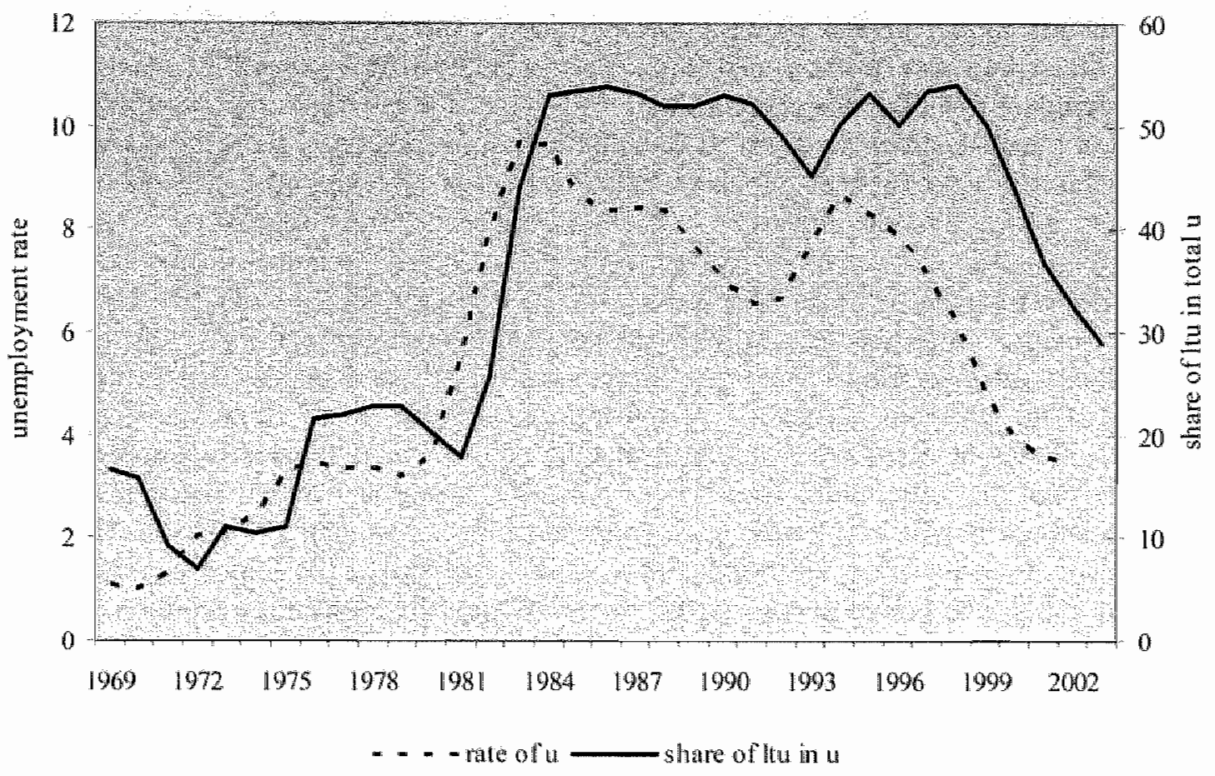

After 1984 the unemployment rates dropped gradually to substantially lower levels at the end of the nineties. Much of this remarkable turn around has been attributed to the Wassenaar Accord agreed upon in 1982 . The declaration of intent by both employers" organizations and labour unions and the acknowledgement of the trade-off between wage restraint and the employment outcome, the foundations for which were laid in the Wassenaar Accord, have guided the Netherlands to rellatively healthy conditions on the labour market. Since the Wassenaar Accord has made a tremendous impact on the Dutch industrial relations and has been an important motivation for Philips to start the PES, we briefly discuss its origin and contents.

The awkward conditions on the labour market in the early eighties asked for a cohesive policy. That is, a policy supported by the three parties involved: the government, employers" organizations and labour unions. A tough task as such a collective agreement had only been 
achieved once since the abandonment of the policy of guided wages in 1969. The first collective agreement was concluded in 1972 - not surprisingly in the middle of the lirst oil crisis - showing the exceptional conomic circumstances required to effectuate a centrul agreement backed by all three parties. ${ }^{10 \%}$

However, the conditions on the labour market were threatening to such an extent that a second central agreement was indeed entered into in 1982. That agreement is called the "Wassenaar Accord". Although the Wassenaar Accord has attained a mythical status in the Netherlands in later years, the actual Accord only covers one page. The Accord outlines how the three parties expect to contain unemployment rates and, equally important, what the individual tasks of the three parties are to achieve that goal. The latter part clearly shows the atmosphere of distrust among the three parties, which arises from the roaring seventies in which central agreements were rare. The govemment was supposed to focus on sound economic principles with regard to the economic policy of the Netherlands and should refrain from wage interventions: a typical manoeuvre the government applied in the seventies.

This meant that employers' organizations and labour unions obtained what they strived for: responsibility for wage negotiations. The Accord also describes which main elements the wage agreements between employers' organizations and labour unions should contain. On the one hand labour unions should approve wage moderation, which would reduce labour costs and consequently increase employment. On the other hand employers" organizations should endorse work sharing and part time employment, which was believed to increase employment levels.

The situation of youngsters receives special attention in the Accord. Youth unemployment rates were substantially higher than overall unemployment rates, showing the precarious situation youngsters found themselves in. The Accord forces both employers" organizations and labour unions to explicitly take the situation of school leavers into consideration when looking for solutions to fight unemployment.

\section{Philips " contribution to solving the unemployment puzzle}

Against this background Philips entered into negotiations with unions in 1983. Its position, as one of the largest Dutch suppliers of employment placed a heavy responsibility on Philips to take the initiative in finding solutions to the impasse on the labour market. A few months earlier, Frans Van Der Brand, Director of Social Affarrs at the time, took the initiative to introduce a plan to fight youth unemployment - cf. Van Der Bruggen en Van Schagen (2001). The plan offered the opportunity for youngsters to work at a Philips division for a fixed period of time: one year. The work experience, gained during that year, should considerably increase the job find probability of youngsters as a lack of work experience was thought to be the main reason why youngsters faced substantial difficulties in entering employment.

The proposal encountered strong opposition at the industry level, which made Van Den Brand realize that introducing the plan could only be achieved at the company level. However, also at the company level scepticism prevailed. Unions did not support the plan, as there was no job guarantee for youngsters after the one-year contract expired. In view of the high unemployment rates, this surely meant that participants, who did not get a job guaramtee, would fall back to unemployment again. The division management was also reluctant; it was unclear how to implement such an ambitious plan (i.e. the plan comprised 700 jobs for youngsters on a yearly basis which was about $1 \%$ of the Philips population at that time).

The only party backing the project was the top management. This caused surprise, ats one would not expect the top management to be in favour of an expensive plan in the poor

${ }_{107}$ For a thorough overview of Dutch industriat relations in the post war era, see Vand Veen (1997). 
economic conditions that prevailed at the time. Actually, the support indicates a hidden agenda: the role the youth scheme could play in the 1983 union negotiations. As outlined in the Wassenarar Accord, employers" organizations were willing to discuss issues like work sharing and part time work as a trade-off for wage moderations. Phillips was strongly opposed to work sharing, as it would - according to Philips - run up the substantial shortage of technically skilled workers that prevailed at the time. To be able to obstruct work-sharing notwithstanding the possibility the Wassenaar Accord offered to introduce it - Philips had to make an altemative offer: the youth employment scheme.

Consequently not only social responsibility played a role to introduce a youth employment seheme. Also strategic behaviour played its part in the decision Philips made to start a youth employment scheme in 1983. As will appear later, the latter argument seems to be instrumental in explaining the achievements of the scheme in later years.

\subsection{The Philips (youth) employment scheme}

The design of the youth employment scheme contained two pillars. Philips created additional jobs in its divisions throughout the Netherlands. Unemployed out of employment for at least half a year - aged 23 or less - could employ such jobs for a maximum period of a year. Philips paid them the legal minimum wage. Next to jobs, Philips offered educational facilities to youngsters within its own training facilities. Philips committed itself to placing around 700 youngsters per year for a period of three years.

Despite the scepticism expressed by various parties involved the youth employment scheme appeared to generate satisfying results, as about $60 \%$ of its participants found a job after fintshing the scheme. Nonetheless, Philips decided to change its policy slightly: both with regard to concept and to the participants. A look at Figure 6.1 reveals that the strong increase in unemployed is accompanied by an equally strong increase in the share of longterm unemployment in total unemployment. Being unemployed for more than a year seriously reduces re-employment probabilities. Subsequentlly, long-term unemployed face the threat of being excluded from the labour market permanently, unless they receive help from outside.

In 1986 Phillips decided to provide this help and the firm raised the maximum age criterion to be entitled to participate from 23 to 45 . From then on the word "youth" has been left out of the name, which explains for the name the programme currently holds: Philips Employment Schene. The original two-pillar system has been replaced by an integrated onepillar design. That is, work experience and training activities have been integrated into one job, as long-term unemployed appear to benefit most from the combination of the two. Since 1986 the PES structure has not undergone any significant changes any more, although the PES has gradually become more demand side oriented in terms of the type of jobs and training offered, as we will discuss later.

In Figure 6.2 we give a schematic overview of the process of starting, filling and closing a PES „job. The process roughly consists of four phases: job allocation, demand for labour, skill augunentation and outflow.

At the start of the year the HRM department of Philips Eindhoven considers the allocation of PES jobs over the Philips establishments. The main argumentation to justify this allocation is the future job prospects of participants. Since Philips has several establishments in the Netherلands operating in various sectors (Semiconductors in Nijmegen, Lighting in Roosendaal, Domestic Appliance and Personal Care in Drachten), the job prospects among sectors differ and subsequently the choice as to which establishment is allocated to open PES 
jobs matters. Moreover, it is not current job prospects that decide, but future job prospects, as participants have to finish the PES job first, which takes a year.

Figiore 6.2 Schematic overview of the Philips Employment Scheme

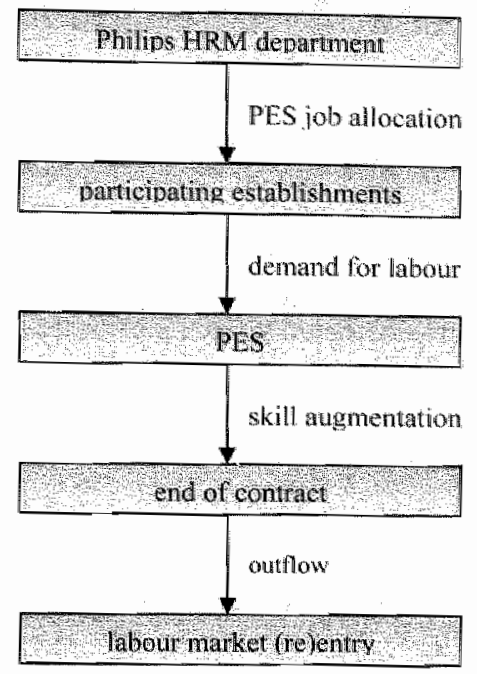

After deciding on which establishments and on how many PES jobs per establishment should be created the establishments start selecting qualified candidates. A qualified candidate meets three criteria. First ( $s$ )he must be a long-term unemployed and/or be part of a pre-defined disadvantaged group. ${ }^{109}$ Furthermore the candidate needis the intellectual capacities to be educated up to a certain level. ${ }^{110}$ Finally, the candidate is expected to be motivated to train and work at Philips.

The selection procedure consists of two plases. The first two criteria are tested externally; the third internally. Philips outsources the first selection phase to private or public employment offices. The employment office's main task is to find candidates who meet the first two criteria. "If the employment oflice thinks they have found a qualified candidate, (s)he is sent to the Philips establishment. The establishment focuses on the third criterion: the candidate"s motivation. The establishment informs the candidate about the PES job. A PES job is a full time job and, apart from working 36 hours, the participant has to obtain the educational degree (mainly) in non-working hours, though under contract to Philips. If the candidate is still motivated after having been informed about the job contents, the establishment decides to hire the candidate.

\footnotetext{
10* That is, originally a PES job took one year. Due to a reduction in the quality of candidates (following a tightening labour market and Plitips. target group policy), candidates now need more time to linish the PES job successfully. Philips allows candidates to extend their stay for hall a year.

${ }_{109}$ Long-tern unemployment is defned as more than one year out of employment. In large cities - expertiencing thigh unemployment rates - long-term unemployment starts at six months. Disadvantaged groups are women re. entering the labour market, ethnical munorities, partially disabied and highly educaled having poor job prospects.

${ }_{310}$ During the stay at Philips, participants are supposed to obtain a VaPro degree, which is a certified and generally accepted degree in the process indusiry.

TII Due to tight labour market conditions in the late nineties and subsequent difficuities to find qualified candidates for PES jobs, employment offices and Philips started to organize intensive training courses (up to six months) before entering the PES job.
} 
After having determined the candidate "s ability and motivation to finish the PES job successfully, the candidate turns into a PES participant. During the stay the participant is going to accomplish the VaPro training, which consists of both a theoretical and a practical component. The practical component can be completed on the Philips work floor and bears strong similanities to what regular Philips employees do, which enables Phillips to integrate the PES participant smoothly into the regular work process. In principle the participant is responsible for the theoretical component, although some establishments provide time and support to alleviate the participant"s task. Finding a job in the Dutch process industry is difficult without a VaPro degree. Since participants do not hold that degree at the start of the PES job, but obtain it at the end of their stay at Philips, successful participation in the PES increases the job find probability of participants significantly.

After having taken the VaPro degree at the end of the year, the participant has to flow out. Two possible employment destinations are available: regular employment within or outside the Philips organization. A substantial part of participants remain employed at Philips, which demonstrates that Philips does not only use the PES to help long-term unemployed back to the labour market, but also as a recruitment source.

\section{Revenues from the Philips Employment Scheme}

Philips is a profit maximizing firm and though it receives subsidies for part of its PES participants (roughly $20 \%$, it finances the majority of the costs of the PES itself. Apparently, in some way or other Philips reaps benefits from the PES; otherwise it cannot be explained why Philips has continued the PES for more than 20 years now. Based on interviews with various managers we found out that benefits from the PES result from four sources.

First, Philips uses the PES in negotiations with labour unions and the government. In negotiations with labour unions Philips occasionally uses the PES to obstruct work sharing or to moderate wage claims; in negotiations with the government Philips uses the PES to satisfy requirements on "corporate social responsibility", for example. Second, the PES is a recruitment channel for Philips. Although employment at Philips after finishing the PES job is no objective, still about $15 \%$ of PES participants find employment at Philips. Apparently, division managers use the PES as a probationary period in which they select the best participants. Third, PES participants are productive, which Philips tries to maximize. Competition induces Philips to move production facilities to low wage countries in Eastern Europe. To save employment in the Netherlands, the skills of employees have to be upgraded. The main cost from upgrading skills is not the cost of training, but the production loss incurred during training. Therefore Philips uses PES participants as substitutes for its own employees, during the absence for training of the latter. Consequently, the production of PES participants becomes relevant for Philips, which makes careful counselling of these participants relevant too. Finally, the PES is used to develop teaching methods, which are useful to upgrade skill levels of regular personnel as well. Since regular personnel need continuous skill upgrading, Philips benefits from the experience it gains from the PES.

\subsection{Effectiveness of the PES}

Ultimately, Philips' support to continue the PES depends on its success in terms of reintegrating disadvantaged groups into the labour market. For, if the scheme is not successful, the above-mentioned benefits disappear. To measure success Philips uses the outflow rate of participants to employment. It measures the outflow rate at two points in time: one month and roughly one year after outflow. Philips focuses on the latter rate as it attaches more value to the long-term effects of participation. The expected effects of training offered 
within the scheme - which augment the participant's employability - indeed suggest that only a long-term ewaluation of the PES scheme is useful, which is more robust to exogenous disturbances. Unfortunately, Philips has collected the long-tem outflow rate since 1996 only, which is too short a period for a proper analysis. Therefore for the time being, we focus on the short-term outflow rate, which Philips has collected since $1986 .^{112}$

In Figure 6.3 the bold dotted line represents the outflow rate of participants to employment. The average outflow rate in 20 years PES equals $63 \%$. The outflow to employment at Philips is relatively constant between 10 and $20 \%$ of participants except for the cohorts 1993 and $1994 .^{113}$ The outflow of participants to employment outside Phillips fluctuates more widely, which subsequently shows up in the total outflow rate of participants to employment. Given the absence of major changes in the design structure of the PES throughout the years, the design structure of the PES scheme cannot explain for the volatility of the outflow rate and hence the outflow rate Philips relies on must be a noisy indicator of the success of the scheme.

\section{Figure 6.3 Ouflow rates of PES participants}

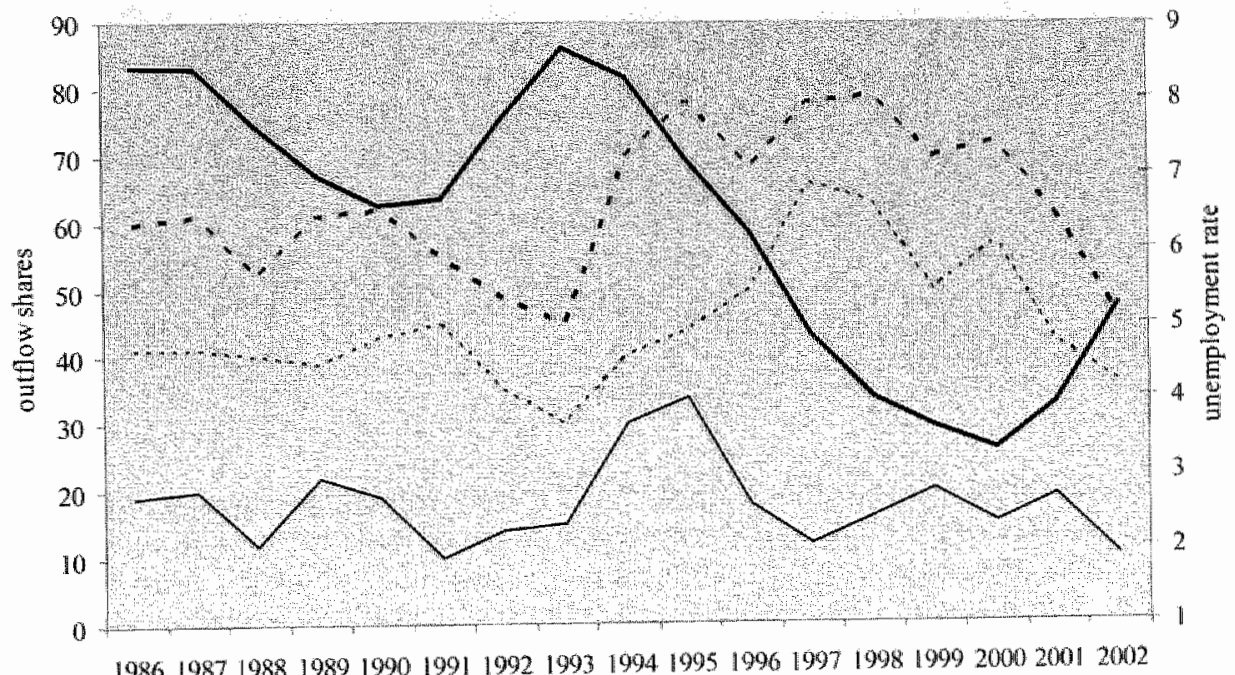

19861987198819891990199119921993199419951996199719081999200020012002

outflow to Philips ....... out flow outside Philips - - - total out flow —_ unemployment rate

Source: Van Der Bruggen (1987-2003)

A glimpse of an external feature that influences the outflow rate of the PES is included in Figure 6.3: labour market conditions in the year of outflow. If the labour market is tight, participants leaving the scheme will find it relatively easy to find employment as compared to slack labour market conditions in which it is difficult to find a job. The counter cyclical movement of the unemployment rate and the pro cyclical movement of the outflow rate hint at this 'outsider competition effect", which is exogenous to the functioning of the PES.

12 Ouflow percentages in year $"$ go logether with cohorts of unemployed participating in year $\delta-1$. All years mentioned in this chapter refer to the year of participation and not to year of outhow, unless explicitly stated otherwise.

n3 In 1993 and 1994 Phiths Nijmegen decided to extend the contract of a significant share of ats PES participants beyond the annual contract. In the annual reports of 1994 and 1995 philips looks upon these participants as outflow, which gives a somewhat distorted view in Figure 6.3. 
Nonetheless it infuences the oufllow rate. To test for the outsider competition effect on the outflow rate, we regress the outflow rate on the unemployment rate ( $u$ rate) and the absolute change in the unemployment rate ( $\Delta u$ rate). We expect both the level of and the change in the unemployment rate to affect the outfow rate negatively. We include the latter because we expect employers not to take risks (i.e. hite from long-term unemployed) when conditions deteriorate.

Table 6.1 shows that the level and the change in the unemployment rate significantly matter for the outfow rate, hence outsider competition matters. ${ }^{14}$ Since both variables explain $65 \%$ of the variance of the ouflow rate, this supports our intuition that the outflow rate as an indicator for the sucess of the programme is a poor guide.

Table 61 Explaining the outfow rate to employment

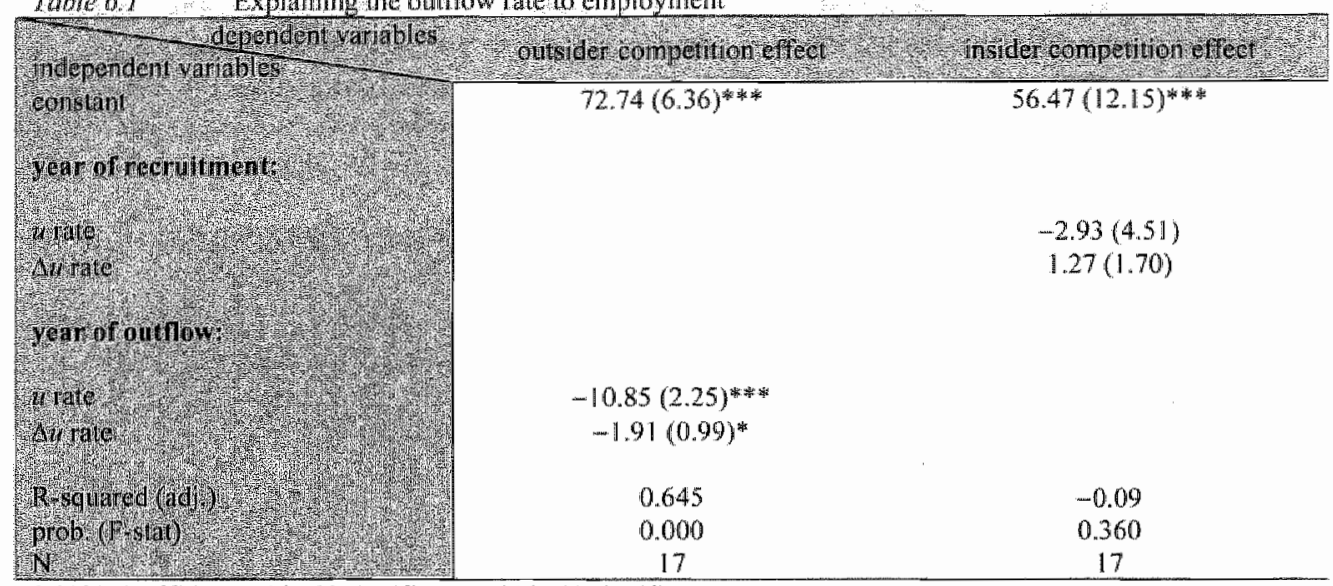

* $10 \%$ significance, $5 \%$ significance, $1 \%$ significance

Stardard emors in parentheses.

Apart from the outsider competition effect, labour market conditions can also influence the quality of entrants. That is, if unemployment is low and decreasing Philips will find it hard to attract qualified candidates for PES participation, as qualified candidates have reasonable alternatives. A reduction of the competitive strength of participants will subsequently depress the oufflow rate as participants leave the scheme. We call this effect the 'insider competition effect".

Table 6.1 contains the results of a regression we ran to test for the insider competition effect. However, the insider competition effect does not explain the variance of the outflow nate. Hence either, Philips - in close cooperation with employment agencies who are responsible for recruiting PES participants - succeeds in keeping participant quality constant, irrespective of labour market conditions or, as an alternative view, participant quality does not affect the outflow rate. There are two arguments supporting the latter view. As a reaction to reduced quality of participants, Philips can exert itself to upgrade candidates. These additional efforts might explain why lower quality at the entry level does not lead to lower outflow rates. Alternatively, Philips can accommodate the yearly number of PES participants to labour market conditions. Lowering the number of participants when it is hard to find qualified

\footnotetext{
21: We also included the share of long-term unemployed in total employment as an explanatory variable. If this share is low, most competitors on the labour market of PES participants are short-term unamployed and hencetorward nough competitors. However, this variable does not lead to a significant effect and is therefore dropped from the presented regression.
} 
candidates reduces the insider competition effect. Since we only use relative measures in the form of outhow rates, we cannot include this potential effect in the regression analysis.

Table 6.2 contains descriptive evidence on the consequences of changes in labour market conditions on the background of participants and eventually on its impact on the outlow rate; as we compare the PES schemes of 1997 (tight labour market conditions) and 2001 (slack labour market conditions). Compared to 1997, participants in 2001 experienced longer spells of unemployment, had lower educational levels, were more often part of an ethnic minority and were older. Apparently, Philips faces difficulties in recruiting qualified participants in prosperous times, which shows up in the background characteristics of participants. But - as we demonstrated in Table 6.1 - that is not the main reason for the lower outllow rate in 2001 compared to 1997. It is labour market conditions at the time of outllow that matter:

Table 6.2 Participant and labour market characteristics PES for collonts 1997 and 2001

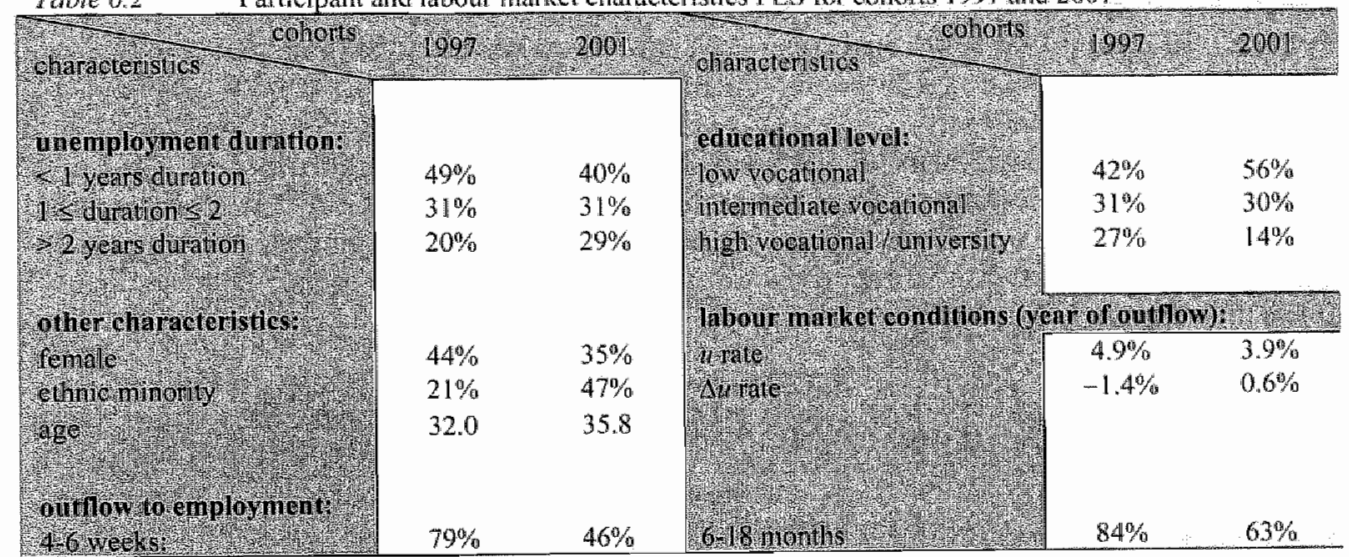

Source: Van der Bruggen (1987-2003)

The outflow rates in the table are therefore not surprising. The outflow rate measured after four to six weeks was 33\%-points lower in 2001 as compared to 1997 . Six to 18 months after leaving the PES the difference decreased substantially, which suggests that the long-term outflow rate was more robust to exogenous disturbances like labour market conditions. However, the difference remains considerable at $21 \%$-points. Since no major design changes took place between 1997 and 2001, the long-term outflow rate is also a poor measure of the effectiveness of the PES scheme.

The above-mentioned analysis demonstrates that both the short-term and long-term outflow rates are biased measures for the success of the PES. Both out low rates only measure the gross effect on a participant's job find probability, whereas one would like to measure the net effect of the scheme, the so-called treatment effect. That is, the added value of the scheme in terms of raising the job find probability of participants, purified from factors like participant characteristics and especially labour market conditions.

Yet determining the influence of participant characteristics and labour market conditions on the outflow rate is difficult due to a lack of detailed information, but fortuitously unnecessary as we have an alternative indicator: deadweight loss. Deadweight loss measures the share of participants that would have found a job in the absence of participation in the scheme and this is exactly the effect we want to deduct from the gross. effect of the programme (i.e. the outflow rate). The level of deadweight loss typically depends 
on participant characteristics and if we measure it at the time of outfow, it also comprises labiour market conditions.

Unfortunately Philips does not determine the deadweight loss share among PES participants, which urges us to determine it ourselves. We have - in terms of recruitment of PES participants - interviewed the three most important employment agencies. Based on the judgment of the three employment agencies, we construct a weighted average deadweight loss estimate for the 2001 cohort, which equals $12 \%$. $^{15}$ Given the scarce information we have, we treat this figure with some caution - it is within the range of $0-20 \%$. Since the outflow rate of the 2001 PES cohort was $46 \%$, we estimate the treatment effect of the PES in 2001 at $34 \%$.

\subsection{The Philips Employment Scheme in perspective}

To put the achievements of the Philips Employment Scheme in perspective, we contrast its design and results to comparable programmes initiated by the government in the last two decades. Though different in many respects, the six government programmes we review, share the same objective: guide poorly qualified unemployed back to regular employment within a fixed time-window. ${ }^{116}$

Some key characteristics of the six programmes have been summarized in Table 6.3 . Though all programmes have a fixed time-window, the subsidy period differs. Nonetheless, all programmes focus on long-term unemployed. The programmes differ as to the sector they are oriented at. Some focus on the private sector; others on the public sector. Some explicitly focus on low paid jobs; others do not.

Table 6.3 PES characteristics and comparable programmes initiated by the government:

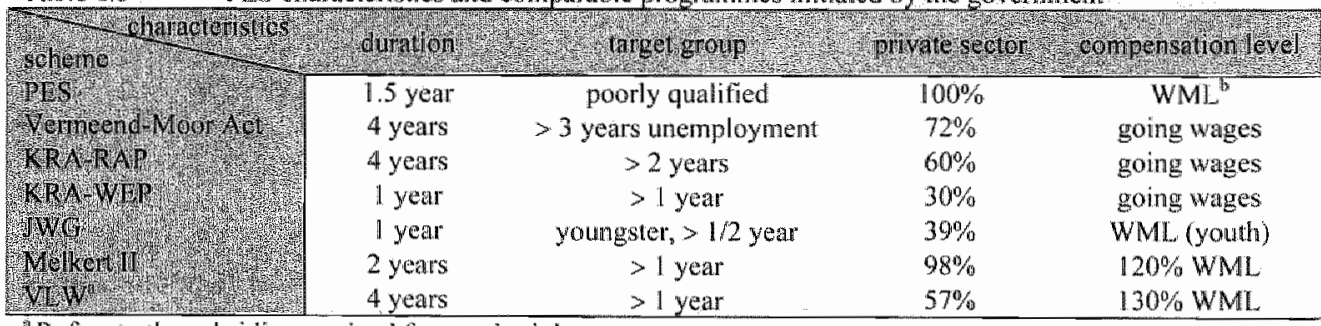

"Refers to the subsidies received for regular jobs.

"Legal Miningun Wage

Source: Welters (1998), Van Polanen Petel at al. (1999)

Although different in many respects, a review of the various publicly initiated programmes yields one common factor, as Table 6.4 reveals: rates of outflow to regular employment are typically between 55 and $60 \%$, which is substantially above the 2001 outflow rate of the PES. The result is not surprising, as of all seven measured outflow rates, the PES outflow rate was the only one measured in a deteriorating labour market. ${ }^{117}$

However, the outflow rate is only the gross effect of a programme. To obtain the treatment effect of a programme we should control for participant characteristics and labour market conditions. As we have explained above, we can do this by controlling for deadweight loss. Table 6.4 also contains deadweight loss shares. The 'PES 2001 cohort' deadweight loss share is substantially below the share of all public schemes, even when we take the

\footnotetext{
"1s Sef Appendix 6.1 for an elaboration of the DWL-calculation within the PES.

"We do not review the relief schemes inituated by the government (like the Job pool, Melkert I, III and IV), as their design and purpose deviate too much from the PES to justify a comparison.

"17 the change in the unemployment rate sems to be more mportant in explaning outflow rates than the unemployment rate itself at the time of outfow - see the last two columns of Table 6.4 .
} 
uncertainty margin into accoun. This is in line wh ou expectations under the given labour market conditions. Hence labour maket condhons seen to steer deadweight loss. The improving labour market conditions at the the the Melkert II scheme and the VLW scheme were operative, led to high deadweigh loss shares within these schemes. The opposita holds for the PES: the deteriorating labour market condions in 2002 explain the low deadweight loss share of the PES. Only the RAP deadweight loss cannot be explained by abour matket conditions.

Table $6.4 \quad$ Characteristics Dutch wage subsidy schemes

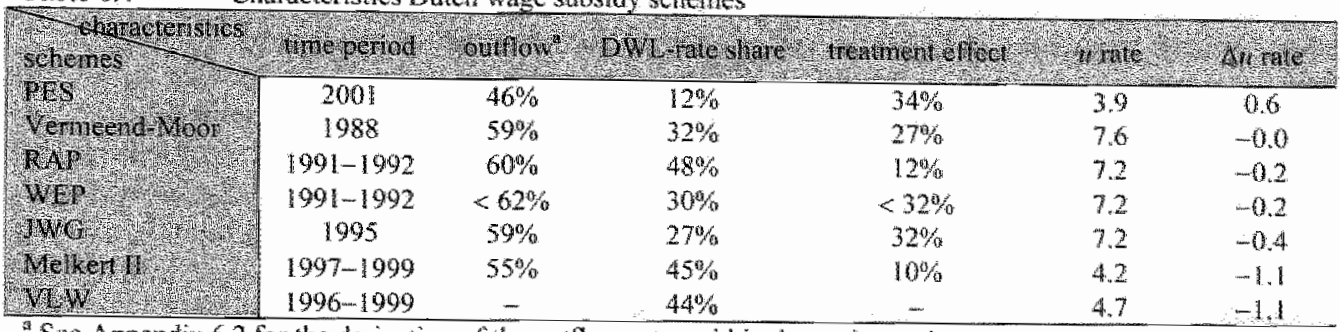

"See Appendix 6.2 for the devivation of the outfow rates whin the whrous schemes. Solnce: Welters (1998), Van Polanen Petel ef at. (1999)

By subtracting deadweight loss from the outfow rate we find the treatment effect of the schemes. This effect varies substantially among the various programmes. The VermeendMoor Act, the JWG and potentially the WEP are more effective programmes than the RAP and the Melkert II scheme. The PES yields comparable or slightly better results than the best performing publicly initiated wage subsidy scheme introduced in the last two decades: the JWG. If we abstract from the JWG - which aims at youngsters and is therefore not perfectly comparable to the other schemes - the PES outperforms publicly initiated schemes.

To illustrate the robustness of our indicator for the effectiveness of a wage subsidy schene, we derive the treatment effect of the 'PES 1997 cohort' using the 'PES 1997 cohort" ouffow rate (79\%) and deadweight loss shares of the VLW (44\%) and the Melkert II scheme $(45 \%)$. Both schemes were operative in 1997, which means we control for labour market conditions. Assuming participant characteristics of the Melkert If scheme and the VLW scheme to be comparable to the PES, we can easily calculate the PES 1997 treatment effect, which equals 34-35\%. Given the lew design changes that have been made in this four-year time spell, the similarity between the 1997 and the 2001 treatment effect of the PES does not come as a surprise. Hence, the better performance of the PES scheme seems a robust result.

We should take into consideration that the short-term outflow rate is not the outhow rate Philips uses to determine the success of its employment scheme. Philips focuses on the longterm unemployment rate, as it expects training effects to be long-term effects. That is, training ensures that employees hold their jobs even in poor economic condirions. The few observations Philips gathered so far seem to support that view: the long-term outflow rate is without exception - above the short-term outflow rate indicating structural attachment to the labour matket of the majority of participants.

Studies of long-term effects on Dutch public wage subsidy schemes are rare. Only for the Melkert II scheme such an analysis has been done. Jansen (2001) finds similar results. Outflow rates increase according to the length of the spell between outhlow and measurement. Apparently, participants need time to settle on the labour market. Nonetheless, it seems reasonable to assume that training not only raises the immediate job find probability but also job safety. The employment development of the 2001 cohort underlines this. Labour markat 
conditions worsened throughout 2003 , but the outlow rate of the 2001 cohort went up from $46 \%$ to $63 \%$.

Information on training activitues in public wage subsidy schenes is scarce. We found that $27 \%$ of participants of the Vermeend-Moor Act, $29 \%$ of RAP participants and $38 \%$ of WEP participants followed training during their subsidized stay. These shares are considerably lower as compared to the 2001 PES cohort, $76 \%$ of whom followed training. Therefore it seems likely that the gap in the treatment effect in favour of the PES immediately after outflow increases overtime.

\subsection{Keys to success of PES and lessons for public schemes}

The above analysis demonstrates that employment schemes can function properly without major subsidies. This conclusion justifies an examination of the keys to success of the PES. We mention three main factors that were conspicuous during observation of the scheme and discussions with insiders: efficiency, work floor support and demand side orientation.

Efficiency has lain at the route of the PES since it started in 1983 . Philips is a profit maximizing organization and the PES is an expensive scheme. To continue the scheme benefits arising from it must balance the costs. We mentioned four sources of benefits in Section 6.3. Efficient execution of the PES improves the success rate, which makes the scheme more powerful in negotiations. Efficiency increases the feasibility of the scheme to serve as a recruitment channel. Furthermore efficiency steps up productivity within the scheme and finally, efficiency enhances the accuracy of the teaching methods developed within the PES.

Work floor support encourages the success rates of the scheme for two reasons. On the one hand, the relevance of the work (i.e. replacing absent employees) done by participants leads to support on the work floor for the scheme, which is crucial for its success. The success rate of the PES depends on the mastering of skills (both in terms of work experience and educational level) that takes place during the year the participant stays. This mastering of skills depends on the interaction between the participant and Philips employees. If employees are not motivated to assist participants, mastering of skills will hamper. To receive this support employees must have the impression that the work done by participants is important, but is at the same time no threat to the position of regular employees, i.e. participants should not be competitors for regular employees. Though there is a trade-off between the relevance of the work done and the competitive threat of participants for regular employees, Philips has been able - by deploying participants to replace absent employees - to circumvent that trade-off.

On the other hand, participants get the impression that their contribution matters to the firm if there is work floor support, which is constructive in rebuilding self-esteem - see for example Layard et al. (1991). Bearing in mind that low levels of self-esteem are often a major reason why long-term unemployed are not successful on the labour market, this effect should not be underestimated.

From the start of the PES the objective has been clear: increase the employment probability of participants. Philips recognizes that this objective can only be met if participants fulfil the requirements of recruiting firms. That is, Philips adheres to a demand side approach to solve the problems unemployed face on the labour market. The demand side approach shows up in several decisions Philips makes.

Philips allocates the supply of PES jobs to divisions that have promising employment prospects, thereby, explicitly taking the demand side of the labour market into consideration. 
Grubb (1993) points out the importance of taking employment prospects into account. Moreover, the focus on training demonstrates the attention Philips pays to raising the employability of participants, as it is widely recognized that traning is one of the most effective measures to increase the job find tate of unemployed - see Dolton (1993). The VaPro A degree is a general traning. Acquiring it, not only raises employability in the sector in which the work experience was ganed during a PES job but also outside that sector. Finally, acquiring a training degree is also a positive signal to employers as to the quality of participants.

Consequently, central in any decision Philips makes with regard to the design of the PES is its effect on the job-find rate and subsequently the outllow rate of the participants. In public wage subsidy schemes this focus on maximizing the outflow rate is less evident. Employers participating in such schemes maximize the difference between the revenues of employing a participant (production and subsidy) and wage costs. Since the subsidy is only temporary, investment in training need not be in the interest of the firm. Moreover, the most profit generating input of the participant to the firm need not be the input, that raises the participant's job-find probability most. As a result the firm's interests need not run parallel to the participant's interests. ${ }^{118}$

\subsection{Potential pitfalls of the PES}

Crucial in maintaining the treatment effect of the PES on a high level is the interaction between participants and regular employees, which is vital in terms of mastering skills. There are three main threats to work floor support.

First, the allocation of PES jobs among Philips establishments. "The HRM department of Philips Eindhoven decides on the establishments and on how many PES jobs they have to open. If Philips Eindhoven does not provide sufficient arguments for its allocation decision or sufficient means to support the scheme at the establishments, establishments experience the decision of Philips Eindhoven to be a dictate. Subsequently, the management of the establislmment will neither be enthusiastic nor be committed to promote the PES on the work floor. A lack of commitment on the part of the management is detrimental to the commitment on the work floor to support the scheme. This will harm the mastering of skills of participants and will eventually show up in the effectiveness of the scheme.

Second, the quality and motivation of participants. Although lower quality of candidates is controlled for in the treatment effect, participants need a sufficiently high educational level to be able to do the VaPro training. If Philips - potentially due to tight labour market conditions - has to make concessions as to the quality level of candidates in order to meet its quota of PES jobs, the support on the work floor vanishes. ${ }^{20}$ "That is, if" employees observe that participants lack basic qualities (e.g. too low educational levels but also insufficient knowledge of the Dutch language) needed to enable mastering of skills; they

An To solve this conflict of interest, the government may decide to differenciate the atwatded wage subsidy. Part of the subsidy should be a hamp-sum payment to the firm for biving a long-tem unemployed; an other part should be made contingent on the direction of outflow of the participant. That is, if (s)he finds a job, the second. part of the subsidy will be awarded, otherwise no bonus subsidy will be awaded. This will provide incentives to the firm, which ensure that it acts in the interest of the subsidized participant. This will improwe the performance of such schemes. However, such differentiation would complicate the design structure of a wage subsidy scheme which might provoke subsidy abuse.

H' Lower quality of participants reduces the oufflow rate, but at the same time if reduces deadwefigh lloss. Hence in terms of the treatment effect, quality is mo isste.

${ }_{120}$ Beal" in mind that the quota of PES jobs to be opened in a yedr is determined in central wage batgains, which means that Philips has to meet this quota regardless the wailability of qualified candidates. 
are not motivated to support participants as any exertion made is wasted. It is obvious that the same holds for participants who are not motiwated to do the PES job. Hence, Philips should not reduce its hiring standard in an attempt to meet a quota, as doing so, has detrimental effects on the treatment effect. Even more so as stigma effects might arise. Burtless (1985) showed that employers interpret participation in a scheme which is known for its policy to recruit exclusively from disadvantaged groups as a signal not to recruit from such participants.

Third, the trade-off between the relevance of the work done and the competitive threat to participants for regular employees should be carefully ballanced. If the job content is not challenging, participants lose motivation, which has negative repercussions on employee support on the work floor. On the other hand, in poor economic conditions when Philips has to eut back employment; work floot support for the PES will be low, as participants are considered to be cheap rivals. In such circumstances the scheme will not be productive. Consequently Philips should ensure that it is in the interest of both participants and employees that the PES job is of high quality.

Whereas Philips exploits the effect of mastering of skills owing to the success of the PES, it does not exploit the potential success raising effect of an outflow policy. Two measures are worth mentioning.

Philips should unambiguously inform participants - preferably in an early stage whether there is a future in store for them with Philips at the end of the PES contract. Edin and Holmlund (1991) show that participants reduce their search intensity for a regular job during their stay in a wage subsidy scheme. Hence, when job prospects with Philips remain unclear, participants will reduce job search effort even further, because staying with Philips remains an option. This lower search effort will harm the outflow rate and hence the treatment effect of the scheme.

Next to clarity about job prospects, Philips could also develop an outflow policy. Philips establishments must have an extensive network of supply companies, the influence of which could be exerted to support participants who will not obtain a job with Philips at the end of the PES contract and who have to look for external employment. Lehmann (1993) shows the positive effects of job coninselling on the job find rate of unemployment.

An inquiry into the reasons lor outflow to unemployment should be a second pillar under such an outflow policy. Feedback from Philips Eindhoven to the respective establishments on determinants of success or failure would enhance the success of the progranme. Now - at least on the establishment level - it remains unclear what the main causes of failure are and subsequently which lessons should be drawn.

\subsection{Private employment schemes as a contribution to the public initiative}

The above analysis demonstrates that private employment schemes yield at least as good and probably better - results as publicly initiated wage subsidy schemes, without major subsidies. This finding justifies to explore for which part of the unemployed, private schemes are useful and whether such schemes can - in terms of volumes - deliver a significant contribution to helping unemployed to find employment.

To encourage other firms to follow the example set by Philips, incentives are needed. To do so, the government should - wherever possible - make the potential revenues of operating a private employment scheme more explicit. One option is to allow firms - who are expected to obey guidelines of "corporate social responsibility" - to set up a private employment scheme which enables them to meet the various standards of corporate social responsibility in one 
go. ${ }^{21}$ This might induce firms to start a private employment scheme, as the revenues of such a scheme become clearer.

The revenues of private employment scheme as outlined in Section 6.3 fall more to large than to small firms. Large firms typically need to meet criteria of corporate social responsibility', whereas small firms are exempted. Besides, gaining experience in developing training methods from a private employment scheme is not as valuable to small firms - which hardly use their own training methods - as it is to large firms. Economies of scale in counselling participants also suggest that large firms are more likely to run a private employment scheme successfully.

We assume the type of unemployed Philips recruits to be the type of unemployed that maximizes Philips' revenues from the PES. If we want to extrapolate the success of the PES to other firms, this is the type of umemployed we should concentrate on. To obtain an estinate of the size of the relevant part of the unemployment pool, we classify PES participants into categories that employment offices use to categorize unemployed. Dutch employment offices classify unemployed into four categories, so called phases - see Kooreman (1999). Phase 1 contains unemployed, who are supposed to find employment without help from the employment office. Phase 2 consists of unemployed who need assistance (training, schooling courses) for one year at the most; phase 3 contains unemployed who need assistance for more than a year and finally phase 4 consists of unemployed, who - on closer inspection - are so remote from the labour market that one cannot expect them to return to the labour market in the short or medium-term future. Table 6.5 contains characteristics of unemployed, classified according to phase. We also include characteristics of the PES 2001 cohort and observe that PES participants bear a close resemblance to unemployed out of phases 2 and 3 . Since a PES job lasts for one year, phase 2 seems to be the most natural classification of a PES participant, which contains around 90,000 unemployed in February 2004.

Table $65 \quad$ Characteristics Dutch unemployment pool

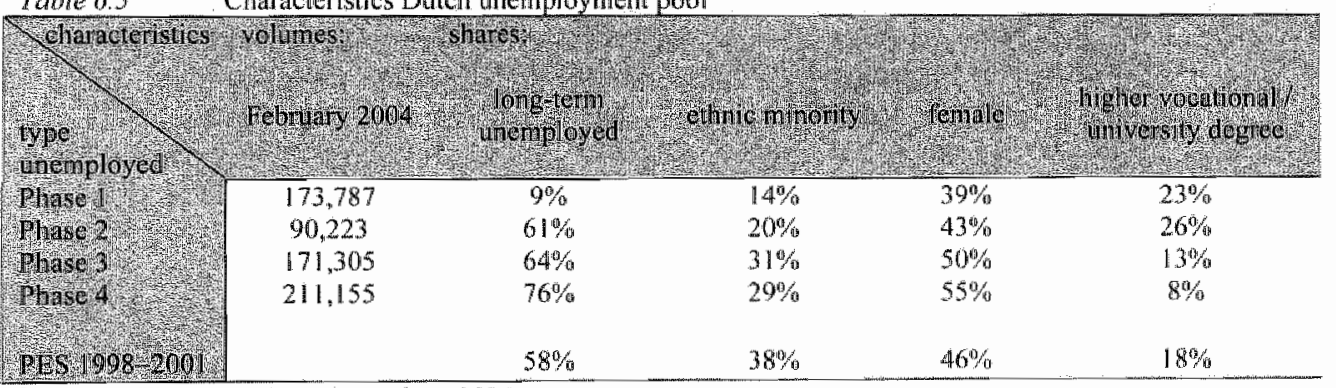

"Sourea: CWI Arbeidsmarktmonitor, 2004.

Some back-of-the-envelope calculations demonstrate the impact of scaling-up the PES to a nation wide level. We assume the revenues of a private employment scheme - as outlined in Section 6.3 - to fall more to large than to small firms and hence we concentrate on large firms. Let us say, $5 \%$ of the Dutch firms having more than 100 employees (in total 7,700 ) would create a private employment scheme in which ten temporary jobs are available for 'phase $2^{\prime}$ unemployed. ${ }^{122}$ This would generate nearly 4,000 temporary jobs on at yearly basis.

121 A typical example of 'corporate social responsibility" is the agreonen "large firms' which urges large firme to create employment for ethnic minorities. Smmitar agreements exist for young unemployed and women row entering the labour market.

122 On average Philips has allowed 500 participants into its PES per year since 1983. 
This would be a small but nonetheless significant contribution to the public efforts to fight long-term unemployment.

\subsection{Conclusions}

We have demonstrated that private employment schemes - like the Philips Employment Scheme - can be a superior and subsidy saving alternative to wage subsidy schemes in an attempt to reintegrate part of the long-term unemployed. To come to this conclusion we had to show that the PES outperforms public wage subsidy schemes and can be run privately.

To measure performance we defined the treatment effect as the difference between the outflow rate and the deadweight loss share. This measure is - unlike the outflow rate as a measure of success - robust to labour market and participant characteristics and can therefore be used to compare the PES to public wage subsidy schemes and throughout time. Immediately after outflow, the $\mathrm{PES}$ appears to yield slightly better results than the best performing publicly initiated scheme. Given the better training efforts within the PES we expect the performance gap between the Philips scheme and public initiatives to increase in the long rum. Three factors seem instrumental in the superior performance of the PES: efficiency, work floor support and the demand side approach.

The PES hardly enjoys any government subsidy, but nonetheless Philips has operated the PES for twenty years, which suggests Philips accrues revenues from it. Philips uses the PES in negotiations with unions and the government, it uses the PES as a recruitment channel, it uses it to develop training methods for its regular personnel and participants are productive. The revenues Philips accrues from these four sources apparently suffice to run the scheme privately and suggest the format can be applied on a wider scale, though typically among large firms. Scaling up private employment schemes would be a welcome contribution to public efforts to fight long-term unemployment. 


\section{Appendix 6.1}

Appendix 6.1 motivates the calculation of the deadweight loss share in the Philips Employment Scheme. Table A6.1 presents the distribution of PES participants over Philips establishments in the Netherlands. To control for regional differences concerning labour market conditions - which might show up in deadweight loss estimates - we have interviewed employment agencies responsible for recruitment of PES participants in regions that employed the largest shares of participants, namely KLIQ Eindhoven (responsible for recruitment at several Philips establishments in Eindhoven), CWl Nijmegen (responsible for recruitment at Philips Semiconductors Nijmegen), PCN Eindhoven (responsible for recruitment at Philips Lighting Roosendaal and Vitrite Works Middelburg) and Brug naar Werk Groningen (responsible for recruitment at Philips Domestic Appliance and Personal Care in Drachten and Philips Semiconductors Stadskanaal).

Together these four employment agencies recruit nearly $70 \%$ of all PES-participants. We have interviewed representatives of these employment agencies and asked them to estimate the share of unemployed they guided to the PES in 2001, and for whom they had expected to find a job in 2002 in the absence of participation in the PES.

Table A6.1 Deadweight loss in the Philips Employment Scheme

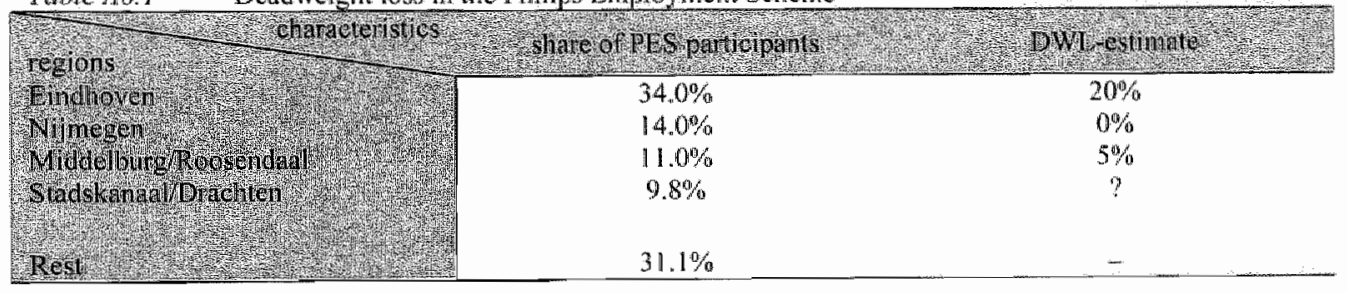

Unfortunately, Brug nalar Werk Gromingen was not able to give an estimate of deadweight loss, which reduced our sample to the three most important employment agencies (responsible for the recruitment of $60 \%$ of PES participants). The estimates are in Table A6.1. The individual deadweight loss estimates range from no deadweight loss among participants according to CWI Nijmegen to one in five participants who would have found a job in 2002 in the absence of the PES job according to KLIQ Eindhoven. Since the semiconductor industry is a substantial contributor to low wage employment in Nijmegen, potential PES participants are, when looking for employment, to a large extent dependent on this sector and on its derivative sectors. Consequently the current poor economic conditions in this sector worsen job find probabilities of long-term unemployed in the region, which shows up in the low deadweight loss share we obtained for Nijmegen.

Based on the share of mediated PES participants per employment agency and the deadweight loss estimate per region, we are able to construct a weighted average deadweight loss share of $12 \%$, which is based on $60 \%$ of PES participants. Given the scarce information we have, we treat this figure with some caution. 


\section{Appendix 6.2}

Appendix 6.2 provides motivation for the choices we made in determining outlow rates of the various publicly initiated wage subsidy schemes. Some evaluation studies report outflow rates, some do not. In the latter case we needed to construct them ourselves given the avallable information. We discuss the five schemes separately. ${ }^{123}$

\section{Vermeend-Moor Act}

To obtain an indication of the outlow rate, we rely on De Koning and Van Nes (1989) who condicted an evaluation study two years after the introduction of the Vermeend-Moor Act. ${ }^{128}$ Participants can be divided into three categories conceming contract duration. A group containing $20 \%$ of the population holds a half-year contract the minimum required contract duration); another $30 \%$ hold a temporary contract but duration longer than 6 months. Finally half of all participants hold a fixed contract. The outflow rate of participants holding a fixed contract should be estimated at $100 \%$. However, as Table A6.2 shows, not all participants starting the subsidized job on a fixed contract stay at that job. A small part finds employment elsewhere but still $14 \%$ fall back to unemployment. As a result, the outflow rate of participants holding a fixed contract is not $100 \%$, but $86 \%$ instead.

Tiable A6.2 Contract duration Vermeend-Moor Act in 1988

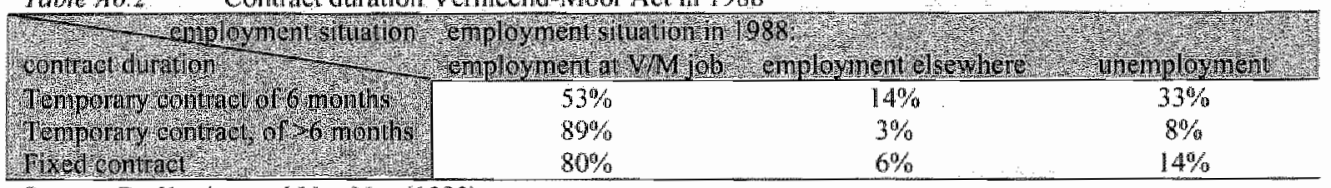

Sounce: De Koning and Van Nes (1989)

It is more complicated to estimate the outflow rate of the participants holding a temporary job, as termination of the contract when the subsidy expires remains an option. Nonetheless, the labour market situation of participants initially holding a six months contract gives an indication of the outflow rate. Bearing in mind that the evaluation was conducted more than a year after the introduction of the $\mathrm{Act}_{x}$ it seems reasonable to assume that a significant part of the six-month contracts had expired once the evaluation was conducted. Subsequently the first row of Table A6.2 gives an indication of the employment prospects of participants whose contract expired. It shows that roughly half of the participants still hold the Vermeend-Moor job, 14\% have found employment elsewhere and one third has fallen back to unemployment. Therefore the maximum outflow rate of participants holding a temporary contract should be estimated at $67 \%{ }^{125}$

Consequently, the maximum total outflow rate of the Vermeend-Moor Act should be estimated around $76 \%(0.5 \% 86 \%+0.5 * 67 \%)$. The minimum outflow rate is the share of participants that received a fixed-term contract at the start of the subsidy period and still hold that contract two years later, which is $43 \%$.

\footnotetext{
${ }^{122}$ No ovaluation siudy has been conducted of the VLW, hence we are not able to construct an outflow rate.

12 Since the Ad provides for a houn year subsidy, the evaluation study does not cover employeremployee retations that completed the subsidy scheme. The avalability of the subsidy at the time the evaluation took place complicates the detarmination of the outhow rate of the Act. Consequently the Vermeend-Moor outhow rate we deriwe shonld be treated catiously.

12.5 This is a maximum as employers who decide to extend the six-month contract are still entitled to subsidization, which obscures the determination of the outfow rate, as the outlow rate measures the share of participants that finds unsubsidized employment at the end of the subsidy period.
} 


\section{KRA-RAP}

Based on the scarce evidence De Koning et al. (1993) provide, we can at most compute an indication of the RAP outflow rate. Three out of five participants still hold their RAP job after two (of potentially four) years of subsidization. The remaining $40 \%$ are equally divided over employment elsewhere and unemployment. Subsequently, nearly $80 \%$ of all participants are still employed after two years of subsidization. However, this number cannot be interpreted as the outflow rate, since subsidization continued for at least two years. Hence it is a maximum outflow rate.

We also have an indication of the minimum outflow rate, since we have information on RAP-dropouts. Dropouts are participants in the RAP who have left the firm with which they held the RAP job before the subsidy had expired. From these dropouts $39 \%$ find employment; the remaining fall back to umemployment. We consider this statistic to be the minimum outflow rate of the RAP.

\section{KRA-WEP}

De Koning et al. (1993) conduct two studies that enable us to construct the outflow rates of the WEP for two consecutive years (1991 and 1992). Of the first cohorts of WEP leavers, $59 \%$ held a job within one year after leaving. This outflow rate increases to $65 \%$ for the second cohort one year later. We therefore set the WEP outflow rate at the average of both cohorts, which is $62 \%$.

Nonetheless, we consider $62 \%$ to be an overestimate of the outflow rate, since employers are entitled to a four-year RAP subsidy for the same employee at the expiration of the WEP subsidy. The availability of the RAP subsidy after a WEP subsidy improves the labour market position of unemployed, which also positively affects the outflow rate of the WEP. It appears that this construction is applied for one in five employees, which implies that the $62 \%$ outflow rate should be regarded as a maximum.

\section{JWG}

Olieman et al. (1996) report an outflow rate of $59 \%$ of youngsters leaving the JWG. Since exparticipants (or employers who hire them) of the JWG are no longer entitled to any subsidy, the outflow rate is unbiased. The aim of the JWG is to prevent participants from falling back into unemployment, which means that both employment and training are desired outcomes at the end of the JWG contract. Besides the $59 \%$ of participants that flow out to employment there is an additional $15 \%$ of participants that return to school.

\section{Melkert II scheme}

Based on the evaluation studies conducted by Van Diepen and Jansen (1999) and Jansen (2001) we are able to show the evolution in the outflow rate of the Melkert II scheme. One month after the subsidization had been stopped $55 \%$ of participants found regular employment. Five months later the outflow rate had increased to $59 \%$; one and a half year after leaving the subsidized job $70 \%$ of participants hold a job. 


\section{Chapter VII: Conclusions}

\subsection{Recapitulating}

In this dissertation we have studied the origins of deadweight loss in employment subsidy schemes. The disagreement between micro and macroeconometric studies of the added value of such schemes in guiding long-term unemployed back to the labour market lias been the reason for this research. Microeconometric studies find positive treatment effects for participating long-term unemployed. That is, their re-employment probability improves as compared to similar non-participating long-term unemployed. Consequently, micro studies are positive about employment subsidy schemes. Macroeconometric studies - unlike micro studies - take the overall employment effect of employment subsidy schemes into account and find that employment subsidy schemes hardly lead to additional employment. As a consequence, such studies are more conservative with respect to the role employment subsidy schemes should play in reducing long-term unemployment.

Deadweight loss - the share of long-term unemployed the firm would have hired in the absence of the subsidy - is one of the main and most harmful impediments to extending employment as a consequence of introducing the subsidy. In case of deadweight loss, the microeconomic effect (i.e. productivity gain) cannot be attributed to the subsidy, as the employee in question would also have found the job without that subsidy. The same holds for the macro effect (i.e. extending the effective labour supply). In case of deadweight loss, firms would have considered subsidized employees even without the subsidy, which implies they are already part of the effective labour supply.

\section{Firm's hiring behaviour}

To reduce the share of deadweight loss and consequently to improve the effectiveness of employment subsidy schemes, we studied the hiring behaviour of firms to unravel under which conditions firms recruit from long-term unemployed. We developed a model in which firms use unemployment duration as a screening device. That is, firms split up the unemployment pool into two parts, where the screening device standard is the threshold value. Only unemployed who have been unemployed for a shorter period than the screening device standard are considered for a vacancy. If the firm is subsidized for any of these unemployed, deadweight loss occurs. Because the start value of subsidy entitlement is usually a fixed minimum length of an unemployment spell, the inctdence of deadweight loss depends on the firm's choice of the screening device standard.

In Chapters II, IV, and V we presented the employer search model in which we linked hiring costs to the screening device standard. We found that assessment costs are linked negatively to the screening device standard. Extending the screening device standard reduces the expected productivity of an applicant, which raises the failure rate of an assessment. Costs of foregone productivity are linked positively to the screening device standard. Extending the screening device standard implies that more unemployed are allowed to enter the hiring procedure which speeds up the recruitment procedure and hence reduces the length of the hiring procedure. Moreover we found that schooling costs are linked negatively to the screening device standard. Low schooling costs enable the firm to make up for productivity deficiencies at low costs. This allows the firm to recruit from long-term unemployed (i.e. extend its screening device standard) who may have such productivity deficiencies. Finally, we found that labour market conditions influence the firm's screening device standard choice. In tight conditions more time evolves between applicants, which lengthens the hiring period. This incites firms to set a less strict screening device standard in tight conditions. 
Chapter III considered the likelihood that once the government grants a subsidy to firms for unemployed these firms would also have considered without a subsidy, they indeed capitalize on that unnecessary subsidy. We distinguish between wage subsidy schemes and training subsidy schemes. Within the scope of the former the firm is free to spend the subsidy; in the latter the firm has to spend the subsidy on training. We showed that if the potential to cause deadweight loss is present in a uniform wage subsidy scheme, firms do cause deadweight loss, either intentionally or accidentally. In the setting of a non-uniform wage subsidy scheme, firms cause deadweight loss accidentaly if the government's misperception on the firm"s sereening device standard is large. The non-uniformity structure of a wage subsidy scheme enables the government to steer the firm's applicant selection choice. This allows the government to avert the deadweight loss risk. A training subsidy is less vulnerable to the incidence of deadweight loss than a wage subsidy, as a second condition has to be met. The government must not only misjudge the firm's screening device standard, it must also misjudge the firm's productivity requirements.

\section{The empirical evidence}

To test for our predictions arising from Chapters. II and III we analysed three data sets of two countries in Chapters IV and $V$. The first data set contained information on a Dutch wage subsidy scheme: the VLW. The second contained information on a British wage subsidy scheme: the NDLTU and a third containing information on a British training subsidy scheme: the NDYP. Apart from firm, job and labour market characteristics, all three data sets also contain an estimate by the employer as to the likelihood that he would have hired the subsidized employee even without the subsidy. We used the empirical employer search" literature to link firm characteristics to the various hiring cost aspects, as discussed in Chapter 11. The resulting information enabled us to link hiring costs - through firm characteristics - to deadweight loss incidence.

The analyses in Chapter IV of the Dutch and British data on wage subsidy schemes support our hypotheses partly. Assessment costs are linked negatively to deadweight loss incidence. High assessment costs indeed deter firms from recruiting from long-term unemployed. The opposite holds for high costs of foregone productivity. Costs of foregone productivity are linked positively to the incidence of deadweight. Firms eager to fill a vacancy are not in a position to disregard long-term unemployed. In tight conditions, we expected firms to extend the screening device standard, as in such conditions it is a more effective instrument to raise the arrival rate of applicants than in easy conditions. This implies that lirms are more willing to consider long-term unemployed for a vacancy, if their cost structure requires a quick filling of the vacancy. However, the empirical analysis produced the opposite cffect. Firms are significantly more likely to extent the screening device standard (and subsequently cause deadweight loss) in easy conditions. A possible explanation for this finding is that the most able unemployed profit more than proportionally from improving labour market conditions, $i$.e they have left the unemployment pool in tight conditions. This implies that in tight conditions the unemployment pool consists predominantly of low ability unemployed, which raises the failure rate of assessment and therefore erodes the effectiveness to raise the arrival rate of applicants in tight conditions. Consequently, firms refrain from extending the screening device standard precisely in tight conditions.

The analysis in Chapter $V$ of the British data set on the training subsidy reveals that a training subsidy produces a pattern of deadweight loss that differs from a wage subsidy. That is, in a training subsidy scheme assessment costs play a less important role in the firm"s choice of the sereening device standard. Since firms can train applicants, the firm can lower its productivity 
requirements, which reduces the failure rate of an assessment and hence the average number of assessments needed to find a qualified candidate. Cost of foregone productivity play a more important role in a training subsidy scheme than in a wage subsidy scheme. Extending the screening device standard increases the arrival rate of applicants, which speeds up the hiring process. However, extending the screening device standard also raises the failure rate of an assessment, which lengthens the hiring process. If a subsidy is available, the failure rate can be reduced by providing training, which makes an extension of the screening device to speed up the hiring procedure and hence to economize on costs of foregone productivity more effectively. The empirical analysis supports this distinct deadweight loss pattern. Moreover, training costs appear to be linked negatively to deadweight loss incidence.

\section{The private initiative}

Our analysis indicates that firms are in a better position to judge the qualities (in terms of reemployment probabilities) of long-term unemployed than the government. This raises the question whether a private employment scheme is an adequate alternative to wage / training subsidy schemes. In Chapter VI we examined the initiative Philips took. The Philips Employment Scheme (PES) aims at re-employing long-term unemployed, which makes it comparable to many Dutch wage subsidy schemes. A comparison - which controls for differences in labour market conditions using deadweight loss - shows that the PES produces better results than the public initiatives. This finding produces strong support for an integration of the private initiative into the government's mission to reduce long-term unemployment. The more so, as the PES provides Philips with revenues, which enable the firm to run the PES without major subsidization. Philips uses the PES in negotiations with unions and the government, it uses the PES as a recruitment channel, to develop training methods for its regular personnel and participants are productive. Nonetheless, the extent to which the private initiative might assist in reducing long-term unemployment is restricted both in terms of number and quality of long-term unemployed. The revenues fall predominantly to large firms, which restricts the potential number of participating firms. Moreover, the private initiative seems to be restricted to the most promising long-tern unemployed.

\subsection{Recommendations}

We have looked for patterns in deadweight loss incidence in wage and training subsidy schemes. We found that firms facing low assessment costs, high costs of foregone productivity, low training costs and firms operating in slack conditions are more likely to recruit from long-term unemployed in an unsubsidized labour market. Such firms cause deadweight loss once a subsidy is made available to recruitment of long-term unemployed.

A government that aims at improving the effectiveness of employment subsidy schemes should differentiate the start value of subsidy entitlement to the type of firm. That is, firms whose hiring cost structure suggests they would hire from long-term unemployed may obtain an employment subsidy for unemployed facing a longer period of unemployment than firms whose hiring cost structure suggests they would not hire from long-tem unemployed without a subsidy. We have seen that frm size is linked negatively to assessment costs, as large firms enjoy economies of scale in assessments. A government trying to reduce the share of deadweight loss in a wage subsidy scheme should, for example, make the start value of subsidy entitlement dependent on the size of the firm. A government trying to reduce the share of deadweight loss in a training subsidy scheme should focus on firms having high costs of foregone productivity of a vacancy. We have seen that the workload is related positively to 
costs of foregone productivity. Hence, linking the start value of subsidy entitlement to the workload of the job will reduce deadweight loss in a training subsidy.

Of course there are other firm characteristics that indicate hiring costs structures and that subsequently could be used to differentiate the start value of subsidy entitlement. However, implementing the two above-mentioned characteristics hardly leads to complicating the design of a wage / training subsidy scheme, as tax authorities - who specifically execute such schemes - have this information readily awailable.

If governments act upon our recommendations and indeed succeed in reducing deadweight loss, the desired micro en macro economic effects will indeed be more substantial. The more significant macro effects are, the more significant its wage moderating effects are. Up to now, the latter effect is not found in empirical studies of employment subsidy schemes. This wage moderating effect creates additional (unsubsidized) employment, which is needed to employ subsidized long-term unemployed at the expiration of the subsidy. The more substantial micro effects - in terms of training - certify that otherwise disregarded subsidized employees receive productivity enhancing training. This ensures that long-term unemployed not only escape from unemployment, but also have the educational attaimments which will enable them to escape from the low wage employment segment in the future.

Finally, to enhance the productivity effect, the government may also decide to make the subsidy partially lump-sum and partially contingent on the direction the participant takes when flowing out. That is, if the participant finds a job, the second part of the subsidy will be awarded; otherwise no bonus subsidy will be awarded. This will provide incentives to the firm, which ensure that it acts in the interest of the subsidized participant, i.e. provide training. The Philips Employment Scheme shows that such incentives produce better structural job find probabilities for long-term unemployed.

\subsection{Limitations}

The analysis we present in this dissertation is of a high partial nature. This type of analysis is suited when discussing ways to limit deadweight loss in wage and/or training subsidy schemes to raise the efficiency of such schemes. Nonetheless, this should not be interpreted as support to reduce deadweight loss shares in employment subsidy schemes at any price.

In our partial analysis we - for example - do not discuss the firm's spending of the obtained subsidy. We know that firms that do not cause deadweight loss, spend the subsidy on additional recruitment costs (in case of a wage subsidy) or on training (in case of a training subsidy), but what do firms, that cause deadweight loss, spend the subsidy on? In case of the training subsidy, firms spend the subsidy on additionai training of Iong-term unemployed, which might enable the formerly long-term unemployed to advance his career more quickly than a long-term unemployed who got hired by a firm that did not cause deadweight loss. The same might hold good for a wage subsidy. Again the firm that causes deadweight loss might spend the unnecessary subsidy on training the long-term unemployed. These effects require a long-term analysis, which is beyond the scope of this dissertation, but relevant to obtain a complete overview of the effects of deadweight loss on the labour market prospects of participating long-term unemployed. 


\section{References}

Albrecht, J., P. Edirn, M. Sundström and S. Vroman (1998), Career Interruptions and Subsequent Earnings: A Reexamination Using Swedish Data, Jommal of Human Resontees, Vol. $34(2)$, pp. 294-311.

Amisano, G., M. Serati (2003), What Goes Up Sometimes Stays Up: Shocks and Institutions As Determinants of Unemployment Persistence, Scomish Jownal of Polincal Economy, Vol. 50 (4), pp. 440-70.

Angrist, J., G. Imbens and D. Rubin (1996), Identification of Casual Effects using Instrumental Variables, Journal of American Sratistical Association, Vol. 91 (434), pp. 444455.

Arthur, W., W. Bennett, P. Stanush and T. McNelly (1998), Factors That Influence Skill Decay and Retention: A Quantitative Review and Analysis, Human Performance, Vol. $11(1)$, pp. 57-101.

Balmaceda, M., J. Dolado and D. Lopez Salido (2000), The dynamic effects of shocks to labour markets: evidence from OECD countries, Oxford Economic Papers, Vol. 52 (1), pp. 3-23.

Barnow, B., G. Cain and A. Goldberger (1980), Issues in the Analysis of Selectivity Bias, in: E. Stromsdorfer and G. Farkas, Evaluation shudies review ammal, Vol. 5, Beverly Hills, CA and London, pp. $43-59$.

Barron, J., M. Berger and D. Black (1997), Employer Search, Training, and Vacancy Duration, Economic Inquiry, Vol. 35 (1), pp. 167-192.

Batron, J., M. Berger and D. Black (1999), Do Workers Pay for On-the-Job Training?, The Journal of Human Resowres, Vol. 34 (2), pp. 235-252.

Barron, J. and J. Bishop (1985), Extensive Search, Intensive Search, and Hiring Costs: New Evidence on Employer Hiring Activity, Economic Inquiry, Vol. 23 (3), pp. 363-382.

Barron, J., J. Bishop and W. Dunkelberg (1985), Employer Size: The Interviewing and Hiring of New Employees, The Review of Economics and Statistics, Vol. 67 (1), pp. 43-52.

Barron, J., D. Black and M. Loewenstein (1987), Employer Size: The Implications for Search, Training, Capital Investment, Starting Wages, and Wage Growth, Journal of Labor Economics, Vol. 5 (1), pp. 76-89.

Barron, J. and M. Mellow (1982), Labor contract formation, search requirements, and the use of a public employment service, Economic Inquiry, Vol. 20 (3), pp. 381-387.

Bean, C. (1994), European Unemployment: A Survey, Jownal of Economic Literature, Vol. $32(2)$, pp. 573-619.

Bean, C., R. Layard and S. Nickell (1986), The rise in unemployment: a multi-country study, Economica, Vol. 53 (2), pp s1-s22.

Blanchard, O. and P. Diamond (1994), Ranking, Unemployment Duration, and Wages, Review of Economic Studies, Vol. 61 (3), pp. 417-434.

Blanchard, O. and $\mathbb{L}$. Summers (1987), Hysteresis and the European Unemployment Problem, NBER Working Paper No. 1950.

Bloom, H., L. Orr, G. Cave, S. Bell, F. Doolittle, W. Lin (1994), The National ITPA

Study: Overview of Impacts, Benefits and Costs of Title $1 \%, 4$, Bethesda Maryland.

Budd, A., P. Levine and P. Smith (1988), Unemployment, Vacancies and the LongTerm Unemployed, The Economic Joumal, Vol. 98 (393), pp. 1071-1091.

Burda, M. and C. Wyplosz (1994), Gross worker flows in Europe, European Economic Review, Vol. 38 (6), pp. $1287-1315$.

Burdett, $K$ and E. Cunningham (1998), Toward a Theory of Vacancies, Joumd of Labor Economics, Vol. 16 (3), pp. 445-478. 
Burgess, S. (1993), A Model of Competition Between Unemployed and Employed Job Searchers: An Application to the Unemployment Outflow Rate in Britain. The Economic Jounal, Vol. 103 (420), pp. $1190-1204$.

Burtless, G. (1985), Are targeted wage subsidies harmful? Evidence from a voucher experiment, Industrial and Labor Relations Review, Voll. 39 (1), pp. 105-114.

Calmfors, L. (1993), Lessons from the macroeconomic experience of Sweden, European Youmal of Political Economy, Vol. 9 (1), pp. $25-72$.

Calmfors, L. (1994), Active Labour Market Policy and Unemployment-A Framework for the Analysis of Cructal Design Features, OECD Economic Studies, no. 22, OECD, Paris.

Calmfors, L. and A. Forslund (1991), Real-wage adjustment and labour market policies: the Swedish experience, Economic Joumal, Vol. 101 (408), pp. $1130-1148$.

Calmfors, L., A. Forslund and M. Hemström (2001), Does active labour market policy work? Lessons from the Swedish Experiences. Swedish Economic Policy Review, Vol. 85 (2), pp. $6 !-124$.

Calmfors, L. and H. Lang (1995), Macroeconomic effects of active labour market programmes in a union wage-setting model, Economic Journal, vol. 105 (430), pp. 601-619.

Calmfors, L. and R. Nymoen (1990), Real wage adjustment and employment policies in the Nordic countries, Economic Policy, Vol. 5 (11), pp. 397-448.

Crafts, N. (1989), Long-term Unemployment and the Wage Equation in Britain, 19251939. Economica, Vol. 56(222), pp. 247-254.

Dar, A. and Z. Tzannatos (1999), Active Labour Market Programmes: A Review of the Evidence from Evaluations, Working paper no. 20116, World Bank, Washington.

De Grip, A. and J. Van Loo (2002), The Economics of Skills Obsolescence: A Review, in: A. De Grip, J. Van Loo and K. Mayhew, The Economics of Skills Obsolescence, Research in Labor Economics, vol. 21, JAI Press, pp. 1-26.

De Koning, J. and P. Van Nes (1989), De Wet Vermeend-Moor: pladisingseffecten en witwoerpraktijk, Onderzoeksropport 1988, Nederlands Economisch Instituut, Rotterdam.

De Koning, J., J. Gravesteijn-Ligthelm, N. 't Hoen and A. Verkaik (1993), Met Subsidie aan het Werk, Eindrapport Evaluatie KRA, Centraal Bestuur voor de Arbeidsvoorziening.

Devine, T, and N. Kiefer (1991), Empirical Labour Economics, Oxford University Press, Oxford.

Dolton, P. (1993), The Economics of Youth Training, The Economic Joumal, Vol. $103(420)$, pp. $\llbracket 261-1278$.

Edin, P. and B. Holmlund (1991), Unemployment, vacancies and labour market programmes, in Sweden, in: F". Padoa-Schioppa (ed.), Mismatch and Labour Mobility, Cambridge University Press, Cambridge.

European Commission (1997), Labour Market Srudies.: Germany, Employment \& social affairs, Brussels.

Fay, R. (1996), Enhancing the Effectiveness of Active Labour Market Policies: Evidence from Programme Evaluations in OECD Countries, Labour Market and Social Policy Occasional Papers, No. 18, OECD, Paris.

Forslund, A. (1995), Unemployment - is Sweden still different?, Swedish Economic Policy Review, Vol. 1, pp. 15-58.

Forslund, A. and A. Krueger (1994), An Evaluation of the Swedish Acrive Labow Market Policy: New and Received Wisdom, NBER Working Paper No. 4802.

Friedlander, D., D. Greenberg and P. Robins (1997), Evaluating Government Training Programs for the Economically Disadvantaged, Journal of Economic Literature, Vol. 35 (4), pp. 1809.1855 . 
Gorter, C., W. Hassink and G. Russo (2002), The Structure of Hiring and Labour Market Tightness, Economics Letters, Vol. 80 (1), pp 99-103.

Gorter, C., P. Nijkamp and P. Rietveld (1996), Employers' Recruitment Behaviour and Vacancy Duration: an Empirical Analysis for the Dutch Labour Market, Applted Economics, Vol. 28 (11), pp. 1463-1474.

Greenwald, B. (1986), Adverse Selection in the Labour Market, Review of Economic Studies, Vol. 53 (3), pp. 325-347.

Grubb, D. (1993), Some indirect effects of active labour market policies in OEOD countries, mimeo, OECD, Paris.

Guasch J. and A. Weiss (1980), Wages as Sorting Mechanisms in Competitive Markets with Asymmetric Information: A Theory of Testing, Review of Economic Studies, Vol. $47(4)$, pp. $653-664$.

Guasch, J. and A. Weiss (1981), Self-Selection in the Labour Market, American Economic Review, Vol. 71 (3), pp. 275-284.

Gueron, J. (1990), Work and Welfare: Lessons on Employment Programs, Journal of Economic Perspectives, Vol. 4 (1), pp. 79-98.

Hale, J. (1998), Strategic Rewards: Keeping your best talent from walking out the door, Compensation \& Benefits Management, Vol. 14 (3), pp. 39-50.

Hales, J., D. Collins, C. Hasluck and S. Woodland (2000), New Deals for Young People and Long-Term Unemployed, Unemployment Service, Sheffield.

Ham, J. and S. Rea (1987), Unemployment Insurance and Male Unemployment Duration in Canada, Journal of Labor Economics, Vol. 5 (3), pp. 325-353.

Heckman, J. and G. Borjas (1980), Does Unemployment Cause Future Unemployment? Definitions, Questions and Answers from a Continuous Time Model of Heterogeneity and State Dependence, Economica, Vol. 47 (187), pp. 247-283.

Heckman, J. and J. Hotz (1996), Choosing among Alternative Nonexperimental Methods for Estimating the Impact of Social Programs: The Case of Manpower Training, In: C. Ashenfelter and R. LaLonde, The economics of training, Volame 2. Empirical evidence, pp. $458-470$.

Heckman, J., L. Lochner and C. Taber (1998), General-Equilibrium Treatment Effects: A Study of Tuition Policy (in Theoreticall and Empirical Developments in CostBenefit Analysis and Program Evaluation), American Economic Review, Vol. 88 (2), Papers and Proceedings of the Hundred and Tenth Annual Meeting of the American Economic Association, pp. 381-386.

Hermstein, R. and C. Murray (1994), The Bell Curve: Intelligence and class structure in American life, the Free Press, New York.

Holzer, H. (1990), Wages, Employer Costs, and Employee Perfortnance in the Irim, Industrial and Labour Review, Vol. 43 (3), pp S147-S164.

Holzer, H. (1996), What Employers Want: Job Prospects for Less-Educared Workers, Russell Sage Foundation, New York.

Holzer, H. and D. Neumark (1999), Are Affirmative Action Hires Less Qualified? Evidence form Employer-Employee Data on New Hires, Journal of Labor Econonics, Vol. 17 (3), pp. 534-569.

Holzer, H. and D. Neumark (2000), What Does Affumative Action Do?, Industrial and Labor Relations Review, Vol. 53 (2), pp. 240-271.

ILO (1986), Unemployment and labow market flexibility: The United Kingdom, Geneva.

Jansen, H. (2001), De arbeidswarktpositie van de ex-deehemers aan de EAU, meting situatie rot en mer 1999, Ministerie van Sociale Zaken en Werkgelegenheid, Den Hang. 
Jongen, E. E. Van Gameren and J. Grafaland (2003), Exploning the macroeconomic impact of subsidized employment, De Economist, Vol. 151 (1), pp. $81-118$.

Katz, L. (1994), Active Labour Market Policies to Expand Employment and Opportunity, in: Reducing unemployment: Current issues an policy options, Federal Reserve Bank of Kansas City, Kansas City, Missouri, pp. $239-290$.

Kerckhoffs, C., C. De Neubourg and F. Palm (1994), The Determinants of Unemployment and Jobsearch Duration in the Netherlands, De Economist, Vol. 142 (l), Pp. 21-42.

Kim, M. and S. Polachek (1994), Panel Estimates of Male-Female Earnings Functions, Journal of Human Resources, Vol. 29 (2), pp. 406-428.

Kooreman, A. (1999), De kansmeter: fasering werkzoekenden, Tijdschrift voor loopbaanadviseurs en -begeleiders, Vol. 4 (6), pp. 26-29.

Korpi, T. (1997), Is utility related to employment status? Employment, unemployment, labor market policies and subjective well-being among Swedish youth, Labour Economics, Vol. 4 (2), pp. $125-147$.

Lalonde, R. (1996), Evaluating the Econometric Evaluations of Training Programs with Experimental Data, In: C. Ashenfelter and R. LaLonde, The economics of training, Volwme 2. Empirical evidence, pp. 407-423.

Lancaster, T. (1990), The econometric analysis of transition data, Cambridge University Press, New York.

Lang, K. and D. Kropp (1986), Human Capital Versus Sorting: The Effects of Compulsory Attendance Laws, Quarterly Journal of Economics, Vol. 101 (3), pp 609-624.

Layard, R. and S. Nickell (1980), The Case for Subsidising Extra Jobs, The Economic Journal, Vol. $90(357)$, pp. 51-73.

Layard, R., S. Nickell and R. Jackman (1991), Unemployment, Macroeconomic Performance and the Labour Market, Oxford University Press, New York.

Layard, R. and G. Psacharopoulos (1974), The Screening Hypothesis and the Returns to Education, Joumal of Political Economy, Vol. 82 (5), pp 985-998. New York.

Lazear, E. (1998), Persomnel Economics for Managers, Jolnn Wiley and Sons, Inc.,

Lehmann, H. (1993), The effectiveness of the restart programme and the enterprise allowance scheme, Centre for Economic Performatce, Discussion Paper No. 139.

Leon-Ledesma, M. (2002), Unemployment Hysteresis in the US States and the EU: A Panel Approach, Builetin of Economic Research, Vol. 54 (2), pp. $95-103$.

Lindbeck, A. and D. Snower (1988), Cooperation, Harassment, and Involuntary Unemployment: An Insider-Outsider Approach, American Economic Review, Vol. 78 (1), pp $167-188$.

Lindbeck, A and D. Snower (1989), The Insider-Owsider Theory of Employment and Unemploymen, MTT Press, Cambridge Massachusetts.

Lindeboom, M., J. Van Ours and G. Renes (1994), Matching employers and workers: an empirical analysis on the effectiveness of search, Oxford Economic Papers, Vol. 46 (1), pp. $45-67$

Lockwood, B. (1991), Informational Externalities in the Labour Market and the Duration of Unemployment, Review of Economic Studies, Vol. 58 (4), pp. 733-753.

J.ynch, L. (1985), State Dependency in Youth Unemployment, Journal of Econometrics, Vol. 28 (1), pp. 71-84.

Lynch, L. (1989), The Youth Labour Market in the Eighties: Determinants of ReEmployment Probabilities for Young Men and Women, Review of Economics and Statistics, Vol. 71 (1), pp. 37-45. 
Martin, J. (1998), What works anong active labow market policies: evidence from OECD countries" experiences, Labour Market and Social Policy Occasional Papers, No. 35. OECD, Paris.

McCullagh, P. (1980), Regression Models for Ordinal Data, Jowrnal of the Royal Statistical Society, Vol. 42 (1), Series B, pp. 109-142.

Meager, N. and C. Evans (1998), The Evaluation of Actwe Labor Markel Measwes for the Long-Term Unemployed, Employment and Training papers No. 16, ILO, Geneva.

Mencken F. and I. Winfield (1998), In search for the right stuff: the advantages and disadvantages of informal recruitment practices in external labor markets, American Jownal of Economics and Sociology, Vol. 57 (2), pp. 135-153.

Meyer, B. (1995), Lessons from U.S. Unemployment Insurance Experiments, Jownal of Economic Lirerature, Vol. 33 (1), pp. 99-131.

Mincer, J. and H. Ofek (1982), Interrupted Work Careers: Depreciation and Restoration of Human Capital, Journal of Human Resonnces, Vol. 17 (1.), pp. 3-24.

Mincer, J. and S. Polachek (1978), Women's Earnings Reexamined, Jownal of Human Resources, Vol. 13 (1), pp. 118-134.

Ministry of Social Affairs and Employment (2001). Aan de slag, eindrappost van de werkgroep Toekomst van het arbeidsmarktbeleid, Den Haag.

Montgomery, J. (1991), Social Networks and Labor-Market Outcomes: Toward an Economic Analysis, American Economic Review, Vol. 81 (5), pp. 1408-1417.

Mortensen, D. (1982), The matching process as a non-cooperative bargaining game, In: J. McCall (eds.), The Economics of Information and Uncertainty, NBER University of Chicago Press, Chicago.

Neumann, S. and A. Weiss (1995), On the effects of schooling vintage on experienceearnings profiles: Theory and evidence, European Economic Review, Vol. 39 (5), pp. 943955.

Newell, A. and J, Symons (1987), Corporatism, laissez-faire and the rise in unemployment, European Economic Review, Vol. 31 (3), pp. 567-601.

OECD (1993), Employment Outlook, OECD, Paris.

OECD (1994), The OECD Jobs Study: Facts, Analysis, Strategies, OECD, Paris.

OECD (2002), Employment Outlook 2003, towards more and better jobs, OECD, Paris. Pariis.

OECD (2003), OECD Employment Owllook, Towards more and better jobs, OECD,

Olieman, R., J. Gravesteijn-Ligthelm, I. van der Weijde, A. Verkaik, P. Nijhuis and J. De Koning (1996), Evaluavie JeugdWerkGarantiewet, Nederlands Economisch Instituut, Rotterdam.

Omori, Y. (1997), Stigma Effects of Nonemployment, Economic Inguiry, Vol 35 (2), pp. 394-416.

Petrongolo, B. (2001), Reemployment Probabilities and Returns to Matching, Jourmal of Labor Economics, Vol. 19 (3), pp. 716-741.

Pissarides, C (1986), Unemployment and vacancies in Britain, Ecomonic Policy, Vol. 3, pp. 499-559.

Pissarides, C. (2000), Equilibrium Unemployment Theory, 2nd edition, MI Press, London.

Rees, A. (1966), Information networks in labor markets, American Economic Review, Vol. $56(1 / 2)$, pp. 559-566.

Richardson, J. (1997), Can Active Labour Market Policy Work? Some Theorelical Considerations, CEPR Discussion paper, No. 331. 
Ridder, G. (1987), The Sensitwity of Duration Models to Mispecified Unobserwed Heterogeneity and Dutation Dependence, Mimeo, University of Amsterdam.

Riley, J. (1976), Information, Screening and Human Capital, American Economic Review, Vol. 66 (2), Papers and Proceedings of the Eighty-eighth Annual Meeting of the American Economic Association, pp. 254-260.

Roed, K. (2002), Unemployment Hysteresis and the Natural Rate of Vacancies, Empirical Economics, Vol. 27 (4), pp. $687-704$.

Russo, G, C. Gorter, P. Nijkamp and P. Rietveld (1997a), Employers" Recruitment Behaviour: An Empirical Analysis of the Role of Personnel Management Attitudes, Labour, Vol. $11(3)$, pp. 599-623.

Russo, G., C: Gorter and C. Schettkat (1997b), Searching, ranking and hiring, Free University Research Memoranda, 1997-0017, Amsterdam.

Russo, G., P. Rietveld, P. Nijkamp and C. Gorter (2000), Recruitment channel use and applicant arrival: An empirical analysis, Empirical Economics, Vol. 25 (4), pp. 673-697.

Sanders, M. and R. Welters (2004), Recruitment in Recovery, Mimeo.

Snower, D. (1994), Converting Unemployment Benefits into Employment Subsidies, American Economic Review, Vol. 84 (2), Papers and Proceedings of the Hundred and Sixth Annual Meeting of the American Economic Association, pp. 65-70.

Spence, M. (1973), Job Market Signaling, Quarterly Joumal of Economics, Vol. 87 (3), pp. 355-374.

Stiglitz, J. (1975), The Theory of "Screening," Education, and the Distribution of Income, American Economic Review, Vol. 65 (3), pp. 283-300.

Taubman, P. and T. Wales (1973), Higher Education, Mental Ability, and Screening, Joumal of Political Economy, Vol. 81 (1), pp 28-55.

Trivedi, P. and J. Alexander (1989), Reemployment Probability and Multiple Unemployment Spells: A Partial-Likelihood Approach, Journal of Business and Economic Siatistics, Vol. 7 (3), pp. 395-400.

Van den Berg, G. and J. Van Ours (1994), Unemployment Dynamics and Duration Dependence in France, The Netherlands and the United Kingdom, The Economic Journal, Vol. 104 (423), pp. 432-443.

Van den Berg, G. and J. Van Ours (1996), Unemployment Dynamics and Duration Dependence, Jownal of Labor Economics, Vol. 14 (1), pp. 100-125.

Van der Bruggen, A. (1987-2003), Werkgelegenheidsplan: Annual Report, Philips Human Resources Management Nederland, Eindhoven.

Van der Bruggen, A. and J. Van Schagen (2001), Met het oog op de arbeidsmarkt, erharingen met her Philips Werkgelegenheidsplan, Lecturis, Eindhoven.

Van Diepen, P. and H. Jansen (1999), Nienwe bruggen naar werk, OAI-338, Regioplan, Amsterdam.

Van Ours, J. (1994), Matching unemployed and vacancies at the public employment office, Empirical Economics, Vol. 19 (1), pp. 37-54.

Van Ours, J. and G. Ridder (1992), Vacancies and the Recruitment of New Employees, Jownal of Labour Economics, Vol. 10 (2), pp. 138-155.

Van Polanen Petel, V., T. Hu, J. De Koning and C. Van der Veen (1999), Werkgelegenheidseffecten wan de SPAK en de $V L W$, Nederlands Economisch Instituut.

Van Veen, T. (1997), Studies in Wage Bargaining, the infuence of taxes and social security contributions on wages, Thesis, nr. 97-39, Maastricht.

Vishwanath, T. (1989), Job Search, Stigma Effect, and escape rate from Unemployment, Joumal of Labor Economics, Vol. 7 (4), pp. 487-502.

Weiss, A. (1980), Job Queues and Layoffs in Labour Markets with Flexible Wages, Jownal of Political Economy, Vol. 88 (3), pp. 526-538. 
Welters, R. (1998), De effectiviteit van het Nederlandse actieve arbeidsmarktbeleid, Maandschrift Economie, Vol. 62 (8), pp. 257-272.

Whitley, J. and R. Wilson (1983), The Macroeconomic Merits of a Marginal Employment Subsidy, The Economic Jonmat, Vol. 93 (372), pp. $862-880$.

Wolpin, K. (1977), Education and Screening, American Economic Review, Vol. 67 (6), pp $949-958$. 


\section{Samenvatting}

\section{Efficiëntie van Loonkostensubsidies en Wervingsstrategieën van Bedrijven}

De twee oliecrises in de jaren zeventig van de vorige eeuw hebben niet alleen geleid tot een toename van de werkloosheid maar ook tot een verandering in de samenstelling van de werklloosheidspoule: lagere aantallen werklozen, maar degenen die werkloos zijn, zijn langduriger zonder betaald werk. In de literatuur wordt alangenomen dat de lengte van de werkloosheidsperiode de kans op het vinden van werk negatief beilnvloedt. Verouderende vaardigheden en afnemende motivatie (na herhaalde afwijzingen) om te zoeken naar werk liggen hieraan ten grondslag. De duur van werkloosheid wordt dus een verklarende variabele voor de baanvindkans. Deze verandering in de samenstelling van de werkloosheid, heeft midden jaren tachtig de populariteit van loonkostensubsidies aangewakkerd. De intentie van loonkostensubsidies is dat een (langdurig) werkloze - door middel wan het verlenen van een tijdelijke subsidie aan een werkgever die hem in dienst neemt - aan de slag kan. De tijdens de gesubsidieerde periode opgedane werkervaring moet de kans van de gesubsidieerde werknemer op het vinden van regulier (niet-gesubsidieerd) werk na afloop van de subsidie periode vergroten. Kortom, een loonkostensubsidie kan de negatieve spiraal waarin een langdurige werkloze zich bevindt, doorbreken.

Als de langdurige werkloze inderdaad in staat is om zijn vaardighedenverlies ongedaan te maken, versterkt hij zijn positie op de arbeidsmarkt. Deze vergroting van het competitief arbeidsaanbod zal - bij een gegeven arbeidswraag - leiden tot neerwaartse loondruk, die weer zal leiden tot een structureel hoger werkgelegenheidsniveau dat de langdurige werkloze ook de mogelijkheid biedt om een structurele verbetering van zijn arbeidsmarktpositic te realiseren.

Echter, in de praktijk blijken loonkastensubsidie programma's gebukt te gaan onder een grote mate van inefficiêntie. De inefficiëntie kent drie oorzaken: verdringing, substitutie en dodegewichtsverlies. Deze drie concepten hebben gemeen dat de subsidiëring niet leidt tot vergroting wan de werkgelegenheid. Bij verdringing is er weliswaar sprake van vergroting van de werkgelegenheid bij het bedrijf waar de gesubsidieerde werknemer gaat werken. Echter, dit gaat ten koste van werkgelegenheid in een concurrerend bedrijf dat als gevolg van de subsidiëring van thet eerste bedrijf haar concurrentiepositie ziet verslechteren en als gevolg daarvan haar werkgelegenheid ziet afkalwen. Büj substitutie en dodegewichtsverlies heeft de geintroduceerde subsidiemogelijkheid de werkgever er zelfs niet toe anngezet een additionele baan te creéren. Bij substitutie vervult de gesubsidieende werkloze een vacature die zonder subsidie vervuld zou zijn door iemand die niet voldoet aan de criteria voor gesubsidieerde arbeid (bijwoorbeeld een niet-langdurige werkloze); bij dodegewichtsverlies zou de functie vervuld zijn door iemand die wel deel uitmakt van de doelgroep.

Programma"s van loonkostensubsidies blijken doorgaans vergezeld te gaan van substantiele aandelen substitutie en dodegewichtsverlies. Met name dodegewichtswerlies is ongewenst omdat de subsidie geen invloed heeft op werkgeversgedrag en ook niet leidt tot een verbetering van de positie van langdurige werklozen (dit laatste in tegenstelling tot substitutie).

Dit proefschrift concentreert zich op de meest kwaadaardige inefficientie: dodegewichtsverlies. De hoofdvraag luidt: kunnen we verklaren welk type bedrijven veroorzaakt voor welk type banen onder welke arbeidsmarktomstandigheden dodegewichtsverlies? Een antwoord op die vraag kan anleiding geven het ontwerp van loonkostensubsidies zodanig aan te passen dat de ermee gepaard gaande inefficiëntie afneemt waardoor de effectiviteit van het beleidsinstrument toeneemt. 
Ik beschrijf het gedrag van werkgevers op zoek naar nieuw personeel. Ik veronderstel dat een werkgever een vacature heeft waarwoor hij een werknemer zoekt die een minimaal productiviteitsniveau heeft. Werkgevers laten de duur van de werkloosheidsperiode van sollicitanten mee wegen in hun afweging, wat ertoe leidt dat werkzoekenden met een - in de ogen van de werkgever - te lange werkloosheidsduur niet in aanmerking komen voor de vacature. Deze werkloosheidsdrempel (maximale werkloosheidsduw on toch nog in aanmerking te komen voor de vacature) is cruciaal bij het veroorzaken van dodegewichtsverlies. Ligt de werkloosheidsdrempel namelijk lager dan de werkloosheidsdrempel die de overheid hanteert om te bepalen voor welk type werklozen een werkgever een subsidie kan krijgen, dan kan subsidiering leiden tot dodegewichtsverlies. Stel de werkgever neemt elke werkloze die minder dan twee jaar werkloos is in aanmerking voor de vacature, terwijl de overheid als voorwaarde voor subsidiëring stelt dat een werkloze langer dan één jaar werkloos moet zijn. Onder die voorwaarden kan een werkgever een subsidie krijgen voor een werkloze die hij ook zonder subsidie had aangenomen.

Aangezien de overheid star is in het vaststellen wan de noodzakelijke werkloosheidsduur van een werkloze om in aanmerking te komen voor een subsidie (meestal is dat én jaar werkloosheid), hangt de kwetsbaarheid van een loonkostensubsidie voor dodegewichtsverlies af van de werkloosheidsdrempel die bedrijven hanteren.

In mijn model beargumenteer ik dat de werkloosheidsdrempe $\rrbracket$ afhankelijk is van 1) de beoordelingskosten die een werkgever maakt wanneer hij een sollicitant onderzoekt op zijn geschiktheid, 2) het productiviteitsverlies dat een werkgever lijdt als zijn vacature onvervuld blijft en 3) de krapte op de arbeidsmarkt. Hoge beoordelingskosten betekenen dat de werkgever zo weinig mogelijk sollicitanten wil onderwerpen aan een onderzoek voordat hij een geschikte kandidaat gevonden heeft. Dat betekent dat hij een hoge werkloosheidsdrempel moet opwerpen om de kwaliteit van sollicitanten hoog te houden zodat de kans dat hij snel een geschikte kandidaat vindt, hoog is. Als het onvervuld blijven van een vacature tot hoog productiviteitsverlies leidt, heeft de werkgever baat bij een snelle vervulling. Daartoe heeft hij behoefte aan een grote toeloop van sollicitanten en dus is een lage werkloosheidsdrempel gewenst. Een gelijkaardige redenering geldt voor toenemende arbeidsmarktkrapte. Als de krapte op de arbeidsmarkt toeneemt, daalt de toeloop van sollicitanten voor een vacature, met toenemend productiviteitsverlies als gevolg. Om dit proces te stoppen zal een werkgever zijn werkloosheidsdrempel verlagen in krappe arbeidsmarktomstandigheden. Kortom, het model voorspelt dat bedrijven mei lage beoordelingskosten, hoog productiviteitsverlies van een openstaande vacature en bedrijven die opereren in krappe arbeidsmarktomstandigheden sneller dodegewichtsverlies veroorzaken dan andere.

De uit het model voortkomende hypotheses toets ik gebruikmakend van een Nederlandse en een Britse dataset. De Nederlandse dataset heeft betrekking op de afdrachtsVermindering Langdurig Werklozen, die Nederlandse bedrijven tussen 1996 en 1999 de mogelijkheid bood om langdurige werklozen met een subsidie in dienst te nemen. De Britse dataset heeft betrekking op de New Deal for Long-term Unemployed. In het kader van dit programma kunnen Britse bedrijven sinds 1997 een subsidie krijgen als ze een langdurige werkloze in dienst nemen.

Uit beide analyses blijkt dat de hoogte van beoordelingskosten inderdaad het verwachte effect op de kans op het veroorzaken van dodegewichtsverlies heeft. Bedrijven die hoge beoordelingskosten kennen veroorzaken minder vaak dodegewichtsverlies. Kleine bedrijven (nawwelijks schaalvoordelen in wervings- en selectiemethodes), zelfstandige bedrijven (geen mogelijkheid gebruik te maken van wervingsexpertise bij het moederbedrijf) en bedrijven die hoger opgeleiden zoeken onder langdurige werklozen (een weinig gangbare 
selectiemethode, waarmee dus hoge beoordelingskosten gemoeid zijn) veroorzaken inderdand significant minder vaak dodegewichtsverlies.

Beide analyses tonen ook aan dat er een positief verband bestaat tussen het veroorzaken van dodegewichtsverlies en de hoogte van het productiviteitsverlies per periode dat de vacature onvervuld is. Het productiviteitswerlies meet ik onder andere af aan de omvang van de baan. Een vacature voor een fulltime functie zal namelijk tot meer productiviteitsverlies leiden dan een partime functie. Beide analyses bevestigen dit beeld: een vacature voor een fulltime baan (of een baan waarin overwerk gedalan moet worden) levert vaker dodegewichtsverlies op dan een vacature voor een partime functie.

Ten slotte blijkt uit de Nederlandse analyse dat ook de krapte op de arbeidsmarkt een verklarende factor is van dodegewichtsverlies (de Britse dataset bevat geen variabelen die gerelateerd zijn aan arbeidsmarktkrapte). Echter, het verband is tegengesteld aan onze verwachting. Krapte op de arbeidsmarkt leidt niet tot meer, maar juist tot minder dodegewichtsverlies. De oorzaak van deze bevinding ligt buiten het model. Een mogelijke oorzaak is dat zodra de arbeidsmarktomstandigheden verbeteren, de meest productieve werklozen als eerste de werkloosheidspoule verlaten, wardoor de kwalliteit van de werkloosheidspoule in krappe omstandigheden laag is. In zulke omstandigheden zall een werkgever veel beoordelingsgesprekken moeten uitvoeren om een geschikte kandidat te vinden. Kwaliteitsverhogende maatregelen zijn in zulke omstandigheden wenselijk. Het verhogen van de werkloosheidsdrempel is er daar éen van.

Naast gewone loonkostensubsidies heb ik ook gekeken naar loonkostensubsidies waarbij het ontvangende bedrijf verplicht wordt de subsidie te besteden aan training. Ook bij trainingssubsidies blijkt de inefficiëntie substantieel te zijn. Desondanks verwacht ik op basils van mijn theoretisch model een ander patroon in de veroorzaking van dodegewichtsverlies. De optie tot scholing geeft de werkgever de mogelijkheid om zijn productiviteitseis naar beneden bij te stellen om vervolgens het productiviteitsverschil via scholing teniet te doen. Een verlaging van de productiviteitseis betekent ook dat er minder beoordelingsgesprekken nodig zijn om een sollicitant te vinden die voldoet aan de verlaagde productiviteitseis. De scholingsmogelijkheid maakt het dus - naast bedrijven met lage beoordelingskosten - ook mogelijk voor bedrijven met hoge beoordelingskosten om een lage werkloosheidsdrempel te hanteren. Kortom, ik verwacht dat het verklarende effect van beoordelingskosten op dodegewichtsverlies bij een trainingssubsidie minder is dan bij een gewone loonkostensubsidie. Het tegenovergestelde geldt voor het periodieke productiviteitsverlies van een openstaande vacature. Als het periodieke productiviteitsverlies van een openstatande vacature substantieel is, dan is de werkgever geneigd de werkloosheidsdrempel latg te houden om de vacature zo snel mogelijk te vervullen. Het nadeel daarvan is dat er veel beoordelingsgesprekken nodig zijn ondat de kwaliteit van sollicitanten lijdt onder de lage werkloosheidsdrempel. Echter, als de negatieve gevolgen hiervar ondervangen kunnen worden door scholing, staat de werkgever met hoog periodiek productiviteitsverlies van een openstaande vacature niets meer in de weg on de werkloosheidsdrempel te verlagen. Uiteraard geldt hier de voorwaarde dat de kosten van bijscholing laag moeten zijn. We verwachten dus ook dat bedrijven die te maken hebben met hoge scholingskosten minder snel de werkloosheidsdrempel verlagen dan bedrijven met lage scholingskosten. Kortom, de verwachting is dat hoge scholingskosten leiden tot minder dodegewichtsverlies.

De resultaten van een analyse van het Britse New Deal for Young People programma ondersteunen het theoretische vermoeden. Factoren (bijvoorbeeld bedrijfsgrootte) die bij een gewone loonkostensubsidie bepalend waren voor het patroon in de veroorzaking van dodegewichtsverlies zijn dat niet meer in een trainingssubsidie. Factoren gerelateerd atan periodiek productiviteitswerlies van een openstaande vacature zijn zowel in een gewone 
laonkostensubsidie als in een tramingsubsidie verklarend voor patronen in dodegewichtsverhes. Verder vind ik ook bewijs voor de hypothese dat hoge scholingskosten leiden tot minder dodegewichtswerlies. Bedrijven die aangeven dat de gesubsiclieerde werkloze is opgenomen in en bestaand opleidingsplan (lage scholingskosten) veroorzaken vaker dodegewichtsverlies.

De patronen die ik heb geconstateerd in de veroorzaking van dodegewichtsverlies kumen gebruikt worden bij het verbeteren van het ontwerp van programma"s van loonkostensubsidies. Aanpassingen die een loonkostensubsidie beter bestand maken tegen inefficientie, wat tewens leidt tot een verhoging van de effectiviteit van zulke programma s. Te denken valt aan het koppelen van de werkloosheidsdrempel van de owerheid (die de overheld hanteert on te bepalen voor welke werklozen een werkgever een subsidie kan krigen) aan bedrijfsgrootte. We weten dat grote bedrijven een lagere werkloosheidsdrempel hanteren dan kleine bedrijven. Het ligt dus voor de hand dat grote bedrijwen pas voor een subsidie in aanmerking komen als de aangenomen werkloze langer werkloos is dan wanneer een klein bedrijf een werkloze in dienst neemt. Deze maatregel zal vooral bij een gewone loonkostensubsidie leiden tot een verlaging van het dodegewichtsverlies. Een gelijkarardige redenering is denkbaar bij het koppelen van de werkloosheidsdrempel van de overheid aan de omvang van de baan (het aantal werkuren per week). Voltijdse banen leiden tot meer dodegewichtsverlies, dus een bedrijf dat een subsidie wil ontvangen voor een voltijdse baan zal moeten rekruteren uit langdurigere werklozen dan een bedrijf dat een subsidie wil voor een niet-voltijdse baan.

Beide voorgestelde aanpassingen hoeven niet te leiden tot een ongewenste complicatie van loonkostensubsidie programma's. De aanpassingen zijn namelijk vrij eenvoudig door te voeren. De belastingdienst - meestal de uitvoerende organisatie van loonkostensubsidies beschilkt over informatie als bedrijfsgrootte en omvang van hei contract, waardoor zonder veel moeite de efficiëntie van loonkostensubsidies verhoogd kan worden.

Tenslotte beschrijf ik in dit proefschrift de waarde van het particuliere initiatief bij het terugleiden van langdurige werklozen aan de hand van het Philips WerkgelegenheidsPlan (WGP). Philips neemt sinds 1983 elk jaar een groep (voomamelijk langdurige) werklozen in dienst, die een jaar in dienst blijven waarin ze werkervaring opdoen en bijgeschoold worden. Na een jaar worden deze werklozen geacht uit te stromen naar betaald werk. Het WGP vertoont dus sterke gelijkenissen met de publieke loonkostensubsidie programma"s. Uit bovenstaande analyse blijkt dat private ondernemingen beter (getuige de inefficièntie) in staat zijn om de kwaliteiten van werklozen te beoordelen dan de overheid en dus mag ook verwacht worden dat het WGP betere resultaten behaalt dan de publieke programma's.

Uit onze analyse blijkt dit ook inderdaad het geval te zijn. Het WGP behaalt betere resultaten (in termen van uitstroom naar betald werk) dan de publieke inspanningen. Voeg daarbij dat Philips het WGP draaiende houdt zonder substantiële overheidssteun en de vraag rijst of het voorbeeld van het WGP niet op bredere schaal ingevoerd kan worden. Hoewel het antwoord positief luidt, moet de rol die het private intiatief kan spelen bij het terugleiden van langdurige werklozen naar de arbeidsmarkt niet overschat worden. De revenuen die Philips genereent van het WGP zijn sterk gerelateerd aan bedrijfsgrootte. Philips gebruikt het WGP in onderhandelingen met vakbonden (primaire en secundaire arbeidsvoorwaarden) en de overheid (maatschappelijk verantwoord ondernemen). Verder gebruikt Philips het WGP als rekruteringsbron en om scholingsmethoden (voor het reguliere personeel) te ontwikkelen. Louter grote bedrijven kumnen voldoende profiteren van deze revenuen om een werkgelegenheidsplan kostendekkend draaiende te houden, waardoor de schaal waarop het 
particuliere initiatief ingezet kan worden beperkt is. Desondanks kan het private initiatief toeh als een welkome ondersteuning van het publieke initiatief gezien worden. 


\section{Curriculum Vitae}

Riceardo Ama Martinus Hubertus Maria Welters was born in Heerlen on April 17th 1974. He attended secondary education at Scholengroep Treviamum in Sittard-Geleen from 1986 to 1992. In the latter year, he started studying Economics at the University of Maastricht. In 1996 he spent a semester at l'Universitá degli Studi di Trento (Italy), before obtaining an MSc in General Economics in 1997. Between 1997 and 1999 he worked as a researcher at the Research Centre for Education and the Labour Market at the University of Maastricht. Next he spent one year as a lecturer at the General Economics department of the University of Maastricht. Between 2000 and 2004 he was a Ph.D.-student at the University of Maastricht, graduating from the NAKE-programme in 2004. Since September 2004 he is lecturer at the University of Maastricht. 